\title{
The role of colonization of the upper intestinal tract in the pathogenesis of ventilator-associated pneumonia
}

Citation for published version (APA):

Bonten, M. J. (1994). The role of colonization of the upper intestinal tract in the pathogenesis of ventilatorassociated pneumonia. [Doctoral Thesis, Maastricht University]. Datawyse / Universitaire Pers Maastricht. https://doi.org/10.26481/dis.19940916mb

Document status and date:

Published: 01/01/1994

DOI:

10.26481/dis.19940916mb

Document Version:

Publisher's PDF, also known as Version of record

\section{Please check the document version of this publication:}

- A submitted manuscript is the version of the article upon submission and before peer-review. There can be important differences between the submitted version and the official published version of record.

People interested in the research are advised to contact the author for the final version of the publication, or visit the DOI to the publisher's website.

- The final author version and the galley proof are versions of the publication after peer review.

- The final published version features the final layout of the paper including the volume, issue and page numbers.

Link to publication

\footnotetext{
General rights rights.

- You may freely distribute the URL identifying the publication in the public portal. please follow below link for the End User Agreement:

www.umlib.nl/taverne-license

Take down policy

If you believe that this document breaches copyright please contact us at:

repository@maastrichtuniversity.nl

providing details and we will investigate your claim.
}

Copyright and moral rights for the publications made accessible in the public portal are retained by the authors and/or other copyright owners and it is a condition of accessing publications that users recognise and abide by the legal requirements associated with these

- Users may download and print one copy of any publication from the public portal for the purpose of private study or research.

- You may not further distribute the material or use it for any profit-making activity or commercial gain

If the publication is distributed under the terms of Article $25 \mathrm{fa}$ of the Dutch Copyright Act, indicated by the "Taverne" license above, 
The role of colonization of the upper intestinal tract in the pathogenesis of

Ventilator-Associated Pneumonia 
. 


\section{The role of colonization of the upper intestinal tract in the pathogenesis of Ventilator-Associated Pneumonia}

\section{Proefschrift}

ter verkrijging van de graad van doctor aan de Rijksuniversiteit Limburg te Maastricht, op gezag van de Rector Magnificus, Prof.Dr. H. Philipsen, volgens het besluit van het College van Dekanen, in het openbaar te verdedigen op vrijdag 16 september 1994 om 16.00 uur

door

Marcus Johannes Marie Bonten 
Promotor

Prof.dr. P.W. de Leeuw

Co-promotores

Dr. C.A. Gaillard

Dr. E.E. Stobberingh

Beoordelingscommissie

Prof.dr. P.B. Soeters, voorzitter

Prof.dr. R. van Furth, Universiteit van Leiden

Prof.dr. J.W.M. van der Meer, Katholieke Universiteit Nijmegen

Prof.dr. R.W. Stockbrügger

Prof.dr. E.F.M. Wouters

\section{CIP-DATA KONINKLIJKE BIBLIOTHEEK, DEN HAAG}

Bonten, Marcus Johannes Marie

The role of colonization of the upper intestinal tract in the pathogenesis of Ventilator-Associated Pneumonia / Marcus Johannes Marie Bonten. - Maastricht :

Universitaire Pers Maastricht. - Ill.

Thesis Maastricht. - With ref. - With summary in Dutch.

ISBN 90-5278-150-8

Subject headings: pneumonia / gastro-enterology /

intensive care.

De studies gepresenteerd in dit proefschrift werden gefinancierd met behulp van grant 28-2125 van het Praeventiefonds. 
aan mijn ouders 


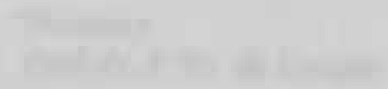

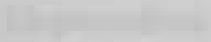

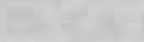

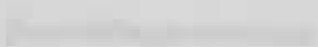

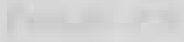

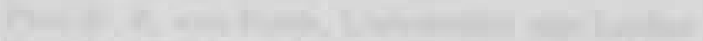

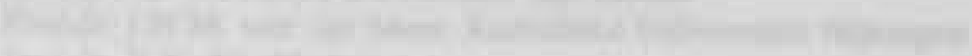

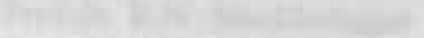

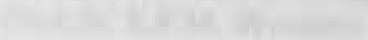

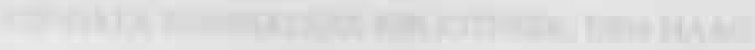

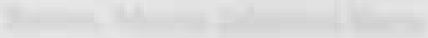

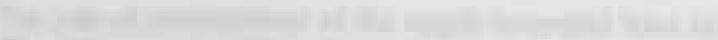

ran

(19)

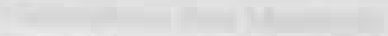

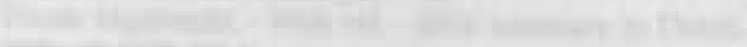

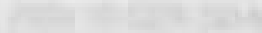

and

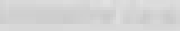

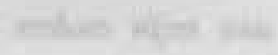

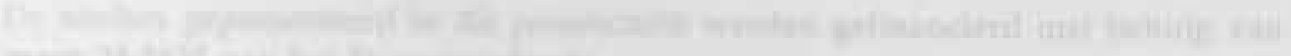

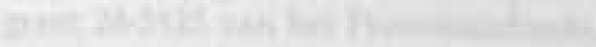




\section{General introduction}

chapter 1

The pathogenesis of nosocomial pneumonia in mechanically ventilated patients

chapter 2

Selective decontamination of the Digestive Tract in mechanically ventilated patients: evidence against its use

chapter 3

Problems in diagnosing pneumonia in mechanically ventilated patients: a review

chapter 4

Introduction to the studies and Questions

Topical antimicrobial prophylaxis and cross-acquisition

chapter 5

Microbiological observations during topical antimicrobial prophylaxis of oropharynx and stomach in mechanically ventilated patients

chapter 6

Continuous enteral feeding counteracts preventive measures for gastric colonization in ICU-patients

chapter 7

Colonization and cross-acquisition in patients receiving and not-receiving topical antimicrobial prophylaxis 
The role of the stomach in the pathogenesis of Ventilator Associated Pneumonia

chapter 8

Assessment of gastric acidity in intensive care patients: incidental $\mathrm{pH}$ registration can not replace continuous $\mathrm{pH}$ monitoring

chapter 9

The relevance of the stomach as a source for colonization of the upper respiratory tract and pneumonia in ICU patients

chapter 10

Colonization of the stomach and intragastric acidity are not important for the development of respiratory tract colonization and infection in mechanically ventilated ICU-patients.

chapter 11

Summary, Answers to the Questions, and Concluding Remarks

Samenvatting

List of publications

Naschrift

Curriculum vitae 


\section{Chapter 1}

THE PATHOGENESIS OF NOSOCOMIAL PNEUMONIA IN MECHANICALLY VENTILATED PATIENTS

Patterns of colonization leading to pneumonia 


\section{INTRODUCTION}

Among mechanically ventilated patients pneumonia is an important infection associated with increased morbidity and mortality (1-6). Due to its association with mechanical ventilation this infection has also been called Ventilator Associated Pneumonia (VAP), although this falsely suggests a predominant causative role of the ventilator in the pathogenesis. Many studies elucidating pathogenic pathways, therapeutic options, prevention and accurate diagnosis of VAP have been performed over the last twenty years. The pathogens causing VAP have been assumed to be from endogenous origin, and current hypothesis suggests that the gastropulmonary route of colonization is of main importance in the pathogenesis of VAP $(7,8)$. The gastropulmonary route assumes that enteric microorganisms colonize the stomach, migrate to the oropharynx and eventually reach the lungs of mechanically ventilated patients by aspiration. The purpose of this review is to critically assess the evidence for the existence and the importance of the gastropulmonary route of colonization and infection in mechanically ventilated patients. Although the gastropulmonary route has been assumed to be of main importance, other routes of colonization, like exogenous colonization and the rectopulmonary route, may also lead to the development of VAP. The possible role of these routes will be discussed as well.

\section{Incidence and mortality}

Incidences of VAP among ICU-patients ranged between $7 \%$ and $85 \%$, depending on the severity of illness of patients studied as well as on the diagnostic modalities and criteria used to establish the diagnosis (9-13). In most studies the diagnosis of VAP was based on a combination of nonspecific clinical criteria such as fever, leucocytosis, cultures of tracheal aspirates and infiltrates on chest radiograph. However, recent studies clearly demonstrate that these criteria are unreliable for diagnosing VAP, because they do not enable us to distinguish between colonization and infection of the lower respiratory tract $(1,14,15)$. Bronchoscopic techniques to obtain uncontaminated samples from the distal airways in combination with quantitative culture techniques are nowadays recommended to diagnose VAP and studies, using these techniques, are needed to establish the true incidence of this infection (16). The problems in diagnosing VAP will be discussed in more detail in chapter 3.

Clear associations between the incidence of VAP and increased mortality have been reported $(3,5,10)$, but it remains uncertain whether a patient succumbs due to VAP or whether the infection is merely a marker of the patients' physical deterioration eventually leading to death. In keeping with the former a retrospective case-control study recently demonstrated an attributable mortality 
risk ratio of VAP of 2.0, and even 2.5 when VAP was caused by Pseudomonas spp. or Acinetobacter spp., and a mean excess of 20 days in ICU stay for surviving patients as compared to unaffected controls (6).

\section{Etiology of VAP}

In most cases VAP is caused by enteric Gram-negative bacteria. In the National Nosocomial Infection Study (NNIS), performed between 1985 and 1988 in the United States, $58.7 \%$ of the cases were associated with Gram-negative bacteria, especially Pseudomonas aeruginosa $(17.2 \%)$, Enterobacter species $(10.4 \%)$, and Klebsiella pneumoniae (7.4\%) (17). Percentages comparable to those observed in this large multicenter study were reported by many single hospital studies $(2,3,10,18)$. Staphylococcus aureus is, after Pseudomonas aeruginosa, the second most frequent pathogen causing VAP: $14.6 \%$ of all cases in the NNIS-study and $56 \%$ of all cases among multiple trauma patients in coma (11). However, it must be stated that in many cases these percentages were derived from studies not using bronchoscopic techniques to diagnose VAP. Therefore, the real incidence of this infection may be lower when diagnosed more accurately.

Because bacteria such as Enterobacteriaceae, Pseudomonas spp. and Staphylococcus aureus are known to cause serious infections under certain circumstances they are grouped together and labelled as potentially pathogenic microorganisms (ppmo).

\section{PATHOGENESIS}

In infectious diseases the pathogenic pathway consists of three entities: The source of pathogenic microorganisms (a), from where microorganisms reach the porte d'entree (b) via a certain route (c). In the human body the intestine is the most important source of bacteria. However, other body cavities, that do not contain ppmo under physiological circumstances, may be colonized under pathologic conditions, and serve as reservoirs of bacteria. In case of pneumonia the distal airways are the porte d'entree. In theory, the source of microorganisms can be situated within the patient (the intestine; an endogenous source) or anywhere in its surroundings (an exogenous source). Although the oropharynx is not a sterile cavity, it is usually colonized with anaerobes and Gram-positive cocci, labelled as normal oropharyngeal flora. These bacteria are definitely able to cause pneumonia, although they seldomly cause VAP (17). In addition, the trachea and stomach do not harbor ppmo under physiologic circumstances, and may, therefore, not be considered as likely sources of microorganisms causing VAP, although colonization at these sites occurs frequently before the onset of VAP (1921). Important exogenous sources are contaminated mechanical equipment, enteral feedings, or other patients in the ICU. 
The exact route of colonization has been the subject of much debate. Microorganisms may reach the distal airways after colonization of the trachea, the oropharynx, the stomach or the small and large intestine. In all cases, the source of bacteria may have been either endogenous or exogenous (Figure 1). For instance, intestinal bacteria may reach the lungs via the stomach, the oropharynx and the trachea, but may also colonize the trachea directly via hands of nurses after contact with colonized skin or perineum. The importance of the different routes of colonization and the sources of microorganisms will be discussed in detail below.

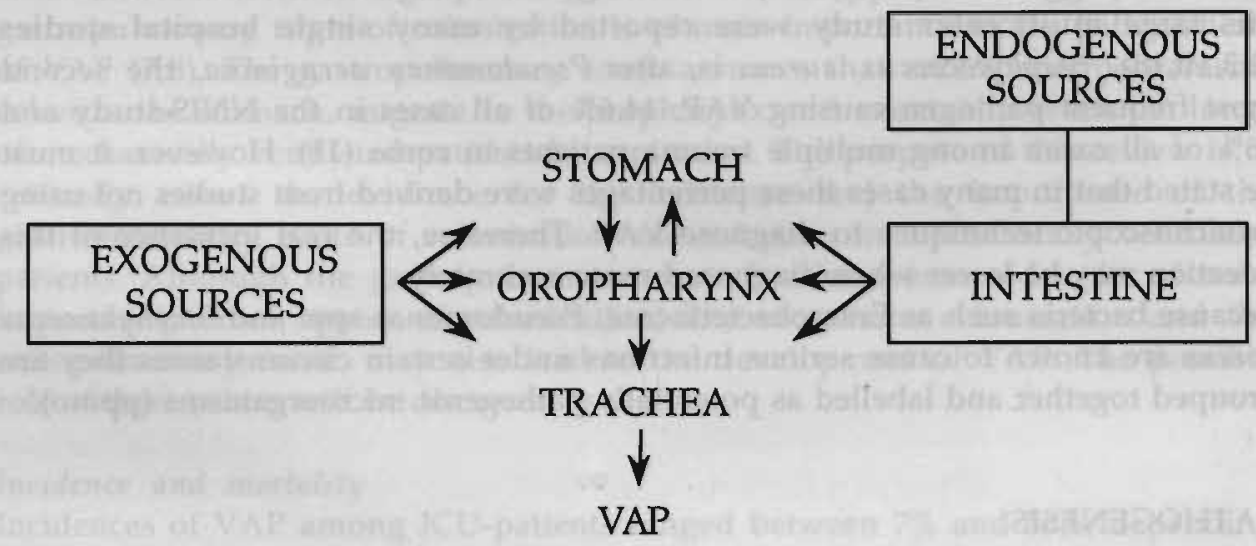

Figure 1: Bacterial sources and routes leading to Ventilator Associated Pneumonia

Colonization of the upper respiratory tract

Colonization of the upper respiratory tract (i.e. oropharynx and trachea) by ppmo is common among critically ill patients on mechanical ventilation. Reported percentages of patients colonized ranged from $16 \%$ in moderately ill patients $(19,20)$ to $57 \%$ in critically ill patients and even $100 \%$ in those with long-term intubation $(22,23)$. Although a substantial percentage of patients might enter the ICU at a stage where they are already colonized, many patients acquire colonization during their stay in ICU $(20,22)$. There is no doubt about the relationship between colonization of the upper respiratory tract and development of VAP. Johanson et al demonstrated twenty years ago how $23 \%$ of colonized ICUpatients developed nosocomial respiratory infections as compared to only $3 \%$ of noncolonized patients (20). Bacteria reach the lungs after aspiration of oropharyngeal fluid containing colonizing bacteria, an event that has been demonstrated to occur frequently in critically ill patients (24). Factors associated 
with increased colonization of the respiratory tract in ICU-patients have been listed in Table 1.

Table 1: Factors associated with increased colonization and infection of the respiratory tract in ICUpatients:

Factor

Reference

Systemic

Underlying disease

COPD

1,5

Thoracoabdominal surgery

Malnourishment/depletion

Depressed consciousness

Intracranial pressure monitoring

Fall-winter season

Age (>70)

Upper respiratory tract

Nasogastric tube

\section{5}

Size of the NG-tube

52

27

Intubation

Mechanical ventilation

Duration of MV

PEEP

1

1

Tracheostomy

Viral infection

27

Stomach

Position of the patient

Stress ulcer prophylaxis

$\mathrm{H}_{2}$-antagonists

Antacids

Enteral feeding

Gastric aspiration
24

$3,12,42-45$

12,41

50

$1,5,24$

Reason for increased colonization

Increased colonization of the upper respiratory tract could either be a result of increased exposure to ppmo, or of a diminished capacity to clear such organisms from the upper respiratory tract or both. Extensive exposure of the upper respiratory tract to ppmo only does not seem to be an adequate explanation for the increased colonization rates observed in these patients. Indeed, members of the medical and nursing staff, working in the same environment, rarely become 
colonized with ppmo and massive exposure of normal subjects to ppmo does not lead to colonization of the upper respiratory tract $(25,26)$. Therefore, defective clearance mechanisms are more likely to account for the increased colonization rates of the upper respiratory tract in critically ill patients.

An increased cell binding capacity of tracheal epithelial cells probably is an essential step in the pathogenesis of colonization, as schematically depicted in Figure 2. Both decreased immunologic functions of the host and destruction of the integrity of the epithelium, leading to exposure of the underlying connective tissue, have been shown to increase the cell binding capacity $(27,28)$. The first occurrence of colonization initiates a vicious cycle, facilitating colonization with other bacteria. For instance, bacteria such as Pseudomonas aeruginosa, Haemophilus influenzae or Gram-positive bacteria, may impair mucociliary clearance or produce pro-inflammatory enzymes, such as elastase, which can degrade IgA (29). In addition, colonization can be stimulated by the production of proteases which results in loss of fibronectin from the epithelial surface (30). Besides a risk factor for development of VAP, colonization of the upper respiratory tract may, therefore, also be a marker for critically ill patients who have multiple deficiencies in the host defense system of their respiratory tract (28).

\section{THE GASTROPULMONARY ROUTE}

In the etiology of VAP enteric Gram-negative bacteria form the largest group of pathogens. The question is how these microorganisms, originally colonizing the intestine, reach the upper respiratory tract. Since gastric colonization with these bacteria is a common finding in critically ill patients $(21,23,31,32)$, colonization at this site has been presumed to have an etiologic role in the development of VAP (the gastropulmonary route of colonization). The putative role of the stomach as a reservoir for microorganisms causing VAP was based on correlations between the occurrence of VAP and simultaneous or preceding gastric colonization with the same bacterial species $(31,33)$. However, a definite proof of the existence of the gastropulmonary route would need accurate monitoring of colonization in the stomach and the upper respiratory tract over time. Moreover, a reliable diagnosis of VAP by isolation of the pathogens from the distal airways would be needed and similarity of the bacteria that cause VAP and previously colonized the stomach should be proven biochemically. Up till now, no such studies have been published. 
Other Loss of fibronectin

Age

Underlying disease

Acquired systemic illness

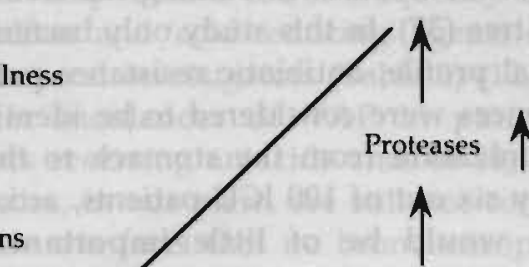

Immunologic functions

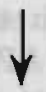

A Tracheal cell binding capacity

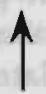

A Exposure to

connective tissue

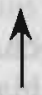

Viral infection Intubation

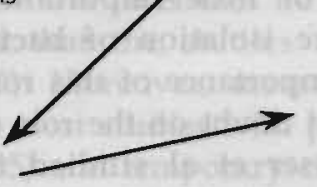

Colonization with bacteria

Intubation

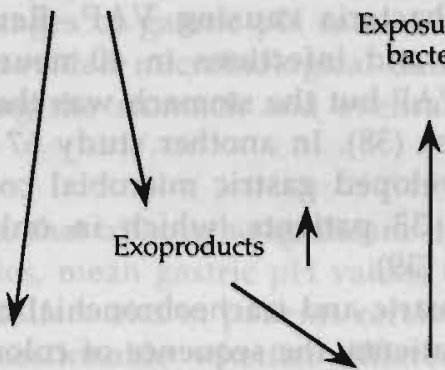

Inflammatory enzymes

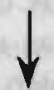

bacteria
basure to

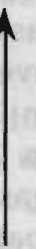

Mucociliary clearance

Figure 2: Pathogenesis of bacterial colonization of the upper respiratory tract

Despite the lack of definite proof many researchers felt that there was compelling evidence for the importance of the gastropulmonary route of colonization. For instance, Daschner et al studied the $\mathrm{pH}$ of gastric aspirates together with bacterial counts in gastric fluid and tracheal secretions in 142 mechanically ventilated ICUpatients (23). When isolates from both samples were identical, they were typed by agglutination, bacteriocin or phage typing. Bacterial counts, especially for Gramnegative organisms, increased with rising gastric $\mathrm{pH}$. In $31.6 \%$ of all patients identical bacterial species were first isolated from gastric aspirate and subsequently from tracheal secretions. The incidence of VAP was correlated with gastric $\mathrm{pH}$, being $40.6 \%$ when gastric $\mathrm{pH}$ was below 3.4 and $69.2 \%$ when gastric $\mathrm{pH}$ was above 5.0 (23). However, the high incidences of VAP might have been an overestimation as no bronchoscopic techniques were used to establish the diagnosis accurately. Moreover, gastric acidity was measured incidentally with $\mathrm{pH}$ papers, a method which has been criticized extensively $(34,35)$. Computerized continuous intragastric $\mathrm{pH}$ monitoring probably is a more reliable method to study intragastric acidity (36) (chapter 8). 
Inglis et al also demonstrated that bacteria colonizing the stomach can eventually colonize the tracheobronchial tree (37). In this study only bacterial isolates with the same plasmid and biochemical profile, antibiotic resistance pattern and repetitive extragenic palindromic sequences were considered to be identical. However, as a chronological pattern of colonization from the stomach to the tracheobronchial tree was demonstrated in only six out of 100 ICU-patients, according to this study the gastropulmonary route would be of little importance in mechanically ventilated ICU-patients. Moreover, since isolation of bacteria from tracheal aspirates was used as an endpoint, the importance of this route for VAP would even be lower (37). Other studies also cast doubt on the role of the stomach as a source for bacteria causing VAP. Reusser et al studied the role of gastric colonization and infections in 40 neurosurgical patients (38). Fifteen patients developed VAP but the stomach was the evident source of the causative agent in only one case (38). In another study 67 out of 100 mechanically ventilated ICUpatients developed gastric microbial colonization. Nasopharyngeal colonization occurred in 33 patients, which in only eight cases was preceded by gastric colonization (39).

Although gastric and tracheobronchial colonization are common in mechanically ventilated patients, the sequence of colonization and the role of the stomach as a source of bacteria causing VAP in this patient population have not yet been firmly established and need further study (chapter 9 and chapter 10).

In the studies mentioned above evidence for a causal relationship between gastric colonization and VAP was derived mainly from observations of coincidental colonization at both sites. The alleged importance of the gastropulmonary route would be further supported if modulation of gastric colonization indeed changed the incidence of VAP. In this respect, several regimens have been developed to decrease gastric bacterial colonization as a preventive measure for the development of VAP. The three topics receiving the most attention (i.e. stress ulcer prophylaxis, selective decontamination of the digestive tract and modulation of enteral feeding) will be discussed below in more detail.

\section{Stress ulcer prophylaxis}

In physiologic circumstances gastric acidity serves as a very adequate protection against bacterial growth. However, among critically ill patients who need mechanical ventilation, gastric acidity may be reduced due to stress ulcer prophylaxis. Antacids, for instance, neutralize gastric acid whereas $\mathrm{H}_{2}$-antagonists decrease acid production. In contrast, sucralfate has been claimed to prevent stress ulcers without altering gastric acidity (40). Theoretically, therefore, patients receiving sucralfate should have lower intragastric $\mathrm{pH}$ values as compared to patients receiving antacids or $\mathrm{H}_{2}$-antagonists, and, as a result, gastric colonization 
and VAP should develop with a lower frequency in sucralfate-treated patients. The effects of sucralfate and 'acid-reducing' agents on the incidence of VAP has been addressed by several investigators (Table 2) (12,41-45). Although four studies demonstrated lower incidences of VAP in patients receiving sucralfate as compared to patients receiving antacids and/or $\mathrm{H}_{2}$-antagonists $(12,41,43,45)$, the results of these studies, in our view, are still not conclusive. Criticisms regarding these studies include the facts that no bronchoscopy was applied to accurately diagnose VAP and that the studies were neither double-blind nor placebocontrolled (12,41-45). Moreover, measurements of gastric $\mathrm{pH}$ were performed incidentally, and in most studies with $\mathrm{pH}$ papers. The reliability of the latter has been criticized $(34,35)$ and temporary changes of gastric $\mathrm{pH}$ cannot be measured (46). Furthermore, none of the studies provided microbiological data that prove the identity of bacterial strains colonizing the stomach and eventually causing VAP.

The most important objection, however is, that although significant differences in $\mathrm{pH}$-values were demonstrated in all studies, mean gastric $\mathrm{pH}$ values were always above 4.25 , both in patients receiving sucralfate and in patients receiving antacids and/or $\mathrm{H}_{2}$-antagonists. It is, indeed, questionable whether differences in pHvalues above 4.0 have any influence on bacterial growth $(12,41-45)$. Similar to the analyses of $\mathrm{pH}$-measurements, the observed incidences of VAP, determined in five studies, are subject to discussion $(12,41,43-45)$. No significant differences between patients receiving sucralfate and those receiving other prophylactic agents were observed in three studies $(12,43,44)$, although the differences bordered on significance in two of these $(12,43)$. In the study of Driks et al significance was reached when crossover patients were excluded from analysis (12). Despite the methodological drawbacks, a meta-analysis of these studies demonstrated a significantly lower incidence of VAP among patients receiving sucralfate as compared to patients receiving antacids or $\mathrm{H}_{2}$-antagonists (47).

In summary, an association between lower gastric pH-values and a lower incidence of VAP was demonstrated in only two out of five studies $(41,45)$, the interpretation of which is seriously hampered because of methodological problems. Therefore, it remains difficult to see that small differences in mean gastric $\mathrm{pH}$ values can explain the observed differences in VAP. Alternatively, a bactericidal effect of sucralfate might be an explanation, but this effect has only been demonstrated in vitro $(48,49)$ and its relevance in vivo remains to be established. Therefore, a double-blind placebo-controlled study comparing sucralfate and antacids or $\mathrm{H}_{2}$-antagonist, and using continuous gastric $\mathrm{pH}$ measurement and bronchoscopic techniques to diagnose VAP is warranted (chapter 10). 
Table 2: Studies on the influence of sucralfate as compared to acid reduced agents on intragastric acidity and the incidence of VAP in mechanically ventilated ICU patients

\begin{tabular}{|c|c|c|c|c|c|c|}
\hline Author: & Driks '87 & Tryba 87 & Laggner '88 & Kappstein '91 & Simms '91 & Eddleston'91 \\
\hline Design: & $x^{2}=$ & & & & & \\
\hline prosepctive: & + & + & + & + & + & + \\
\hline $\begin{array}{l}\text { randomized: } \\
\text { Population: }\end{array}$ & $\stackrel{+}{\text { mixed }}$ & $\begin{array}{c}+ \\
\text { surgical }\end{array}$ & $\stackrel{+}{+}+$ & mixed & $\begin{array}{c}+ \\
\text { surgical }\end{array}$ & $\stackrel{+}{\text { mixed }}$ \\
\hline \multirow{2}{*}{\multicolumn{7}{|c|}{ Numbers of patients: }} \\
\hline & & & & & & \\
\hline Sucralfate: & 61 & 50 & 41 & 49 & 30 & 21 \\
\hline dosage: & $1 \mathrm{gq} .6 \mathrm{~h}$ & $\operatorname{lgq} \cdot 4 \mathrm{~h}$ & $1 \mathrm{gq} \cdot 4 \mathrm{~h}$ & $1 \mathrm{gq} .6 \mathrm{~h}$ & $1 \mathrm{~g}$ q.i.d. & $1 \mathrm{~g} \mathrm{q.6h}$ \\
\hline Controls I: & & 50 & 43 & 55 & 37 & 17 \\
\hline agent: & $\mathrm{AA}$ and/or $\mathrm{H}_{2}-\mathrm{A}$ & $\mathrm{AA}$ & Ranitidine & Cimetidine & $\mathrm{AA}$ & Ranitidine \\
\hline dosage: & $10 \mathrm{ml} \mathrm{q} \cdot 2 \mathrm{~h}$ & $6 \times 50-100 \mathrm{mg} / \mathrm{d}$ & $2000 ; 3 \times 400 \mathrm{mg} / \mathrm{d}$ & $6 \times 20-40 \mathrm{ml}$ & $4 \times 50 \mathrm{mg} / \mathrm{d}$ & \\
\hline Controls II: & & & & & 32 & \\
\hline $\begin{array}{l}\text { agent: } \\
\text { dosage: }\end{array}$ & & & $x^{2}$ & & $\begin{array}{l}\text { Cimetidine } \\
6 \times 900-1200 \mathrm{mg}\end{array}$ & \\
\hline pH (critical point) & $\leq 4.0$ & $\leq 4.0$ & $<3.5$ & & $<4.0$ & \\
\hline \multicolumn{7}{|l|}{ Proportion (in \%) } \\
\hline Sucralfate: & 47.9 & 46.5 & 47.0 & & 20.0 & \\
\hline Control I: & 25.3 & 10.4 & 25.8 & & 11.1 & \\
\hline Control II: & 9.4 & & & & & \\
\hline p-value: & $<0.001$ & $<0.01$ & $<0.05$ & & n.s & \\
\hline \multicolumn{7}{|l|}{ Mean pH } \\
\hline Sucralfate: & $=0$ & & & 4.34 & 4.73 & 4.26 \\
\hline Control I: & E1 & & trat & 4.85 & 5.55 & 5.50 \\
\hline Control II: & & & & 5.06 & & \\
\hline p-value: & $=$ & & & 0.044 & 0.006 (S vs I) & $<0.01$ \\
\hline \multicolumn{7}{|c|}{ Incidence of VAP (in \%): } \\
\hline Sucralfate: & 11.5 & $10.3(3 / 29)^{\prime}$ & - & 26.5 & 26.7 & 10.3 \\
\hline Control I: & 23.2 & $34.4(11 / 32)$ & - & 45.5 & 29.6 & 35.7 \\
\hline Control II: & 28.1 & & 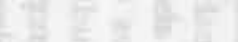 & & & \\
\hline p-value: & 0.11 & $<0.05$ & $=0$ & 0.0549 & n.s & $<0.01$ \\
\hline
\end{tabular}

$A A=$ Antacids; $\mathrm{H}_{2}-\mathrm{A}=\mathrm{H}_{2}$-antagonist; ${ }^{1} 39$ patients were withdrawn because of thoracic trauma or pneumonia on admission 


\section{Enteral feeding}

If administration of enteral feeding would be a risk factor for VAP, it would certainly strengthen the hypothesis of the stomach being an important reservoir for bacteria causing this infection. The suggested mechanism would be that enteral feeding promotes gastric bacterial growth due to dilutional alkalinization of gastric contents and to aspiration of an increased gastric volume. Although increased bacterial colonization of gastric contents following enteral feeding has, indeed, been found $(50,51)$, it remains unclear whether this is a result of reduced gastric acidity. Pingleton et al (50) reported on 18 patients with gastric bacterial colonization during enteral feeding. However, 14 of these patients $(78 \%)$ were already colonized before enteral feeding was started and the mean gastric $\mathrm{pH}$ (5.7 without enteral feeding) did not increase after institution of enteral feeding. Although colonization appeared to proceed from the stomach to the trachea in five patients, a route from the trachea or oropharynx to the stomach was found with equal frequency. Moreover, the identity of the bacteria isolated from gastric contents and of those causing pneumonia, which occurred in 11 patients $(68 \%)$, was not studied (50).

Torres et al demonstrated in mechanically ventilated patients that pulmonary aspiration of gastric fluid depends on the body position of the patient (24). In addition, Ibanez et al demonstrated gastroesophageal reflux in 37 out 50 intubated patients $(74 \%)$ with nasogastric tubes as opposed to seven out of 20 patients, of whom 12 were studied in supine position, without a nasogastric tube $(p<0.05)(52)$. They concluded that the presence of a nasogastric tube is the most important risk factor for gastroesophageal reflux and that this cannot be prevented by placing the patient in a semirecumbent position (52). In both studies radioactive labelled enteral feedings were used to measure reflux $(24,52)$.

The combination of enhanced gastric colonization, increased aspiration of gastric contents, possibly due to enteral feeding, and higher incidences of VAP would support the view that stresses the importance of the gastropulmonary route in the pathogenesis of VAP. However, neither the correlation between administration of enteral feeding and increased aspiration nor that between any of these and an increased incidence of VAP have yet been firmly established. In most ICU's enteral feeding is only instituted when bowel movements are present. If the stomach indeed is an important reservoir for bacteria causing VAP, then patients with massive gastrointestinal fluid retention would be at high risk for VAP. However, to the best of our knowledge, no data are available on this aspect. Therefore, the relation between enteral feeding and gastric colonization needs further study (chapter 6 and chapter 10). 
Selective Decontamination of the Digestive tract

Selective decontamination of the digestive tract (SDD) has been used to decrease the incidence of VAP (13,53-57). With this method of infection prevention antimicrobial activity was established simultaneously in the intestine, the stomach, the oropharynx, systemically and probably also in the tracheobronchial tree (58). Therefore, it remains elusive to what extent each component contributed to the effect of SDD. As a result, a lower incidence of VAP in patients treated with SDD neither proved the importance of the gastropulmonary route of colonization nor that of the intestine as a source for bacteria causing VAP. There are even two reasons to assume that studies using SDD suggested the opposite. The first is that in two studies selective decontamination of the stomach and the intestine exclusively had no influence on infection rates $(59,60)$. Secondly, in two other studies a reduction of VAP was established with application of antibiotics to the oropharynx only, without decontamination of the stomach and the intestine $(61,62)$. Thus, evidence for a pathogenetic role of the stomach and the intestine in the colonization and infection of the upper respiratory tract is far from conclusive (chapter 5). The benefits of selective decontamination of the digestive tract as method of infection prevention in mechanically ventilated ICU-patients will be reviewed in chapter 2 .

\section{THE RECTOPULMONARY ROUTE}

When the role of the stomach as a source of microorganisms causing VAP is not as important as generally assumed, it may be that the importance of other routes has been underestimated. For instance, from the large intestine, the most abundant source of Gram-negative bacteria, microorganisms may spread to the skin of the patient or the nursing personnel and subsequently to the upper respiratory tract of the patient. However, this rectopulmonary route of colonization has not been studied extensively, and only three studies have demonstrated the relevance of rectal colonization with Pseudomonas acruginosa in ICU-patients.

In one study the rectum was the most common primary site of colonization of Pseudomonas aeruginosa among surgical ICU-patients (63), and in another study colonization with this species was more frequently demonstrated in the rectum than in the oropharynx (64). Moreover, in those patients colonized at both sites, rectal colonization occurred first (64). Finally, rectal colonization with Pseudomonas aeruginosa was demonstrated to occur more frequently than tracheal colonization, although rectal strains did not appear in tracheal secretions later (65). Unfortunately, in these studies colonization was studied at two sites 
only, so a particular sequence of colonization could not be determined with confidence. Comparable observations were made for Enterobacter spp. During a study on cefazolin prophylaxis, 58 out of 87 cardiac surgery patients became colonized with Enterobacter species in the throat, rectum, groin or sternal area (66). Because Enterobacter spp. were isolated prior to admission from 28 patients, and colonization was most frequently demonstrated in the rectum first, the patients' endogenous flora probably was the main source (66). Moreover, only nine cases of horizontal transmission occurred and bacterial typing showed 50 distinct strains of Enterobacter (66). Among patients undergoing cardiothoracic surgery groin flora was found to be the source of bacteria causing mediastinal infections following transfer on contaminated saphenous vein grafts or by the hands of surgeons after harvesting the vein (67).

As for the gastropulmonary route, accurate monitoring of colonization is needed to establish the real importance of the rectopulmonary route of colonization.

\section{EXOGENOUS SOURCES}

\section{Environment and equipment}

Many reports described outbreaks of nosocomial infections due to microorganisms that had contaminated complex medical devices, such as respirators, which are difficult to clean and sterilize (68-72). Likewise, enteral feeding may be a reservoir of microorganisms, especially after preparation under non-sterile circumstances or storage at room temperature (73). Contaminated enteral nutrition occasionally leads to nosocomial sepsis with Enterobacter cloacae and Klebsiella pneumoniae (74) or nosocomial pneumonia due to Acinetobacter baumannii (75). Strict hygienic measures with continuous control are therefore needed to exclude the permanent danger of acquired colonization from contaminated sources.

\section{Other patients}

Several studies indicated that patients themselves, rather than the inanimate environment, were major reservoirs of microorganisms $(65,76,77)$. Weinstein et al demonstrated that 'antibiotic-resistance precautions' decreased the spread of aminoglycoside-resistant Enterobacteriaceae, suggesting that these strains can spread by cross-acquisition $(76,77)$. As airborne transmissions only sporadically contribute to spread of Gram-negative microorganisms (78), transfer most probably occurs via hands of the nursing and medical staff. Pseudomonas species have been isolated frequently from the hands of personnel, even after hand washing and after gloves had been put on for contact with patients $(65,79)$. Widmer et al described an outbreak of Pseudomonas aeruginosa infections in an ICU in which identical strains were isolated from three patients and from the hands of a health 
care worker providing care for all three patients (80). Further evidence for the role of hands in cross-acquisition was provided by studies demonstrating lower incidences of infections after increasing the frequency of hand washing, and the use of gloves (81) or antiseptic hand washing products (82-84). Taken together, data demonstrating carriage of pathogens by hands of health care workers and those demonstrating poor compliance with hand-washing procedures, especially in the ICU and with physicians being the worst offenders (85-87), suggest that colonized patients may be an important exogenous source of microorganisms within an ICU. Therefore, it would be interesting to study the influence of decontamination of, for instance, half the ICU-population on colonization rates of the other, nondecontaminated half (chapter 7).

\section{STAPHYLOCOCCUS AUREUS}

Among the pathogens frequently associated with VAP, Staphylococcus aureus has, when compared to Gram-negative bacteria, an exceptional source, since this microorganism is derived exclusively from human reservoirs (78). The principal site of staphylococcal colonization are the anterior nares; up to $80 \%$ of adults are found to harbor Staphylococcus aureus transiently, while $20-40 \%$ of adults are colonized permanently $(63,88)$. Therefore, the gastropulmonary route probably is of no importance for colonization and infection with Staphylococcus aureus. Thus, although several microorganisms (Enterobacteriaceae, Pseudomonas aeruginosa and Staphylococcus aureus) are generally grouped together and labelled as potential pathogenic microorganisms, their role and behaviour in the pathogenesis of VAP may differ significantly. Moreover, since the group of Enterobacteriaceae is a mixture of different bacteria, individual bacteria may have different colonization patterns as well. These patterns of colonization of different species of bacteria need to be studied in more detail (chapter 8 and chapter 10).

\section{CONCLUSIONS}

The etio-pathogenesis of VAP can only be studied, when the sequence of colonization at several body sites is monitored in time, and the diagnosis of VAP is established with bronchoscopic techniques. The effects of stress ulcer prophylaxis or enteral feeding on gastric acidity should be studied with continuous intragastric $\mathrm{pH}$ monitoring, instead of incidental measurements of acidity in aspirated gastric juice with indicator papers. Up till now, no such studies have been performed and interpretation of available data is, therefore, hampered by methodological pitfalls. 
Although there is no doubt that enteral microorganisms can reach the lungs via stomach and oropharynx, and eventually cause VAP in mechanically ventilated ICU-patients, the importance of this route has yet to be established. In addition, the patterns of colonization of different species of microorganisms should be determined.

It is also important to realize that, besides the gastropulmonary route of colonization, bacteria may reach the lungs via other routes, either from exogenous sources or from the intestine after spreading outside the patient. The importance of these routes of colonization need to be established as well.

In conclusion, the studies reviewed above demonstrate a sharp contrast between the limited knowledge of the patterns of colonization leading to VAP and the widespread medical consequences of this dreaded infection. Therefore, it is essential to elucidate these patterns in order to develop preventive strategies. 


\section{REFERENCES}

1. Torres A, Aznar R, Gatell JM, Jimenez P, Gonzalez J, Ferrer A, et al. Incidence, risk, and prognosis factors of nosocomial pneumonia in mechanically ventilated patients. Am Rev respir Dis 1990; 142: 523-8

2. Jimenez P, Torres A, Rodriguez-Roisin R, Puig de la Bellacasa J, Aznar R, Gatell JM, et al. Incidence and etiology of pneumonia acquired during mechanical ventilation. Crit Care Med 1989; $17: 882-6$

3. Craven DE, Kunches LM, Kilinsky V, Lichtenberg DA, Make BJ, McCabe WR. Risk factors for pneumonia and fatality in patients receiving continuous mechanical ventilation. Am Rev Respir Dis 1986; 133: 792-6

4. Leu HS, Kaiser DL, Mori M, Woolson RF, Wenzel RP. Hospital-acquired pneumonia. Attributable mortailty and morbidity. Am J Epidem 1989; 129: 1258-67

5. Celis R, Torres A, Gatell JM, Almela M, Rodriguez-Roisin R, Agusti-Vidal A. Nosocomial pneumonia. A multivariate analysis of risk and prognosis. Chest 1988; 93: 318-24

6. Fagon JY, Chastre J, Hance AJ, Montravers P, Novara A, Gibert C. Nosocomial pneumonia in ventilated patients: a cohort study evaluating attributable mortality and hospital stay. Am J Med 1993; 94: 281-8

7. Heyland D, Mandell LA. Gastric colonization by Gram-negative bacilli and nosocomial pneumonia in the intensive care unit patients: evidence for causation. Chest 1992; 101: 187-193

8. Tryba M. The gastropulmonary route of infection - fact or fiction? Am J Med 1991; 91 (suppl 2A): 135-146

9. Fagon JY, Chastre J, Domart Y, Trouillet JL, Pierre J, Darne C, et al. Nosocomial pneumonia in patients receiving continuous mechanical ventilation. Am Rev Respir Dis 1991; 139: 877-84

10. Rello J, Quintana E, Ausina V, Castella J, Luquin M, Net A, Prats G. Incidence, etiology and outcome of nosocomila pneumonia in mechanically ventilated patients. Chest 1991; 100: 439-44

11. Rello J, Ausina V, Castella J, Net A, Prats G. Nosocomial respiratory tract infections in multiple trauma patients. Influence of level of consciousness with implcations for therapy. Chest 1992; 102: 525-29

12. Driks MR, Craven DE, Celli BR, Manning M, Burke RA, Garvin GM, Kunches LM, Farber HW, Wedel SA, McCabe WR. Nosocomial pneumonia in intubated patients give sucralfate as compared with antacids or histamine type 2 blockers. N Engl J Med 1987; 317: 1376-82

13. Kerver AJH, Rommes JH, Mevissen-Verhage EAE, Hulstaert PF, Vos A, Verhoef J, Wittebol P. Prevention of colonization and infection in critically ill patients; a prospective randomized study. Crit Care Med 1988; 16: 1087-93

14. Fagon JY, Chastre J, Hance AJ, Domart X, Trouillet JL, Gibert C. Evaluation of clinical judgement in the identification and treatment of nosocomial pneumonia in ventilated patients. Chest 1993; 103: 547-53

15. Torres A, De la Bella casa JP, Xaubet A, Gonzalez J, Rodriguez-Roisin R, Jimenez de Anta MT, et al. Diagnostic value of quantitative cultures of bronchoalveolar lavage and telescoping plugged 
catheters in mechanically ventilated patients with bacterial pneumonia. Am Rev Respir Dis 1989; 140: 306-10

16. Scheld WM, Mandell GL. Nosocomial pneumonia: Pathogenesis and recent advances in diagnosis and therapy. Rev Infect Dis 1991; 13 (Suppl 9): 743-751

17. Horan T, Culver D, Jarvis W, et al. Pathogens causing nosocomial infections. Antimicrob Newslett 1988; 5: 65-7

18. Bartlett JG, O'Keefe P, Tally FP, Louie TJ, Gorbach SL. Bacteriology of hospital acquired pneumonia. Arch Intern Med 1986; 146: 868-71

19. Johanson WG, Pierce AK, Sanford JP. Changing pharyngeal bacterial flora of hospitalized patients. N Engl J Med 1969; 281: 1137-40

20. Johanson WG, Pierce AK, Sanford JP, Thomas GD. Nosocomial respiratory infections with gram-negative bacilli: The significance of colonization of the respiratory tract. Ann Intern Med 1972; 77: 701-6

21. Torres A, El-Ebiary M, Gonzalez J, Ferrer M, Puig de la Bellacasa J, Gené A, Martos A, Rodriguez-Roisin R. Gastric and pharyngeal flora in nosocomial pneumonia acquired during mechanical ventilation. Am Rev Respir Dis 1993; 148: 352-357

22. Schwarz SN, Dowling JN, Benkovic C, DeQuittner-Buchanan M, Prostko T, Yee RB. Sources of Gram-negative bacilli colonizing the trachea of intubated patients. J Infect Dis 1978; 138: 227231

23. Daschner F, Reuschenbach K, Pfisterer J, Kappstein I, Vogel W, Krieg N, Just H. The influence of stress ulcer prophylaxis on the incidence of pneumonia in artficially ventilated patients. Anaesthesist 1987; 36: 9-18

24. Torres A, Serra-Batlles J, Ros E, Piera C, Puig de la Bellacasa J, Cobos A, Lomena F, RodriguezRoisin R. Pulmonary aspiration of gastric contents in patients receiving mechanical ventilation: the effect of body position. Ann Intern Med 1992; 116: 540-543

25. Reinarz JA, Pierce AK, Mays BB et al. The potential role of inhalation therapy equipment in nosocomial pulmonary infection. J Clin Invest 1967; 44: 831-39

26. McNamara MJ, Hill MC, Balows A et al. A hospital outbreak of Klebsiella pneumonia from inhalation therapy with contaminated aerosol solutions. A Rev Respir Dis 1967; 95: 454-60

27. Ramphal R, Small PM, Shands JW, Fischlschweiger W, Small PA. Adherence of Pseudomanas aeruginosa to tracheal cells injured by influenza infection or by endotracheal intubation. Infect Immun 1980; 27: 614-9

28. Niederman MS, Merill WW, Ferranti RD, Pagano KM, Palmer LB, Reynolds HY. Nutritional status and bacterial binding in the lower respiratory tract of patients with chronic tracheostomy. Ann Intern Med 1984; 100: 795-800

29. Niederman MS, Rafferty TD, Sasaki CT, Merrill WW, Matthay RA, Reynolds HY. Comparison of bacterial adherence to ciliated and squamous epithelial cells obtained from the human respiratory tract. Am Rev respir Dis 1983; 127: 85-90

30. Woods DE. Role of fibronectin in the pathogenesis of gram-negative bacillary pneumonia. Rev Infect Dis 1987; 9 (Suppl 4): 386-390 
31. Du Moulin, Paterson DG, Hedley-Whyte J, Lisbon A. Aspiration of gastric bacteria in antacidtreated patients: a frequent cause of postoperative colonisation of the airway. Lancet $1982 ;: 242$ 5

32. Hillman KM, Riordan T, O'Farrel SM, Tabaqchal S. Colonization of gastric contents in critically ill patients. Crit Care Med 1982; 10: 444-447

33. Garvey BM, McCambley JA, Tuxen DV. Effects of gastric alkalization on bacterial colonization in critically ill patients. Crit Care Med 1989; 17: 211-216

34. Caballero GA, Ausman RK, Quebbeman EJ, Schulte WJ, Lin L. Gastric secretion pH measurement: what you see is not what you get! Crit Care Med 1990; 18: 396-99

35. Dobkin ED, Valcour A, McCloskey CR, Allen L, Kambe JC, Gleason E, Orlando III R, Berger R, Yeston NS. Does pH paper accurately reflect gastric pH? Crit Care Med 1990; 18: 985-8

36. Fimmel $\mathrm{CJ}$, Etienne $\mathrm{A}$, Cilufo $\mathrm{A}$, et al. Long-term ambulatory gastric $\mathrm{pH}$ monitoring: validation of a new method and effect of $\mathrm{H}_{2}$-antagonists, Gastroenterology 1985; 88: 1842-1851

37. Inglis TJJ, Sheratt MJ, Sproat LJ, Gibson JS, Hawkey PM. Gastroduodenal dysfunction and bacterial colonisation of the ventilated lung. Lancet 1993; 341: 911-913

38. Reusser P. Zimmerli W, Scheidegger D, Marbet GA, Buser M, Klaus G. Role of gastric colonization in nosocomial infections and endotoxemia: a prospective study in neurosurgical patients on mechanical ventilation. J Infect Dis 1989; 160: 414-421

39. Cade JF, McOwat E, Siganporia R, Keighly C, Presneill J, Sinickas V. Uncertain relevance of gastric colonization in the seriously ill. Intensive Care Med 1992; 18: 210-217

40. McCarthy DM. Sucralfate. N Engl J Med 1991; 325: 1017-1025

41. Tryba M. Risk of acute stress bleeding and nosocomial pneumonia in ventilated intensive care patients: sucralfate versus antacids. Am J Med 1987; 83 (suppl 3B): 117-24

42. Laggner AN, Lenz K, Graninger W et al. Stressulcusprophylaxe auf einer internen. Anaesthesist 1988; 37: 704-710

43. Kappstein I, Schulgen G, Friedrich T, Hellinger P, Benzing A, Geiger K, et al. Incidence of pneumonia in mechanically ventilated patients treated with sucralfate or cimetidine as prophylaxis for stress bleeding: bacterial colonization of the stomach. Am J Med 1991; 91 (suppl 2A): 125S-31S

44. Simms HH, DeMaria E, McDonald L, Peterson D, Robinson A, Burchard KW. Role of gastric colonization in the development of pneumonia in critically ill trauma patients: results of a prospective randomized trial. J Trauma 1991; 31: 531-537

45. Eddlestone JM, Vohra A, Scott P, Tooth JA, Pearson RC, McCloy RF, et al. A comparison of the frequency of stress ulceration and secondary pneumonia in sucralfate- or ranitidine-treated intensive care patients. Crit Care Med 1991; 19: 1491-6

46. Moore JG, Englert E. Circadian rythm of gastric acid secretion in man. Nature 1970; 226: 12611262

47. Tryba $M$. Sucralfate versus antacids or $\mathrm{H}_{2}$-antagonists for stress ulcer prophylaxis: a metaanalysis on efficacy and pneumonia rate. Crit Care Med 1991; 19: 942-949

48. Tryba MY, Mantey-Stiers F. Antibacterial activity of sucralfate in human gastric juice. Am J Med 1987; 83 (suppl 3B): 125-127 
49. Daschner F, Kappstein I, Engels I. Antibacterielle Aktivität von Sucralfat in kunstlichem Magensaft. Intensivmed 1987; 83: 163-166

50. Pingleton SK, Hinthorn DR, Liu C. Enteral nutrition in patients receiving mechanical ventilation. Am J Med 1986; 80: 827-32

51. Jacobs S, Chang RWS, Lee B, Bartlett FW. Continuous enteral feeding: a major cause of pneumonia among ventilated intensive care unit patients. J Parenteral Enteral Nutrition 1990; 14: $353-6$

52. Ibanez J, Penafiel A, Raurich JM, Marse P, Jorda R, Mata F. Gastroesophageal reflux in intubated patients receiving enteral nutrition: effect of supine and semirecumbent positions. J Parenteral Enteral Nutrition 1992; 16: 419-422

53. Stoutenbeek CP, Van Saene HKF, Miranda DR, Zandstra DF. The effect of selective decontamination of the digestive tract on colonization and infection rate in multiple trauma patients. Intens Care Med 1984; 10: 185-92

54. Aerdts SJA, Clasener HAL, Van Dalen R, Van Lier HJJ, Vollaard EJ, Festen J. Antibiotic prophylaxis of respiratory tract infection in mechanically ventilated patients. Chest 1991; 100: 783-91

55. Gastinne H, Wolff M, Delatour F, Faurisson F, Chevret S. A controlled trial in intensive care units of selective decontamination of the digestive tract with nonabsorbable antibiotics. $N$ Engl J Med 1992; 326: 594-9

56. Hammond JMJ, Potgieter PD, Saunders GL, Forder AA. Double-blind study of selective decontamination of the digestive tract in intensive care. Lancet 1992; 340:5-9

57. Cockerill III FR, Muller SR, Anhalt JP, Marsh HM, Farnell MB, Mucha P, et al. Prevention of infection in critically ill patients by selective decontamination of the digestive tract. Ann Intern Med 1992; 117: 545-53

58. Gastinne H, Wolff M, Lachatre G, Boiteau R, Savy FP. Antibiotic levels in bronchial tree and in serum, during selective deigestive decontamination. Intensive Care Med 1991; 17: 215-218

59. Stoutenbeek CP, Van Saene HKF, Miranda DR, Zandstra DF, Langrehr D. The effect of oropharyngeal decontamination using topical nonabsorbable antibiotics on the incidence of nosocomial respiratory infections in multiple trauma patients. J Trauma 1987; 27: 357-364

60. Brun-Buisson C, Legrand P, Rauss A, Richard C, Montravers F, Besbes M, Meakins J, Soussy C, Lemaire $F$. Intestinal decontamination for control of nosocomial multiresistant gram-negative bacilli: study of an outbreak in an intensive care unit. Ann Intern Med 1989; 110: 873-81

61. Rodriguez-Roldan JM, Altuna-Cuesta A, Lopez A, Carillo A, Garcia J, Leon J, et al. Prevention of nosocomial lung infection in ventilated patients: Use of an antimicrobial pharyngeal nonabsorbable paste. Crit Care Med 1990; 18: 1239-42

62. Pugin J, Auckenthaler R, Lew D, Suter PM. Oropharyngeal decontamination decreases incidence of ventilator-associated pneumonia. JAMA 1991; 265: 2704-10

63. Kropec A, Huebner J, Riffel M, Bayer U, Benzing A, Geiger K, Daschner FD. Exogenous or endogenous reservoirs of nosocomial Pseudomonas aeruginosa and Staphylococcus aureus infections in a surgical intensive care unit. Intensive Care Med 1993; 19: 161-165 
64. Murthy SK, Baltch AL, Smith RP, Desjardin EK, Hammer MC, Conroy JV, Michelsen PB. Oropharyngeal and fecal carriage of Pseudomonas aeruginosa in hospital patients. J Clin Microbiol 1989; 27: 35-40

65. Noone MR, Pitt TL, Bedder M, Hewlett AM, Rogers KB. Pseudomonas aeruginosa colonisation in an intensive therapy unit: role of cross infection and host factors. Br Med J 1983; 286: 341-344

66. Flynn DM, Weinstein RA, Nathan C, Gaston MA, Kabins SA. Patients' endogenous flora as the source of "nosocomial" Enterobacter in cardiac surgery. J Infect Dis 1988; 156: 363-368

67. Wells FC, Newsom SWB, Rowlands C. Wound infection in cardiothoracic surgery. Lancet 1983; 1: $1209-1210$

68. Farmer JJ III, Weinstein RA, Zierdt CH, Brokopp CD. Hosptial outbreaks caused by Pseudomonas aeruginosa: importance of serogroup 011. J Clin Microbiol 1982; 16: 266-70

69. Cefai C, Richards J, Gould FK, McPeake P. An outbreak of Acinetobacter respiratory tract infection resulting from incomplete disinfection of ventilatory equipment. J Hosp Infect 1990; 15: 177-182

70. Freeman R, McPeake PK. Acquisition, spread, and control of Pseudomonas aeruginosa in a cardiothoracic intensive care unit. Thorax 1982; 37: 732-736

71. Craven DE, Conolly MG, Livhtenberg DA. Contamination of mechanical ventilators with tubing changes every 24 or 48 hours. N Engl J Med 1982; 306: 1505-1508

72. Smith PW, Massanari RM. Room humidifiers as the source of Acinetobacter infections. JAMA 1977; 237: 795-798

73. Fagerman KE, Paauw JA, Dean RE. Bacterial contamination of enteral solutions. JPEN 1985; 9 : 378

74. Levy J, Van Laethem Y, Verhaegen G, Perpete C, Bytzler JP, Wenzel RP. Contaminated enteral nutrition solutions as a cause of nosocomial bloodstream infection: a study using plasmid fingerprinting. J Parent Enteral Nutr 1989; 13: 228-234

75. Thurn J, Crossley K, Gerdts A, Maki M, Johnson J. Enteral hyperalimentation as a source of nosocomial infection. J Hosp Infection 1990; 15: 203-217

76. Weinstein RA, Nathan C, Gruenfelder R, Kabins SA. Endemic aminoglycoside resistance in gram-negative bacilli: epidemiology and mechanisms. J Infect Dis 1980; 141: 338-345

77. Gaynes RP, Weinstein RA, Smith J, Carman M, Kabins SA. Control of aminoglycoxide resistance by barrier precautions. Infection Control 1983: 4; 221-4

78. Maki DG. Control of colonization and transmission of pathogenic bacteria in the hospital. Ann Intern Med 1978; 89: 777-780

79. Olson B, Weinstein RA, Nathan C, Chamberlin W, Kabins SA. Epidemiology of endemic Pseudomonas aeruginosa: Why infection control efforts have failed. J Infect Dis 1984; 150: 808-16

80. Widmer AF, Wenzel RP, Trilla A, Bale MJ, Jones RN, Doebbeling BN. Outbreak of Pseudomonas aeruginosa infections in a surgical intensive care unit: probable transmission via hands of a health care worker. Clin Infect Dis 1993; 16: 372-376

81. Mayer JA, Dubbert PM, Miller M, Burkett PA, Chapman SW. Increasing handwashing in an intensive care unit. Infect Control 1986; 7: 259-262 
82. Maki DG, Alvarado CJ, Hassemer CA, Zilz MA. Relation of the inanimate hospital environment to endemic nosocomial infection. N Engl J Med 1982; 307: 1562-1566

83. Massanari RM, Hierholzer WJ Jr. A crossover comparison of antiseptic soaps on nosocomial infection rates in intensive care units [abstract]. Am J Infect Control 1984; 12: 247-248

84. Doebbeling BN, Stanley GL, Sheetz CT, Pfaller MA, Houston AK, Annis L, Li N, Wenzel RP. Comparative efficacy of alternative hand-washing agents in reducing nosocomial infections in intensive care units. N Engl J Med 1992; 327: 88-93

85. Albert RK, Condie F. Hand-washing patterns in medical intensive-care units. N Engl J Med 1981; 304: 1465-1466

86. Quraishi ZA, McGuckin M, Blais FX. Duration of handwashing in intensive care units: a descriptive study. Am J Infect Control 1984; 12: 83-87

87. Graham M. Frequency and durantion of hadwashing in an intensive care unit. Am J Infect Control 1990; 18: 77-81

88. Frank U, Lenz W, Damrath E, Kappstein I, Daschner FD. Nasal carriage of Staphylococcus aureus treated with topical mupirocin in a children's hospital. J Hosp Infect 1989; 13: 117-120 


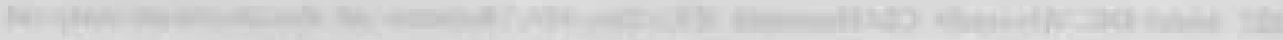

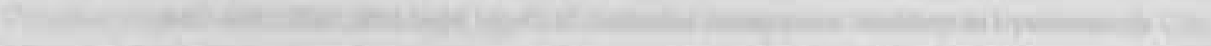

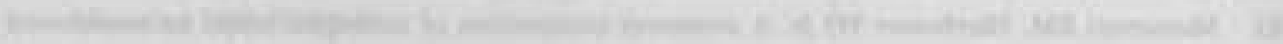

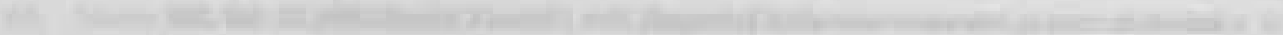
Than

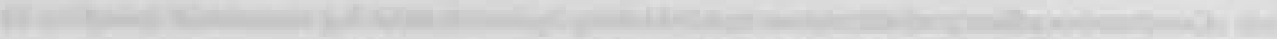

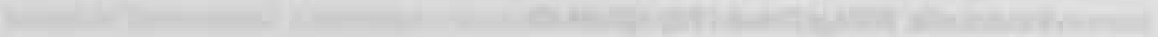

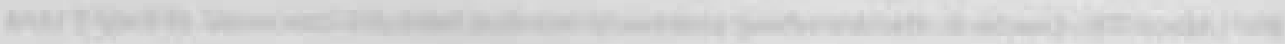

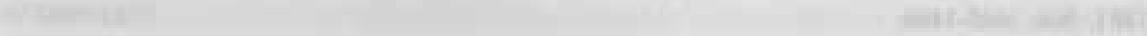

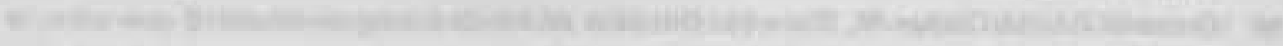

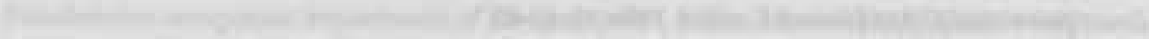

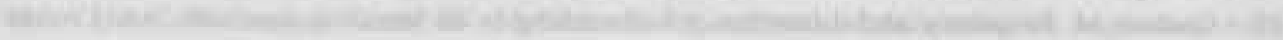
-

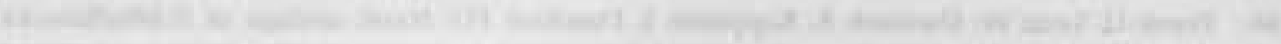
-

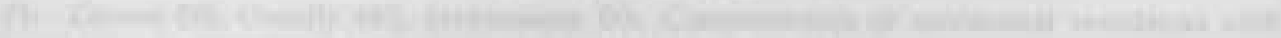
a

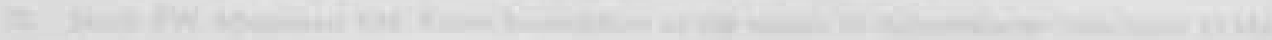

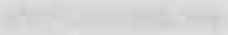

3nt

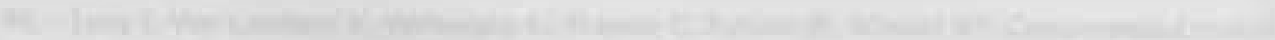

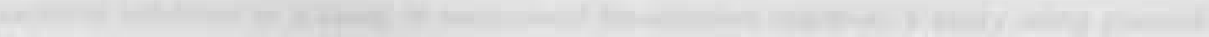

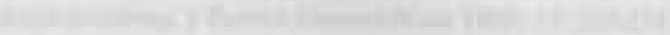

(19)

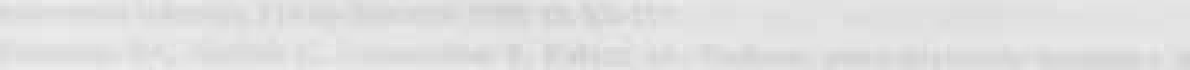

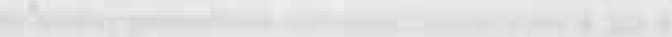

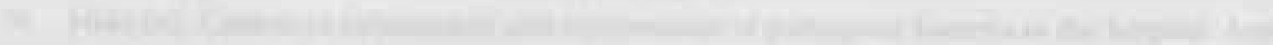

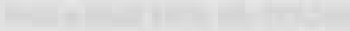

then

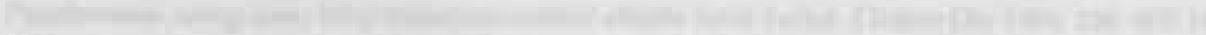

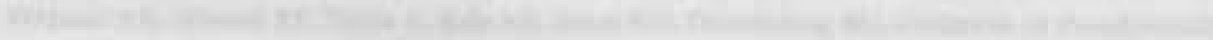
tran 
Chapter 2

SELECTIVE DECONTAMINATION OF THE DIGESTIVE TRACT IN ICUPATIENTS: MORE EVIDENCE AGAINST ITS USE 


\section{INTRODUCTION}

The results of the European Prevalence of Infections on Intensive Care Study (EPIIC Study), conducted in 1992, demonstrated that Selective Decontamination of the Digestive Tract (SDD) as a method of infection prevention, was used by $47 \%$ of the Dutch Intensive Care Units (National Symposium of Hospital Infections in Intensive Care, Amsterdam, March 12th 1993). Although SDD is an established method of infection prevention in long-term granulocytopenic patients (1), its use remains controversial with respect to mechanically ventilated ICU-patients, because no beneficial effects on mortality and costs have been demonstrated so far, and, at least theoretically, a constant risk of increased antibiotic resistance is present.

Van Dalen and van der Meer concluded three years ago that "the benefits of this potentially attractive method of infection prevention as well as the subgroup of patients who are likely to benefit most have yet to be established (2)". A definitive judgement on the value of SDD in mechanically ventilated ICU-patients can only be made when based on results obtained from well-designed studies, preferably double-blind, with patient populations large enough to draw statistically reliable conclusions, and in which not only clinical endpoints but also side-effects, such as selection of antibiotic resistant bacteria and costs, were studied. The aim of this paper is to review recent studies on the routine use of SDD in mechanically ventilated ICU-patients.

\section{SELECTIVE DECONTAMINATION}

Nosocomial infections in the ICU, especially pneumonia, are associated with prolonged ICU-stay, increased costs for medical care and increased mortality $(4,5)$. The incidence of pneumonia in mechanically ventilated patients varies between 10 and $85 \%$, depending on the criteria used to establish the diagnosis $(6,7)$. The correlation between colonization of the upper respiratory tract with Enterobacteriaceae, Pseudomonas aeruginosa and Staphylococcus aureus, the socalled potential pathogenic microorganisms (ppmo), and the development of nosocomial pneumonia has already been demonstrated in the early seventies $(8,9)$.

The intestinal flora of the patient has been assumed to be the most important source of ppmo, eventually causing infection of the lower respiratory tract $(10,11)$. SDD is based on the enteral administration of non-absorbable antibiotics and the application of an oropharyngeal paste, containing the same antimicrobial agents. The anaerobic intestinal flora should remain unaffected (12), because of its alleged 
preventive effect on colonization with aerobic Gram-negative bacteria: the principal of colonization resistance (13). Colistin and an aminoglycoside are generally used in the SDD-regimen, because both agents are hardly absorbed, do not affect the anaerobic flora, and are effective against Gram-negative microorganisms and Staphylococcus aureus, the most important species in the etiology of nosocomial pneumonia. To prevent overgrowth with yeasts, amphotericin B has been added to the regimen (12). In addition, systemic prophylaxis has been used in many studies to prevent 'early' infections, occurring before selective decontamination is achieved.

\section{CLINICAL STUDIES}

The patient populations, the inclusion criteria, the SDD-regimens used, the results and the costs of SDD of seven recently published clinical studies are summarized in Table 1 (14-20). In contrast to studies published in the eighties (2), the patient populations under study, the SDD-regimens and study designs were comparable in these recent studies. In all studies mixed populations of surgical, medical and trauma patients were investigated, and patients were comparable regarding underlying disease, APACHE II-score and age (14-20). All studies were prospective and randomised (14-20), and three were double-blind and placebo-controlled. Systemic antibiotic prophylaxis during the first days of admission was administered in six out of seven studies $(14,16-20)$.

Finally, a distinction between 'early' and 'late' (or primary and secondary) pneumonia was made in all analyses (14-20). Early (or primary) infections are usually caused by microorganisms already colonizing the patient on admission, such as Streptococcus pneumoniae, Moraxella catarrhalis and Haemophilus influenzae (12). Pneumonia caused by these species of bacteria cannot be prevented by SDD, in the first place because eradication of these pathogenic microorganisms by SDD takes several days $(7,12,21)$, and secondly because SDD cannot eradicate bacteria already colonizing the lower respiratory tract, which in most cases has already occurred before admission to the ICU. Late (or secondary) pneumonia is usually caused by typical species, such as Enterobacteriaceae, Pseudomonas aeruginosa and Staphylococcus aureus, which colonize patients during their ICUstay. In most studies the distinction between 'early' and 'late' cases of pneumonia is based on the moment of diagnosis of infection; prior to or after 48-96 hours after admission to the ICU (14-20). 
Table 1: The regimens of SDD, clinical outcomes and costs in seven recently published trials.

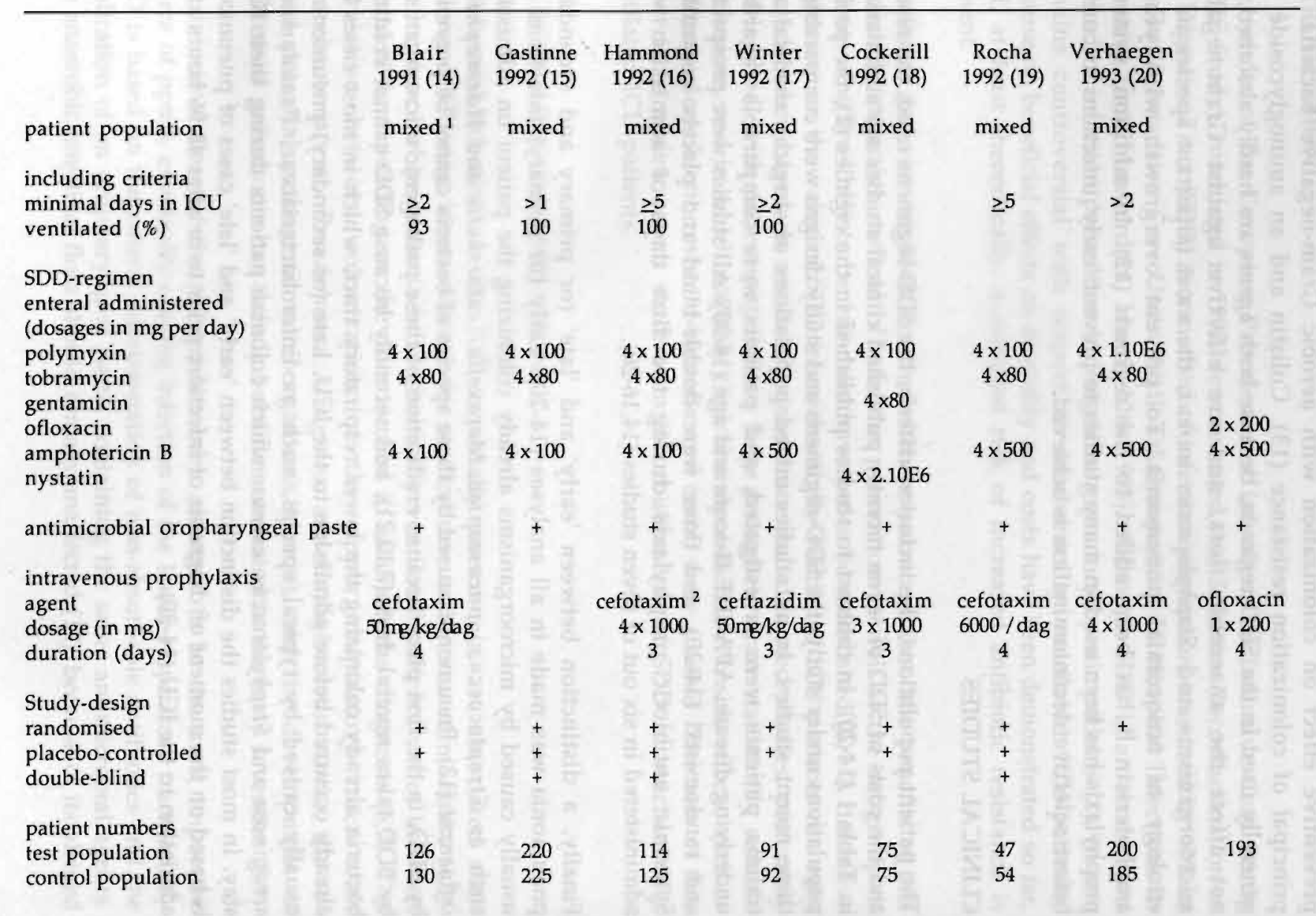


historical control group

Clinical outcome

test population

control population

historical control group

p-value

Mortality (\%)

test population

control population

historical control group

p-value

Costs SDD-medication (in $\mathrm{fl})^{4}$

per patient/ per day

mean per patient

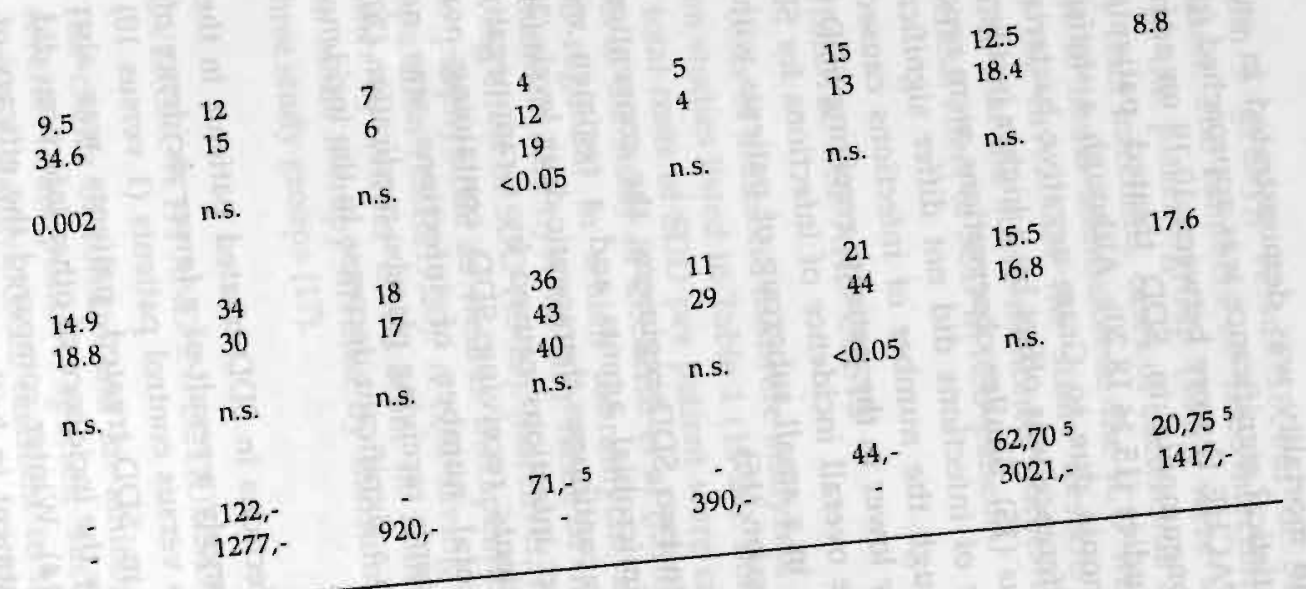

1 = surgical, trauma and medical patients

nopulation also received systemic prophylaxis

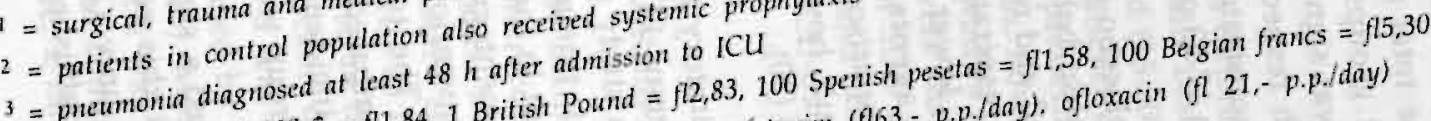

$4=$ valuta change: 1 US $\$=f 11,84,1$ British Pound $=f(2,83,100$ Spentsh pestaxim $(f 163,-p . p . /$ day $)$, ofloxacin $(f l 21,-p . p . /$ day $)$

$5=$ exclusive the costs of ceftazidim (jt212,- p.p./day).

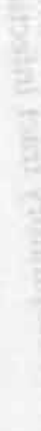


A statistically significant reduction in mortality was demonstrated in only one study (19), while in another study statistical significance was approached $(p=0.07)$ in a subgroup of patients with an APACHE II-score between 10-19 on admission (14). A lower incidence of 'late' pneumonia in SDD treated patients was demonstrated in four out of seven studies $(15,16,18,20)$. Although a statistically significant lower incidence of pneumonia due to Gram-negative bacteria was demonstrated in a French trial, this difference was offset by a higher incidence of pneumonia due to Staphylococcus aureus (15). Similar observations were reported by Hammond et al.: the total number of infections did not differ significantly between both treatment groups, although the number of infections caused by Gram-negative bacteria was significantly lower in the patients receiving SDD (16). A significant benefit with respect to the overall incidence of infections for SDDtreated patients was demonstrated only in a small subgroup of patients with an APACHE II-score between 17-23 on admission (16).

Verhaegen compared a placebo-group to two SDD-regimens: the conventional SDD-regimen with non-absorbable antimicrobial agents and a regimen with ofloxacin, which is absorbed and results in continuous therapeutic drug levels (20). Although the number of respiratory tract infections caused by Gram-negative bacteria was significantly lower in patients receiving SDD containing nonabsorbable antimicrobial agents, the total number of infections was not significantly reduced, in comparison to patients receiving placebo-medication (20). The use of ofloxacin did result, however, in a significant decrease in the incidence of respiratory tract infections (20).

The lower incidence of respiratory tract infections in SDD-treated patients in the study of Cockerill et al (4 versus 14) was largely a result of a lower incidence of purulent tracheobronchitis in study patients versus control patients (1 versus 10) (18). A lower incidence of pneumonia in SDD-treated patients was also demonstrated by Blair et al, but in their study the incidence of other infections did not differ between both treatment groups (14). Winter compared the efficacy of SDD in ICU-patients with conventional treatment in both a concomitant and a historical control group (17). The total number of 'late' infections in patients receiving SDD was lower as compared to both control groups (3\% versus $32 \%$ and $35 \%$ ), and the difference in incidence between the SDD-population and the concomitantly studied control group was statistically significant (17).

Finally, Rocha et al demonstrated a significant decline in the overall incidence of respiratory tract infections, but this reduction was based on differences in the incidence of 'early' infections only (19). In this study, the diagnosis 'early' respiratory tract infection was established in one out of 47 SDD-patients (receiving 
cefotaxim $6 \mathrm{~g} /$ day), versus 18 out of 54 (33\%) patients receiving placebo medication. The numbers of 'late' infections, six in the SDD-group (13\%) and seven in the placebo-group (13\%), were similar. In addition, the numbers of urinary tract infections, cases of bacteremia and wound infections developing after at least 48 hours admission to the ICU were similar in both study groups (19). Given the caveats of the study designs and endpoint evaluation, one may conclude that the above-metioned studies fail to provide convincing evidence for a beneficial effect of SDD in ICU-patients.

\section{ANTIBIOTIC USE AND COSTS}

The costs of antibiotic use were analyzed, albeit in different ways, in six out of the seven studies listed in Table 1 (15-20). Both the daily costs of SDD-medication and the total costs of SDD per patient were calculated (15-20). The relatively low total costs in the study of Cockerill et al ( $\{390$,- per patient) were a result of a cheaper SDD-regimen, in which tobramycin and amphotericin B were replaced by gentamicin and nystatin (18). None of the studies, however, demonstrated a costsaving effect of SDD (15-20). Moreover, in four studies the total costs of antibiotics (for prophylactic as well as therapeutic use) were distinctly higher in the SDDpopulation $(15,16,19,20)$. A cost-saving effect of SDD could not be demonstrated either by Winter et al, who, in addition, found that the number of days of antibiotic therapy divided by the number of ICU-days was comparable in their three study groups (17).

\section{OVERGROWTH AND INFECTIONS DUE TO GRAM-POSITIVE COCCI}

The choice of colistin and an aminoglycoside in the SDD-regimen implies that several Gram-positive species, such as Enterococcus faecalis and Coagulase negative staphylococci, resistant to these agents, will not be attacked. Although overgrowth and infections due to these resistant species have been reported by some (22), these complications were considered as innocent side-effects by others (23). Nevertheless, recent publications underscore the pathogenetic importance of these phenomena. For instance, a significant decrease in the incidence of pneumonia caused by Gram-negative bacteria was almost completely offset by an increase in the incidence of pneumonia caused by Gram-positive bacteria, in two of the seven studies listed in Table $1(15,16)$. Moreover, the number of cases of bacteremia with staphylococci or enterococci was significantly higher in patients receiving the conventional SDD-regimen as compared to control patients in the study of Verhaegen et al (20). Furthermore, a fatal case of peritonitis caused by 
Staphylococcus epidermidis after intestinal perforation was described in a patient receiving SDD (24). Finally, an epidemic of infections with methicillin-resistant Staphylococcus aureus, also resistant to the antibiotics used in SDD, has been described (25). Although the use of SDD was not the primary cause of the epidemic, the authors suggested that SDD substantially contributed to spreading of the bacteria to cause the epidemic within the ICU (25).

\section{SDD AND ANTIBIOTIC RESISTANCE}

Antibiotic resistance associated with the use of SDD is encountered with increasing frequency. Rocha et al reported on a significant increase of Staphylococcus aureus and Acinetobacter species resistant to cefotaxim and tobramycin, although the number of infections caused by these resistant species did not increase (19). In addition, Nau and coworkers found the number of Staphylococcus aureus resistant to cefuroxim, oxacillin and gentamicin, and of Pseudomonas aeruginosa resistant to gentamicin, to be significantly increased following SDD, when compared to historical data (26). However, in both studies it remained unclear how many copy strains were included in the analysis $(19,26)$. Verhaegen performed an analysis of only those strains causing infection (20). In this study conventional SDD resulted in an increase of tobramycin-resistant Enterobacteriaceae and of Staphylococcus aureus resistant to oxacillin and amikacin. The prophylactic regimen containing ofloxacin resulted in an increase of Enterobacteriaceae resistant to tobramycin, amikacin and ofloxacin, and of Pseudomonas aeruginosa resistant to ofloxacin. Because almost all oxacillinresistant strains were also resistant to tobramycin and ofloxacin, both SDDregimens probably contributed to the selection of oxacillin-resistant strains of Staphylococcus aureus (20). Recently, an increase of tobramycin-resistant strains of Pseudomonas aeruginosa was reported after the use of SDD for four years in one out of two ICU-wards. In this study only one isolate per patient, derived from samples obtained by protected specimen brush, was analysed (28). The increase in the number of resistant isolates, from $0 \%$ in 1987 to $42.9 \%$ in 1991 , was observed only in the ICU-ward where SDD was used. The percentage of resistant isolates did not change in the other ward: $6.3 \%$ in 1987 and 6.5\% in 1991 (27).

\section{CONCLUDING REMARKS}

\section{Incidence of pneumonia}

Remarkably, a decrease in the incidence of 'late' pneumonia was not observed in five out of seven recent studies $(15,16,18-20)$. This is in contrast to earlier studies, 
in which almost without exception a lower incidence of pneumonia was reported in patients treated with SDD $(7,12,28-32)$. Interestingly, this difference seems to be a result of the differences in the incidence of pneumonia in control patients. In the seven studies listed in Table 1 the incidence among control patients ranged from 13 to $35 \%(14-20)$. However, in previous investigations the incidences among control patients ranged from 45 to $85 \%(7,12,28-30,32)$. Exceptionally low incidences of pneumonia were reported in the study from Ledingham et al, both in treated and in non-treated patients ( $2 \%$ and $11 \%$ respectively) (31). However, since only $38 \%$ of the patients were intubated, the results could hardly be compared to those reported in other studies. In contrast to the large differences in incidence of pneumonia in control patients, the incidence in patients receiving SDD did not differ much: 2 to $15 \%$ and 4 to $15 \%$ in the early and recently published studies respectively $(7,12,14-20,28,32)$. Therefore, the lack of a positive effect of SDD on the incidence of pneumonia in the later investigations seems to be a result of a lower incidence of pneumonia among control patients, rather than absence of the alleged protective effect of SDD in the test populations.

Several explanations could be put forward to account for the apparent decline in pneumonia incidence in control patients. For instance, no distinction was made between 'early' and 'late' cases of pneumonia in three studies, and as a result, 'early' infections might have influenced the total incidence of pneumonia to a substantial degree $(12,28,30)$. In addition, the combination of clinical, radiographic and microbiological criteria to establish the diagnosis of pneumonia, which combination has a high sensitivity but low specificity (33), might also have contributed to the high incidences $(7,12,28-32)$. When using these criteria, falsepositive diagnoses may be made because colonization of the lower respiratory tract or tracheobronchitis might erroneously be interpreted as pneumonia. Indeed, tracheobronchitis occurs more frequently in a population with an expected higher incidence of pneumonia (i.e. control patients). Moreover, the use of criteria with low specificity might have influenced the results in another way. For instance, antibiotics present in the oropharyngeal paste may yield effective drug levels in tracheal secretions, leading to false-negative results of microbiological cultures in patients receiving SDD (34). Therefore, bronchoscopy with bronchoalveolar lavage (BAL) and/or protected specimen brush (PSB) probably provide the most accurate diagnosis of pneumonia in mechanically ventilated patients (33). However, since bronchoscopic techniques were used in only three of the seven studies listed in Table $1(15,17,19)$, this argument cannot explain the differences between the earlier and the more recently published trials. Finally, one should realize that of the older studies mentioned $(7,12,28-32)$, four were not randomised $(12,30-32)$ - although in one study a crossover model in two ICU's was used -, and three used a historical 
control group $(12,31,32)$; of the randomised studies none was placebo-controlled or double-blind $(7,12,28-32)$.

\section{The SDD-regimen}

The composition of the conventional SDD-regimen is open for discussion. BrunBuisson et al demonstrated that selective decontamination of the intestine did not influence the total number of infections (22), underscoring prior observations made by Stoutenbeek and coworkers (32). In the latter study the addition of an oropharyngeal paste to the regimen appeared to decrease the incidence of 'late' pneumonia, but the total incidence of pneumonia still did not differ significantly from the incidence in a historical control group. Only when systemic prophylaxis was added a significant fall in the incidence of respiratory tract infections was observed (32). Therefore, systemic prophylaxis was given until all ppmo were eradicated in several early SDD-studies $(7,12,32)$. In two of these the mean duration of systemic prophylaxis was 9 and 8,4 days respectively, whereas the mean duration of ICU-stay was 11 and 13,4 days respectively $(7,12)$. Probably, the prolonged systemic prophylaxis has had a substantial influence on the reported difference between treated and non-treated patients. In later studies the duration of systemic prophylaxis was given independently of the eradication of ppmo from the gastrointestinal tract, and shortened to three or four days, or abandoned completely (14-20,30,31). However, because of differences in study-design, patient populations and criteria for infection in these studies, it remains unknown to what extent incidences of pneumonia have been influenced by systemic prophylaxis.

The 'selective' part of SDD refers to the fact that the anaerobic intestinal flora remains intact, while ppmo are eliminated, which is presumed to offer protection against colonization with ppmo. Van der Waay et al demonstrated in an animal model that an intact anaerobic flora contributed to so-called colonization resistance, thereby preventing overgrowth with ppmo (35). However, the impact of colonization resistance on the effects of SDD on intestinal colonization has never been studied. It is possible that antibiotics, administered orally, eradicate ppmo and prevent new colonization, independent of colonization resistance. The secondary Gram-positive infections during SDD even indicate that colonization resistance has been disturbed. In addition, the impact of amphotericin B on SDD has never been studied in a controlled design.

The effects of SDD on colonization of oropharynx and rectum have been studied by Tetteroo et al (21). Incomplete decontamination was observed in 49 out of 154 episodes (32\%) and recolonization with Gram-negative bacteria resulting in three respiratory tract infections was observed after SDD had been stopped (36). 
Therefore, SDD may only suppress rather than eliminate the targeted microbial flora.

\section{Final conclusions}

Based on the available data there is no scientific justification for the routine use of SDD in an Intensive Care unit. The growing number of publications reporting overgrowth and infections due to Gram-positive microorganisms $(15,16,20,24,25)$, and the absence of any cost saving effects of SDD (15-20) should further discourage its routine use in mechanically ventilated ICU-patients. Finally, the incidental reports of increases in bacterial resistance to the antibiotics used in SDD should caution us even more $(19,20,26,27)$. 


\section{REFERENCES}

1. Clasener HAL, Vollaard EJ, Saene HKF van. Long-term prophylaxis of infection by selective decontamination in leukopenia and in mechanical ventilation. Rev Infect Dis 1987; 9: 295-328

2. Dalen $\mathrm{R}$ van, Meer JWM van der. Klinisch belang van selectieve decontaminatie bij patiënten op de intensive care-afdeling. Ned Tijdschr. Geneeskd 1990; 134: 1165-8

3. Loirat $\mathrm{Ph}$. Selective digestive decontamination in Intensive Care Unit patients. Intensive Care Med 1992; 18: 182-8

4. Craven DE, Kunches LM, Kilinsky V, Lichtenberg DA, Make BJ, McCabe WR. Risk factors for pneumonia and fatality in patients receiving continuous mechanical ventilation. Am Rev Respir Dis 1986; 133: 792-6

5. Kappstein I, Schulgen G, Beyer U, Geiger K, Schumacher M, Daschner FD. Prolongation of hospital stay and extra costs due to ventilator-associated pneumonia in an intensive care unit. Eur J Clin Microbiol Infect Dis 1992; 11: 504-8

6. Fagon JY, Chastre J, Domart Y, et al. Nosocomial pneumonia in patients receiving continuous mechanical ventilation. Am Rev Respir Dis 1991; 139: 877-84

7. Kerver AJH, Rommes JH, Mevissen-Verhage EAE, et al. Prevention of colonization and infection in critically ill patients; a prospective randomized study. Crit Care Med 1988; 16: 1087-93

8. Johanson WG, Pierce AK, Sanford JP. Changing pharyngeal bacterial flora of hospitalized patients: Emergence of gram-negative bacilli. New Engl J Med 1969; 281: 1137-40

9. Johanson WG, Pierce AK, Sanford JP, Thomas GD. Nosocomial respiratory infections with gram-negative bacilli: The significance of colonization of the respiratory tract. Annals Intern Med 1972; 77: 701-6

10. Tryba M. The gastropulmonary route of infection: fact or fiction? Am J Med 1991; 91 (Suppl 2A): 135S-146S

11. Heyland D, Mandell LA. Gastric colonization by Gram-negative bacilli and nosocomial pneumonia in the Intensive Care Unit patient: evidence for causation. Chest 1992; 101: 187-93

12. Stoutenbeek CP, Saene HKF van, Miranda DR, Zandstra DF. The effect of selective decontamination of the digestive tract on colonization and infection rate in multiple trauma patients. Intens Care Med 1984; 10: 185-92

13. Waaij $D$ van der. Colonization resistance of the digestive tract: clinical consequences and implications. J Antimicrob Chemother 1982; 10: 263-70

14. Blair P, Rowlands BJ, Lowry K, Webb H, Armstrong P, Smilie J. Selective decontamination of the digestive tract: A stratified, randomized, prospective study in a mixed intensive care unit. Surgery 1991; 110: 303-10

15. Gastinne H, Wolff M, Delatour F, Faurisson F, Chevret S. A controlled trial in intensive care units of selective decontamination of the digestive tract with nonabsorbable antibiotics. N Engl J Med 1992; 326: 594-9

16. Hammond JMJ, Potgieter PD, Saunders GL, Forder AA. Double-blind study of selective decontamination of the digestive tract in intensive care. Lancet 1992; 340: 5-9 
17. Winter R, Humphreys H, Pick A, MacGowan AP, Willats SM, Speller DCE. A controlled trial of selective decontamination of the digestive tract in intensive care and its effect on nosocomial infection. J Antimicrob. Chemother. 1992; 30: 73-8

18. Cockerill III FR, Muller SR, Anhalt JP, et al. Prevention of infection in critically ill patients by selective decontamination of the digestive tract. Ann Intern Med 1992; 117: 545-53.

19. Rocha LA, Martin MJ, Pita S et al. Prevention of nosocomial infection in critically ill patients by selective decontamination of the digestive tract. Intensive Care Med 1992; 18: 398-404

20. Verhaegen J. Randomized study of selective digestive decontamination on colonization and prevention of infections in mechanically ventilated patients in the ICU. Leuven 1992. Proefschrift

21. Tetteroo GWM. Infection prevention in the surgical intensive care unit using selective decontamination. Rotterdam 1993. Proefschrift

22. Brun-Buisson C, Legrand P, Rauss A, et al. Intestinal decontamination for control of nosocomial multiresistant gram-negative bacilli: study of an outbreak in an intensive care unit. Ann Intern Med 1989; 110: 873-81

23. Humphreys $H$, Winter $R$, Pick $A$. The effect of selective decontamination of the digestive tract on gastrointestinal enterococcal colonization in ITU patients. Intensive Care Med 1992; 18: 45963

24. McClelland P, Coakley J, Williams PG, Bone JM, Mostar SM. Staphylococcal peritonitis following selective decontamination of digestive tract. [letter] Lancet 1988; 2: 800

25. Kaufhold A, Behrendt W, Krauss $T$, Saene $H$ van. Selective decontamination of the digestive tract and methicillin-resistant Staphylococcus aureus. [letter] Lancet 1992; 339: 1411-12

26. Nau R, Rüchel R, Mergerian H, Wegener U, Winkelmann T, Prange HW. Emergence of antibiotic-resistant bacteria during selective decontamination of the digestive tract. J Antimicrob Chemtother 1990; 110: 881-3

27. Allaouchiche B, Guillaume C, Godard J et al. Emergence of tobramycin resistance during selective decontamination of the digestive tract. [abstract 1446] Proceedings of the 32nd Interscience Conference on Antimicrobial Agents and Chemotherapy, Anaheim 1992: 352

28. Aerdts SJA, Clasener HAL, Van Dalen R, Van Lier HJJ, Vollaard EJ, Festen J. Antibiotic prophylaxis of respiratory tract infection in mechanically ventilated patients. Chest 1991; 100: 783-91

29. Ulrich C, Harinck JE, Bakker NC, Jacz K, Doornbos L, De Ridder VA. Selective decontamination of the digestive tract with norfloxacin in the prevention of ICU acquired infections: a prospective randomised study. Intens Care Med 1989; 15: 424-31

30. Hartenauer U, Thülig B, Diemer W, et al. Effect of selective flora suppression on colonization, infection, and mortality in critically ill patients: A one-year, prospective consecutive study. Crit Care Med 1991; 19: 463-73

31. Ledingham IM, Alcock SR, Eastaway AT, McDonald JC, McKay IC, Ramsay G. Triple regimen of selective decontamination of the digestive tract, systemic cefotaxime, and microbiological surveillance for prevention of acquired infection in intensive care. Lancet 1988; i: 785-90 
32. Stoutenbeek CP, Saene HKF van, Miranda DR, Zandstra DF, Langrehr D. The effect of oropharyngeal decontamination using topical nonabsorbable antibiotics on the incidence of nosocomial respiratory tract infections in multiple trauma patients. J Trauma 1987; 27: 357-64

33. Scheld WM, Mandell GL. Nosocomial pneumonia: pathpogenesis and recent advances in diagnosis and therapy. Rev Infect Dis 1991; 13 (Suppl 9): S743-51

34. Gastinne H, Wolff M, Lachatre G, Boiteau R, Savy FP. Antibiotic levels in bronchial tree and in serum during selective digestive decontamination. Intensive Care Med 1991; 17: 215-218

35. Waaij D van der, Berghuis-de Vries JM, Lekkerkerk-van der Wees JEC. Colonization resistance of the digestive tract in conventional and antibiotic-treated mice. J Hyg (Camb) 1971; 69: 405411

36. Tetteroo GWM, Wagenvoort JHT, Castelein A, Tilanus HW, Ince C, Bruining HA. Selective decontamination to reduce gram-negative colonisation and infections after oesophageal resection. Lancet 1990; 335: 704-7 


\section{Chapter 3}

PROBLEMS IN DIAGNOSING NOSOCOMIAL PNEUMONIA IN MECHANICALLY VENTILATED PATIENTS: A REVIEW 
Many efforts have been made to diagnose nosocomial pneumonia more accurately. Protected specimen brush and bronchoalveolar lavage, both performed via flexible bronchoscopy, are two promising new diagnostic modalities. Depending on study design and patient selection, sensitivity and specificity of bronchoalveolar lavage and protected specimen brush differ widely, ranging from 50 to $100 \%$. However, interpretation of study results is seriously hampered because a standardized diagnostic threshold is not available, the influence of previous antimicrobial therapy on culture results remains unclear and, most importantly, a well-defined gold standard to study the value of both methods is lacking. Because studies of bronchoalveolar lavage and protected specimen brush are seriously hampered by several pitfalls, these studies as well as clinical results must be interpreted with caution. 


\section{INTRODUCTION}

In the beginning of the twentieth century Sir William Osler called pneumonia the "Captain of the Men of Death", as it was one of the most widespread and fatal causes of acute diseases (1). Now, at the end of the century, pneumonia still is a major cause of death, despite the introduction of an armament of antibacterial, antiviral and antifungal agents. Improved medical care and widespread use of antibiotics have directed the attention from community-acquired pneumonia to nosocomial pneumonia. Pneumonia is considered nosocomial when it develops 72 or more hours after hospital admission (2). Treatment is hampered by increased resistance of typical hospital pathogens to antimicrobial agents. Besides difficulties in treatment, clinicians face another problem: how to diagnose pneumonia. This review describes and compares the benefits and pitfalls of conventional and recently introduced diagnostic modalities. Furthermore epidemiology, etiology and risk-factors of nosocomial pneumonia are described.

\section{EPIDEMIOLOGY}

Nowadays pneumonia is the second most frequent cause of hospital-acquired infections in the United States (3) and adult ICU-patients on mechanical ventilation suffer the highest incidence rates: from 20 to $60 \%$ (4-11). The risk to acquire pneumonia increases with time on mechanical ventilation (12). The mean added hospital stay for patients with ventilator-associated pneumonia was calculated to be approximately 10 days with extra costs attributable to the prolongation of stay of US\$ $8.800(13,14)$.

\section{RISK FACTORS AND MORTALITY}

In general, nosocomial pneumonia is preceded by colonization of the upper respiratory tract with pathogenic microorganisms (15). Among risk factors associated with nosocomial pneumonia, intubation probably is the most important one, leading to a 7 - to 21 -fold higher incidence rate as compared to non-intubated patients $(16,17)$. Other risk factors are underlying lung diseases, high age, large surgical procedures, tracheostomy, immunosuppression, mechanical ventilation, treatment with $\mathrm{H}_{2}$-blockers and reduced consciousness $(6,8,17-19)$. These factors explain the high rates of nosocomial pneumonia in mechanically ventilated ICUpatients, since they usually are exposed to one or more of these conditions.

Of all hospital-acquired infections the highest mortality is accounted for by pneumonia. Recently, an attributable mortality of $27 \%$ and a risk ratio of 2.0 was 
ascribed to nosocomial pneumonia and especially Pseudomonas aeruginosa and Acinetobacter spp. were categorized as "high-risk" pathogens (20). Other risk factors that worsen prognosis are bilateral involvement on chest radiograph, the presence of respiratory failure, age higher than 60 years, an ultimately or rapidly fatal underlying condition and inappropriate antibiotic therapy (8). From these prognostic factors only the choice of antibiotic therapy can be influenced by the medical staff, which underscores the need of a quick and accurate diagnosis.

\section{ETIOLOGY}

Most frequently, nosocomial pneumonia is caused by enteric Gram-negative microorganisms. In the National Nosocomial Infection Study (NNIS), performed between 1985 and 1988 in the United States, half of the cases were associated with enteric Gram-negative bacteria, especially $P_{\text {seudomonas aeruginosa }}(\mathbf{1 7 . 2 \%}$ ), Enterobacter spp. $(10.4 \%)$ and Klebsiella pneumoniae (7.4\%) (3). The results of this large multicenter study were confirmed by many single hospital data $(6,7,10,18,21)$.

Overall, Staphylococcus aureus is, after Pseudomonas aeruginosa, the second most frequent pathogen causing nosocomial pneumonia (14.6\% of all cases in the NNISstudy) (3). Other Gram-positive microorganisms were only seldomly associated with nosocomial pneumonia (3). Incidentally, enterococcal pneumonia has been documented as a superinfection among patients receiving broad spectrum cephalosporin therapy and enteral feeding (22). A change in the spectrum of etiologic agents has been observed in recent years. Sporadic outbreaks of nosocomial pneumonia due to Acinetobacter spp. were reported in the 1970s and $1980 \mathrm{~s}(3,23)$, but an increasing incidence of nosocomial pneumonia caused by this microorganism has been described lately $(6-9,24)$. Recently, nosocomial pneumonia due to Enterococcus faecalis has been described as a side-effect of a regimen that is directed towards prevention of infections with Gram-negative microorganisms and Staphylococcus aureus (25). Despite the availability of sophisticated diagnostic modalities, the etiologic agent of nosocomial pneumonia remains unknown in a number of cases, in some studies ranging from $38-60 \%(7,10,17,26)$.

\section{DIAGNOSIS}

To establish a diagnosis of nosocomial pneumonia in the ICU-setting is difficult. Usually, pulmonary infection is diagnosed using several easily available parameters: fever, leucocytosis, positive culture from tracheal aspirate with many leucocytes and bacteria in the Gram stain and new or worsening infiltrates on chest radiograph. Although each variable may have a reasonable sensitivity for 
pneumonia, specificity certainly is very poor, since fever, leucocytosis or radiological abnormalities in ICU-patients are often due to noninfectious causes and culture results of tracheal aspirate, even in combination with the Gram stain, do not enable one to distinguish colonization from pneumonia (27-32). Two studies among patients with the Adult Respiratory Distress Syndrome (ARDS) clearly showed the risks of basing the diagnosis on these criteria, since pneumonia was misdiagnosed in respectively $29 \%$ and $38 \%$ of cases due to false positive as well as false negative results, as verified later by cultures and histology from lung tissue $(27,33)$. In another study, clinical diagnoses and therapeutic plans were related to final results based on strict histopathologic and/or bacteriologic criteria. The clinical diagnosis of nosocomial pneumonia was accurate in $62 \%$ of the cases while the proposed therapeutic plans proposed were appropriate in only $33 \%$. Reasons for inappropriate or inadequate treatment included missed diagnoses of pneumonia and failure to effectively treat highly resistant microorganisms. Moreover, in 16\% of cases therapeutic plans included unnecessary antimicrobial therapy (34).

Quantitative and semi-quantitative cultures from tracheal aspirates, performed routinely in mechanically ventilated patients, have a very poor specificity in the diagnosis of pneumonia $(8,35-38)$. Since these patients are frequently colonized in their oropharynx with a complex microbial flora at high concentrations $\left(>10^{6}\right.$ $\mathrm{cfu} / \mathrm{ml})$, contamination of tracheal secretions often occurs $(15,21,36,39,40)$. However, by using the number of bacteria in Gram stains and analyzing tracheal aspirates for the presence of elastin fibers, Salata and associates reported a specificity of $73 \%$ for diagnosing nosocomial pneumonia (41). The presence of elastin fibers, however, is a specific indicator for pulmonary necrosis (42), so its specificity for nosocomial pneumonia may decrease due to noninfectious necrotizing lung diseases like ARDS (38). Although Staphylococcus aureus, Gram-negative rods and anaerobic microorganisms can cause pulmonary necrosis, the sensitivity of $67 \%$ reported in Salatas' study is rather low $(41,42)$. Furthermore, Streplococcus pneumoniae, Mycoplasma pneumoniae and respiratory viruses cause pneumonia without necrosis (38). Nevertheless, in view of its high positive predictive value, examination of tracheal aspirates for elastin fibers for the diagnosis of necrotizing pneumonia may be a readily available method, which needs further validation.

In another attempt to use a combination of easily available clinical, bacteriological and radiological parameters to make a diagnosis of nosocomial pneumonia, Pugin and coworkers developed a clinical pulmonary infection score (38). Although the results of this scoring system look very promising, more studies are needed to validate it. Other cultures, such as those from blood and pleural fluid, have little value in diagnosing nosocomial pneumonia. Although they have high specificity, sensitivity is rather low (21). 
Table 1: Results of quantitative cultures of samples obtnined by bronchoscopic techniques in dingnosing nosocomial pneumonia.

\begin{tabular}{|c|c|c|c|c|c|c|}
\hline Reference & Method & $A / B^{a}$ & $\begin{array}{l}\text { cutoff-point } \\
(\mathrm{cfu} / \mathrm{ml})\end{array}$ & $\begin{array}{l}\text { sensitivity } \\
(\%)\end{array}$ & $\begin{array}{l}\text { specificity } \\
(\%)\end{array}$ & $\begin{array}{l}\text { criteria used as "gold standard" for the presence of } \\
\text { nosocomial pneumonia }\end{array}$ \\
\hline $\begin{array}{l}\text { Pollock } \\
\text { (57) }\end{array}$ & $\mathrm{PSB}^{\mathrm{b}}$ & $113 / 78$ & $>10^{3}$ & 96 & 94 & $\begin{array}{l}\text {-clinical parameters } \\
\text {-response to antibiotic-therapy }\end{array}$ \\
\hline $\begin{array}{l}\text { Winterbauer } \\
(58)\end{array}$ & PSB & $91 / 33$ & $>4 \times 10^{3}$ & 88 & 100 & $\begin{array}{l}\text {-fever } \\
\text {-chest radiograph } \\
\text {-purulent tracheal aspirate and/or leukocytosis } \\
\text {-response to antibiotic-therapy }\end{array}$ \\
\hline $\begin{array}{l}\text { Chastre } \\
(28)\end{array}$ & PSB & $26 / 6$ & $>10^{3}$ & 100 & 60 & -autopsy \\
\hline $\begin{array}{l}\text { Lorch } \\
(59)\end{array}$ & PSB & $20 / 15$ & $>4 \times 10^{3}$ & 60 & 100 & $\begin{array}{l}\text {-fever } \\
\text {-chest radiograph } \\
\text {-leukocytosis }\end{array}$ \\
\hline $\begin{array}{l}\text { Fagon } \\
(29)\end{array}$ & PSB & $147 / 34$ & $>10^{3}$ & 100 & 96 & -postmortem histology \\
\hline $\begin{array}{l}\text { Torres } \\
(60)\end{array}$ & PSB & $15 / 15$ & $>10^{3}$ & 53 & 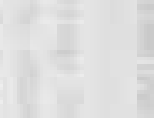 & $\begin{array}{l}\text {-response to antibiotic-therapy } \\
\text {-positive elastin fiber test } \\
\text {-autopsy }\end{array}$ \\
\hline $\begin{array}{l}\text { Thorpe } \\
(61)\end{array}$ & BAL c & $92 / 15$ & $\begin{array}{l}>10^{4} \\
>10^{5}\end{array}$ & $\begin{array}{c}100 \\
87\end{array}$ & $\begin{array}{c}95 \\
100\end{array}$ & $\begin{array}{l}\text {-clinical history } \\
\text {-response to antibiotic therapy } \\
\text {-cytological or pathological specimens }\end{array}$ \\
\hline
\end{tabular}




\begin{tabular}{|c|c|c|c|c|c|c|}
\hline $\begin{array}{l}\text { Kahn } \\
(35)\end{array}$ & BAL & $75 / 13$ & $>10^{3}$ & 10 & 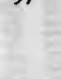 & $\begin{array}{l}\text {-chest radiograph } \\
\text {-positive cultures from blood and sputum }\end{array}$ \\
\hline $\begin{array}{l}\text { Cantral } \\
(62)\end{array}$ & $B A L$ & $154 / 8$ & $\begin{array}{l}>10^{4} \\
>10^{5}\end{array}$ & $\begin{array}{l}88 \\
50\end{array}$ & $\begin{array}{c}98 \\
100\end{array}$ & $\begin{array}{l}\text {-response to antibiotic tnerapy } \\
\text {-postmortem findings } \\
\text {-response to antibiotic therapy } \\
\text {-confirmation by biopsy or autopsy } \\
\text {-positive blood culture }\end{array}$ \\
\hline $\begin{array}{l}\text { Meduri } \\
\text { (63) }\end{array}$ & PBAL d & $46 / 13$ & $>10^{4}$ & 97 & 92 & $\begin{array}{l}\text {-fever } \\
\text {-chest radiograph } \\
\text {-purulent tracheal aspirate or leucocytosis }\end{array}$ \\
\hline $\begin{array}{l}\text { Pugin } \\
\text { (38) }\end{array}$ & $\frac{\text { BAL }}{\text { NB-BAL }}$ & $28 / 13$ & $\mathrm{BI}>5^{\mathrm{f}}$ & $\begin{array}{l}93 \\
73\end{array}$ & $\begin{array}{r}100 \\
96\end{array}$ & -CPIS $>6 \mathrm{~g}$ \\
\hline
\end{tabular}

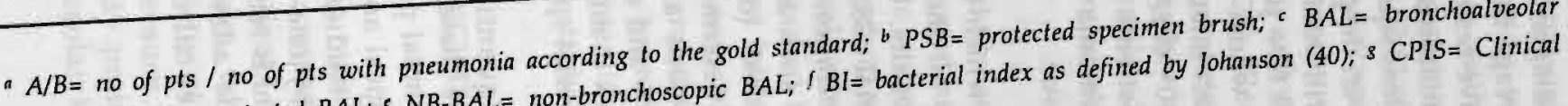
lavage; $d \mathrm{PBAL}=$ protected $\mathrm{BAL} ; \mathrm{C} B-\mathrm{BAL}=$ non-bror
Pulmonary Infection Score as defined by Pugin (38). 
Semiquantitative or quantitative cultures of lavage fluid are difficult to interpret without referring to a well-defined diagnostic threshold. In one study all patients with pneumonia had $>10^{4} \mathrm{cfu} / \mathrm{ml}$ lavage fluid. Raising the diagnostic threshold to $>10^{5} \mathrm{cfu} / \mathrm{ml}$ resulted in 2 false negative results in 15 patients (61). In another study, Kahn and Jones tried to exclude contamination of the upper respiratory tract by evaluating only cultures with $1 \%$ or less squamous epithelial cells on a differential cell count of the lavage pellet. However, despite a sensitivity of $100 \%$ a threshold of $10^{5} \mathrm{cfu} / \mathrm{ml}$ did not allow strict discrimination between acute bacterial bronchitis and pneumonia (35). For instance, all five patients with acute bacterial bronchitis had culture results of $>10^{4} \mathrm{cfu} / \mathrm{ml}$, of whom 3 even had $>10^{5} \mathrm{cfu} / \mathrm{ml}$. Moreover, in 28 patients without any respiratory tract infection, the mean number of $\mathrm{cfu} / \mathrm{ml}$ was $3.3 \times 10^{3}$ and from 12 isolates even $>10^{4} \mathrm{cfu} / \mathrm{ml}$ were cultured. Unfortunately, in these two studies the number of patients on mechanical ventilation was not metioned and the diagnosis of pneumonia was not verified by histological or bacteriological examination of lung tissue.

Table 1 lists several other studies in which bronchoalveolar lavage was used to diagnose nosocomial pneumonia. They all show that a diagnostic threshold of $10^{5}$ $\mathrm{cfu} / \mathrm{ml}$ can lead to false negative results. Moreover, a significant amount of nosocomial pneumonia is polymicrobial $(28,35,64,68)$. In these cases, a culture yielding two microorganisms in concentrations of $10^{3} \mathrm{cfu} / \mathrm{ml}$, for example, would be considered negative. To circumvent such an erroneous classification, Johanson and coworkers calculated a "bacterial index" (defined as the sum of the logarithmic concentrations of individual species) to determine lower respiratory tract infection. When in mechanically ventilated baboons a bacterial index $>6$ was taken as diagnostic threshold, a sensitivity of $100 \%$ and a specificity of $92 \%$ were found. The authors concluded that the bacterial index is more accurate in detecting pneumonia than the concentration of individual bacterial species (40).

Consensus on the cutoff point of quantitative cultures, especially from bronchoalveolar lavage, is essential before these procedures can be introduced into routine practice. As in many cases nosocomial pneumonia is polymicrobial, the use of a bacterial index probably is more logical and accurate. However, the value of this index in patients has hardly been studied yet and certainly has not been validated in cases of pneumonia caused by one single pathogen. Nevertheless, for the time being a cutoff point of $>10^{4} \mathrm{cfu} / \mathrm{ml}$ is recommended (69). As is also true for the protected specimen brush, antibiotic administration before the diagnostic procedure may lead to false negative cultures of bronchoalveolar lavage $(40,52,63,72)$. 
A benefit of bronchoalveolar lavage may be the immediate microscopic examination of lavage fluid $(68,73)$. Although total and differential counts of leukocytes had little value in diagnosing pneumonia $(35,53,61)$, extracellular bacteria, polymorphonuclear leukocytes with intracellular bacteria and elastin fibers were more often observed in Gramstained samples of cytocentrifuged lavage fluid in patients with pneumonia $(38,41,53,61,63)$.

The complications of bronchoalveolar lavage in ventilated patients are mainly those that accompany fiberoptic bronchoscopy and are usually minor $(64,65,71,74)$. They include a drop in $\mathrm{PaO}_{2}(54,55,64)$, arrhythmias (65), transient progression of pulmonary infiltrates and fever $(73,75)$. Recently - following bronchoalveolar lavage -, a significant rise in body temperature, a decrease in mean systemic arterial pressure and arterial oxygenation, together with high endotoxin levels in lavage fluid was observed in mechanically ventilated patients with pneumonia. This may have been caused by intravascular translocation of toxins or mediators producing pyrogenic and hypotensive effects (76).

As bronchoscopy requires specific skills and is costly, bronchoalveolar lavage without bronchoscopy has been evaluated as well. Obtaining lavage fluid using a flexible catheter, introduced blindly, is associated with lower sensitivity $(73 \%)$ and specificity ( $96 \%$ ) than culture of lavage fluid sampled by bronchoscopy ( 93 and $100 \%$ respectively). Similar results for qualitative and quantitative bacteriology and microscopic examination of fluids obtained by both procedures was found, even if lavage fluids originated from different lobes or from the contralateral lung (38). If further studies confirm the usefulness of non-bronchoscopic bronchoalveolar lavage it may become be a simpler and cheaper alternative for the bronchoscopic procedure. Recently, a protected bronchoalveolar lavage method has been developed to avoid or minimize contamination (63). However, the extra value of this expensive method has yet to be established.

\section{COMPARISON OF PROTECTED SPECIMEN BRUSH AND BRONCHOALVEOLAR LAVAGE}

In several studies the diagnostic values of protected specimen brush and bronchoalveolar lavage have been compared (Table 2). Chastre et al reported false positive results in 5 out of 13 patients and false negative results in 2 out of 5 patients with bronchoalveolar lavage, whereas cultures from protected specimen brush had a sensitivity and specificity of $100 \%$ (53). Drawing definite conclusions from this study is hampered because of the small number of patients with pneumonia $(n=5)$. In another study protected specimen brush also led to higher specificity $(86 \%)$ than bronchoalveolar lavage $(71 \%)$, but a cutoff point of $>10^{3}$ 
$\mathrm{cfu} / \mathrm{ml}$ was set for both techniques, which explains the low specificity of bronchalveolar lavage (36). After studying the merit of bronchoalveolar lavage and protected specimen brush in baboons, Johanson concluded that bronchoalveolar lavage was the best method to establish infection of the lungs. When related to histologic and bacteriologic findings of open-lung biopsy, false positive culture results were found with similar frequency for specimens obtained by means of bronchoalveolar lavage as for those obtained by protected specimen brush. However, cultures of lavage fluids recovered $74 \%$ of all species present in the lung tissue as compared with only $41 \%$ to those of protected specimen brush (40).

\section{GOLD STANDARD}

The interpretation of the data reviewed here is seriously hampered because the populations studied vary widely and the use of antimicrobial agents, strongly influencing the yield of bacteriologic procedures, was not always taken into account. The greatest problem, however, relates to the gold standard used to verify the value of the diagnostic procedures. Histological and bacteriological examination of lung tissue remains the optimal standard to establish pneumonia, but this can only be obtained via open-lung biopsy or at autopsy.

In the absence of an easily available gold standard alternative "standards" have been developed, frequently combining clinical, radiological, bacteriological and (if possible) histological parameters. There is no question that comparing any diagnostic procedure with a standard that lacks $100 \%$ sensitivity and specificity weakens correct interpretation of the results. Furthermore, the technique of postmortem examination of lung tissue is important. The risk of using small lung specimens was demonstrated by histological examination of both small lung biopsies and of total lungs. Histological features of pneumonia, demonstrated in complete lung examination, were absent in $25 \%$ of biopsies (81). Moreover, cultures of lung tissue with histologically proven bronchopneumonia remained sterile, reflecting either pneumonia in its resolution phase or suppressed microbial growth due to a combination of antimicrobial agents and antibacterial defences of the host (82).

\section{CONCLUSION}

A rapid diagnosis of nosocomial pneumonia remains a challenge, especially in mechanically ventilated patients. Bronchoalveolar lavage and protected specimen brush are promising diagnostic tools, although the results of most studies are not conclusive due to the lack of a gold standard with $100 \%$ sensitivity and specificity. 
Table 2: Results of studies comparing quantitative cultures obtained by PSB and BAL in dingnosing pneumonia.

\begin{tabular}{|c|c|c|c|c|c|c|}
\hline Reference & method a & $\mathrm{A} / \mathrm{B}$ & $\begin{array}{l}\text { cutoff-point } \\
(\mathrm{cfu} / \mathrm{ml})\end{array}$ & $\begin{array}{l}\text { sensitivity } \\
(\%)\end{array}$ & $\begin{array}{l}\text { specificity } \\
(\%)\end{array}$ & $\begin{array}{l}\text { criteria used as "gold standard" for the presence of } \\
\text { nosocomial pneumonia }\end{array}$ \\
\hline Chastre (53) & $\begin{array}{l}\text { BAL } \\
\text { PSB }\end{array}$ & $18 / 5$ & $\begin{array}{l}>10^{4} \\
>10^{3}\end{array}$ & $\begin{array}{c}60 \\
100\end{array}$ & $\begin{array}{c}85 \\
100\end{array}$ & $\begin{array}{l}\text {-positive culture of pleural fluid } \\
\text {-rapid cavitation on chest radiograph } \\
\text {-histopathology }\end{array}$ \\
\hline Torres (36) & $\begin{array}{l}\text { BAL } \\
\text { PSB }\end{array}$ & $41 / 34$ & $\begin{array}{l}>10^{3} \\
>10^{3}\end{array}$ & $\begin{array}{l}56 \\
56\end{array}$ & $\begin{array}{l}71 \\
86\end{array}$ & $\begin{array}{l}\text {-favorable clinical response to antimicrobial therapy } \\
\text {-postmortem histology }\end{array}$ \\
\hline Martos (37) & $\begin{array}{l}\text { BAL } \\
\text { PSB }\end{array}$ & $10 / 0$ & $\begin{array}{l}>10^{5} \\
\mathrm{BI}>6 \mathrm{~b} \\
>10^{3} \\
\mathrm{BI}>6\end{array}$ & 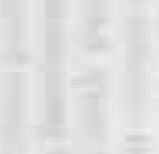 & $\begin{array}{l}70 \\
70 \\
50 \\
90\end{array}$ & $\begin{array}{l}\text { nosocomial pneumonia excluded by: } \\
\text {-no new antimicrobial therapy necessary } \\
\text {-absence pathological signs at autopsy }\end{array}$ \\
\hline Meduri (77) & $\begin{array}{l}\text { PBAL } \\
\text { PSB }\end{array}$ & $11 / 4$ & $\begin{array}{l}>10^{4} \\
>10^{3}\end{array}$ & $\begin{array}{c}100 \\
25\end{array}$ & $\begin{array}{l}100 \\
100\end{array}$ & $\begin{array}{l}\text {-response to antimicrobial therapy } \\
\text {-positive culture of blood }\end{array}$ \\
\hline Padro (78) & $\begin{array}{l}\text { BAL } \\
\text { PSB }\end{array}$ & $13 / ?$ & $\begin{array}{l}>10^{5} \\
>10^{3}\end{array}$ & $\begin{array}{l}50 \\
55\end{array}$ & $\begin{array}{c}78.5 \\
76\end{array}$ & $\begin{array}{l}\text {-histology and bacteriology via open-lung biopsy and } \\
\text { autopsy (in } 8 \text { cases) }\end{array}$ \\
\hline Ebiary (79) & BAL & $49 / 26$ & $\begin{array}{l}>10^{3} \\
>10^{4} \\
>10^{5} \\
>10^{4} \\
>10^{5}\end{array}$ & $\begin{array}{c}100 \\
62.5 \\
25 \\
72.7 \\
66.6\end{array}$ & $\begin{array}{c}56 \\
70.8 \\
75 \\
66.6 \\
88\end{array}$ & -postmortem histology for those who died \\
\hline Violan $(80)$ & $\begin{array}{l}\text { BAL } \\
\text { PSB }\end{array}$ & $45 / 20$ & $\begin{array}{l}>10^{5} \\
>10^{3}\end{array}$ & $\begin{array}{l}76 \\
64\end{array}$ & $\begin{array}{l}100 \\
100\end{array}$ & $\begin{array}{l}\text {-positive blood culture } \\
\text {-histology and bacteriology via autopsy }\end{array}$ \\
\hline
\end{tabular}

a $B A L=$ bronchalveolar lauage, $P S B=$ protected specimen brush $P B A L=$ protected $B A L ; b \quad B l=b a c t e r i a l$ index as defined by Johanson (40); $A / B=n o$ of ptsino of pts with pneumonin according to the gold standard 
As discussed, consensus on the cutoff point of quantitative cultures is essential before introducing these procedures into routine practice. More studies are needed with strictly defined uniform populations, either with or without previous antibiotic therapy and also with bacteriologic and histologic results of lung tissue as gold standard. The use of a bacterial index should be validated in the same way and more attention should be paid to microscopic analysis of lavage fluid, as it can offer a quick answer whether to start antimicrobial therapy or not. In addition, more conventional methods like quantitative cultures of tracheal aspirates and analysis of elastin fibers might prove to be useful adjunctive modalities to establish or reject the diagnosis of nosocomial pneumonia. Since bronchoscopic techniques are expensive, its use should be evaluated in a formal cost-benefit analysis. In one study, use of protected specimen brush resulted in fewer costs compared to the projected costs entailed in treating all patients clinically suspected of having nosocomial pneumonia (29).

The studies reviewed demonstrate the risks of using only clinical criteria, like fever, leucocytosis, positive cultures from tracheal aspirates and abnormalities on chest radiograph, for diagnosing nosocomial pneumonia in mechanically ventilated patients. However, most studies providing data on epidemiology, etiology and risk factors of nosocomial pneumonia relied on these nonspecific clinical criteria and should therefore be interpreted with caution. Bronchoalveolar lavage and protected specimen brush have a higher specificity in diagnosing nosocomial pneumonia, despite inconsistent results and difficulties in validation. As a result, the use of these procedures may have a significant influence on incidence rates, etiology and risk factors of pneumonia in mechanically ventilated patients. For instance, use of protected specimen brush resulted in only 52 cases of nosocomial pneumonia out of 162 clinically suspected episodes (30).

Accurate determination of the agent causing nosocomial pneumonia is of paramount importance for treating patients. In the first place because antimicrobial therapy can be optimalized or withheld, so to prevent the risk of bacterial resistance and saving costs. Moreover, inappropriate or unnecessary antimicrobial therapy will hamper interpretation of further diagnostic procedures and will increase the risk of infections with high-risk pathogens.

Given the above-mentioned difficulties and uncertainties in diagnosing pneumonia in the intensive care setting, what practical approach can be advised to the physician who is facing a patient suspected of having pneumonia? If there is a high likelihood for nosocomial pneumonia, on account of high clinical suspicion and no other underlying diseases that can be held responsible for the clinical symptoms, antimicrobial therapy should be started. In fact, in these situations 
invasive procedures that lack $100 \%$ sensitivity and specificity hardly contribute to establishing the diagnosis. Likewise, antimicrobial therapy should also be started in the critically ill patient with a systemic inflammatory response syndrome and suspected pneumonia, because of the high mortality in this clinical setting. In both situations protected specimen brush and bronchoalveolar lavage do not influence the decision to start antimicrobial therapy. However, since ICU-patients are frequently colonized with different microorganisms in the upper respiratory tract, cultures from bronchoscopic techniques may add specific information on the strains of bacteria that cause the infection, thereby guiding the choice for the most appropriate antibiotics.

In contrast to these situations in which antibiotics have to be started immediately, in many situations it is unclear whether a patient has pneumonia or not. In these circumstances bronchoscopic techniques may determine the decision to institute antimicrobial therapy. However, when using these techniques, the clinician has to be aware of the pitfalls of these techniques and should interpret the culture results with caution. 


\section{REFERENCES}

1. Osler W. The principles and practice of medicine, ed 4. New York: D Appleton and Co, 1901: 108

2. Garner JS, Jarvis WR, Emori TG, Horan TC, Hughes JM. CDC definitions for nosocomial infections. J Infect Control 188; 16: 128-40

3. Horan T, Culver D, Jarvis W, et al. Pathogens causing nosocomial infections. Antimicrob Newslett 1988; 5: 65-7

4. Garibaldi RA, Britt MR, Coleman ML, Reading JC, Pace NL. Risk factors for postoperative pneumonia. Am J Med 1981; 70: 677-80

5. Stevens RM, Teres D, Skilman JJ, Feingold DS. Pneumonia in an intensive care unit. Arch Intern Med 1974; 134: 106-11

6. Craven DE, Kunches LM, Kilinsky V, Lichtenberg DA, Make BJ, McCabe WR. Risk factors for pneumonia and fatality in patients receiving continuous mechanical ventilation. Am Rev Respir Dis 1986; 133: 792-6

7. Jimenez P, Torres A, Rodriguez-Roisin R, Puig de la Bellacasa J, Aznar R, Gatell JM, et al. Incidence and etiology of pneumonia acquired during mechanical ventilation. Crit Care Med 1989; 17: 882-6

8. Torres A, Aznar R, Gatell JM, Jimenez P, Gonzalez J, Ferrer A, et al. Incidence, risk, and prognosis factors of nosocomial pneumonia in mechanically ventilated patients. Am Rev respir Dis 1990; 142: $523-8$

9. Füssle R, Biscoping J, Zeiler D, Michaelis G, Sziegoleit A. Mikrobiologische Betreuung von beatmeten Intensivpatienten. Anaesthesist 1991; 40:491-6

10. Rello J, Quintana E, Ausina V, Castella J, Luquin M, Net A, et al. Incidence, etiology and outcome of nosocomila pneumonia in mechanically ventilated patients. Chest 1991; 100: 439-44

11. Mahul Ph, Auboyer C, Jospe R, Ros A, Guerin C, El Khouri Z, et al. Prevention of nosocomial pneumonia in intubated patients: respective role of mechanical subglottic secretions drainage and stress ulcer prophylaxis. Intens Care Med 1992; 18: 20-5

12. Fagon JY, Chastre J, Domart Y, Trouillet JL., Pierre J, Darne C, et al. Nosocomial pneumonia in patients receiving continuous mechanical ventilation. Am Rev Respir Dis 1991; 139: 877-84

13. Leu HS, Kaiser DL, Mori M, Woolson RF, Wenzel RP. Hospital-acquired pneumonia. Attributable mortailty and morbidity. Am J Epidem 1989; 129: 1258-67

14. Kappstein I, Schulgen G, Beyer U, Geiger K, Schumacher M, Daschner FD. Prolongation of hospital stay and extra costs due to ventilator-associated pneumonia in an intensive care unit. Eur J Clin Microbiol Infect Dis 1992; 11: 504-8

15. Johanson WG, Pierce AK, Sanford JP, Thomas GD. Nosocomial respiratory infections with gramnegative bacilli: The significance of colonization of the respiratory tract. Annals Intern Med 1972; 77: 701-6

16. Haley RW, Hooton TM, Culver DH, Stanley RC, Emori TC, Hardison CD, et al. Nosocomial infections in U.S. hospitals, 1975-1976: estimated frequency by selected chracteristics of patients. Am J Med 1981; 70: 947-59 
17. Celis R, Torres A, Gatell JM, Almela M, Rodriguez-Roisin R, Agusti-Vidal A. Nosocomial pneumonia. A multivariate analysis of risk and prognosis. Chest 1988; 93: 318-24

18. Nielsen SL, Roder B, Magnussen P, Engquist A, Frimodt-moller N. Nosocomial pneumonia in an intensive care unit in a Danish university hospital: incidence, mortality and etiology. Scand J Infect Dis 1992; 24: 65-70

19. Rello J, Ausina V, Castella J, Net A, Prats G. Nosocomial respiratory tract infections in multiple trauma patients. Influence of level of consciousness with implcations for therapy. Chest 1992; 102: 525-29

20. Fagon JY, Chastre J, Hance AJ, Montravers P, Novara A, Gibert C. Nosocomial pneumonia in ventilated patients: a cohort study evaluating attributable mortality and hospital stay. Am J Med 1993; 94: 281-8

21. Bartlett JG, O'Keefe P, Tally FP, Louie TJ, Gorbach SL. Bacteriology of hospital acquired pneumonia. Arch Intern Med 1986; 146: 868-71

22. Berk SL, Verghese A, Holtsclaw SA, Smith JK. Enterococcal pneumonia: Occurence in patients receiving broad-spectrum antibiotic regimens and enteral feeding. Am J Med 1983; 74: 153-4

23. Buxton AE, Anderson RL, Werdegar D, Atlas E. Nosocomial respiratory tract infection and colonization with Acinetobacter calcoaceticus. Am J Med 1978; 65: 507-13

24. Bergogne-Bérézin E, Joly-Guillou ML. Hospital infection with Acinetobacter spp.: an increasing problem. J Hospital Infect 1991; 18 (suppl A): 250-5

25. Bonten M, van Tiel F, van der Geest S, Stobberingh E, Gaillard C. Pneumonia due to Enterococcus faecalis: a side-effect of topical antimicrobial prophylaxis? N Engl J Med [letter] 1993; 328: 209. 210

26. Potgieter PD, Hammond JMJ. Etiology and diagnosis of pneumonia requiring ICU admission. Chest 1992; 101: 199-203

27. Andrews CP, Coalson JJ, Smith JD, Johanson WG. Diagnosis of nosocomial bacterial pneumonia in acute, diffuse lung injury. Chest 1981; 80: 254-8

28. Chastre J, Viau F, Brun P, Pierre J, Dauge M-C, Bochama A, et al. Prospective evaluation of the protected specimen brush for the diagnosis of pulmonary infections in ventilated patients. Am Rev Respir Dis 1984; 130: 924-9

29. Fagon J-Y, Chastre J, Hance AJ, Guiguet M, Trouillet JL, Domart Y, et al. Detection of nosocomial lung infection in ventilated patients: use of a protected specimen brush and quantitative cultures in 147 patients. Am Rev Respir Dis 1988; 138: 110-6

30. Chastre J, Fagon J-Y, Soler P, Domart Y, Pierre J, Dombret MC et al. Quantification of BAL cells containing intracellular bacteria rapidly identifies ventilated patients with nosocomial pneumonia. Chest 1989; 95: 190-2

31. Langer M, Mosconi P, Cigada M, Mandelli M. Long-term respiratory support and risk of pneumonia in critically ill patients. Am Rev Respir Dis 1989; 140: 302-5

32. Mauldin GL, Meduri GU, Wunderink RG, Leeper KV, Jones CB, Estes RJ. Causes of fever and pulmonary infiltrates inmechanically ventilated patients [abstract]. Am Rev Respir Dis 1991; 143: A109 
33. Bell RC, Coalson JJ, Smith JD, Johanson WG. Multiple organ system failure and infection in adult respiratory distress syndrome. Ann Intern Med 1983; 99: 293-8

34. Fagon JY, Chastre J, Hance AJ, Domart Y, Trouillet JL, Gibert C. Evaluation of clinical judgement in the identification and treatment of nosocomial pneumonia in ventilated patients. Chest 1993; 103: $547-53$

35. Kahn FW, Jones IM. Diagnosing bacterial respiratory infection by bronchoalveolar lavage. I Infect Dis 1987; 155: 862-9

36. Torres A, De la Bella casa JP, Xaubet A, Gonzalez J, Rodriguez-Roisin R, Jimenez de Anta MT, et al. Diagnostic value of quantitative cultures of bronchoalveolar lavage and telescoping plugged catheters in mechanically ventilated patients with bacterial pneumonia. Am Rev Respir Dis 1989; 140: 306-10

37. Martos JA, Ferrer M, Torres A, Gonzalea J, Puig, de la Bellacasa J, Celis R, et al. Specificity of quantitative cultures of protected specimen brush and bronchoalveolar lavage in mechanically ventilated patients [abstract]. Am Rev Respir Dis 1990; 141: A276

38. Pugin J, Auckenthaler R, Mili N, Janssens JP, Lew PD, Suter PM. Diagnosis of ventilatorassociated pneumonia by bacteriologic analysis of bronchoscopic and nonbronchoscopic blind bronchoalveolar lavage fluid. Am Rev Respir Dis 1991; 143: 1121-9

39. Bartlett JG, Finegold SM. Bacteriology of expectorated sputum with quantitative culture and wash technique compared to transtracheal aspirates. Am Rev Respir Dis 1978; 117: 1019-27

40. Johanson WG, Seidenfeld JJ, Gomez P, De los Santos R, Coalson J. Bacteriologic diagnosis of nosocomial pneumonia following prolonged mechanical ventilation. Am Rev Respir Dis 1988; 137: 259-64

41. Salata RA, Lederman MM, Schlaes DM, Jacobs MR, Eckstein E, Tweardy D, et al. Diagnosis of nosocomial pneumonia in intubated, intensive care unit patients Am Rev Respir Dis 1987; 135: 426-32

42. Shlaes DM, Lederman MM, Chmielewski R, Tweardy D, Krause G, Safai C. Sputum elastin fibers and the diagnosis of necrotizing pneumonia. Chest 1984; 85: 763-6

43. Bjerkestrand G, Digranes A, Schreiner A. Bacteriological findings in transtracheal aspirates from patients with chronic bronchitis and bronchiectasis. Scand J Respir Dis 1975; 56: 201-7

44. Spencer DC, Beatty HN. Complications of transtracheal aspiration. N Engl J Med 1972; 286: 3046

45. Pratter MR, Irwin RS. Transtracheal aspiration: guidelines for safety. Chest $1979 ; 76: 518-20$

46. Gherman CR, Simon HJ. Pneumonia complicating severe underlying disease: a current appraisal of transthoracic lung puncture. Dis Chest 1965; 115: 777-82

47. Zavala DC, Schoell JE. Ultrathin needle aspiration of the lung in infectious and malignant disease. Am Rev Respir Dis 1981; 123: 125-31

48. Dijkman JH, van der Meer JWM, Bakker W, Wever AMJ, van der Broek PJ. Transpleural lung biopsy by the thoracoscopic route in patients with diffuse interstitial pulmonary disease. Chest 1982; 82: 76-83

49. Mathur P, Martin WJ. Clinical utility of thoracoscopy. Chest 1992; 102: 2-4

50. Lewis RJ, Caccavale RJ, Sisler GE. Imaged thoracoscopic lung biopsy. Chest 1992; 102: 60-62 
51. Wimberley NW, Faling LJ, Bartlett JG. A fiberoptic bronchoscopy technique to obtain uncontaminated lower airway secretions for bacterial culture. Am Rev Respir Dis 1979; 119: 33743

52. Wimberley NW, Bass JB, Boyd BW, Kirkpatrick MB, Serio RA, Pollock HM. Use of a bronchoscopic protected catheter brush for the diagnosis of pulmonary infections. Chest 1982; 81: $556-62$

53. Chastre J, Fagon JY, Soler P, Bornet M, Domart Y, Trouillet JL, et al. Diagnosis of nosocomial bacterial pneumonia in intubated patients undergoing ventilation: comparison of the usefulness of bronchoalveolar lavage and the protected brush, Am J Med 1988; 85: 499-506

54. Moser KM, Maurer J, Jassy L, Kremsdorf R, Konopka R, Shure D, et al. Sensitivity, specificity and risk of diagnostic procedures in a canine model of Streptococcus pneumoniae pneumonia. Am Rev Respir Dis 1984; 125: 436-42

55. Higuchi JH, Coalson JJ, Johanson WG. Bacteriologic diagnosis of nosocomial pneumonia in primates: usefulness of the protected specimen brush. Am Rev Respir Dis 1982; 125: 53-7

56. Marquette C, Ramon P, Courcol R. How far is the protected specimen brush uncontaminated? cyotolgic evaluation of paired tracheal aspirates and PSB specimens [abstract]. Abstracts of the 1992 ICAAC; abstract 1437, 350

57. Pollock HM, Hawkins EL, Bronner JR, Sparkman T, Bass JB. Diagnosis of bacterial pulmonary infections with quantitative protected catheter cultures obtained during bronchoscopy. J Clin Microbiol 1983; 17: 255-9

58. Winterbauer RH, Hutchinson JF, Reinhardt GN, et al. The use of quantitative cultures and antibody coating of bacteria to diagnose bacterial pneumonia by fiberoptic bronchoscopy. Am Rev Respir Dis 1983; 128: 98-103

59. Lorch DG, John JF, Tomlinson JR, Miller KS, Sahn SA. Protected transbronchial needle aspiration and protected specimen brush in the diagnosis of pneumonia. Am Rev Respir Dis 1987; 136: 565569

60. Torres A, Puig de la Bellacasa J, Ferrer M, Gené A, Gonzalez J, Celis R, et al. Do quantitative cultures of endotracheal aspiration samples coincide with quantitative cultures of protected specimen brushes in mechanically ventilated patients with pneumonia? [abstract] Am Rev Respir Dis 1990; 141: A277

61. Thorpe JE, Baughman RP, Frame PT, Wesseler TA, Staneck JL. Bronchoalveolar lavage for diagnosing acute bacterial pneumonia, J Infec Dis 1987; 155: 855-61

62. Cantral D, Thompson AB, Reed E, Woods G, Spurzem J, Rennard S. Quantitative bacterial cultures from bronchoalveolar lavage fluid are sensitive and specific in the diagnosis of bacterial pneumonia [abstract]. Am Rev Respir Dis 1990; :A276

63. Meduri GU, Beals DH, Maijub AG, Baselski V. Protected bronchoalveolar lavage: a new bronchoscopic technique to retrieve uncontaminated distal airway secretions. Am Rev Respir Dis 1991; 143: 855-64

64. Guerra LF, Baughman RP. Use of bronchoalveolar lavage to diagnose bacterial pneumonia in mechanically ventilated patients. Crit Care Med 1990; 18: 169-73 
65. Trouillet JL, Guiguet M, Gibert C, Fagon JY, Dreyfuss D, Blanchet, et al. Fiberoptic bronchoscopy in ventilated patients: evaluation of cardiopulmonary risk under midazolam sedation. Chest 1990; $97:$ 927-33

66. Lambert RS, Vereen LE, George RB. Comparison of tracheal aspirate and protected specimen brush catheter specimens for identifying pathogenic bacteria in mechanically ventilated patients. Am J Med Sci 1989; 297: 377-82

67. Meduri GU, Baselski V. The role of bronchoalveolar lavage in diagnosing nonopportunistic bacterial pneumonia. Chest 1991; 100: 179-90

68. Reynolds HY. Bronchoalveolar lavage. Am Rev Respir Dis 1987; 135: 250-63

69. Meduri GU, Chastre J. The standardization of bronchoscopic techniques for ventilator-associated pneumonia. Chest 1992; 102 (Suppl 1): 557S-65S

70. Baughmann RP, Bosken CH, Loudon RG, Hurtubise P, Wesseler T. Quantification of bronchoalveolar lavage with methylene blue. Am Rev Respir Dis 1983; 128: 266-70

71. Xaubet A, Torres A, Marco F, Puig de la Bellacasa J, Faus R, Agusti-Vidal A. Pulmonary infiltrates in immunocompromised patients: diagnostic value of telescoping plugged catheter and bronchoalveolar lavage. Chest 1989; 95: 130-35

72. Fox RC, Williams GJ, Wunderink RG, Leeper KV, Jones CB. Followup bronchoscopy predicts therapeutic outcome in ventilated patients with nosocomial pneumonia [abstract]. Am Rev Respir Dis 1991; 143: A109

73. Stover DE, Zaman MB, Hajdu SI, Lange M, Gold J, Armstrong D. Bronchoalveolar lavage in the diagnosis of diffuse pulmonary infiltrates in the immunosuppressed host. Ann Intern Med 1984; 101: $1-7$

74. Pereira W, Kovnat DM, Snider GL. A prospective cooperative study of complications following flexible fiberoptic bronchoscopy. Chest 1978; 73: 813-16

75. Standiford TJ, Kunkel SL, Strieter RM. Elevated serum levels of tumor necrosis factor-alpha after bronchoscopy and bronchoalveolar lavage. Chest 1991; 99: 1529-30

76. Pugin J, Suter PM. Diagnostic bronchoalveolar lavage in patients with pneumonia produces sepsis-like effects. Intensive Care Med 1992; 18: 6-10

77. Meduri CU, Maijub AG, Leeper KV, Wunderink RG, Jones CB, Baselski V. Diagnosis of ventilator-associated pneumonia: comparison of protected specimen brushing versus protected bronchoalveolar lavage [abstact]. Am Rev Respir Dis 1990; 141: A278

78. Padro L, Gonzalez J, Torres A, Puig de la Bellacasa J, Xaubet A, Ebiary ME, et al. Diagnostic accuracy of bronchoscopic techniques in pulmonary infections acquired during mechanical ventilation. Comparison with postmortem pulmonary biopsy [abstract]. Am Rev Respir Dis 1991; 143: A109

79. Ebiary ME, Torres A, Gonzalez J, Puig de la Bellacasa J, Celis R, Padro L, et al. Diagnosis of ventilator-associated pneumonia: diagnostic value of quantitative cultures of endotracheal aspirates [abstract]. Am Rev Respir Dis 1991; 143: A108

80. Violan JS, Rodriguez de Castro F, Luna JC, Benitez AB, Alonso JLM. Comparative efficacy of bronchoalveolar lavage and telescoping plugged catheter in the diagnosis of pneumonia in mechanically ventilated patients. Chest 1993; 103: 386-90 


\section{Problems in Diagnosis}

81. Rouby JJ, Rossignon MD, Nicolas MH, De Lasalle EM, Cristin S, Grosset J, et al. A prospective study of protected bronchoalveolar lavage in the diagnosis of nosocomial pneumonia. Anesthesiology 1989; 71: 679-85

82. Rouby JJ, Martin de Lasalle E, Poete P, Nicolas MH, Bodin L, Jarlier V, le Charpentier Y, et al. Nosocomial pneumonia in the critically ill. Am Rev Respir Dis 1992; 146: 1059-66 


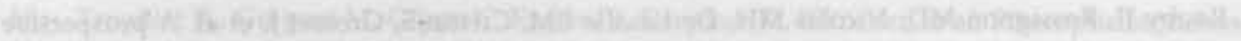

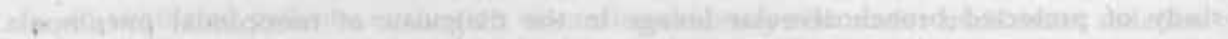

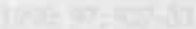

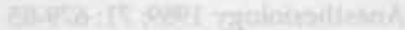

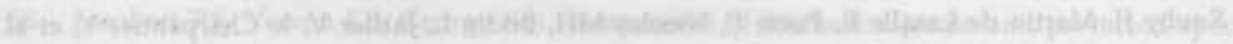

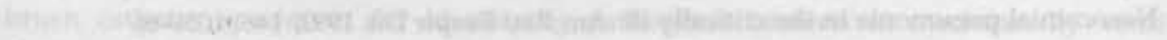

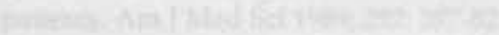

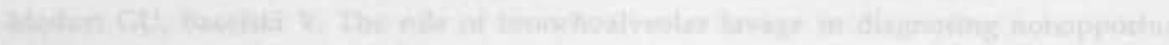

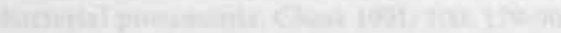

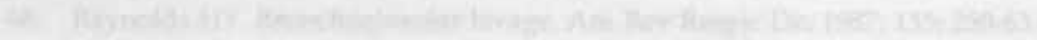

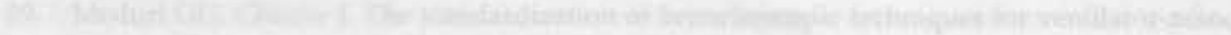

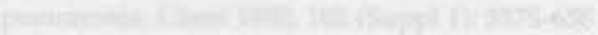

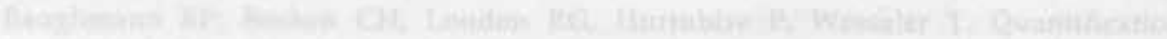

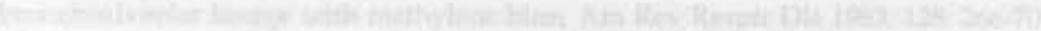

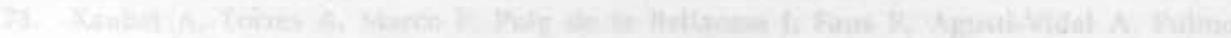

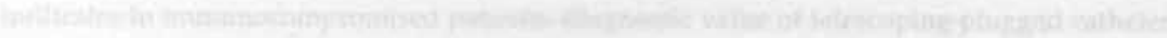

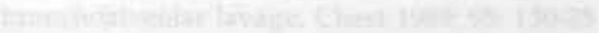

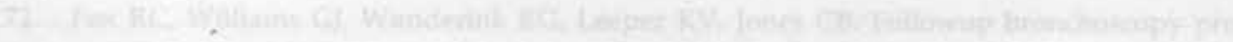

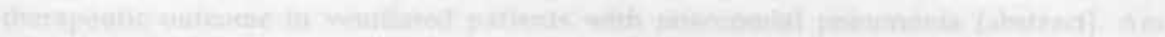

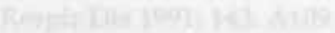

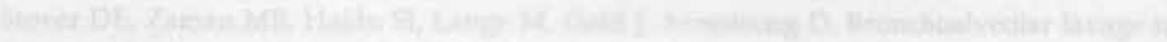

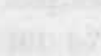

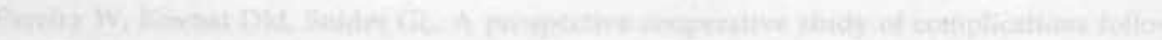

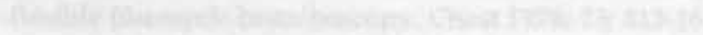

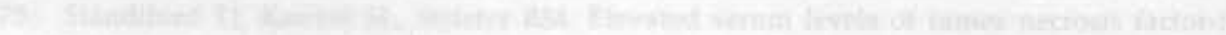

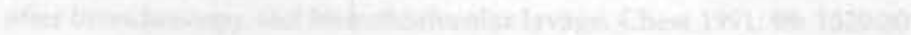

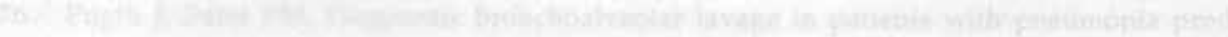

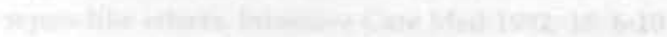

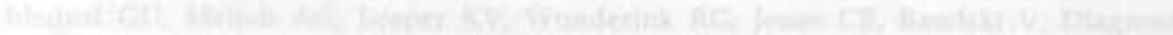

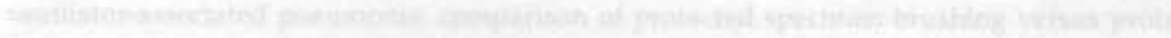

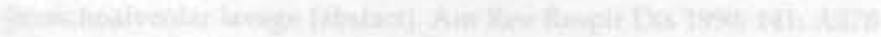

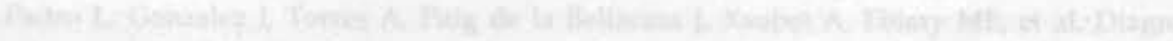

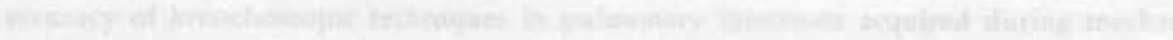

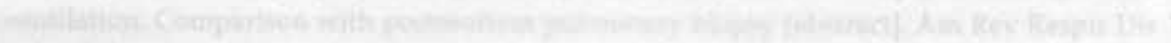

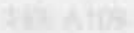

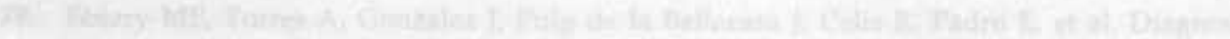

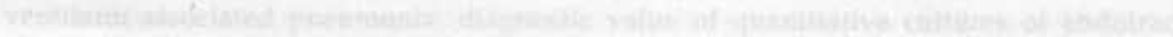

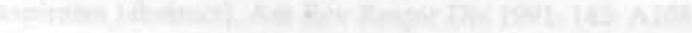

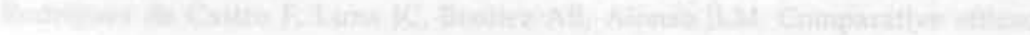

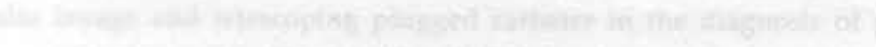

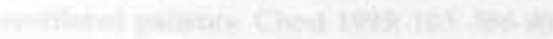


Chapter 4

INTRODUCTION TO THE STUDIES AND QUESTIONS 
Among mechanically ventilated ICU-patients, nosocomial pneumonia (i.e. ventilator associated pneumonia (VAP)) is the most frequent infection, which is associated with increased morbidity and mortality, a longer ICU-stay for survivors, and therefore increased medical costs. For these reasons, prevention of this infection has been the issue of many studies. After improvements in hygienic procedures to protect patients for colonization via exogenous routes, infection prevention in the last 10 years has been directed towards modulating the bacterial flora of the digestive tract, because most bacteria causing VAP were assumed to be from endogenous origin.

In this respect the gastropulmonary route received the most attention as it was presumed to be the most important way of colonization. The intestinal bacteria were thought to retrogradely colonize the stomach and the oropharynx, from where they would reach the distal lung tissue through aspiration. The physiologic defense mechanism against gastric colonization, i.e. gastric acidity, may be absent in critically ill patients, either due to the underlying disease or due to stress ulcer prophylaxis. Therefore, prevention of colonization of the stomach played a key role in the prevention of VAP. Prevention of colonization was attempted by topical application of non-absorbable antibiotics, and by preserving an acid gastric environment using sucralfate for stress ulcer prophylaxis. Sucralfate, in contrast to antacids and $\mathrm{H}_{2}$-antagonists, has been claimed not to lower intragastric acidity.

The pathogenesis of the pulmonary infection, the values of preventive strategies and the problems, and alternatives, for diagnosing pneumonia with optimal accuracy were described in the first 3 chapters. The different routes of colonization leading to pneumonia and a critical appraisal of the relevant studies supporting the putative gastropulmonary route of colonization, have been described in chapter 1 . In chapter 2, the value of Selective Decontamination of the Digestive Tract (SDD) has been reviewed. This method of infection prevention has been used and studied extensively. However, its usefulness for routine practice has not yet been established, and our doubts regarding the benefits of this method formed the starting-point of the studies described in this thesis.

An important issue in the studies addressing the pathogenesis, prevention and treatment of pneumonia in mechanically ventilated, ICU-patients is the diagnosis of the infection. In general, the combination of clinical, radiological and microbiological criteria has been used to establish the diagnosis. However, data from the literature clearly demonstrate the inaccuracies of these criteria. In chapter 3 the problems of diagnosing pneumonia in mechanically ventilated patients and recently developed alternatives with higher specificity have been reviewed. The importance of using bronchoscopic techniques to establish the diagnosis of 
pneumonia in mechanically ventilated, ICU-patients has been stated and, as a consequence, in all studies in this thesis Protected Specimen Brush, and Bronchoalveolar lavage, have been used.

The studies performed in our clinic are described in chapters 5 to 10 . Those addressing the effects of topical antimicrobial prophylaxis in oropharynx and stomach on colonization and infection form the basis of chapters 5,6 and 7 , and those addressing the importance of intragastric acidity and the stomach as a reservoir of pathogens in the development of pneumonia in mechanically ventilated ICU-patients are the subject of chapters 8,9 and 10 .

In chapters 5, 6 and 7 a regimen of Topical Antimicrobial Prophylaxis (TAP) was studied, using non-absorbable antimicrobial agents, that were applicated to the oropharynx and the stomach. In contrast to the concept of SDD, intestinal decontamination was not aimed for and no systemic prophylaxis was given. In chapter 5 the influence of TAP on colonization of the upper respiratory tract was studied. The question behind this pilot study was whether decontamination of the colon, as part of SDD, was necessary to achieve lower colonization rates of the upper respiratory tract.

In chapter 6 we studied the efficacy of TAP to decontaminate the stomach, in patients with and without enteral feeding. Although the institution of enteral feeding in critically ill patients is widely recommended, several studies have reported a relation between institution of enteral feeding and the subsequent occurrence of pneumonia. Allegedly, this was due to dilutional alkalinization of gastric contents, by that favouring the gastropulmonary route of colonization. However, the influence of enteral feeding on the efficacy of a regimen of decontamination has never been studied.

If endogenous sources (i.e. reservoirs of bacteria within the patient) were of major importance for the development of colonization and infection of the upper respiratory tract in mechanically ventilated patients, then modulation of colonization should not influence colonization of other patients. This hypothesis was tested in chapter 7. Colonization was studied in 3 groups of patients: one group receiving topical antimicrobial prophylaxis of oropharynx and stomach, one group not receiving any prophylaxis and treated in the same ICU as patients receiving prophylaxis, and finally one group not receiving prophylaxis and treated in another, identical, ICU.

As described previously, in chapters 8,9 and 10 the role of gastric colonization and intragastric acidity in the pathogenesis of pneumonia was studied. Measuring intragastric acidity with optimal accuracy is absolutely necessary, when studying the 
influence of intragastric acidity on colonization and infection. However, up till now, most studies measured intragastric acidity with color-scaled indicator papers in aspirated gastric juice. Moreover, in most cases these measurements were performed only sporadically, in some studies less than once daily. Computerized intragastric $\mathrm{pH}$ monitoring is a reproducible and accurate method, which probably provides more reliable data on intragastric acidity than occasional measurements in aspirated samples. In chapter $\mathbf{8}$ measurements of gastric $\mathrm{pH}$ performed once daily with color-scaled indicator papers in aspirated gastric juice, were compared to results of computerized continuous intragastric $\mathrm{pH}$ monitoring during 24 hours.

In chapter 9 colonization rates of rectum, stomach, oropharynx and trachea were prospectively determined in 64 mechanically ventilated patients. In addition, initial sites of colonization and chronological colonization patterns were assessed. In this way the importance of the stomach as a source of bacteria for colonization and pneumonia could be studied.

The last study of this thesis, chapter 10, addresses the correlation between intragastric acidity and colonization of stomach and upper respiratory tract as determined in 141 mechanically ventilated patients receiving either sucralfate or antacids for stress ulcer prophylaxis. In addition, the correlation between intragastric acidity and the incidence of nosocomial pneumonia was studied. The influence of sucralfate and antacids on intragastric acidity, colonization rates and incidences of infection were studied in a randomized double-blinded controlled fashion, with stratification according to initial gastric $\mathrm{pH}$. Measurements of intragastric acidity were performed with continuous intragastric monitoring and nosocomial pneumonia was diagnosed with Protected Specimen Brush and Bronchoalveolar Lavage.

Recapitulating, the main questions addressed in this thesis are:

1. Can colonization of the upper respiratory tract be modulated without influencing colonization of the colon? chapter 5

2. Can colonization of the stomach be modulated by topical antimicrobial prophylaxis of stomach and oropharynx? chapter 6

3. Does continuous enteral feeding influence the protective efficacy of topical antimicrobial prophylaxis of the stomach? chapter 6

4. Does modulation of the bacterial flora of the upper respiratory tract by topical antimicrobial prophylaxis influence colonization in other patients notreceiving prophylaxis and treated within the same ICU-ward? chapter 7

5. What is the role of the gastropulmonary route of colonization in the development of nosocomial pneumonia in mechanically ventilated patients? chapters 9 and 10 
6. Do discontinuous measurements of acidity in aspirated gastric juice accurately reflect 24 hour values of intragastric acidity, as obtained with computerized continuous monitoring? chapter 8

7. What is the influence of sucralfate on intragastric acidity as compared to high dosages of antacids? chapter 10

8. Does sucralfate influence colonization rates and incidences of pneumonia as compared to high dosages of antacids? chapter $\mathbf{1 0}$

9. What is the role of intragastric acidity and gastric colonization in the pathogenesis of pneumonia in mechanically ventilated ICU-patients receiving sucralfate or antacids for stress ulcer prophylaxis? chapter $\mathbf{1 0}$

10. What is the influence of enteral feeding on intragastric acidity and gastric colonization? chapter 10 
ylakn

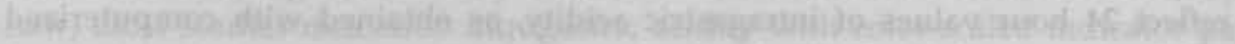

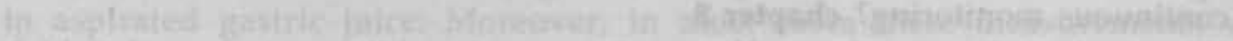

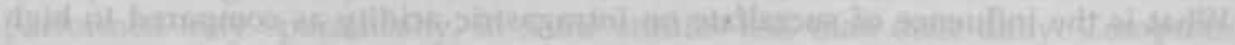

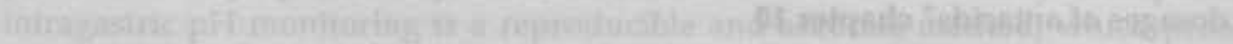

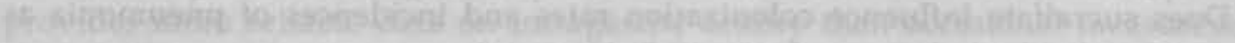

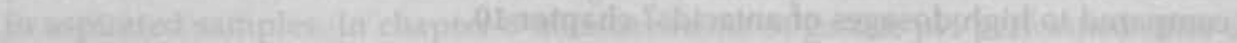

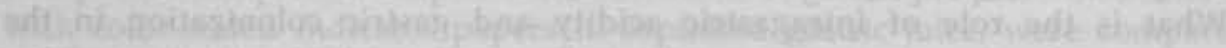

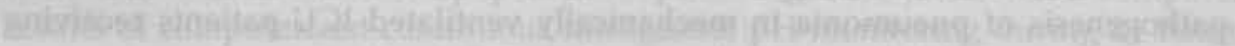

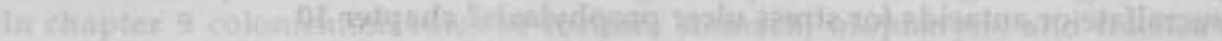

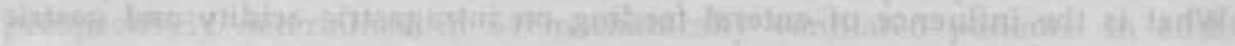

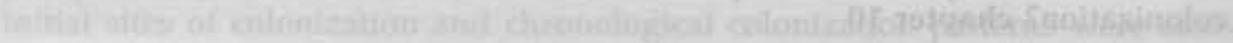

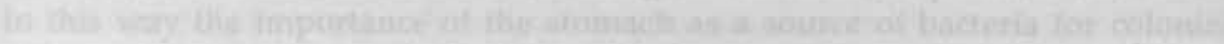

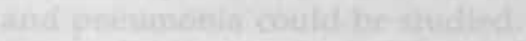

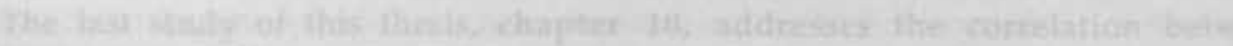

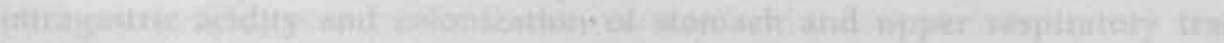

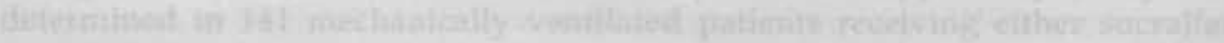

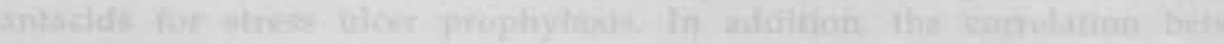

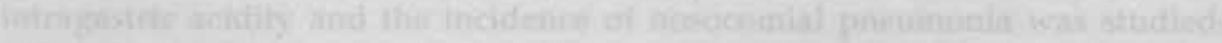

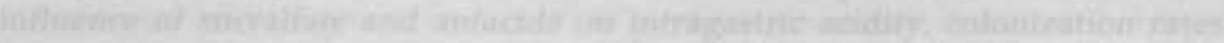

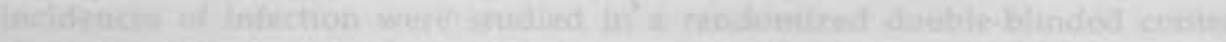

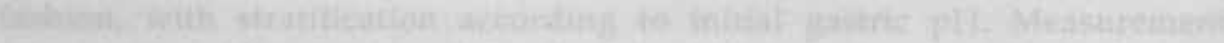

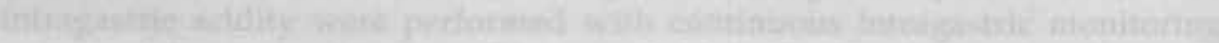

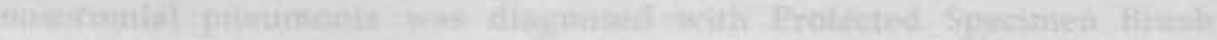

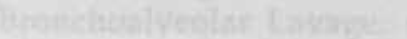

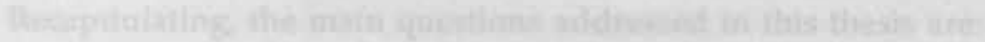

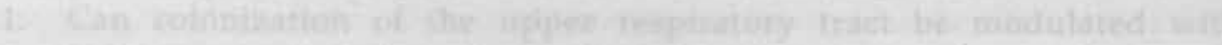

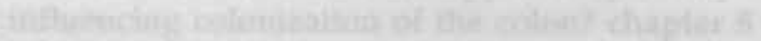

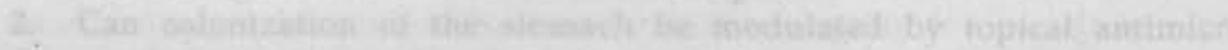

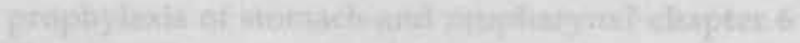

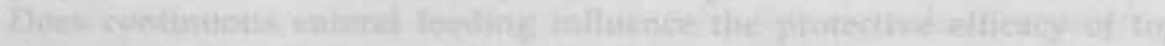

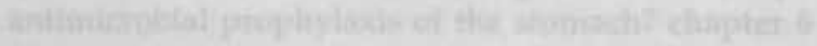

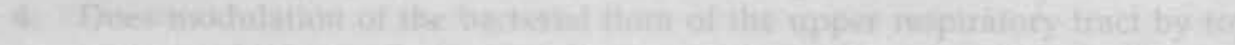

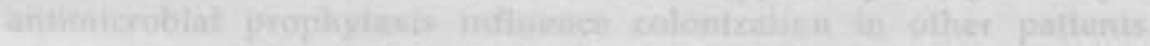

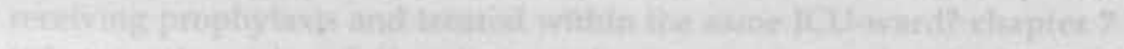

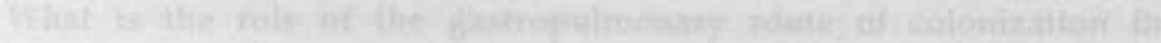

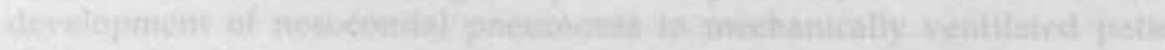

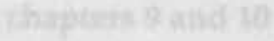




\section{Chapter 5}

MICROBIOLOGICAL OBSERVATIONS DURING TOPICAL ANTIMICROBIAL PROPHYLAXIS OF OROPHARYNX AND STOMACH IN MECHANICALLY VENTILATED PATIENTS. 


\section{INTRODUCTION}

Nosocomial pneumonia is an important cause of morbidity and mortality in hospitalized patients, especially in those receiving ventilatory support. Treatment of manifest infection is usually unsatisfactory and the mortality rate is estimated to be as high as $20-60 \%$ (1).

In general, Ventilator Associated Pneumonia (VAP), i.e. nosocomial pneumonia occurring more than three days after admission to the Intensive Care Unit (ICU), is believed to be caused by microorganisms of endogenous origin. One of the first steps in the development of VAP allegedly is colonization of the oropharynx with Gramnegative bacteria (2). After one week of mechanical ventilation, colonization of the oropharynx by Enterobacteriaceae, Pseudomonas aeruginosa, Staphylococcus aureus or yeasts - so called potentially pathogenic microorganisms (ppmo) - has occurred in $70-90 \%$ of patients $(2,3)$.

Oropharyngeal colonization by ppmo has been described to be preceded by colonization of the stomach, which is facilitated by an increased gastric $\mathrm{pH}$ and by disturbances in gut motility (4). Increased gastric $\mathrm{pH}$ levels may lead to bacterial growth in the stomach for example when $\mathrm{H}_{2}$-blocking agents or antacids are used as stress ulcer prophylaxis (5). Alternatively, sucralfate, a chemical complex of sucrose octasulfate which does not influence the physiologic gastric $\mathrm{pH}$ can be used as stress ulcer prophylaxis (5).

In another approach to reduce the incidence of nosocomial pneumonia antimicrobial agents were administered orally to eradicate ppmo from the colon and the oropharynx without disturbing the allegedly protective anaerobic flora: Selective Decontamination of the Digestive tract (SDD) (6-13). In most studies orally and intravenously administered antibiotics were used concomitantly. Others, however, focused on the use of topical non-absorbable antimicrobial agents in the oropharynx exclusively to prevent development of nosocomial pneumonia (14-16). Most studies showed a significant reduction of colonization by ppmo and morbidity due to nosocomial pneumonia, although mortality rates were not reduced. In addition, the beneficial effects of SDD on the duration of hospitalization and mechanical ventilation, antibiotic use, emergence of antibiotic resistance in bacteria and on medical costs remain unclear. It is mainly for these reasons that the merits of SDD in ICU-patients continue to be debated $(17,18)$.

We studied the microbiological effects of topical antimicrobial prophylaxis (TAP) of oropharynx and stomach in combination with sucralfate as stress ulcer prophylaxis on colonization of the upper respiratory tract and the colon. In contrast to several other studies intravenously administered antimicrobial agents were not included in this prophylactic regimen and orally administered non-absorbable antimicrobial 
agents were given in low doses as eradication of ppmo from the colon was not intended. The main questions of this study were how topical antimicrobial prophylaxis modulated colonization of the upper respiratory tract, and whether topical antimicrobial prophylaxis influenced colonization of the colon.

\section{MATERIAL AND METHODS}

Sixty-nine patients admitted to the ICU of the University Hospital Maastricht, between September 1990 and March 1992 were included in the study. All met the following criteria: newly admitted to ICU, intubation within 24 hours after admission, age between 15 and 90 years and an expected ventilation period of more than five days. Eight patients were withdrawn from the study before day 5 due to detubation $(n=3)$ or death $(n=5)$. The remaining 61 patients were studied until detubation or death.

To assess the severity of the acute illness the APACHE II score was calculated on admission to the ICU as described elsewhere (19). Each patient's demographic characteristics, diagnosis on admission, underlying diseases, reason for intubation, laboratory values, medication and clinical data were recorded and prospectively monitored for evidence of infection. Cultures from oropharynx, tracheal aspirate and rectal swabs were performed within 24 hours after admission and thereafter at least twice a week until extubation. Unfortunately, the culture results from rectal swabs are available only for the first 25 patients under study.

The regimen of Topical Antimicrobial Prophylaxis (TAP) and sucralfate, administered 4 times daily, consisted of:

- suspension of tobramycin $(8 \mathrm{mg} / \mathrm{ml})$ and colistin $(5 \mathrm{mg} / \mathrm{ml}) 1 \mathrm{ml}$ in each nostril and $5 \mathrm{ml}$ through nasogastric tube

- suspension of amphotericin B $(100 \mathrm{mg} / \mathrm{ml}) 0.5 \mathrm{ml}$ in each nostril and $2.5 \mathrm{ml}$ through nasogastric tube

- application of tobramycin/colistin/amphotericin B 2\% in Orabase to oropharynx

$-1 \mathrm{~g}$ sucralfate suspension through nasogastric tube.

In case of clinical suspicion of pneumonia bronchoscopy was performed for bronchoalveolar lavage (BAL) and protected specimen brush (PSB). Diagnosis of pneumonia was established by a positive quantitative culture of PSB or BAL and a new or persistent infiltrate on chest X-ray and when at least three of the following criteria consistent with infection were met: (1) rectal temperature above $38.0^{\circ} \mathrm{C}$ or below $35.5^{\circ} \mathrm{C},(2)$ blood leukocytosis $\left(>10.10^{3} / \mathrm{mm}^{3}\right)$ and/or left shift or blood leukopenia $\left(<3.10^{3} / \mathrm{mm}^{3}\right)$, (3) more than ten leukocytes per high-power field in gram stain of tracheal aspirate, and (4) a positive culture from tracheal aspirate. The cutoff points for positive quantitative culture results from bronchoscopic techniques were $>10^{3} \mathrm{cfu} / \mathrm{ml}$ for PSB and $>10^{5} \mathrm{cfu} / \mathrm{ml}$ for BAL. The chest X-rays 
were retrospectively interpreted by a radiologist, who was unaware of the clinical situation of the patient. In the analysis of ICU-acquired pneumonia, Enterobacteriaceae, Pseudomonadaceae and Staphylococcus aureus were grouped and labelled as potentially pathogenic microorganisms (ppmo).

Collection and processing of samples from PSB and BAL were performed as described elsewhere (20). Colonization was defined as the isolation of microorganisms from oropharynx, tracheal aspirate or feces without signs of infection. Colonization was designated as 'persistent' if there was a positive culture with the same species on admission and from at least one consecutive sample. Colonization was designated as 'acquired' if there were positive cultures with the same species from at least two consecutive samples and no colonization with the same microorganism on admission. Colonization was analyzed semi-quantitatively as follows: Oropharyngeal swabs, rectal swabs, and $10 \mu \mathrm{l}$ of tracheal aspirate were streaked using the four-quadrant streak method on sheep blood, CLED, chocolate, and Sabauroud plates. All media were incubated at $350{ }^{\circ} \mathrm{C}$ for 18 to 24 hours. Growth density was graded as follows: Growth in the first quadrant $=+1$, in the second quadrant $=+2$, in the third quadrant $=+3$, and on the whole plate $=+4$.

Informed consent was obtained from the patient or, if this was not possible because of the clinical condition, from a representative of the family. The study protocol was approved by the hospital ethical committee.

\section{RESULTS}

The characteristics, underlying diseases and admitting medical specialties of the 61 patients are shown in Table 1 . In the study population the diagnosis pneumonia was established in 5 patients (8\%) on admission (Table 2).

\section{Colonization of the oropharynx}

Oropharyngeal colonization with Gram-negative rods on admission was demonstrated in 23 patients $(38 \%) ; 19$ patients $(31 \%)$ were colonized with Enterobacteriaceae and 7 patients (11\%) with Pseudomonadaceae (Table 3). In addition, 4 patients $(7 \%)$ were colonized with Staphylococcus aureus and $2(3 \%)$ with Enterococcus faecalis on admission. In most patients ppmo colonizing the oropharynx on admission were eradicated by TAP, but colonization with Gramnegative rods in the oropharynx persisted in 5 out of 23 patients. Four patients (7\%) acquired colonization with Gram-negative rods in the oropharynx during the study. Interestingly, acquired oropharyngeal colonization with Enterococcus faecalis, intrinsically resistant to the antibiotics used in TAP, was demonstrated in 31 patients $(48 \%)$. 
Table 1: Characteristics of the patients.

Characteristics

No. of patients

$\mathrm{n}=61$

$63(29-89)$

Age *

$4(1-61)$

Days in hospital before admission at ICU *

Days in study *

$18(4-38)$

APACHE II score *

\section{1 \\ 21 \\ 8 \\ 1}

Neurology

Surgical procedures

None 38

17

6

Thoracic surgery

$23(38 \%)$

Mortality $(\%)$

* median (range)

Colonization of the trachea

Fifteen patients $(25 \%)$ were colonized with Gram-negative rods in the trachea on admission; 10 patients with Enterobacteriaceae and 7 with Pseudomonadaceae (Table 3). Four patients (7\%) were colonized with Staphylococcus aureus on admission. Persistent tracheal colonization with Gram-negative rods occurred in 6 patients, and with Staphylococcus aureus in none. Fourteen patients (23\%) acquired colonization with Gram-negative rods despite the use of TAP. Of these patients, 7 (11\%) acquired colonization with Pseudomonadaceae, and 7 patients (11\%) with Gram-negative rods not belonging to the group of ppmo. These patients acquired colonization with Acinetobacter species $(n=5)$, Flavobacterium indologenes $(n=1)$, Achromobacter spp. $(n=1)$ and Alcaligenes xylosoxydans $(n=1)$. Because colonization with these species was not demonstrated in the oropharynx, colonization probably occurred via exogenous routes, thereby bypassing the oropharynx. Acquired colonization with Enterococcus faecalis was demonstrated in 17 patients (28\%). 
Table 2: Numbers of patients with infections on admission and VAP, and the pathogenic microorganisms associated with infection.

Infection

Number of Pathogenic microorganism

patients (\%)

On admission

Septicaemia

origin:

abdomen

$4(7 \%)$

unknown

(2)

Escherichia coli

Staphylococcus aureus

(2)

Clostridium species

(1)

urinary tract

Escherichia coli

ostemyelitis

$1(2 \%)$

$1(2 \%) \quad$ Staphylococcus aureus

necrotizing fasciitis

$1(2 \%)$

e.c.i.

$2(3 \%)$

Streptococcus group A

Pneumonia

$5(8 \%)$

unknown

Klebsiella pneumoniae

Streptococcus group G

Streptococcus pneumoniae

Mycobacterium tuberculosis

ICU-aquired
Pneumonia: total
ppmo
$7(11 \%)$
Pseudomonas aeruginosa
Enterobacter species
non-ppmo
$6(10 \%)$
Enterococcus faecalis
Staphylococcus epidermidis
Acinetobacter species
Alcaligenes xylosoxydans
Streptococcus group B
Recurrent pneumonia
$2(3 \%)$
Pseudomonas aeruginosa
Acinetobacter species

(7)

\section{Fecal colonization}

Enterobacteriaceae and Enterococcus faecalis were cultured on admission from rectal swabs of almost all patients analyzed $(n=25)$, and persisted in most of them (Table 3). Six patients (24\%) were colonized with Pseudomonas aeruginosa on admission. In addition, five patients became colonized with Acinetobacter anitratus, in all cases after preceding tracheal colonization with this microorganism. Staphylococcus aureus were not isolated from rectal swabs of any of the patients. 
Table 3: Number of patients colonized with different genera of microorganisms according to duration of colonization.

\begin{tabular}{|c|c|c|c|c|c|c|c|c|c|}
\hline 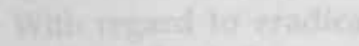 & \multicolumn{3}{|c|}{ Oropharynx } & \multicolumn{3}{|c|}{ Trachea } & \multicolumn{3}{|c|}{ Feces } \\
\hline & A & B & C & A & B & C & A & B & $C$ \\
\hline Cultures available & 58 & 58 & 58 & 60 & 60 & 60 & 25 & 25 & 25 \\
\hline Gramnegative rods & 23 & 5 & 4 & 15 & 6 & 14 & 21 & 17 & 5 \\
\hline Enterobactericeae & 19 & 4 & 2 & 10 & 2 & 2 & 21 & 17 & 3 \\
\hline Pseudomonas aeruginosa & 7 & 2 & 2 & 7 & 4 & 7 & 6 & 5 & 1 \\
\hline non-ppmo & 1 & 0 & 1 & 0 & 0 & 7 & 0 & 0 & 5 \\
\hline Grampositive cocci & 6 & 2 & 31 & 4 & 0 & 17 & 18 & 17 & 6 \\
\hline Enterococcus faecalis & 2 & 2 & 31 & 0 & 0 & 17 & 18 & 17 & 6 \\
\hline Staphylococcus aureus & 4 & 0 & 0 & 4 & 0 & 0 & 0 & 0 & 0 \\
\hline
\end{tabular}

$A=$ colonization on admission; $B=$ persistent colonization; $C=a c q u i r e d$ colonization; ${ }^{7}$ non-ppmo includes Acinetobacter spp., Flavobacterium indologenes, Achromobacter spp. and Alcaligenes xylosoxydans

\section{Infections}

Thirteen patients $(21 \%)$ developed an episode of VAP (Table 2). Ppmo were isolated in significant numbers from samples obtained by PSB and/or BAL in 7 patients $(11 \%)$. In all these cases pneumonia was caused by Pseudomonas aeruginosa, in 1 patient in combination with Enterobacter spp.. In 6 patients $(10 \%)$ pneumonia was caused by bacteria not belonging to the group of ppmo. In all these cases pneumonia was polymicrobial involving Enterococcus faecalis, in combination with Pseudomonas aeruginosa (1 patient), or Staphylococcus epidermidis (3 patients), or Acinetobacter spp. ( 3 patients), or Alcaligenes xylosoxydans (1 patient). In 5 of these patients pneumonia was preceded by colonization of the oropharynx with Enterococcus faecalis, and in two of them it was accompanied by bacteremia (cases 1 and 2, Table 4). Bacteremia with Enterococcus faecalis but without evidence of pneumonia was demonstrated in two patients (cases 7 and 8, Table 4).

\section{DISCUSSION}

This study reveals some important microbiological findings regarding the use of the combination of TAP and sucralfate in mechanically ventilated ICU-patients. In the first place, when compared to colonization rates reported in SDD trials, the results of this open and uncontrolled study strongly suggest that the combination of TAP and sucralfate had, without eradicating ppmo from the fecal flora, a similar preventive effect on colonization of the respiratory tract with ppmo. In addition, 
two limitations of this regimen were encountered: colonization and infection of the respiratory tract by Gram-negative rods from exogenous origin and a tendency towards colonization of oropharynx and trachea by Enterococcus faecalis.

Table 4: Microbiological results of patients developing VAP and/or bacteremia involving Enterococcus faecalis.

\begin{tabular}{lcccccccc} 
case: & 1 & 2 & 3 & 4 & 5 & 6 & 7 & 8 \\
\hline $\begin{array}{l}\text { Pneumonia: } \\
\begin{array}{l}\text { E. faecalis cultured from: } \\
\text { oropharynx: }\end{array}\end{array}$ & + & + & + & + & + & + & - & - \\
$\begin{array}{l}\text { rachea: } \\
\text { Gramstain: }\end{array}$ & + & + & + & + & + & + & + & \\
no of PMN: & + & - & + & - & - & + & - & - \\
no of GPC: & $>10$ & $>10$ & $>10$ & $>10$ & $>10$ & $1-2$ & $2-10$ & 0 \\
$\begin{array}{l}\text { PSB /BAL } \\
\text { blood }\end{array}$ & $>20$ & $<5$ & $>20$ & $>20$ & $<5$ & $5-20$ & $<5$ & 0 \\
& + & + & + & + & + & - & NA & NA \\
& + & + & NA & - & NA & + & + & +
\end{tabular}

$N A=$ no culture available; ${ }^{1}+=$ positive culture for Enterococcus faecalis; $-=$ negative culture for Enterococcus faecalis; 2 PMN = polymorphonuclear leucocytes per high power field $(400 x) ; G P C=$ Gram-positive cocci in pairs or chains per oil field $(1000 x)$

A finding of special interest was the colonization with Enterococcus faecalis of oropharynx or trachea in 31 out of 61 patients enrolled in the protocol. An increased colonization by Gram-positive cocci has been reported by others $(10,11,21)$, but was often considered as representing commensal flora of the oropharynx, and therefore not included in the reported colonization rates $(6-8,14-16)$. However, in the present study eight cases of pneumonia and/or bacteremia, involving Enterococcus faecalis were demonstrated. Although infections caused by Enterococci have been reported in other studies as well $(8,21)$, pneumonia due to these microorganisms is rare. Therefore, an incidence rate of $10 \%$ for VAP is extremely high and has never been reported. The positive quantitative cultures obtained by PSB and BAL, sometimes accompanied by bacteremia, strongly suggested that Enterococcus faecalis had an etiologic role in the development of pneumonia in our patients. Although this was not a randomized controlled study, we hypothesize that TAP modified the bacterial flora of the patients under study, resulting in high colonization rates with species intrinsically resistant to the antibiotics used, and leading to pneumonia caused by a microorganism generally considered not to cause respiratory tract infection. The causal relationship between the use of TAP and the development of colonization 
and infections with Gram-positive bacteria, intrinsically resistant to the topical antibiotics used for prophylaxis, needs confirmation and further study.

With regard to eradication of ppmo from oropharynx and trachea our results are comparable to the results of other studies $(6-16,21)$. In most studies non-absorbable antimicrobial agents were applied to the oropharynx and administered to the digestive tract with or without systemic prophylaxis to eradicate ppmo from the colon $(6-13,16)$. In contrast, our regimen did not attempt to eradicate ppmo from the colon per se and, indeed, it did not. Three other studies using topical antimicrobial prophylaxis of the oropharynx and stomach, but without the use of sucralfate, have been published, but did not report the effect of the regimen on the fecal flora $(15,16,21)$. To our knowledge this is the first study in which it was shown that colonization of the upper respiratory tract with ppmo from endogenous origin could be prevented without eradicating ppmo from the fecal flora.

In the present study three patients developed pneumonia caused by Gram-negative rods not belonging to the defined group of ppmo. These bacteria (i.e. Acinetobacter spp. and Alcaligenes xylosoxydans) colonized the trachea, without colonization of the oropharynx. In six cases acquired colonization probably took place from an exogenous source, thereby bypassing the assumed protective effect of TAP in oropharynx and stomach, since these species were not cultured from oropharynx. Acquisition with Acinetobacter spp. has been described to originate from hands and gloves of nurses and doctors as well as from ventilation machines (22).

In conclusion, this regimen was successful in preventing colonization of oropharynx and trachea with ppmo from endogenous origin, without intravenous antimicrobial prophylaxis and without eradication of ppmo from the colon. However, a tendency towards colonization and infection by Enterococcus faecalis and exogenously acquired Gram-negative bacteria was demonstrated. 


\section{REFERENCES}

1. Craven DE, Steger KA, Barber TW : Preventing nosocomial pneumonia: State of the art and perspectives for the 1990s. Am J Med; 91 (Suppl 3B) (1991): 44S-53S

2. Johanson WG Jr., Pierce AK, Sanford JP, Thomas GD: Nosocomial respiratory infections with gramnegative bacilli: the significance of colonization of the respiratory tract. Ann Intern Med; 77 (1972): 701-6

3. Johanson WG Jr., Pierce AK, Sanford JP: Changing pharyngeal bacterial flora of hospitalized patients: emergence of gramnegative bacilli. N Engl J Med; 281 (1969): 1137-40

4. Daschner F, Reuschenbach K, Pfisterer J, Kappstein I, Vogel W, Krieg N, Just H: Der Einfluß von Streßulcusprophylaxe auf die Häufigkeit einer Beatmungspneumonie. Anaesthesist; 36 (1987): 9 18

5. Tryba M: The gastropulmonary route of infection - fact or fiction? Am J Med; 91 (Suppl 2A) (1991): 135S-46S

6. Stoutenbeek CP, Van Saene HKF, Miranda DR, Zandstra DF: The effect of selective decontamination of the digestive tract on colonization and infection rate in multiple trauma patients. Intensive Care Med; 10 (1984): 185-92

7. Kerver AJH, Rommes JH, Mevissen-Verhage EAE, Hulstaert PF, Vos A, Verhoef J, Wittebol P: Prevention of colonization and infection in critically ill patients: a prospective randomized study. Crit Care Med; 16 (1988): 1087-93

8. Ledingham IMcA, Alcock SR, Eastaway AT, McDonald JC, McKay IC, Ramsay G: Triple regimen of selective decontamination of the digestive tract, systemic cefotaxime, and microbiologically surveillance for prevention of acquired infection in intensive care. Lancet; $i$ (1988): 785-90

9. Brun-Buisson C, Legrand P, Rauss A, Richard C, Montravers F, Besbes M, Meakins JL, Soussy CL, Lemaire F: Intestinal decontamination for control of nosocomial multiresistant gram-negative bacilli. Ann Int Med; 110 (1989): 873-81

10. Ulrich C, Harinck-de Weerd JE, Bakker NC, Jacz K, Doornbos L, de Ridder VA: Selective decontamination of the digestive tract with norfloxacin in the prevention of ICU-acquired infections: a prospective randomized study. Intensive Care Med; 15 (1989): 424-31

11. McClelland P, Murray AE, Williams PS, van Saene HKF, Gilbertson AA, Mostafa SM, Bone JM: Reducing sepsis in severe combined acute renal and respiratory failure by selective decontamination of the digestive tract. Crit Care Med; 18 (1990): 935-39

12. Aerdts SJA, van Dalen R, Clasener HAL, Festen J, van Lier HJJ, Vollaard EJ: Antibiotic prophylaxis of respiratory tract infection in mechanically ventilated patients. Chest; 100 (1991): 783-91

13. Hartenauer U, Thülig B, Diemer W, Lawin P, Fegeler W, Kehrel R, Ritzerfeld W: Effect of selective flora suppression on colonization, infection and mortality in critically ill patients: $A$ one-year, prospective consecutive study. Crit Care Med; 19 (1991): 463-73

14. Rodriguez-Roldan JM, Altuna-Cuesta A, Lopez A, Carrillo A, Garcia J, Leon J, Martinez-Pellus AJ: Prevention of nosocomial lung infection in ventilated patients: Use of an antimicrobial pharyngeal nonabsorbable paste. Crit Care Med; 18 (1990): 1239-42 
15. Pugin J, Auckenthaler R, Lew DP, Suter PM: Oropharyngeal decontamination decreases incidence of ventilator-associated pneumonia. JAMA; 265 (1991): 2704-10

16. Flaherty J, Nathan C, Kabins SA, Weinstein RA: Pilot trial of selective decontamination for prevention of bacterial infection in an intensive care unit. J Infect Dis; 162 (1991): 1393-1397

17. Verhoef J: Selective decontamination of the intestines: an important clinical treatment modality? Eur J Clin Microbiol Infect Dis; 10 (1991): 477-8

18. Vandenbroucke-Grauls CMJE, Vandenbroucke JP: Effect of selective decontamination of the digestive tract on respiratory tract infections and mortality in the intensive care unit. Lancet; 338 (1991): 859-62

19. Knaus WA, Draper EA, Wagner DP, Zimmerman JE: APACHE II: A severity of disease classification system. Crit Care Med; 13 (1985): 818-29

20. Thorpe JE, Baughman RP, Frame PT, Wesseler TA, Staneck JL: Bronchoalveolar lavage for diagnosing acute bacterial pneumonia. J Infect Dis; 155 (1987): 855-61

21. Unertl K, Ruckdeschel G, Selbmann HK, Jensen U, Forst H, Lenhart FP, Peter K: Prevention of colonization and respiratory infections in long-term ventilated patients by local antimicrobial prophylaxis. Intensive Care Med; 13 (1987): 106-13

22. Patterson JE, Vecchio V, Pantelick EL, Farrel P, Mazon M, Zervos MJ: Association of contaminated gloves with transmission of Acinetobacter calconceticus var. anitratus in an Intensive Care Unit. Am J Med; 91 (1991): 497-83 


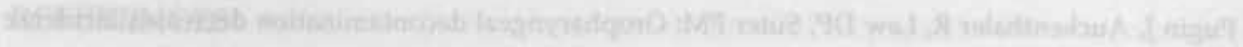

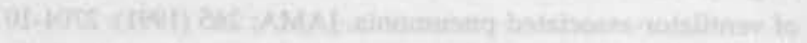

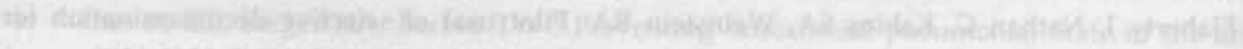
yist

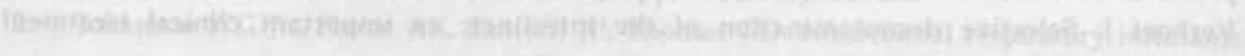

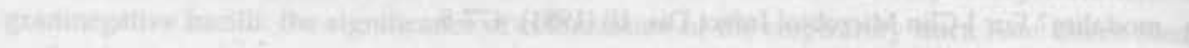

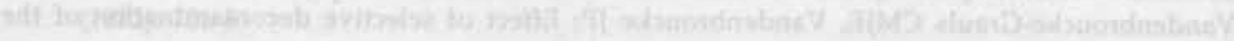

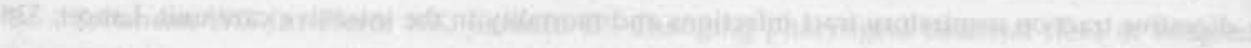

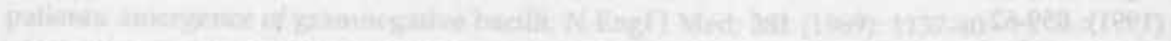

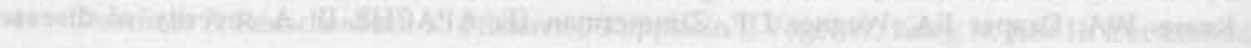

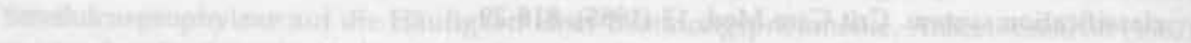

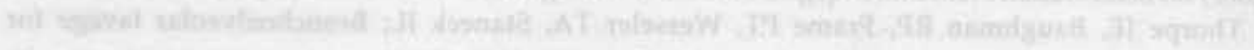

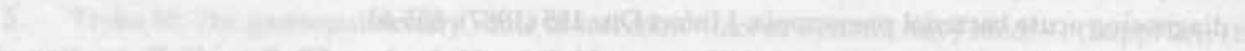

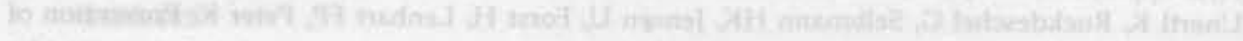

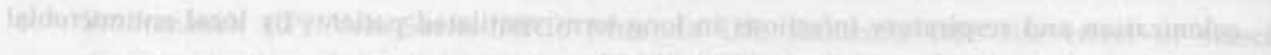

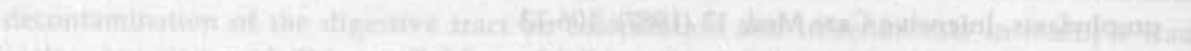

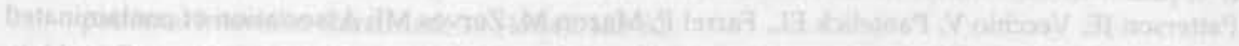

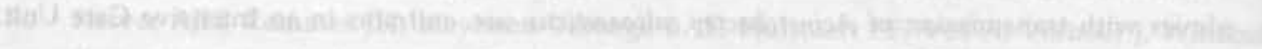

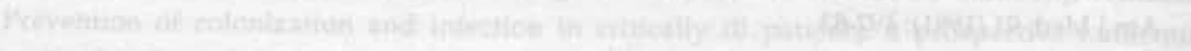

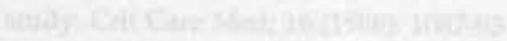

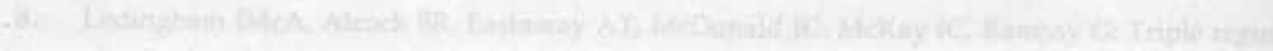

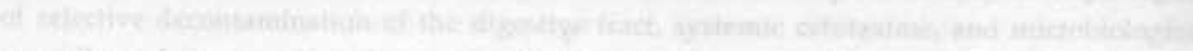

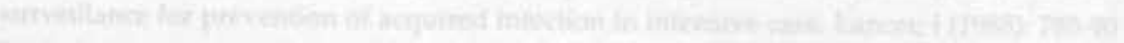

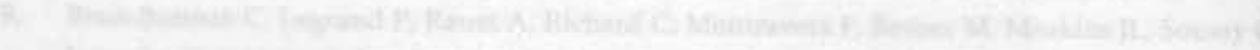

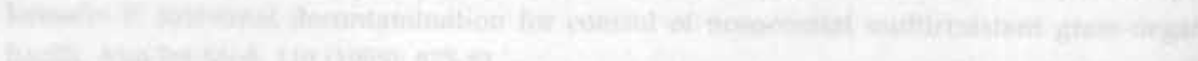

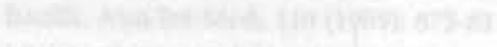

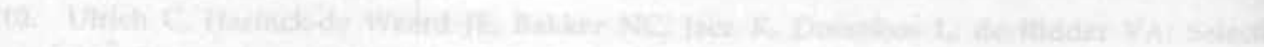

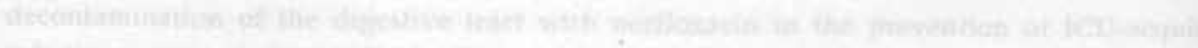

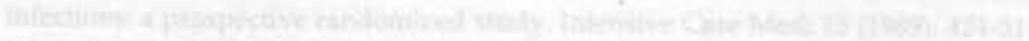

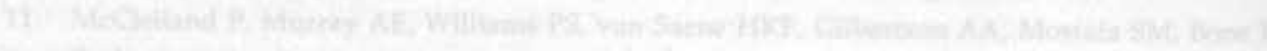

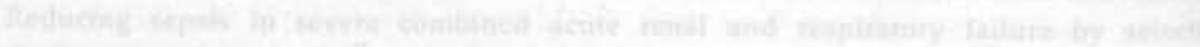

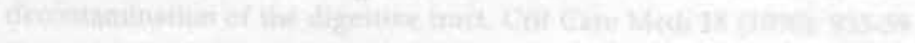

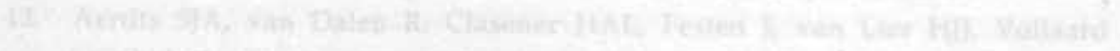

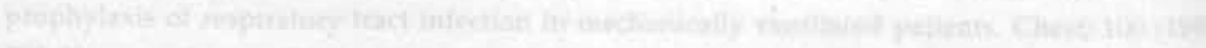

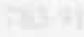

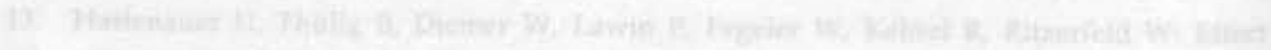

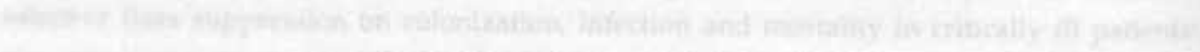

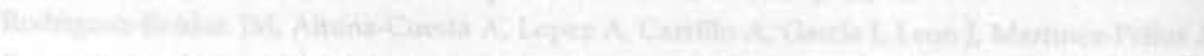

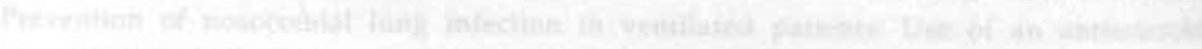

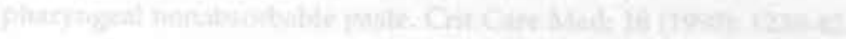




\section{Chapter 6}

CONTINUOUS ENTERAL FEEDING COUNTERACTS PREVENTIVE MEASURES FOR GASTRIC COLONIZATION IN ICU-PATIENTS 
The influence of continuously administered enteral feeding on gastric $\mathrm{pH}$ and gastric colonization was tested in patients receiving and not-receiving Topical Antimicrobial Prophylaxis of oropharynx and stomach, including sucralfate as stress ulcer prophylaxis. This prospective open trial was performed in two general ICU's in a university hospital. Patients admitted to ICU for at least 5 days were eligeble for this study.

Thirty-one patients received antimicrobial agents into the stomach and oropharynx in combination with sucralfate ( $1 \mathrm{~g}$ every 6 hours) as stress ulcer prophylaxis. Sixtyfour other patients did not receive antimicrobial prophylaxis or sucralfate. These patients received stress ulcer prophylaxis with antacids, $\mathrm{H}_{2}$-antagonists, or omeprazole if indicated. Gastric colonization and gastric $\mathrm{pH}$ were measured on admission and subsequently at least twice a week. Forty-eight patients (14 receiving and 34 not-receiving antimicrobial prophylaxis) received enteral feeding.

Both enteral feeding and stress ulcer prophylaxis other than sucralfate independently increased gastric $\mathrm{pH}$ : the risks for gastric $\mathrm{pH}>3.5$ were 4.54 and 2.04 (Odds ratios) respectively. Enteral feeding also increased the risk for gastric colonization by potentially pathogenic microorganisms (Odds ratio $=4.52$ ). Patients receiving both topical antimicrobial prophylaxis and sucralfate remained free of gastric colonization for a longer period than those receiving acid inhibitory stress ulcer prophylaxis. In these two groups, patients without enteral feeding remained free of gastric colonization for a longer period than those receiving enteral feeding. Topical antimicrobial prophylaxis, in combination with sucralfate, successfully prevented gastric colonization with potentially pathogenic microorganisms and seemed to be correlated with lower gastric $\mathrm{pH}$ values. However, the risk of gastric colonization was markedly increased when continuous enteral feeding was administered simultaneously: 


\section{INTRODUCTION}

The stomach has often been described as an important source for colonization of the upper respiratory tract with subsequent pneumonia in mechanically ventilated ICUpatients $(1,2)$. In these patients gastric $\mathrm{pH}$, in physiological situations an effective barrier against bacterial growth (3), may be artificially elevated for several reasons. An alkaline gastric environment may be the result of stress ulcer prophylaxis, either due to inhibited acid production $\left(\mathrm{H}_{2}\right.$-blocking agents, omeprazole) or to alkalization of gastric contents through antacids or enteral feeding. Based on the assumed importance of gastric colonization as a source for nosocomial pneumonia several regimens have been developed to prevent gastric bacterial growth. Topical application of non-absorbable antibiotics to selectively decontaminate the digestive tract included application of these agents to the stomach (4). In another study sucralfate was used as stress ulcer prophylaxis, leaving gastric acidity intact $(5,6)$. Although decreased incidences of nosocomial pneumonia were reported with both regimens $(5,6)$, other reports failed to show any benefit (7-11).

Since enteral feeding may interfere with these preventive measures, due to its effect on gastric $\mathrm{pH}(12)$, we studied the influence of different stress ulcer prophylactic agents and enteral feeding on gastric $\mathrm{pH}$ in $95 \mathrm{ICU}$-patients, admitted to ICU for at least five days. In addition, the efficacy of a regimen to prevent gastric colonization, using both topical antimicrobial prophylaxis and sucralfate, was determined with and without simultaneous administration of enteral feeding. The primary outcome parameters in this study were gastric $\mathrm{pH}$ and gastric colonization.

\section{MATERIAL AND METHODS}

\section{Study-design}

The study was conducted prospectively in two identical eight-bed ICU's at the University Hospital of Maastricht. Both ICU's housed a mixed population of trauma, medical, surgical and neurological patients. Pediatric patients were excluded from the study. Age, gender, severity of illness, medical condition and need of mechanical ventilation were recorded on admission.

Patients admitted to ICU were allocated to receive either no antimicrobial prophylaxis and conventional stress ulcer prophylaxis, if indicated (group A), or topical antimicrobial prophylaxis in combination with sucralfate (group B). Group A $(n=64)$ received, if indicated, stress ulcer prophylaxis with one of the following agents: Antacids ( $\mathrm{n}=34)(40 \mathrm{mg}$ aluminumoxide/ $20 \mathrm{mg}$ magnesiumhydroxide per $\mathrm{ml}, 15 \mathrm{ml} \mathrm{q.4h.,} \mathrm{p.o.),} \mathrm{H}_{2}$-antagonists $(\mathrm{n}=10)$ (ranitidine, $50 \mathrm{mg} \mathrm{q.8h.,} \mathrm{i.v.)} \mathrm{or}$ omeprazole $(n=6)$ ( $40 \mathrm{mg}$ q.8h., i.v.). Group B $(n=31)$ received topical antimicrobial prophylaxis, which included four times a day: 
- suspension of tobramycin $(8 \mathrm{mg} / \mathrm{ml})$ and colistin $(5 \mathrm{mg} / \mathrm{ml}) 1 \mathrm{ml}$ in each nostril and $5 \mathrm{ml}$ through nasogastric tube

- suspension of amphotericin B $(100 \mathrm{mg} / \mathrm{ml}) 0.5 \mathrm{ml}$ in each nostril and $2.5 \mathrm{ml}$ through nasogastric tube

- application of tobramycin/colistine/amphotericin B 2\% in Orabase to oropharynx

- $1 \mathrm{~g}$ sucralfate suspension through nasogastric tube.

To analyze colonization with potentially pathogenic microorganisms with time both groups were subdivided into 2 separate groups (A1 and A2, B1 and B2), according to whether enteral feeding was simultaneously administered or not. Episodes were analyzed, provided gastric samples were free of colonization with potential pathogenic microorganisms on the first day of the episode and the patient could be studied for at least five days. Thus a patient could be included sequentially in two groups, provided there was no gastric colonization with potential pathogenic microorganisms on the first day of the episode studied. Thus, four groups were formed: Patients in group A1 $(n=9)$ did not receive topical antimicrobial prophylaxis with sucralfate or enteral feeding. Patients in group A2 $(n=13)$ did not receive antimicrobial prophylaxis and sucralfate, but did receive enteral feeding. Patients in group B1 $(n=12)$ received topical antimicrobial prophylaxis and sucralfate but no enteral feeding, while those in group B2 $(n=9)$ received antimicrobial prophylaxis, including sucralfate, in combination with enteral feeding.

Informed consent was obtained from the patient or, if this was not possible because of the clinical condition, from a representative of the family. The study protocol was approved by the hospital ethical committee.

To assess the severity of acute illness the APACHE II score was calculated on admission to the ICU as described elsewhere (13). In all patients enteral feeding was started when possible.

\section{Definitions}

Colonization was defined as the isolation of microorganisms from gastric aspirate. Colonization on admission was established by a positive culture obtained within 48 hours after admission to the ICU. Colonization was designated as 'acquired' if there were positive cultures of the same species of microorganisms from at least two consecutive samples, where the first was taken no sooner than 48 hours after admission to the ICU. Sterile cultures were labelled as 'no colonization'. Persistent colonization was defined as colonization, present on admission and persisting for at least three days.

In the analysis of colonization species of microorganisms were grouped as follows: Enterobacteriaceae, Pseudomonadaceae, Enterococcus faecalis and finally yeasts. Enterobacteriaceae and Pseudomonadaceae were considered as potentially pathogenic microorganisms (ppmo). 


\section{Bacteriologic monitoring}

Colonization was assessed by collecting gastric aspirates on admission and subsequently at least twice a week. Samples were taken in the morning immediately before administration of medication. Gastric juice was aspirated into a sterile vial after the first $10 \mathrm{ml}$ of gastric juice had been discarded.

Colonization was analyzed semi-quantitatively as follows: $10 \mu \mathrm{l}$ of gastric aspirate was streaked using the four-quadrant streak method on sheep blood, CLED, chocolate, and Sabauroud plates. All media were incubated at $35.0^{\circ} \mathrm{C}$ for 18 to 24 hours. Growth density was graded as follows: growth in the first quadrant $=+1$, in the second quadrant $=+2$, in the third quadrant $=+3$, and on the whole plate $=+4$. Indicator papers were used to measure the $\mathrm{pH}$ of the aspirate (Schleicher \& Schüll, range from $0-12$ ). All samples were processed and cultured by the same analyst.

\section{Enteral feeding}

Enteral feeding ("Nutrison", Nutricia, Zoetermeer, The Netherlands) was administered by nasogastric tube and prescription was taken care of by the nutritional support team, which also delivered the feedings in sterile containers to the ICU. The $\mathrm{pH}$ of enteral feeding was 7.0. Enteral feeding was administered continuously.

\section{Statistical analysis}

Comparisons of proportions were analyzed by Chi-square test. The relationship between variables influencing gastric $\mathrm{pH}$ and rate of gastric colonization was tested by stepwise logistic regression analysis. The probability of remaining free of colonization with potentially pathogenic microorganisms in time was calculated using the Kaplan-Meyer estimate, followed by a log-rank test for comparisons between groups. A probability value of less than 0.05 was considered significant.

\section{RESULTS}

\section{Patients}

The characteristics of all patients are listed in table 1. No significant differences were observed between group $A$ and $B$. Of those patients not receiving topical antimicrobial prophylaxis (group A), most received either antacids $(34 / 64,53 \%$ ) or $\mathrm{H}_{2}$-antagonists $(10 / 64,16 \%)$. Six out 64 patients $(9 \%)$ received omeprazole because of peptic ulcers in the medical history. In 14 patients (22\%) stress ulcer prophylaxis with antacids or $\mathrm{H}_{2}$-antagonists was discontinued and a period of at least five days without stress ulcer prophylaxis could be studied.

Forty-eight patients, 34 in group A $(53 \%)$ and 14 in group B (45\%) received enteral feeding for a period of at least five days. Forty patients, 26 in group $A(41 \%)$ and 14 in group B (45\%), did not receive enteral feeding for a period of at least five days. Seven patients were studied twice, one period with and one without enteral feeding. 
Table 1: Characteristics of the patients studied

\begin{tabular}{|c|c|c|}
\hline thes & $\begin{array}{c}\text { Group A } \\
\text { no } \operatorname{TAP}^{1}(n=64)\end{array}$ & $\begin{array}{c}\text { Group B } \\
\operatorname{TAP}(n=31)\end{array}$ \\
\hline mean age (range): & $61.0(17-69)$ & $59.9(23-80)$ \\
\hline Male/Female & $42 / 22$ & $20 / 11$ \\
\hline days on ICU; mean (range): & $25.1(5-145)$ & $20.2(6-95)$ \\
\hline APACHE II; mean (SD): & $18.0(8.0)$ & $18.6(9.2)$ \\
\hline \multicolumn{3}{|l|}{ Medical conditions: ${ }^{2}$} \\
\hline cardiovascular disease & 29 & 13 \\
\hline gastrointestinal disease & 10 & 1 \\
\hline respiratory disease & 24 & 9 \\
\hline alcoholism/drug abuse & 4 & 2 \\
\hline neoplastic disease & 14 & 8 \\
\hline diabetes mellitus & 8 & 1 \\
\hline neurologic disease & 10 & 5 \\
\hline \multirow{2}{*}{\multicolumn{3}{|c|}{$\begin{array}{l}\text { Number of patients intubated: } \\
\text { Medical department: }\end{array}$}} \\
\hline & & \\
\hline surgery & $\begin{array}{c}24 \\
9\end{array}$ & $\begin{array}{c}11 \\
3\end{array}$ \\
\hline $\begin{array}{l}\text { trauma } \\
\text { medical }\end{array}$ & $\begin{array}{c}9 \\
16\end{array}$ & $\begin{array}{l}3 \\
9\end{array}$ \\
\hline $\begin{array}{l}\text { medical } \\
\text { pulmonology }\end{array}$ & $\begin{array}{l}16 \\
10\end{array}$ & 7 \\
\hline neurology & 5 & 1 \\
\hline \multirow{4}{*}{$\begin{array}{l}\text { Enteral feeding: }{ }^{3} \\
\text { yes } \\
\text { no } \\
\text { both }\end{array}$} & & \\
\hline & 34 & 14 \\
\hline & 26 & 14 \\
\hline & 4 & 3 \\
\hline
\end{tabular}

${ }^{1}=$ TAP $=$ topical antimicrobial prophylaxis; ${ }^{2}=$ For each patient more than one condition is possible.

${ }^{3}=$ The number of periods, of at least five days, with or without enteral feeding. For 7 patients both periods could be studied.

\section{Gastric $p H$}

Gastric pH of 308 samples was determined. The correlation between enteral feeding, $\mathrm{pH}$-raising medication and a gastric $\mathrm{pH}<3.5$ is shown in figure 1 . Three out of 75 (4\%) gastric samples obtained from patients receiving $\mathrm{pH}$-raising stress ulcer prophylaxis and enteral feeding, had a gastric $\mathrm{pH}<3.5$, whereas 17 out of $52(33 \%)$ of gastric samples obtained from patients with neither stress ulcer prophylaxis nor enteral feeding had a $\mathrm{pH}<3.5$ ( $\mathrm{p}<0.00001$, Chi-square). Stepwise logistic regression 
analysis showed that enteral feeding increased the risk for a gastric $\mathrm{pH}>3.5$ by a factor 4.54 (95\% confidence interval: $2.30-8.96)$ and the absence of sucralfate for stress ulcer prophylaxis increased this risk by a factor 2.04 (95\% confidence interval: 1.06 3.95)

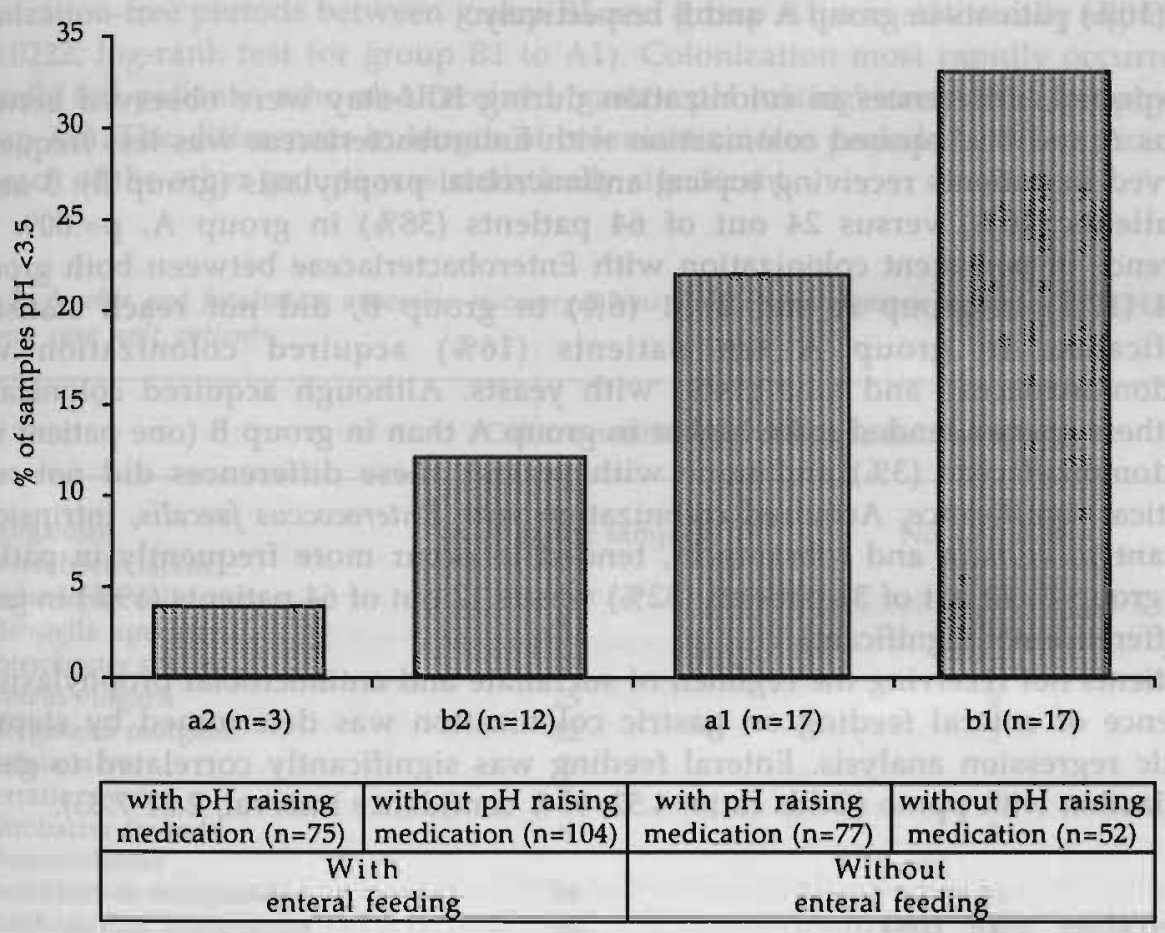

Figure 1: Percentage of gastric samples with $p H<3.5$ according to simulianeously administered enteral feeding and/or 'gastric $p H$ raising' stress ulcer prophylaxis. Statistics: $A 2$ versus $B 2 p=0.13$ : $A 2$ versus $A 1 \mu=0.002 ; A 2$ versus $B 1 \quad p<0.00001 ; B 2$ versus $A 1 p=0.09$; B2 versus $B 1 p<0.00001 ; A 1$ versus $B 1 p=0.0009$ (all by Chi-square).

\section{Gastric colonization}

Altogether, 434 gastric samples from 95 patients were cultured, yielding 699 isolates (Table 2). Enterobacteriaceae were most frequently isolated. Yeasts and Enterococcus faecalis were isolated from 65 and 126 gastric samples, obtained from 41 and 49 patients respectively. 
On admission 24 out of 64 patients (37\%) in group A and 13 out of 31 patients (41\%) in group B were not colonized in the stomach. In those colonized, Enterobacteriaceae $(25 / 64,39 \%$ in group $A$ and $7 / 31,23 \%$ in group $B ; p>0.05)$ and yeasts $(19 / 64,29 \%$ in group A and $9 / 31,30 \%$ in group B) were isolated most frequently. On admission, pseudomonadaceae were not cultured from gastric samples of patients in group A and from samples of only 2 patients (7\%) in group B. On admission, Enterococcus faecalis was isolated from samples of $7 / 64(11 \%)$ and $3 / 31(10 \%)$ patients in group A and B respectively.

As expected, differences in colonization during ICU-stay were observed between groups A and B. Acquired colonization with Enterobacteriaceae was less frequently observed in patients receiving topical antimicrobial prophylaxis (group B): 3 out of 31 patients $(10 \%)$ versus 24 out of 64 patients $(38 \%)$ in group $A, p=.009$. The difference in persistent colonization with Enterobacteriaceae between both groups, $11 / 64(17 \%)$ in group A and $2 / 31(6 \%)$ in group B, did not reach statistical significance. In group $A$ ten patients (16\%) acquired colonization with pseudomonadaceae and nine $(14 \%)$ with yeasts. Although acquired colonization with these species tended to be higher in group A than in group B (one patient with Pseudomonadaceae $(3 \%)$ and none with yeasts), these differences did not reach statistical significance. Acquired colonization with Enterococcus faecalis, intrinsically resistant to colistin and tobramycin, tended to occur more frequently in patients from group B: 20 out of 31 patients (32\%) versus 12 out of 64 patients (19\%) in group A (difference not significant).

In patients not receiving the regimen of sucralfate and antimicrobial prophylaxis the influence of enteral feeding on gastric colonization was determined by stepwise logistic regression analysis. Enteral feeding was significantly correlated to gastric colonization with ppmo (Odds ratio $=4.52 ; 95 \%$ confidence interval; $2.61-7.83$ ).

\section{Colonization with time}

Altogether, 43 episodes of at least five days, without colonization with ppmo on the first day, could be analyzed (Figure 2). The episodes were divided over 4 groups: 9 episodes in group A1 (no topical antimicrobial prophylaxis, no sucralfate, and without enteral feeding), 13 episodes in group A2 (no topical antimicrobial prophylaxis, no sucralfate, and with enteral feeding), 12 episodes in group B1 (topical antimicrobial prophylaxis without enteral feeding) and 9 episodes in group B2 (topical antimicrobial prophylaxis with enteral feeding). Acquisition of colonization with ppmo differed widely between the groups ( $p<0.0001, \log$-rank test). Topical antimicrobial prophylaxis, in combination with sucralfate, prevented colonization successfully, provided no enteral feeding was administered: almost all patients from group B1 remained free of gastric colonization. The length of the colonization-free 
period was shorter in patients receiving antimicrobial prophylaxis combined with enteral feeding (group B2), although the difference did not reach statistical significance ( $p=0.2194$, log-rank test for group B1 to B2). The length in colonizationfree periods of patients in group B2 (topical antimicrobial prophylaxis with enteral feeding) was comparable to the length of these periods in patients not receiving topical antimicrobial prophylaxis and sucralfate, or enteral feeding (group A1) $(p=0.3505$, log-rank test for group $B 2$ to $A 1)$. The difference in length of the colonization-free periods between group B1 and group A1 was statistically significant $(p=0.0222$, log-rank test for group B1 to $A 1)$. Colonization most rapidly occurred in enterally fed patients, who also received 'gastric $\mathrm{pH}$ raising' stress ulcer prophylaxis (group A2). The differences in length of colonization free periods between group A2 and each of the other groups was statistically significant.

Table 2: Aerobic and facultative anaerobic microorganisms isolated from gastric aspirates $(n=434)$ of 95 intensive care unit patients.

Culture positivity according to isolated species

Microorganism

Enterobacteriaceae

Escherichia coli

Klebsiella species

Enterobacter species

Proteus vulgaris

Morganella morganii

Hafnia alvei

Serratia species

Citrobacter freundii

Pseudomonadaceae

Pseudomonas aeruginosa

Xanthomonas maltophilia

Acinetobacter species

Alcaligenes xylosoxydans

Flavobacterium indologenes

Gram-positive m.o.

Staphylococcus aureus

Staphylococcus epidermidis

Enterococcus faecalis

Streptococci
Other Gram-negative m.o.
No. of gastric samples

83

131

39

25

12

2

7

6

39

10

16

2

12

7

5

126

2

65
No. of patients

26

39

27

9

5

1

3

5

21

6

11

2

3

6

4

49

2

Yeasts 


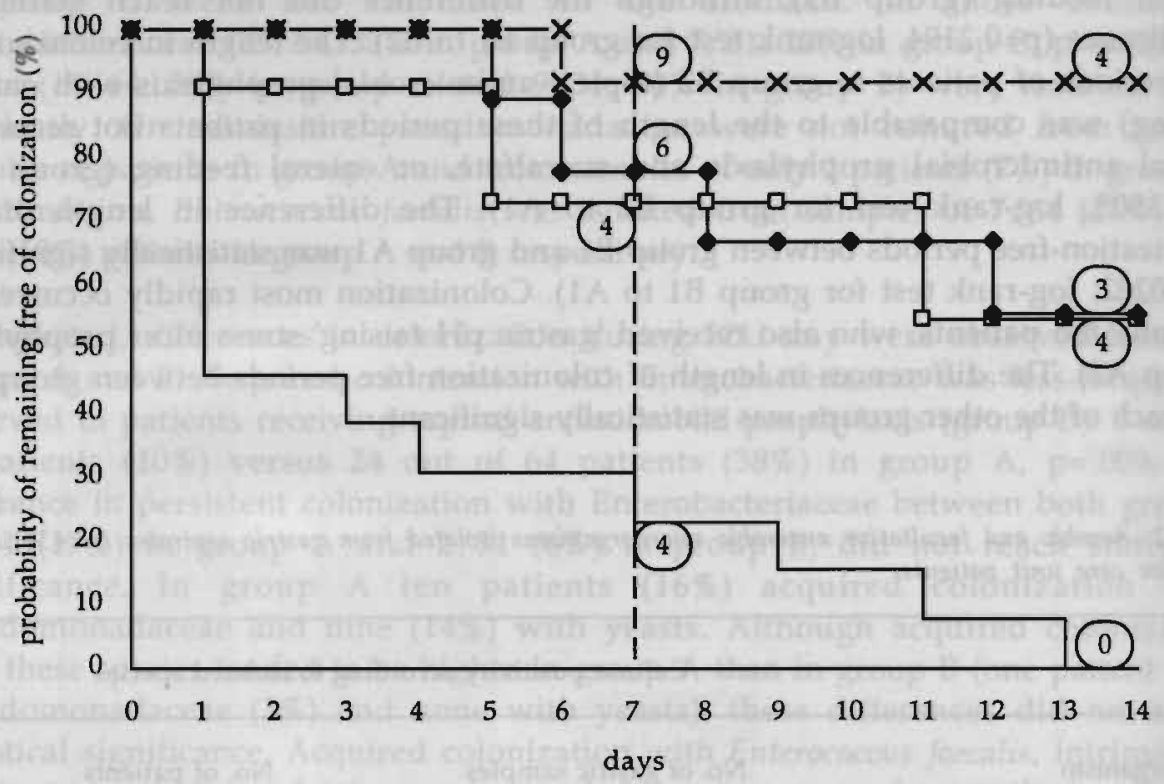

Figure 2: Kaplan-Meier estimate of the probability of remaining free of colonization with potentially pathogenic microorganisms in the stomach in four groups of patients. All patients were free of colonization with potentially pathogenic microorganisms on day 0 . Group A1 (口), receiving 'gastric pH-raising' stress ulcer prophylaxis without enteral feeding; group $A 2(-)$, receiving 'gastric-pH raising' stress ulcer prophylaxis and enteral feeding; group B1 (X), receiving topical antimicrobial prophylaxis without enteral feeding; group B2 $(\diamond)$, receiving topical antimicrobial prophylaxis and enteral feeding. The numbers in the figure refer to the numbers of patients free of colonization with ppmo at days 7 and 14 . Statistics: $B 1$ versus $B 2 p=0.2194 ; B 1$ versus $A 1 p=0.0222 ; B 1$ versus $A 2 p<0.0001$; $B 2$ versus $A 1 p=0.3505$; $B 2$ versus $A 2 p=0.0014 ; A 1$ versus $A 2 p=0036$ (all by log-rank test).

\section{DISCUSSION}

The main feature of this study is that gastric colonization was lower in a group of ICU-patients receiving a combination of non-absorbable topical antimicrobial agents and sucralfate, as compared to a group of patients not receiving antimicrobial prophylaxis and sucralfate for stress ulcer prophylaxis. In addition, we found this difference to be less apparent when enteral feeding was administered simultaneously. Enteral feeding seemed to be an important risk factor for an 
increase in gastric $\mathrm{pH}$ and for gastric colonization at least under the circumstances tested.

There is limited evidence supporting the hypothesis that gastric colonization plays a causal role in the development of nosocomial pneumonia (2). In this gastropulmonary route of colonization and infection the stomach would play a crucial part, as it is the first obstacle for enteric bacteria to pass. In healthy subjects gastric $\mathrm{pH}$ is below 3.5, which proved to be bactericidal for most species of microorganisms $(3,14)$. A correlation between a high gastric $\mathrm{pH}$, either due to hypochlorhydria or achieved artificially with stress ulcer prophylactic agents, and bacterial colonization of the stomach has been described (15-18).

The combination of topical antimicrobial prophylaxis and sucralfate, administered to 31 patients, modulated gastric colonization: a significant lower percentage of patients acquired colonization with Enterobacteriaceae as compared to patients not receiving topical antimicrobial prophylaxis. Moreover, acquired colonization with Pseudomonadaceae and yeasts were also lower in patients receiving antimicrobial prophylaxis, although statistical significance was not reached. In contrast, a tendency towards increased colonization with Enterococcus faecalis, intrinsically resistant to tobramycin and colistin, was observed in patients receiving topical antimicrobial prophylaxis. These differences could not be attributed to differences in colonization on admission, because colonization rates for these microorganisms were comparable for patients receiving and not-receiving topical antimicrobial prophylaxis. Increased colonization with Enterococcus faecalis as a side-effect of this regimen, occasionally leading to pneumonia and bacteremia, has been reported before $(19,20)$.

The use of topical antimicrobial prophylaxis and sucralfate seemed to be associated with lower gastric $\mathrm{pH}$-values as compared to the $\mathrm{pH}$-values obtained from a group of patients of whom most received either antacids, $\mathrm{H}_{2}$-antagonists or omeprazole. However, it should be stated that the administration of topical antimicrobial prophylaxis with sucralfate, and antacids or $\mathrm{H}_{2}$-antagonists, was not performed in a randomized matter, and that a control group without any stress ulcer prophylaxis was lacking. The observation of lower $\mathrm{pH}$ values in gastric samples of patients receiving sucralfate as compared to those from patients receiving antacids or $\mathrm{H}_{2}$ antagonists is in line with other reports $(5,6)$. However, in patients receiving sucralfate a low gastric $\mathrm{pH}$ was less frequently observed when enteral feeding was administered concurrently. As a result, the preventive effect of the prophylactic regimen on gastric colonization was markedly decreased by concurrent administration of enteral feeding. 
The same effect of enteral feeding was observed in those patients receiving stress ulcer prophylaxis aimed to raise gastric $\mathrm{pH}$ : the number of gastric samples with a low gastric $\mathrm{pH}$ was lower in patients receiving enteral feeding. Furthermore, in logistic regression analysis enteral feeding appeared to be an independent risk factor associated with colonization. The same correlations between enteral feeding, increased gastric $\mathrm{pH}$ and gastric colonization have been observed before $(12,21,22)$. Pingleton described 18 mechanically ventilated patients receiving enteral feeding, who had a mean gastric $\mathrm{pH}$ above 4.0 and who all had gastric colonization at some time during the study. However, of only four of these patients no growth was found in the initial gastric culture and patients were studied for only six days (21). In a randomized, double-blind trial acidified enteral feeding resulted in lower mean gastric $\mathrm{pH}$-values and lower gastric colonization rates as compared to those observed among patients receiving normal enteral feeding (22).

Although the current study was neither randomized nor blinded, the results of this study seem to support an important influence of enteral feeding on gastric colonization. However, as in most other studies gastric $\mathrm{pH}$ was determined in infrequent samples with indicator paper. The use of continuous intragastric $\mathrm{pH}$ monitoring probably has major advantages. One of the drawbacks of the $\mathrm{pH}$ paper method is that temporary changes in gastric $\mathrm{pH}$ cannot be measured (23). Moreover, the reliability of the $\mathrm{pH}$ paper has been questioned (24), but others report a good correlation between the $\mathrm{pH}$ paper method and a $\mathrm{pH}$ meter $(\mathrm{r}=.94, \mathrm{p}<0.001)(25)$. To overcome the interobserver variations using indicator paper for $\mathrm{pH}$ measurement (26), all analyses were performed by the same technician, who was unaware of the patients' medication.

In conclusion, the results of the present study show that a combination of nonabsorbable antimicrobial agents and sucralfate modulates gastric colonization in mechanically ventilated ICU-patients, provided enteral feeding is not administered simultaneously. Enteral feeding increased the risk of gastric colonization both in patients receiving, as well as in patients not receiving the prophylactic regimen. Based on these observations, enteral feeding, administered intermittently, may be more appropriate since gastric $\mathrm{pH}$ may fall when enteral feeding is stopped, thereby possibly preventing gastric colonization. The first two studies testing this hypothesis have been reported recently $(27,28)$. In view of the equivocal results of these investigations, further studies, using continuous intragastric $\mathrm{pH}$ monitoring, are therefore needed to confirm this hypothesis. 


\section{REFERENCES}

1. Tryba M. The gastropulmonary route of infection: fact or fiction? Am J Med 1991; 91 (suppl 2A): 135-146

2. Heyland D, Mandell LA. Gastric colonization by Gram-negative bacilli and nosocomial pneumonia in the intensive care unit patient: evidence for causation. Chest 1992; 101: 187-93

3. Wilder-Smith $\mathrm{CH}$, Spirig C, Krech T, Merki HS. Bactericidal factors in gastric juice. Eur J Gastroenterol Hepatol 1992; 4: 885-891

4. Stoutenbeek CP, van Saene HKF, Miranda DR, Zandstra DF. The effect of selective decontamination of the digestive tract on colonisation and infection rate in multiple trauma patients. Intensive Care Med 1984; 10: 185-192

5. Driks MR, Craven DE, Celli BR, et al. Nosocomial pneumonia in intubated patients given sucralfate as compared with antacids or histamine type 2 blockers. N Engl J Med 1987; 317: 1376-82

6. Tryba M. Risk of acute stress bleeding and nosocomial pneumonia in ventilated intensive care unit patients: sucralfate versus antacids. Am J Med 1987; 83 (suppl 3B): 117-124

7. Gastinne H, Wolff M, Delatour F, Faurisson F, Chevret S. A controlled trial in intensive care units of selective decontamination of the digestive tract with nonabsorbable antibiotics. New Engl J Med 1992; 326: 594-599

8. Hammond JMJ, Potgieter PD, Saunders GL, Forder AA. Double-blind study of selective decontamination of the digestive tract in intensive care. Lancet 1992; 340: 5-9

9. Cockerill FR, Muller SR, Anhalt JP, et al. Prevention of infection in critically ill patients by selective decontamination of the digestive tract. Ann Intern Med 1992; 117: 545-553

10. Simms H, DeMaria E, McDonald L, Peterson D, Robinson A, Burchard KW. Role of gastric colonization in the development of pneumonia in critically ill trauma patients: Results of a prospective randomized trial. J Trauma 1991; 31: 531-537

11. Mahul Ph, Auboyer C, Jospe R, et al. Prevention of nosocomial pneumonia in intubated patients: respective role of mechanical subglottic secretions drainage and stress ulcer prophylaxis. Intensive Care Med 1992; 18: 20-25

12. Jacobs S, Chang RWS, Lee B, Bartlett FW. Continuous enteral feeding: A major cause of pneumonia among ventilated Intensive Care patients. J Parenteral and Enteral Nutrition 1990; 14: 353-356

13. Knaus WA, Draper EA, Wagner DP, Zimmerman JE. APACHE II: A severity of disease classification system. Crit Care Med 1985; 13: 818-829

14. Mehta S, Archer JF, Mills J. pH-dependent bactericidal barrier to gram-negative aerobes: its relevance to airway colonisation and prophylaxis of acid aspiration and stress ulcer syndromes study in vitro. Intensive Care Med 1986; 12: 134-136

15. Drasar BS, Shiner M, McLeod GM. Studies on the intestinal flora I: The bacterial flora of the gastrointestinal tract in healthy and achlorhydric persons. Gastroenterology 1969; 56: 71

16. Daschner F, Kappstein I, Engels I, et al. Stress ulcer prophylaxis and ventilation pneumonia: prevention by antibacterial cytoprotective agents. Infect Control Hosp Epidemiol 1988; 9: 59-65

17. Garvey BM, McCambley JA, Tuxen DV. Effects of gastric alkalization on bacterial colonization in critically ill patients. Crit Care Med 1989; 17: 211-216 
18. Apte NM, Karnad DR, Medhekar TP, Tilve GH, Morye S, Bhave GG. Gastric colonization and pneumonia in intubated critically ill patients receiving stress ulcer prophylaxis: A randomized, controlled trial. Crit Care Med; 20: 590-593

19. Bonten MJM, van Tiel FH, van der Geest S, Stobberingh EE, Gaillard CA. Enterococcus faecalis pneumonia complicating topical antimicrobial prophylaxis. [letter] N Engl J Med 1993; 328: 209. 210

20. Bonten MJM, van Tiel FH, van der Geest S, Smeets HGW, Stobberingh EE, Gaillard CA. Topical antimicrobial prophylaxis of nosocomial pneumonia in mechanically ventilated patients. Microbiologic observations. Infection 1993; 21: 137-139

21. Pingleton SK, Hinthron DR, Liu C. Enteral nutrition in patients receiving mechanical ventilation. Am J Med 1986; 80: 827-832

22. Heyland D, Bradley C, Mandell LA. Effect of acidified enteral feedings on gastric colonization in the critically ill patient. Crit Care Med 1992; 20: 1388-1394

23. Moore JG, Englert E. Circadian rythm of gastric acid secretion in man. Nature 1970; 226: 1261-1262

24. Dobkin ED, Valcour A, McCloskey CR et al. Does $\mathrm{pH}$ paper accurately reflect gastric $\mathrm{pH}$ ? Crit Care Med 1990; 18: 985-988

25. Meiners D, Clift S, Kaminski D. Evaluation of various techniques to monitor intragastric pH. Arch Surg 1982; 117: 288-291

26. Caballero GA, Ausman RK, Quebbeman EJ, Schulte WJ, Lin L. Gastric secretion pH measurements: What you see is not what you get! Crit Care Med 1990; 18: 396-399

27. Lee B, Chang RWS, Jacobs S. Intermittent nasogastric feeding: A simple and effective method to reduce pneumonia among ventilated ICU patients. Clinical Intensive Care 1990; 1: 100-102

28. Spilker CA, Hinthron DR, Pingleton SK. Intermittent enteral feeding and gastric colonization in critically ill patients. [Abstract] Am Rev Respir Dis 1993; 147 (Supplement): A200 


\section{Chapter 7}

COLONIZATION IN PATIENTS RECEIVING AND NOT-RECEIVING TOPICAL ANTIMICROBIAL PROPHYLAXIS 


\section{SUMMARY}

The influence of Topical Antimicrobial Prophylaxis (TAP) on colonization of oropharynx and trachea with potential pathogenic microorganisms was studied in patients receiving and not-receiving prophylaxis. Twenty-two patients in ICU I (group 1) received TAP, containing tobramycin, colistin and amphotericine B, applied to the oropharynx and stomach. Simultaneous to group 1, a second group of patients (group $2, n=21$ ) that did not receive TAP was studied in ICU I. In addition, a control group of patients admitted to another, identical, ICU (ICU II), where no TAP was administered, were studied simultaneously (group $3 a, n=23$ ). A second control group (group $3 b, n=31$ ), was formed by collecting data from all patients admitted to ICU I in period II, which started after administration of TAP had been stopped for one month.

Patients receiving prophylaxis were less frequently colonized in oropharynx or trachea as compared to patients not-receiving prophylaxis. Moreover, of the patients not-receiving prophylaxis, those staying in the ICU where prophylaxis was administered (group 2), were less frequently colonized as compared to patients in another ICU where no prophylaxis was administered (group 3). Of the patients not colonized on admission, those staying in the ICU where prophylaxis was administered (groups 1 and 2) remained free of colonization for a longer period of time as compared to non-colonized patients in the ICU where no prophylaxis was administered (group 3). In addition, in the ICU where no prophylaxis was administered more patients were colonized simultaneously and cross-acquisition occurred more frequently. In conclusion, TAP administered to oropharynx and stomach significantly influenced colonization of oropharynx and trachea in patients receiving and not-receiving prophylaxis within the same ICU as compared to patients not-receiving prophylaxis in another identical ICU. 


\section{INTRODUCTION}

Lower respiratory tract infections in mechanically ventilated patients are usually preceded by colonization of oropharynx and trachea with the same microorganisms (1). These microorganisms reach the upper airways from exogenous sources or from the gastrointestinal tract: the endogenous route. The latter has been accepted as an important route of colonization leading to infection, especially in critically ill patients (2). Based on the assumed importance of the endogenous route of colonization several regimens have been developed to prevent colonization and infection of the lungs. Non-absorbable antibiotics applied to oropharynx and digestive tract to selectively eradicate potential pathogenic microorganisms (ppmo) from these sites reduced the incidence of nosocomial pneumonia $(3,4)$, although other studies failed to confirm this $(5,6)$.

To reduce the risk of colonization and infection from exogenous sources standard protocols are used and strict hygienic measures should minimize the risk of acquisition of microorganisms from equipment or ICU employees $(7,8)$. However, cross-acquisition from one patient to another might still be an important cause of colonization in the ICU, where patients, colonized in oropharynx and trachea, act as a reservoir of microorganisms (9).

Therefore, antimicrobial prophylaxis may not only prevent colonization in the individual patient but might also influence cross-acquisition in an ICU. On the one hand, it would be plausible that patients not receiving topical antimicrobial prophylaxis, lying next to patients receiving prophylaxis, are protected against acquisition of microorganisms. On the other hand, prophylactic use of antimicrobial agents could lead to an increased colonization and spread of resistant microorganisms. Indeed, cross-acquisition between patients in an ICU often has been suggested to play an important role in the pathogenesis of nosocomial pneumonia and therefore should be taken into account when developing and evaluating preventive regimens. We studied colonization of oropharynx and trachea in patients receiving Topical Antimicrobial Prophylaxis (TAP) and control patients, not-receiving TAP, in the same ICU as compared to patients in another identical ICU.

\section{MATERIAL AND METHODS}

\section{Study-design}

The study was conducted prospectively in two identical eight-bed ICU's at the University Hospital of Maastricht in two four-months periods. Both ICU's 
contained a mixed population of trauma, medical, surgical and neurological patients. During period I TAP was administered to mechanically ventilated patients in ICU I if they met the following criteria: newly admitted to the ICU, intubation within 24 hours after admission, age above 15 years and an expected ventilation period of more than five days.

For every newly admitted patient who met the inclusion criteria, a decision was made whether to administer TAP or not, based on the number of patients receiving and not-receiving prophylaxis at that moment. As shown in Figure 1, in ICU I two groups were formed consisting of patients receiving (group 1) and not-receiving TAP (group 2). Patients admitted to the other ICU formed group $3 a$ and served as controls. A second control group (group $3 b$ ) was formed by collecting data from all patients admitted to ICU I in period II, which started after administration of TAP had been stopped for one month.

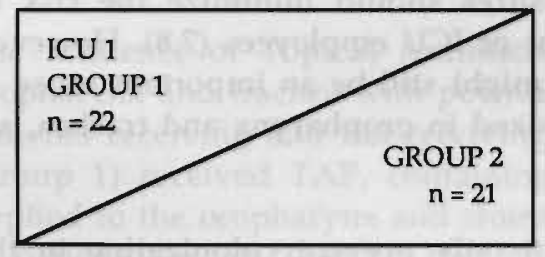

ICU 1

GROUP 3B

$n=31$

\section{ICU 2}

GROUP $3 \mathrm{~A}$

$\mathrm{n}=\mathbf{2 3}$

4 months

4 months

Figure 1: Study design and number of patients in the different groups in ICU I and II.

\section{Medication}

TAP consisted of the following regimen four times a day:

- suspension of tobramycin $(8 \mathrm{mg} / \mathrm{ml})$ and colistin $(5 \mathrm{mg} / \mathrm{ml}) 1 \mathrm{ml}$ in each nostril and $5 \mathrm{ml}$ through nasogastric tube

- application of tobramycin/colistin/amphotericin B 2\% in Orabase to oropharynx 
- suspension of amphotericin B $(100 \mathrm{mg} / \mathrm{ml}) 0.5 \mathrm{ml}$ in each nostril and $2.5 \mathrm{ml}$ through nasogastric tube

- $1 \mathrm{~g}$ sucralfate suspension $(5 \mathrm{ml})$ through nasogastric tube.

A constant equilibrium between patients receiving (group 1) and not receiving the prophylactic regimen (group 2) was aimed for. Since the ward contained eight beds a maximum of four patients were studied simultaneously in group 1 . In case of an equal number of patients receiving and not receiving TAP, the next admitted patient fulfilling the inclusion criteria would receive prophylaxis.

In total 188 patients, newly admitted to the ICU's in the defined periods, were included in the study of whom 97 stayed for at least 5 days in ICU: 22 in group 1, 21 in group 2 and 54 in groups $3 \mathrm{a}$ and $3 \mathrm{~b}$. To assess the severity of acute illness the APACHE II score was calculated on admission to the ICU as described elsewhere (10). Clinical parameters, antibiotic therapy and laboratory values were recorded prospectively.

Informed consent was obtained from the patient or, if this was not possible because of the clinical condition, from a representative of the family. The study protocol was approved by the hospital ethical committee.

Bacteriologic monitoring

Colonization was assessed by collecting oropharyngeal swabs and tracheal aspirates serially on admission and subsequently at least twice a week. Samples were taken in the morning immediately before administration of medication. Oropharyngeal swabs and tracheal aspirates were examined for ppmo. Colonization was analyzed semi-quantitatively as follows: Oropharyngeal swabs and $10 \mu l$ of tracheal aspirate were streaked using the four-quadrant streak method on sheep blood, CLED, chocolate, and Sabauroud plates. All media were incubated at $35.0^{\circ} \mathrm{C}$ for 18 to 24 hours. Growth density was graded as follows: growth in the first quadrant $=+1$, in the second quadrant $=+2$, in the third quadrant $=+3$, and on the whole plate $=+4$.

Gram-negative rods and lactose-fermenting microorganisms were identified using the API20E/20NE-system (Biomérieux). Susceptibilities to antimicrobial agents were determined using a microdilution method in ISO-Sensitest-Broth (Oxoid CM 471). The minimal inhibitory concentration (MIC) was defined as the lowest concentration at which no visible growth was apparent after overnight incubation at $37.0^{\circ} \mathrm{C}$. For all species susceptibilities were determined to at least six different antimicrobial agents, including tobramycin. Antimicrobial susceptibilities were analyzed for the five most frequently isolated Gram-negative microorganisms. The breakpoints for resistance for Gram-negative microorganisms were as follows: $>128$ $\mathrm{mg} / \mathrm{ml}$ for piperacillin (for Pseudomonas aeruginosa and $>64 \mathrm{mg} / \mathrm{ml}$ for Enterobacteriaceae), > $32 \mathrm{mg} / \mathrm{ml}$ for amikacin, amoxycillin, ceftazidim, cefuroxim and tobramycin, $>16 \mathrm{mg} / \mathrm{ml}$ for ciprofloxacin and $>8 \mathrm{mg} / \mathrm{ml}$ for gentamicin. 


\section{Definition of colonization}

Colonization was defined as the isolation of microorganisms from oropharynx and tracheal aspirate. Colonization on admission was established when the first culture obtained in the ICU, and obtained within 24 hours after entrance, was positive at any of these sites. Colonization was designated as 'acquired' if cultures were positive at two consecutive occasions and no colonization with that particular species was present on admission. Persistent colonization was defined as colonization, present on admission and persisting for at least three days.

To determine the time from admission until colonization occurred a KaplanMeyer analysis was performed for patients not colonized with potentially pathogenic microorganisms on admission. The colonization-free periods in ICU I, period I (patients groups 1 and 2) were compared to the colonization-free periods of patients from group $3 \mathrm{~A}$ and $3 \mathrm{~B}$.

For analysis several families of microorganisms were grouped together. "Enterobacteriaceae" included Escherichia coli, Klebsiella pneumoniae, Citrobacter freundii, Morganella morganii, Enterobacter cloacae and Proteus vulgaris. "Pseudomonadaceae" included Pseudomonas aeruginosa and Xanthomonas malthophilia. Enterobacteriaceae and pseudomonadaceae were considered as potentially pathogenic microorganisms (ppmo).

\section{Analysis of cross-acquisition}

The analysis of cross-acquisition was performed for four species (Klebsiella pneumoniae, Pseudomonas aeruginosa, Escherichia coli and Enterobacter cloacae), each separately and grouped as ppmo. Since cross-acquisition was studied in a ward rather than in separate patient groups, groups 1 and 2 were lumped together for this analysis. A patient in whom a member of the specified species was isolated from either the trachea or oropharynx was considered to be colonized. The transmission rate was calculated as follows:

\section{Transmission rate:}

no. of events of transmission

no. of days of non-colonized pts at risk for transmission

The 'number of days of non-colonized patients at risk for transmission' was calculated as follows: The total number of patient days in groups $1 / 2$ and 3 was calculated and from this the number of colonized and non-colonized patient days was derived. Non-colonized patients could be at risk for transmission if another patient in the ward was, at that particular day, colonized. Thus, non-colonized patients at risk to acquire colonization from a colonized patient were identified and the numbers of 'days of non-colonized patients at risk for transmission' were 
calculated. For this analysis each patient could be at risk for transmission of colonization only once a day, no matter how many other patients were colonized on that particular day.

An 'event of transmission' was defined as acquired colonization with a strain, identical to a strain colonizing another patient in the same ward, before or on the same day of colonization. Strains were deemed identical when biochemical reactions (API-profile) were identical and when the MIC's to six antimicrobial agents were concordant, i.e. when three out of six MIC values differed no more than one step of a twofold dilution sequence in the MIC determination.

Infection control measures in the $\mathrm{ICU}$

Both ICU's have an identical floorplan and infrastructure but a separate entrance, approximately 20 meters apart. Each ICU has its own nursing staff, 3.5 nurse per bed. In a rotating system the same medical staff took care of the ICU's. During both study periods surveillance cultures were taken from all sanitary equipment in both ICU's.

\section{Diagnosis of infection}

Pneumonia was considered as ICU-acquired if a clinical condition fulfilling the criteria for pneumonia developed after the patient had been in the ICU for at least three days. The diagnosis of pneumonia was established when at least three of the following criteria were met: (1) Rectal temperature above $38.0^{\circ} \mathrm{C}$ or below $35.5^{\circ} \mathrm{C}$, (2) blood leucocytosis $\left(>10.10^{3} / \mathrm{mm}^{3}\right)$, leucopenia $\left(<3.10^{3} / \mathrm{mm}^{3}\right)$ and /or left shift, (3) more than ten leucocytes per high-power field in Gram stain of tracheal aspirate and (4) a positive culture from tracheal aspirate in combination with a new or changing infiltrate on chest $\mathrm{X}$-ray, not attributable to a noninfectious etiology, and a positive quantitative culture from Bronchoalveolar Lavage (BAL) (cutoff point $10^{4}$ $\mathrm{cfu} / \mathrm{ml})$. Blood cultures were taken in case of fever or suspicion of sepsis. Collection and processing of samples from BAL were performed as described elsewhere (11).

\section{Statistical analysis}

Frequency comparisons were analyzed by Chi-square test or Fisher's exact test. The Kaplan-Meyer estimate of the colonization free periods was tested with Cox regression. In this analysis the number of patients colonized simultaneously in the ward, colonization pressure, was tested as a fixed covariate - being the mean of colonization pressure over the non-colonized days for each patient - and as a timedependent covariate. A Kaplan-Meyer estimate was performed for the three groups separately and for group $1 / 2$ as compared to group 3 .

The analyses of transmission rates were performed with a Chi-square test according to a Poisson Distribution. A probability value of less than 0.05 was deemed significant. 
Chapter 7

\section{RESULTS}

\section{Patients}

The characteristics of patients staying in ICU for at least 5 days are listed in Table 1. The APACHE II-score could not be calculated for 6 patients, due to incomplete data. All patients in group 1 were intubated. In group 2 and 3,86\% and $91 \%$ of the patients, respectively, were mechanically ventilated. The median values for age, APACHE II-score and duration of ICU-stay of the three groups studied were comparable. In all groups the majority of patients were surgical or medical.

Table 1: Characteristics of the patients

Characteristics

group 1

$\mathrm{n}=22$

age

$\mathrm{M} / \mathrm{F}$

days in ICU

APACHE II

No. of patients intubated $(\%)$

Medical specialty

surgery
trauma
medical
pulnonology
neurology

Stress ulcer prophylaxis (\%)

sucralfate

antacids

$\mathrm{H}_{2}$-antagonists

omeprazole

Systemic antibiotic use (\%)

Mortality (\%)

22 (100)
No. of patients group 2

group 3

$\mathrm{n}=54$

65.0

17-90

$32 / 22$

15.5

5-145

$17.0^{3}$

0-36

49 (91)

$18(86)$
21

7

15

7

4

0

$22(100)$

$012(57)$

$6(29)$

$3(14)$

$14(67)$

$6(29)$

\section{0}

$37(69)$

$13(24)$

4 (7)

$44(81)$

$14(26)$

$1-n=21,2=n=17,3=n=53$ 
In groups 2 and 3 comparable percentages of patients received antacids, $\mathrm{H}_{2}$ antagonists or omeprazole for stress ulcer prophylaxis. The number of patients receiving systemic antimicrobial therapy and the mortality rates were also comparable in the 3 groups.

The occupation of ICU-beds in ICU I where TAP was administered during study period I is shown in Figure 2. The ratio of patients receiving and not-receiving TAP was almost constant throughout the study.

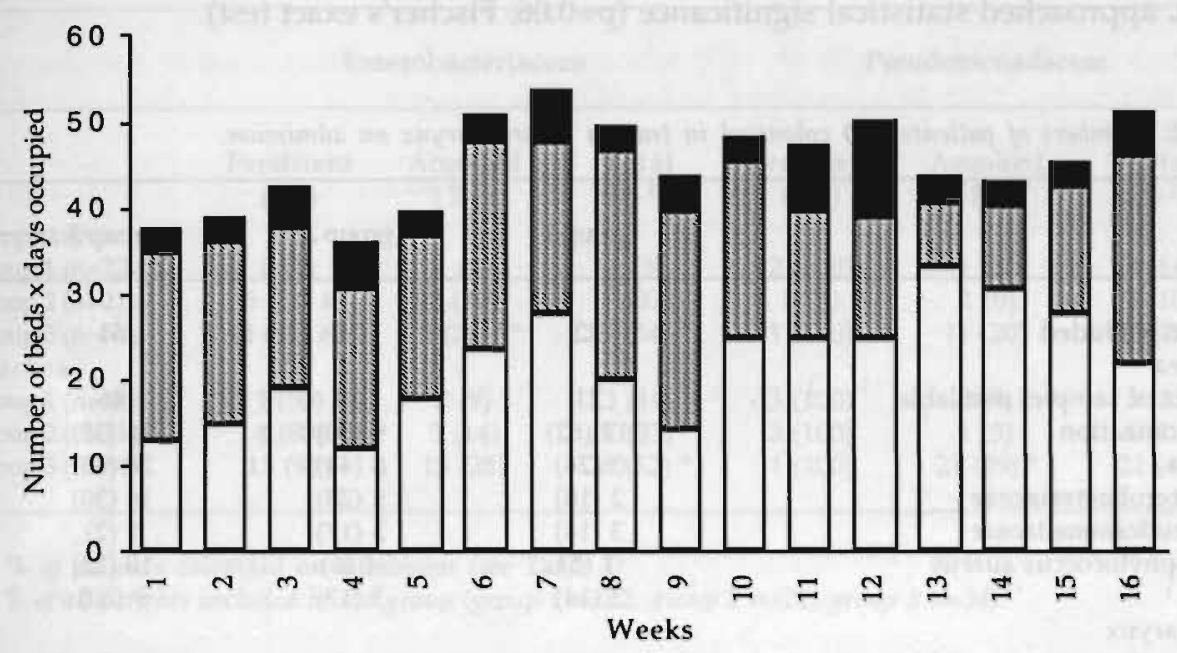

$\square$ group 1 $\quad$ group2 excluded

Figure 2: Occupation of beds by patients receiving and not-receiving TAP in ICU I in period I, expressed in number of bed-days per week. The ICU contained 8 beds, so a full occupation would be 56 bed-days per week. Patients excluded were those with an ICU-stay $<5$ days.

\section{Colonization on admission (Table 2)}

Tracheal aspirates from 85 patients and oropharyngeal swabs from 84 patients were obtained for cultures within 24 hours after admission to the ICU.

Trachea

The number of patients not colonized with microorganisms on admission were 13 $(62 \%), 9(50 \%)$ and $16(35 \%)$ for groups 1,2 and 3 respectively, whereas colonization with ppmo was demonstrated in $5(24 \%), 8(44 \%)$ and $20(43 \%)$ patients in groups 
1,2 and 3 respectively. For the individual bacteria the percentages did not differ significantly among the three groups studied, although significance was approached for colonization rates with Pseudomonadaceae between groups 2 and 3 ( $p=0.06$, Fischer's exact test).

Oropharynx

In oropharynx $6(30 \%), 8(44 \%)$ and $15(32 \%)$ patients were not colonized with microorganisms on admission for groups 1,2 and 3 respectively and at this site colonization with ppmo was demonstrated in $7(35 \%), 8(44 \%)$ and $19(40 \%)$ patients for groups 1,2, and 3 respectively. The differences in number of patients colonized with Pseudomonadaceae in oropharynx in group $3(2 \%)$, as compared to group 2 $(17 \%)$, approached statistical significance ( $p=0.06$, Fischer's exact test).

Table 2: Numbers of patients (\%) colonized in trachea or oropharynx on admission.

$\begin{array}{lll}\text { group } 1 & \text { group } 2 & \text { group } 3\end{array}$

$\begin{array}{lccc}\begin{array}{l}\text { Patients included } \\ \text { Trachea }\end{array} & 22 & 21 & 54 \\ \text { number of samples available } & 21 & 18 & 46 \\ \text { No colonization } & 13(62) & 9(50) & 16(35) \\ \text { P.p.m.o. } & 5(24) & 8(44) & 20(43) \\ \quad \text { Enterobacteriaceae } & 2(10) & 5(28) & 14(30) \\ \quad \text { Pseudomonadaceae } & 3(14) & 3(17) & 1(2) \\ \quad \text { Staphylococcus aureus } & 1(5) & 1(6) & 10(22) \\ \text { others 1 } & 3(14) & 3(17) & 9(20) \\ \text { Oropharynx } & & & 47 \\ \text { number of samples available } & 19 & 18 & 15(32) \\ \text { No colonization } & 6(30) & 8(44) & 19(40) \\ \text { P.P.m.o. } & 7(35) & 8(44) & 16(34) \\ \quad \text { Enterobacteriaceae } & 5(25) & 7(39) & 1(2) \\ \quad \text { Pseudomonadaceae } & 2(10) & 3(17) & 3(6) \\ \quad \text { Staphylococcus aureus } & 1(5) & 0 & 13(28) \\ \text { others } 1 & 9(45) & 5(28) & \end{array}$

1 = "others" include yeasts, streptococci, Moraxella catharalis and Enterococcus faecalis

Persistent colonization (Table 3)

Enterobacteriaceae

Persistent oropharyngeal colonization with Enterobacteriaceae occurred less frequently in patients from group 1 as compared to patients from group 3 ( $p<0.01$, Fischer's exact test), and group 2 ( $p<0.05$, Fischer's exact test). Of those patients not- 
receiving TAP (groups 2 and 3), equal proportions were persistently colonized with Enterobacteriaceae in trachea and in oropharynx, indicating that colonization was not eliminated in these patients.

Pseudomonadaceae

Persistent colonization with Pseudomonadaceae, in oropharynx and trachea, was demonstrated in comparable numbers of patients in the three groups.

Table 3: Numbers of patient with persistent and acquired colonization in oropharynx and trachea according to study group

Enterobacteriaceae

Pseudomonadaceae

\begin{tabular}{lccc|ccc}
\hline & $\begin{array}{c}\text { Persistent } \\
\left(\%^{1}\right)\end{array}$ & $\begin{array}{c}\text { Acquired } \\
\left(\%^{2}\right)\end{array}$ & $\begin{array}{c}\text { Total } \\
\left(\%^{2}\right)\end{array}$ & $\begin{array}{c}\text { Persistent } \\
\left(\%^{1}\right)\end{array}$ & $\begin{array}{c}\text { Acquired } \\
\left(\%^{2}\right)\end{array}$ & $\begin{array}{c}\text { Total } \\
\left(\%^{2}\right)\end{array}$ \\
$\begin{array}{l}\text { Oropharynx } \\
\text { group 1 }(\mathrm{n}=22)\end{array}$ & $0(0)$ & $1(5)$ & $1(5)$ & $2(100)$ & $1(5)$ & $3(14)$ \\
group 2 $(\mathrm{n}=21)$ & $5(71) \#$ & $2(10)$ & $7(33)$ & $0(0)$ & $210)$ & $2(10)$ \\
group 3(n=54) & $14(88) \# \#$ & $15(28) *$ & $29(54) *$ & $1(100)$ & $11(20)$ & $12(22)$ \\
Trachea & $15(50)$ & $2(9)$ & $3(14)$ & $3(100)$ & $2(9)$ & $5(23)$ \\
group 1 $(\mathrm{n}=22)$ & $4(80)$ & $3(14)$ & $7(33)$ & $3(100)$ & $1(5)$ & $4(19)$ \\
group 2 $(\mathrm{n}=21)$ & $13(93)$ & $15(28)$ & $28(52) *$ & $1(100)$ & $21(39) *$ & $22(41)$ \\
group 3(n=54) & & & & & & \\
\hline
\end{tabular}

${ }^{1}=\%$ of patients colonized on admission (see Table 2)

${ }^{2}=\%$ of all patients included in the group (group $1 n=22$, group $2 n=21$, group $3 n=54$ )

\# $p<0.05$, Fischer's exact test for group 2 and 3; \# \# $p<0.01$. Fischer's exact test for group 1 and 3 ;

* $p<0.01$, Chi-square for three groups; ${ }^{* *} p<0.01$, Chi-square for group 1 and 3

\section{Acquired colonization (Table 3)}

\section{Enterobacteriaceae}

Acquired colonization with Enterobacteriaceae in oropharynx occurred less frequently in patients from group 1 as compared to patients from group 3 ( $p=0.01$ ). In addition, patients from group 2 tended to acquire oropharyngeal colonization less frequently as compared to patients from group 3, although the difference did not reach statistical significance: $15 / 54(28 \%)$ versus $2 / 21(10 \%) \quad(p=0.08$, Fischer's exact test).

Acquired colonization in trachea also tended to occur less frequently in patients from group 1 and 2 as compared to patients from group 3 . 


\section{Pseudomonadaceae}

Acquired colonization with Pseudomonadaceae occurred most frequently in patients from group 3 . The differences among the 3 groups were statistically significant for acquired colonization in the trachea $(\mathrm{p}<0.01)$.

\section{Total colonization (Table 3)}

Patients with persistent and/or acquired colonization were considered to form the group of colonized patients within an ICU.

\section{Enterobacteriaceae}

Numbers of patients colonized with Enterobacteriaceae differed significantly between the three groups, both in trachea ( $p<0.01$, Chi-square) and in oropharynx $(p<0.001)$, being highest in group 3 and lowest in group 1 .

\section{Pseudomonadaceae}

In contrast, total colonization with Pseudomonadaceae in the trachea was demonstrated in comparable proportions of patients in the three groups. However, this lack of difference was partly influenced by the lower proportion of patients from group 3 being colonized with Pseudomonadaceae on admission. There was a tendency of patients from group 3 to be more often colonized with Pseudomonadaceae in the oropharynx as compared to patients from group 2 $(\mathrm{p}=0.06)$.

The proportion of patients in each group colonized with ppmo in oropharynx and trachea in subsequent five day periods is shown in Figure 3. Patients from group 1 had lower colonization rates when compared to patients from groups 2 and 3 . Moreover, patients from group 2 had lower colonization rates when compared to patients from group 3.

To exclude a selection bias between patients from group 2 and 3, a case-control analysis was performed, in which all patients from group 2 were matched with 21 patients from group 3. Matching was based on age, hospitalization before admission to ICU, APACHE II-score, intubation and medical specialty. In this analysis the proportions of patients colonized in both control subgroups were comparable to those obtained from the complete groups (data not shown). In addition, a separate analysis of both subgroups $3 a$ and $3 b$ demonstrated comparable percentages of patients colonized with Enterobacteriaceae and Pseudomonadaceae (Table 4). 


\section{Tracheal colonization Oropharyngeal colonization}

Patients included Colonization on admission:

Cultures available ppmo (\% )

Enterobacteriaceae

Pseudomonadaceae

Staphylococcus aureus

Acquired colonization $\left(\%^{2}\right)$ :

Enterobacteriacea

Pseudomonadaceae

Persistent and acquired colonization ( $\left({ }^{2}\right)$ :

Enterobacteriaceae

Pseudomonadaceae

$\begin{array}{cccc}\begin{array}{c}\text { Group 3A } \\ 23\end{array} & \begin{array}{c}\text { Group 3B } \\ 31\end{array} & \begin{array}{c}\text { Group 3A } \\ 23\end{array} & \begin{array}{c}\text { Group 3B } \\ 31\end{array} \\ 20 & 26 & 20 & 27 \\ 10(50) & 10(38) & 8(40) & 11(41) \\ 7(35) & 7(27) & 6(30) & 10(37) \\ 0(0) & 1(4) & 0(0) & 1(4) \\ 6(30) & 4(15) & 3(15) & 0(0) \\ & & & \\ 5(22) & 10(32) & 6(26) & 9(29) \\ 10(43) & 11(35) & 5(22) & 6(19) \\ 12(52) & 16(52) & 11(48) & 18(58) \\ 10(43) & 12(39) & 5(22) & 7(23)\end{array}$

${ }^{l}=\%$ of samples available; ${ }^{2}=\%$ of patients included in the groups (group $3 A n=23$, group $3 B n=31$ )

Oropharynx

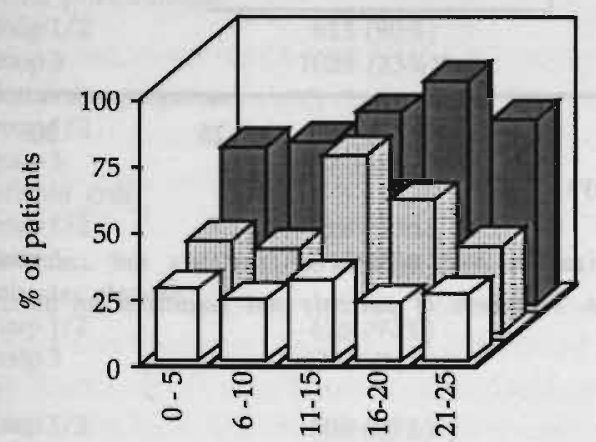

Days in ICU
Trachea

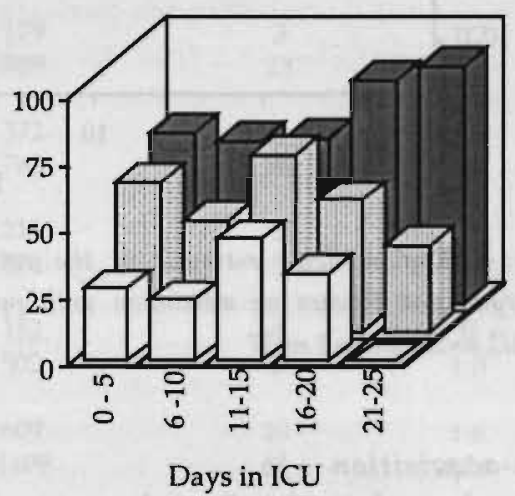

group 1

group 2

group 3

Figure 3: Percentages of patients in the 3 study groups with either persistent or acquired colonization with ppmo in trachea or oropharynx. 
Colonization with time

The time patients, not colonized with ppmo in oropharynx and trachea on admission, remained free of colonization was estimated by Kaplan-Meyer analysis. Thirty-two out of 43 patients $(74 \%)$ admitted to the ICU where TAP was administered (group 1 and 2) and 37 out of $54(69 \%)$ patients admitted to the ICU where no prophylaxis was administered were free of colonization with ppmo. Patients in the ICU where TAP was administered remained free of colonization for a longer period as compared to patients from group $3(n=37,69 \%)(p<0.05)$ (Figure 4).

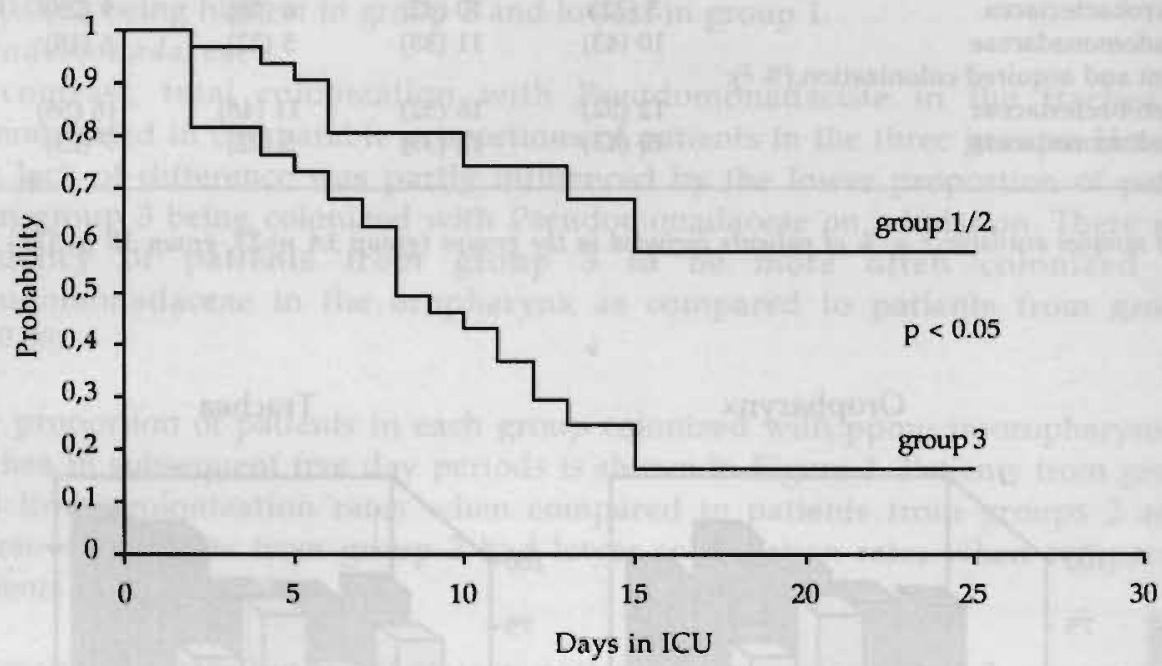

Figure 4: Kaplan-Meier estimate of the colonization free periods of patients not colonized in oropharynx and trachea on admission with ppmo. Numbers of patients not colonized on admission; group $1 / 2 n=32$, group $3 n=37$

\section{Cross-acquisition}

The total number of patient days was 681 for group $1 / 2$ and 1409 for group 3. Since patients in group $1 / 2$ had lower incidences of acquired colonization, the numbers of non-colonized patientdays were proportionally higher in this group for Klebsiella pneumonia $(\mathrm{p}<0.00001$, Chi-square), Pseudomonas aeruginosa $(\mathrm{p}=0.005)$, Escherichia coli $(p<0.00001)$ and ppmo $(p<0.00001)$, as compared to group 3 (Table 5). Such a difference was not observed for Enterobacter species $(92 \%$ and $91 \%)$. In order 
to determine the transmission rates, the number of days for non-colonized patients at risk for transmission were calculated from the total numbers of non-colonized patient days in each group. In addition, the numbers of events for each group of microorganisms were calculated. In both groups none of the patients was colonized with all four bacteria simultaneously. Therefore, all patients from group 3 were constantly at risk for transmission and the number of days at risk was equal to the total number of patientdays. However, in group $1 / 272$ patientdays were calculated without any patient being colonized with ppmo. Thus, for group $1 / 2$ the number of days at risk for transmission was lower than the total number of patientdays. For ppmo the transmission rate was higher among patients from group 3 as compared to group $1 / 2(p<0.001)$. For the individual microorganisms the differences in transmission rates did not reach statistical significance.

Table 5: Number of non-colonized patientdays, days at risk for transmission, events of transmission and transmission rates for patients treated in the ICU were topical antimicrobial prophylaxis was administered as compared to patients treated in an ICU were no prophylaxis was administered.

$\begin{array}{cccc}\begin{array}{c}\text { number of non- } \\ \text { colonized }\end{array} & \begin{array}{c}\text { number of days for non- } \\ \text { colonized patients at } \\ \text { patient days }\end{array} & \begin{array}{c}\text { number of } \\ \text { risk for transmission }\end{array} & \begin{array}{c}\text { transmission } \\ \text { transmission }\end{array}\end{array}$

(\%) ${ }^{1}$

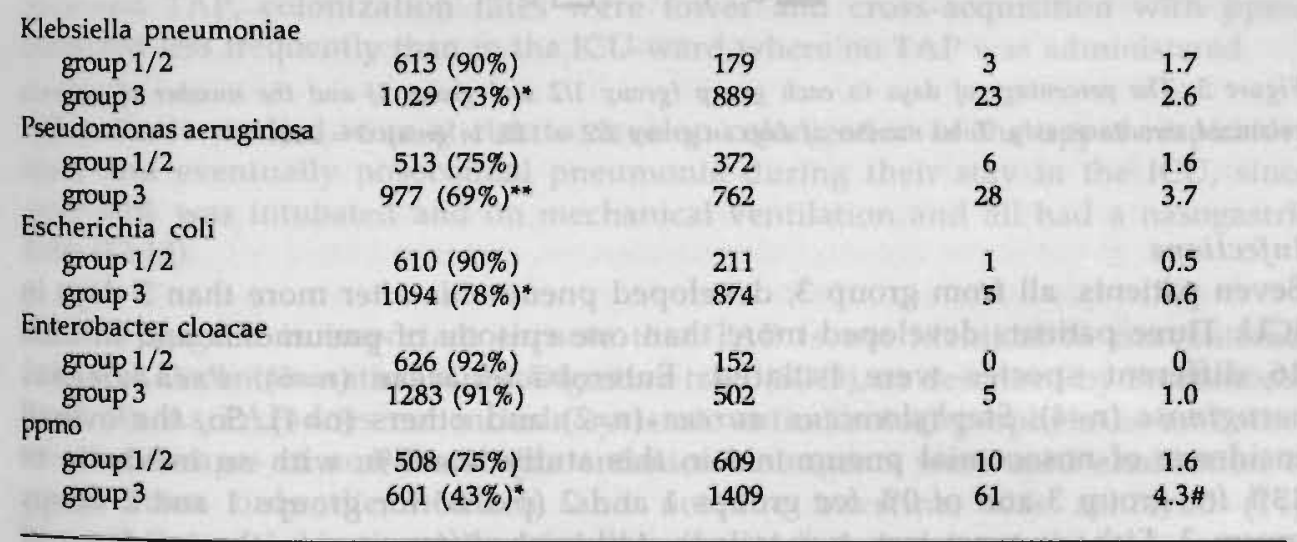

1 = the percentage of the total number of patientdays in each group (681 for group 1/2; 1409 for group 3);

$2=$ 'number of events of transmission'/ number of days of non-colonized patients at risk for transmission

"p<0.00001, group $1 / 2$ to group 3, Chi-square; ${ }^{* *} p=0.005$, group $1 / 2$ to group 3, Chi-square

\# $p<0.001$, group $1 / 2$ to group 3. Chi-square according to a Poisson distribution 


\section{Colonization pressure}

The number of patients colonized with ppmo in oropharynx or trachea at the same day ranged from 0 to 3 in group $1 / 2$ and from 1 to 7 in group 3 , and as clearly shown in Figure 5 more patients were colonized simultaneously in group 3 as compared to group $1 / 2$, which probably contributed to the higher transmission rate in this group.

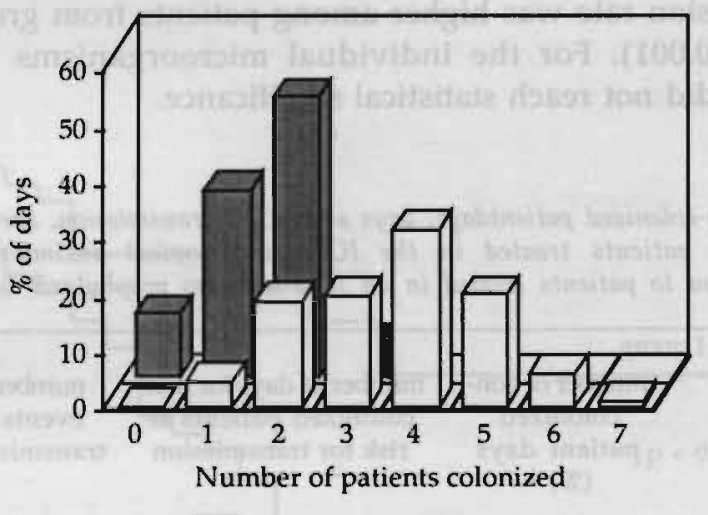

group $1 / 2$ group 3

Figure 5: The percentage of days in each group (group $1 / 2$ and group 3) and the number of patients colonized simultaneously. Total number of days in group $1 / 2=115$, in group $3=232$.

Infections

Seven patients, all from group 3, developed pneumonia after more than 3 days in ICU. Three patients developed more than one episode of pneumonia and in total 16 different species were isolated: Enterobacteriaceae $(n=6)$, Pseudomonas aeruginosa $(n=4)$, Staphylococcus aureus $(n=2)$ and others $(n=4)$. So, the overall incidence of nosocomial pneumonia in this study was $7 \%$, with an incidence of $13 \%$ for group 3 and of $0 \%$ for groups 1 and 2 ( $p<0.05$ for groups 1 and 2 versus group 3, Fisher's exact test, two-tailed). Although differences in the incidence of nosocomial pneumonia were observed, the small number of patients studied does not allow one to draw definite conclusions. 
Antimicrobial susceptibility

Overall, no differences in proportions of patients harboring resistant Gramnegative microorganisms were observed. Four strains were found to be resistant to tobramycin. All these strains were cultured from samples obtained from patients not-receiving TAP. However, the duration of the study and the number of patients studied were too small to detect differences in antimicrobial susceptibility.

\section{Infection control}

During both study periods surveillance cultures were taken from all sanitary equipment and respiratory machines in both ICU's. Ppmo were not identified from any of these cultures.

\section{DISCUSSION}

The main feature of this study is that the practice of Topical Antimicrobial Prophylaxis (TAP) of oropharynx and stomach significantly reduced colonization with ppmo both in patients receiving prophylaxis and in those not receiving prophylaxis within the same ICU as compared to patients without prophylaxis in another ICU. In the ICU where TAP was administered, patients not colonized with ppmo on admission remained free of colonization for a longer period of time than those in the other ICU. In addition, in the ICU-ward in which half of the patients received TAP, colonization rates were lower and cross-acquisition with ppmo occurred less frequently than in the ICU-ward where no TAP was administered.

All patients studied were at risk to develop colonization of the upper respiratory tract and eventually nosocomial pneumonia during their stay in the ICU, since over $90 \%$ was intubated and on mechanical ventilation and all had a nasogastric tube $(12,13)$.

At this stage it is important to note that TAP is not identical to conventional Selective Decontamination of the Digestive tract (SDD), as described by Stoutenbeek et al (3). As TAP does not include systemic antimicrobial prophylaxis, and since smaller dosages of non-absorbable antimicrobial agents were used eradication of ppmo from only the stomach, and not the intestine, was achieved (14). Nevertheless, colonization rates of the upper respiratory tract observed in patients receiving TAP (group 1) in the present study were comparable to those reported by others, who have used conventional $\operatorname{SDD}(3,4,6,15)$. This is in line with observations of Rodriguez, who reported decreased colonization rates in oropharynx and lower incidences of pneumonia after using only an antimicrobial oropharyngeal paste (16). 
The high colonization rates ( $>50 \%$ ) with Enterobacteriaceae in oropharynx and trachea in patients from group 3 are similar to those reported by others. One of us reported an incidence of colonization with Gram-negative microorganisms, including Pseudomonas aeruginosa in $45 \%$ of 213 mechanically ventilated ICU. patients (17). Yet, half of them (22\%) were shown to be colonized on their first hospital day, and so, in fact, were probably already colonized on admission.

Several factors enhancing the risk of acquisition and spread of microorganisms are present in Intensive Care Units, such as crowding of patients and personnel, necessity of performing patient related procedures and use of antimicrobial agents on large scale $(7,18,19)$. The first objective of this study was to investigate whether TAP, in such an environment, would influence colonization of unprotected patients within the same ICU. The results of the present study clearly demonstrate the beneficial effect of TAP on microbiological ecology between patients in an ICU where a prophylactic regimen is instituted and patients in another ICU: the rates of acquired colonization were lower and non-colonized patients remained free of colonization for a longer period of time in the ICU where antimicrobial prophylaxis was administered. Moreover, the number of patients colonized simultaneously and the number of events of transmission were higher in the ICU where patients did not receive prophylaxis.

Besides the prophylactic regimen, other factors may have been responsible for these differences as well. The survival analysis of the colonization free periods excludes the possible influence of differences in ICU-stay on colonization rates. Acquisition of ppmo from the inanimate environment of the ICU could also have led to differences between study groups. During both study periods, surveying bacteriological examinations of all sanitary equipment neither revealed bacterial contamination with ppmo, nor were microorganisms cultured from artificial ventilators. In addition, colonization rates were comparable in groups $3 a$ and $3 b$ (Table 4), thereby excluding differences in hygienic procedures between medical and nursing staffs of both ICU's.

Although hands and clothes of medical and nursing staff were not cultured in this study, transfer via these vectors often has been documented $(7,18,20)$ and crossacquisition is likely to occur within ICU's, even despite barrier precautions (21).

Although, the analysis of cross-acquisition (Table 5) did not demonstrate differences in transmission rates between Gram-negative bacteria and Pseudomonas aeruginosa, colonization (Table 3 ) tended to occur more frequently with Enterobacteriaceae than with Pseudomonadaceae, thereby suggesting a wider spread of Enterobacteriaceae. The latter would be in agreement with data reported by Weinstein et al (21). These investigators studied the epidemiology of endemic 
aminoglycoside-resistant Enterobacteriaceae and concluded that these microorganisms spread largely by cross-acquisition. In contrast, colonization with Pseudomonas aeruginosa seemed to originate from undetected endogenous sources, rather than cross-acquisition. The authors suggested that patients who appeared to acquire Pseudomonas aeruginosa in the ICU actually entered the unit colonized with this microorganism in numbers below the threshold for detection (21). Although our analysis of acquired colonization indeed demonstrated a larger influence on Enterobacteriaceae, our data also suggest spreading of Pseudomonas aeruginosa within an ICU by cross-acquisition. This would be in agreement with other studies that emphasize the importance of exogenous sources, since colonization with Pseudomonas aeruginosa occurred more frequently and earlier in trachea than in oropharynx or intestine $(18,22)$. The importance of both routes of colonization needs further study.

The positive influence of TAP on cross-acquisition within an ICU has, to our knowledge, never been studied before, although the existence of such an effect has been suggested (23). Brun-Buisson et al demonstrated in a randomized trial that enteral decontamination resulted in decreased intestinal colonization rates with Gram-negative bacteria, both in the test group as well as in the control group that was studied concomitantly (24). Unfortunately, no data on oropharyngeal and tracheal colonization were provided. As almost all studies on SDD were designed and executed with treated and untreated patients in the same ICU, the differences measured in these studies might have been diluted, because control patients ran a lower risk of acquisition of microorganisms than under normal situations. The real benefit of prophylactic regimens with topical, non-absorbable antimicrobial agents can only be established when treated and untreated patients are studied in separate but otherwise comparable ICU's. However, we would like to stress that the results of the present study do not provide evidence to support the use of SDD in mechanically ventilated patients, because colonization and cross-acquisition, rather than infection, mortality and side-effects, were studied and our regimen differed from the conventional SDD regimen. Recently, two randomized double-blind placebo-controlled studies failed to show any benefit of SDD on the incidence of pneumonia and mortality among mechanically ventilated patients $(5,6)$. Moreover, SDD has been associated with increasing bacterial resistance of Pseudomonas aeruginosa to the antibiotics used $(25,26)$ and increased incidences of colonization and infections with Gram-positive bacteria $(5,6,26,27)$.

In conclusion, the results of the present study demonstrate that modulation of the upper respiratory tract flora, by TAP, reduced colonization rates of patients receiving and of patients not-receiving the prophylactic regimen in the same ICU. In addition, in the ICU where part of the patients received TAP, non-colonized 
patients remained free of colonization for a longer period of time. Moreover, the number of patients colonized simultaneously was lower and cross-acquisition occurred less frequently in this group, as compared to patients in an identical ICU where no prophylaxis was administered. This strongly suggests that crossacquisition plays an important role in colonization of patients within an ICU, and this should be taken into account when developing strategies to prevent nosocomial pneumonia. 


\section{REFERENCES}

1. Johanson WG Jr, Pierce AK, Sanford JP, Thomas GD. Nosocomial respiratory infections with gram-negative bacilli: the significance of colonization of the respiratory tract. Ann Intern Med 1972; 77: 701-6

2. Tryba M. The gastropulmonary route of infection - fact or fiction? Am J Med 1991; 91 (2A): 135S$146 \mathrm{~S}$

3. Stoutenbeek CP, van Saene HK, Miranda DR, Zandstra DF. The effect of selective decontamination of the digestive tract on colonisation and infection rate in multiple trauma patients. Intens Care Med 1984; 10: 185-92

4. Cockerill III FR, Muller SR, Anhalt JP, Marsh HM, Farnell MB, Mucha P, et al. Prevention of infection in critically ill patients by selective decontamination of the digestive tract. Ann Intern Med 1992; 117: 545-53

5. Gastinne H, Wolff M, Delatour F, Faurisson F, Chevret S. A controlled trial in intensive care units of selective decontamination of the digestive tract with nonabsorbable antibiotics. New Engl J Med 1992; 326: 594-9

6. Hammond JMJ, Potgieter PD, Saunders GL, Forder AA. Double-blind study of selective decontamination of the digestive tract in intensive care. Lancet 1992; 340: 5-9

7. Maki DG. Control of colonization and transmission of pathogenic bacteria in the hospital. Ann Intern Med 1978; 89: 777-780

8. Haley RW, Culver DH, White JW, Morgan WM, Emori TG, van Munn P. Hooton TM. Am J Epid 1985; 121: 182-205

9. Brun-Buisson C, Legrand P, Rauss A, Richard C, Montravers F, Besbes M, Meakins JL, Soussy CJ, Lemaire $\mathrm{F}$. Intestinal decontamination for control of nosocomial multiresistant gram-negative bacilli. Ann Intern Med 1989; 110: 873-81

10. Knaus WA, Draper EA, Wagner DP, Zimmerman JE. APACHE II: A severity of disease classification system. Crit Care Med 1985; 13: 818-29

11. Thorpe JE, Baughman RP, Frame PT, Wesseler TA Staneck JL. Bronchoalveolar lavage for diagnosing acute bacterial pneumonia. J Infect Dis 1987; 155: 855-61

12. Craven DE, Kunches LM, Kilinsky V, Lichtenberg DA, Make BJ, McCabe WR. Risk factors for pneumonia and fatality in patients receiving continuous mechanical ventilation. Am Rev Respir Dis 1986; 133: 792-6

13. Joshi N, Localio AR, Hamory BH. A predictive risk index for nosocomial pneumonia in the intensive care unit. Am J Med 1992; 93: 135-42

14. Bonten MJM, van Tiel FH, van der Geest S, Smeets HGW, Stobberingh EE, Gaillard CA. Topical antimicrobial prophylaxis of nosocomial pneumonia in mechanically ventilated patients. Microbiologic observations. Infection 1993; $21: 137-9$

15. Ledingham IMcA, Alcock SR, Eastaway AT, McDonald JC, McKay IC, Ramsay G. Triple regimen of selective decontamination of the digestive tract, systemic cefotaxime, and micrbiologic surveillance for prevention of acquired infection in intensive care. Lancet 1988; i: 785-90 
16. Rodriguez-Roldan JM, Altuna-Cuesta A, Lopez A, Carrillo A, Garcia J, Leon J, Martinez-Pellus A. Prevention of nosocomial lung infection in ventilated patients: Use of an antimicrobial pharyngeal nonabsorbable paste. Crit Care Med 1990; 18: 1239-42

17. Johanson WG Jr, Pierce AK, Sanford JP. Changing pharyngeal bacterial flora of hospitalized patients: emergence of gram-negative bacilli. N Engl J Med 1969; 281: 1137-40

18. Noone MR, Pitt TL, Bedder M, Hewlett AM, Rogers KB. Pseudomonas aeruginosa colonisation in an intensive therapy unit: role of cross infection and host factors. Br Med J 1983; 286: 341-4

19. Albert RK, Condie F. Hand-washing patterns in medical intensive-care units. N Engl J Med 1981; 304: 1465-66

20. Olson B, Weinstein RA, Nathan C, Chamberlin W, Kabins SA. Epidemiology of endemic Pseudomonas aeruginosa: Why infection control efforts have failed. J Infect Dis 1984; 150: 808-16

21. Weinstein RA, Nathan C, Gruenfelder R, Kabins SA. Endemic aminoglycoside resistance in gram-negative bacilli: epidemiology and mechanisms. J Infect Dis 1980; 141: 338-45

22. Niederman MS, Mantovani R, Schoch P, Papas J, Fein AM. Patterns and routes of tracheobronchial colonization in mechanically ventilated patients. Chest 1989; 95: 155-61

23. Thulig B, Hartenauer U, Lawin P. Letter to the editor. Lancet 1992; 340: 605

24. Brun-Buisson C, Legrand P, Rauss A, Richard C, Montravers F, Besbes M, Meakins JL, Soussy CJ, Lemaire F. Intestinal decontamination for control of nosocomial multiresistant gram-negative bacilli. Ann Intern Med 1989; 110: 873-81

25. Allaouchiche B, Guillaume C, Godard J, Mohammedi I, Vedrinne JM, Bui-Xuan B, Reverdy ME, Motin J. Emergence of tobramycin resistance during selective decontamination of the digestive tract. [Abstract 1446] Proceedings of the 32nd Interscience Conference on Antimicrobial Agents and Chemotherapy, Anaheim 1992: 352

26. Nardi G, Valentinis U, Proietti A, De Monte A, Di Silvestre A, Muzzi R, Peresutti R, Troncon MG, Giordani F. Epidemiological impact of prolonged systematic use of topical SDD on bacterial colonization of the tracheobronchial tree and antibiotic resistance. A three year study. Intensive Care Med 1993; 19: 273-278

27. Bonten MJM, van Tiel FH, van der Geest S, Stobberingh EE, Gaillard CA. Enterococcus faecalis preumonia complicating topical antimicrobial prophylaxis. [Letter] N Engl J Med 1993; 328: 209210 
Chapter 8

ASSESSMENT OF GASTRIC ACIDITY IN INTENSIVE CARE PATIENTS: INCIDENTAL $\mathrm{pH}$ REGISTRATION CAN NOT REPLACE CONTINUOUS $\mathrm{pH}$ MONITORING 


\section{SUMMARY}

The accuracy of color-scaled indicator papers to measure $\mathrm{pH}$ values was tested, and the correlation between measuring gastric juice $\mathrm{pH}$ once daily with this method and the 24-hour continuous intragastric $\mathrm{pH}$-monitoring was studied in intensive care patients. The accuracy of indicator papers was tested in the laboratory in colorless solutions and aspirated gastric juice and verified with a laboratory $\mathrm{pH}$ meter. Continuous intragastric $\mathrm{pH}$ monitoring was performed in mechanically ventilated ICU-patients, 150 registrations in 91 patients. Percentages of time with a $\mathrm{pH}$ value $<3.0$ and median $\mathrm{pH}$ values of 24 -hour continuous intragastric $\mathrm{pH}$ monitoring were compared to $\mathrm{pH}$ values measured once daily with indicator paper. Correlation between $\mathrm{pH}$ measured with indicator paper and verified with a laboratory $\mathrm{pH}$-meter in colorless solutions was 0.96 (regression coefficient (RC) 0.98 , $95 \%$ confidence interval (CI) 0.91 to 1.05 ) and in gastric juice 0.95 (RC $0.95,95 \% \mathrm{Cl}$ 0.88 to 1.01 ). Correlation between median $\mathrm{pH}$ values, determined with 24 -hour continuous intragastric $\mathrm{pH}$-monitoring, and values measured with indicator papers was 0.39 ( $\mathrm{RC} 0.43,95 \% \mathrm{CI} 0.26$ to 0.59 ). The mean difference in $\mathrm{pH}$, as determined with the analysis of Bland and Altman, was 0.9 with a standard deviation of 4.7. The correlation between the percentage of time with $\mathrm{pH}<3.0$, as obtained with continuous registration, and median gastric $\mathrm{pH}$ values (also obtained with continuous registration) was -0.94 (RC $-0.06,95 \% \mathrm{CI}-0.06$ to -0.05 ) and gastric $\mathrm{pH}$ values (measured with indicator papers) was -0.40 ( $\mathrm{RC}-0.0234,95 \% \mathrm{CI}-0.03$ to -0.02 ).

The color-scaled indicator paper is a reliable method to measure $\mathrm{pH}$ values, but there is a poor correlation between once daily measured gastric $\mathrm{pH}$ values and 24hour continuous intragastric $\mathrm{pH}$ monitoring. Changes in intragastric $\mathrm{pH}$ values cannot be accurately studied when measuring acidity once daily. The influence of various treatment regimens on intragastric acidity in relation to the development of gastric colonization and nosocomial pneumonia should be investigated with continuous intragastric monitoring. 


\section{INTRODUCTION}

Gastric colonization has been assumed to be important in the pathogenesis of nosocomial pneumonia in mechanically ventilated ICU-patients $(1,2)$. Bacterial overgrowth in the stomach is facilitated by alkalinization of the intragastric environment (3-5). Therefore, maintainance of intragastric acidity has been used to prevent gastric colonization and pneumonia in mechanically ventilated ICUpatients (6-13). In all studies the effect of stress ulcer prophylactic agents and enteral feeding on intragastric $\mathrm{pH}$ was determined with color-scaled indicator papers in aspirated gastric juice samples (6-13). Measurements were performed discontinuously, in some studies once daily $(10,12,13)$ or with an unknown frequency (6).

However, it is questionable whether results obtained by randomly measured intragastric $\mathrm{pH}$ values with indicator papers are valid for definite conclusions regarding modulation of intragastric acidity. In the first place, two studies demonstrated a poor accuracy of indicator papers, when compared to values obtained with $\mathrm{pH}$ electrodes $(14,15)$. Secondly, most probably physiologic diurnal changes of the intragastric acidity are not registered when samples are obtained infrequently. Both pitfalls can be overcome by using computerized continuous intragastric $\mathrm{pH}$-measurement with intraluminal electrodes. In other research settings this method has become an established technique because of its high accuracy and reproducibility (16-19).

We determined the accuracy of color-scaled indicator papers for the determination of $\mathrm{pH}$ in gastric samples of intensive care patients, and compared the results of this method with those obtained by continuous intragastric $\mathrm{pH}$-monitoring.

\section{PATIENTS AND METHODS}

Accuracy of indicator paper

First, the accuracy of color-scaled indicator papers was studied in two in vitro experiments. In the first experiment 60 measurements with indicator paper (Schleicher \& Schüll, range of 1.0 to 12.0 , with steps of 0.5 ) were performed in a blinded fashion in colorless solutions with $\mathrm{pH}$ values ranging from $\mathrm{pH} 1.0$ to 7.5 . As a standard, the $\mathrm{pH}$ values of these solutions were verified with a laboratory $\mathrm{pH}$ meter (PHM82 Standard pH Meter, Radiometer a/s Copenhagen, Denmark). To account for factors that possibly affect the accuracy of measurements with pH paper in gastric samples, in a second experiment $\mathrm{pH}$ values of 93 random and unprocessed gastric samples were determined in parallel with a laboratory $\mathrm{pH}$ meter and with indicator paper. In all cases measurements with $\mathrm{pH}$ papers were performed first. 


\section{Patients}

For the in-vivo comparison of random and continuous $\mathrm{pH}$ monitoring, 91 patients admitted to the ICU who needed mechanical ventilation were prospectively enrolled in the study. All patients were endotracheally intubated and had a nasogastric tube.

The protocol was approved by the institutional review board of the hospital and informed consent was obtained from all participants, or if this was not possible because of the clinical condition, from a representative of the family.

\section{Intragastric $p H$ recording}

A pH stomach probe with a glass electrode at the tip (LoT 440, Ingold AG, Urdorf, Switzerland) was transnasally positioned in the stomach with the tip situated approximately $10 \mathrm{~cm}$ below the cardia. The position of the tip was verified by radiography. The distance from tip to nostrils was kept constant for the entire recording period. Recording of intragastric acidity was performed for 24 hours and $\mathrm{pH}$ values were registered every 4 seconds. The $\mathrm{pH}$-data were stored in a Digitrapper Mk III (Synectics Medical, Alphen aan den Rijn, The Netherlands) and after the procedure transferred to a personal computer. Analysis was performed using Esophogram software (Gastrosoft Inc., Synectics Medical). Electrodes and recorders were calibrated at $20^{\circ} \mathrm{C}$ using commercial buffer solutions at pH 7.0 and 1.3 (Ingold AG), before starting every experiment and repeated afterwards.

\section{pH recording of gastric samples}

Gastric juice samples of the patients were obtained routinely once daily at 9:00 am by aspirating gastric fluid into a syringe. Thereafter, $\mathrm{pH}$ values were determined with indicator paper. All measurements of $\mathrm{pH}$-values with indicator papers were performed by the same technician, who was unaware of the results of the continuous intragastric $\mathrm{pH}$-measurements.

\section{Data analysis}

Because of the non-parametric data, the median $\mathrm{pH}$ and the percentage of recording time with a $\mathrm{pH}$-value below 3.0 were calculated from continuous intragastric $\mathrm{pH}$ measurements. The $\mathrm{pH}$ value of 3.0 was arbitrarily chosen. The median $\mathrm{pH}$ values from continuous $\mathrm{pH}$ monitoring and the $\mathrm{pH}$ values obtained by color-scaled $\mathrm{pH}$ papers were analyzed by the method of Bland and Altman (20) and by calculating the correlation coefficient ( $r$ value) and the $95 \%$ confidence interval of the regression line. 


\section{RESULTS}

Accuracy of indicator papers

In the two laboratory experiments good correlations were observed between $\mathrm{pH}$ values measured with indicator papers and those determined with a laboratory $\mathrm{pH}$ meter. The correlation coefficient between the indicator paper method and the $\mathrm{pH}$ values of colorless solutions was 0.96 (regression coefficient (RC) $0.98,95 \%$ confidence interval (CI) $0.91-1.05$ ). The correlation coefficient of $\mathrm{pH}$ values of gastric samples, measured in the laboratory with indicator papers and verified with a laboratory $\mathrm{pH}$-meter, was 0.95 ( $\mathrm{RC}=0.95,95 \%$ CI 0.88-1.01).

\section{Patients}

In total 150 episodes of intragastric $\mathrm{pH}$ monitoring were performed in 91 patients. Mean age $( \pm S D)$ of the patients was $61 \pm 18$ years with a range from 19 to 88 years and the mean APACHE II score on admission was $21(\mathrm{SD}=8)$ with a range from 6 to 40. Thirty-seven patients were surgical, 22 medical, 15 pulmonary, 9 trauma and 8 neurologic. All patients were mechanically ventilated.

In 46 patients more than one episode of 24-hours intragastric $\mathrm{pH}$ monitoring was performed ( 2 episodes $n=36,3$ episodes $n=7$ and 4 episodes $n=3$ ).

Table 1: Results of continuous intragastric pH-measurements and the indicator paper technique

Intragastric pH-monitoring

no of recordings

(91 patients)

mean of $\mathrm{pH}$-values $\pm \mathrm{SD}$

range

mean \% of time with $\mathrm{pH}<3.0 \pm \mathrm{SD}$

range

no of recordings with $\mathrm{pH}<3.0$

$1=$ mean of median values; ${ }^{2}=$ median $\mathrm{pH}$ value $<3.0$
150

Indicator paper

150
$4.4 \pm 2.2^{1}$
$5.3 \pm 2.0$
0.5-8.0
1.0-8.5

$34.2 \pm 34.9$

$0-100$

$46(31 \%)^{2}$

$24(16 \%)$

Comparison of once-daily measurements and continuous intragastric $p H$ monitoring

The average of the median $\mathrm{pH}$ values and the average percentage of time with $\mathrm{pH}$ values below 3.0 obtained from 24 hours intragastric monitoring are listed in Table 
I. The mean $\mathrm{pH}$ value of aspirated gastric samples obtained with indicator papers is also listed in Table I. The average $\mathrm{pH}$ value, determined from median values of continuous intragastric measurements, was lower than the mean $\mathrm{pH}$ value as determined once daily with indicator paper $(4.4 \pm 2.2(\mathrm{SD})$ versus $5.3 \pm 2.0)$.

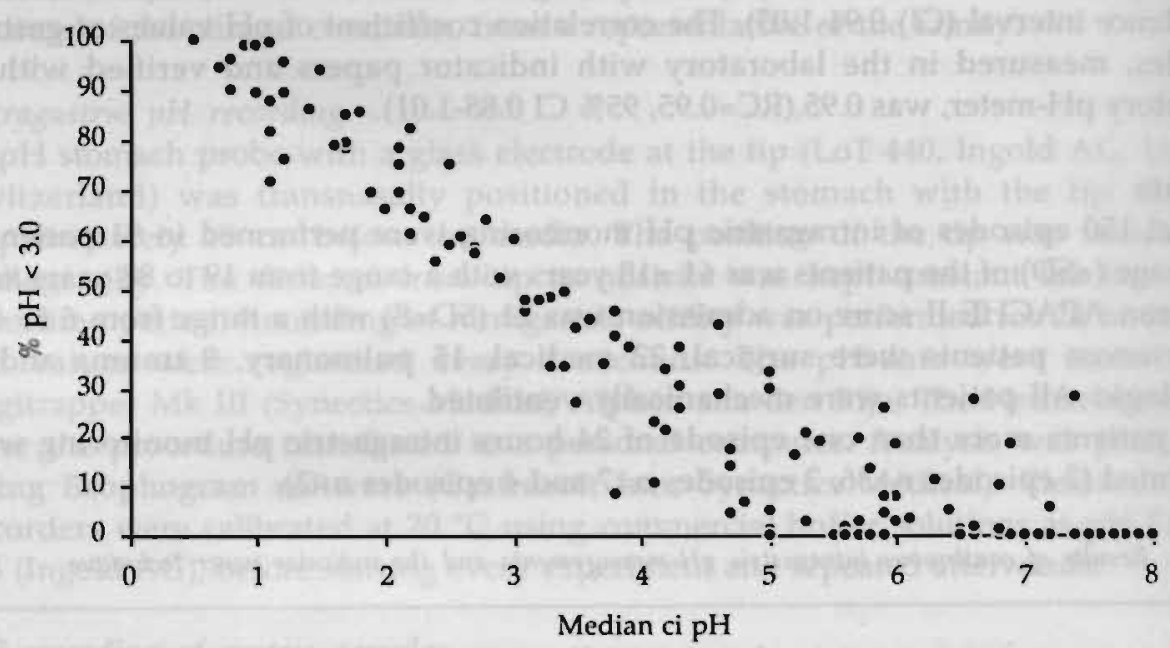

Figure 1: Correlation between median $p H$ values (median ci $p H, X$-axis) and the percentage of time with $\mathrm{pH}$ values $<3.0(\% \mathrm{pH}<3, \gamma$-axis), both obtained by contimuous intragastric pH monitoring, $\quad r=-$ 0.94 .

Median gastric $\mathrm{pH}$-values and percentages of time with gastric $\mathrm{pH}$-values $<3.0$, both obtained with continuous intragastric $\mathrm{pH}$-measurement, are plotted in Figure 1 ( $\mathrm{r}=$ $-0.94, \mathrm{RC}=-0.06,95 \% \mathrm{CI}-0.06$ to -0.05 ). In contrast, the correlation between the gastric $\mathrm{pH}$-values, obtained once daily with indicator papers, and the percentages of time with $\mathrm{pH}$-values below 3.0 was only -0.40 , ( $\mathrm{RC}=-0.02,95 \% \mathrm{CI}-0.03$ to -0.02 , Figure 2 ).

The median $\mathrm{pH}$-values from continuous intragastric recordings and the corresponding $\mathrm{pH}$ value of the indicator paper method are plotted in Figure 3. Considerable differences between both methods were observed.

The analysis according to Bland and Altman (20) is shown in Figure 4: Averages of $\mathrm{pH}$-data obtained with the two methods are plotted against their differences. The average difference between the two methods was -0.9 , with a standard deviation of 4.7. 


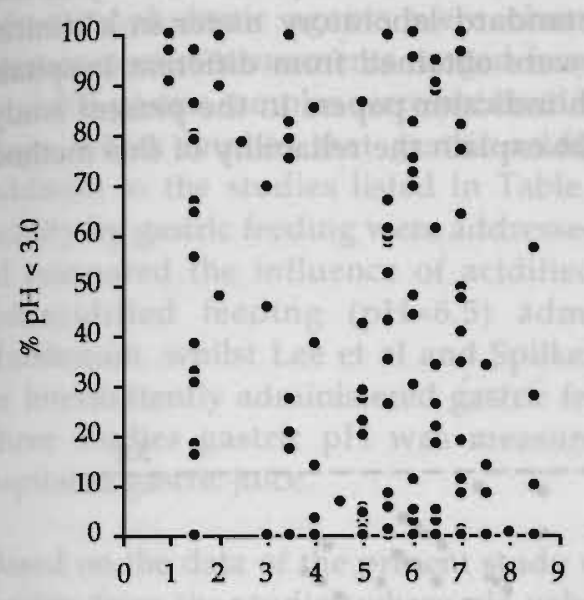

Stick $\mathrm{pH}$

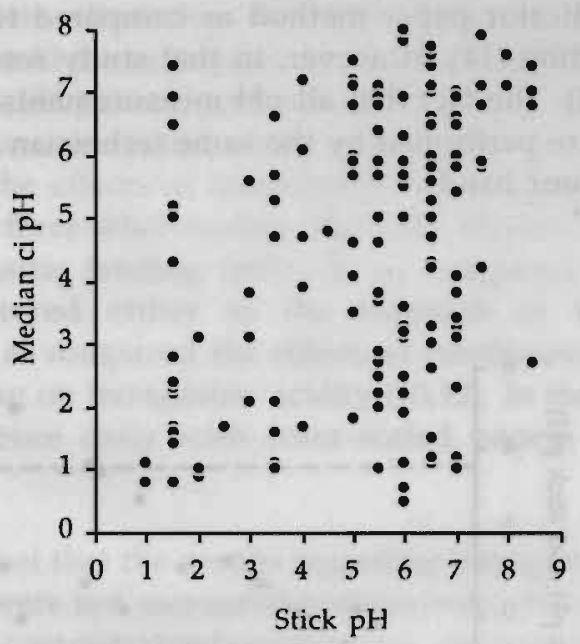

Stick $\mathrm{pH}$

Figure 2 and 3: Correlation between $p H$ values obtained by indicator papers (stick $p H, X$-axis) and (Fig.2) the percentage of time with $\mathrm{pH}$ values $<3.0$ obtained by continuous intragastric $\mathrm{pH}$ monitoring $(\% p H<3, Y$-axis, $r=-0.40)$, and (Fig3) median $p H$ values as obtained with 24-hours intragastric monitoring (median ci $\mathrm{pH}, Y_{\text {-axis, }}=0.39$ ).

\section{DISCUSSION}

The main feature of the present study is that there is a poor correlation between results of gastric $\mathrm{pH}$ values obtained once daily with color-scaled indicator papers and $\mathrm{pH}$-data obtained with continuous 24 -hour intragastric $\mathrm{pH}$ monitoring.

It seems unlikely that the difference between the two methods was caused by inaccuracies of either one. Continuous intragastric $\mathrm{pH}$-measurements have been validated repeatedly (16), and in this study calibration of the electrodes was performed before each measurement and verified afterwards. Moreover, the reliability of the indicator paper method was studied and showed a good correlation when $\mathrm{pH}$ measurements were verified with measurements performed with a laboratory $\mathrm{pH}$ meter, both in colorless solutions and in gastric juice. This is in line with observations made by others (21), although two other studies have demonstrated a poor accuracy of the indicator paper method $(14,15)$. In one study the indicator paper method had a sensitivity of $67 \%$ and a specificity of $95 \%$ for determining $\mathrm{pH}$ values $\geq 4$, taking electrode measurements as gold standard. The authors suggested that the inhomogeneous mixture of gastric acid, mucus, bile pigments and antacids interfered with the accurate measurement of $\mathrm{pH}$ values 
with indicator paper (15). Caballero et al also demonstrated poor accuracy of the indicator paper method as compared to a standard laboratory meter in a clinical setting (14). However, in that study results were obtained from different hospitals (14). The fact that all $\mathrm{pH}$ measurements with indicator papers in the present study were performed by the same technician might explain the reliability of this method in our hands.

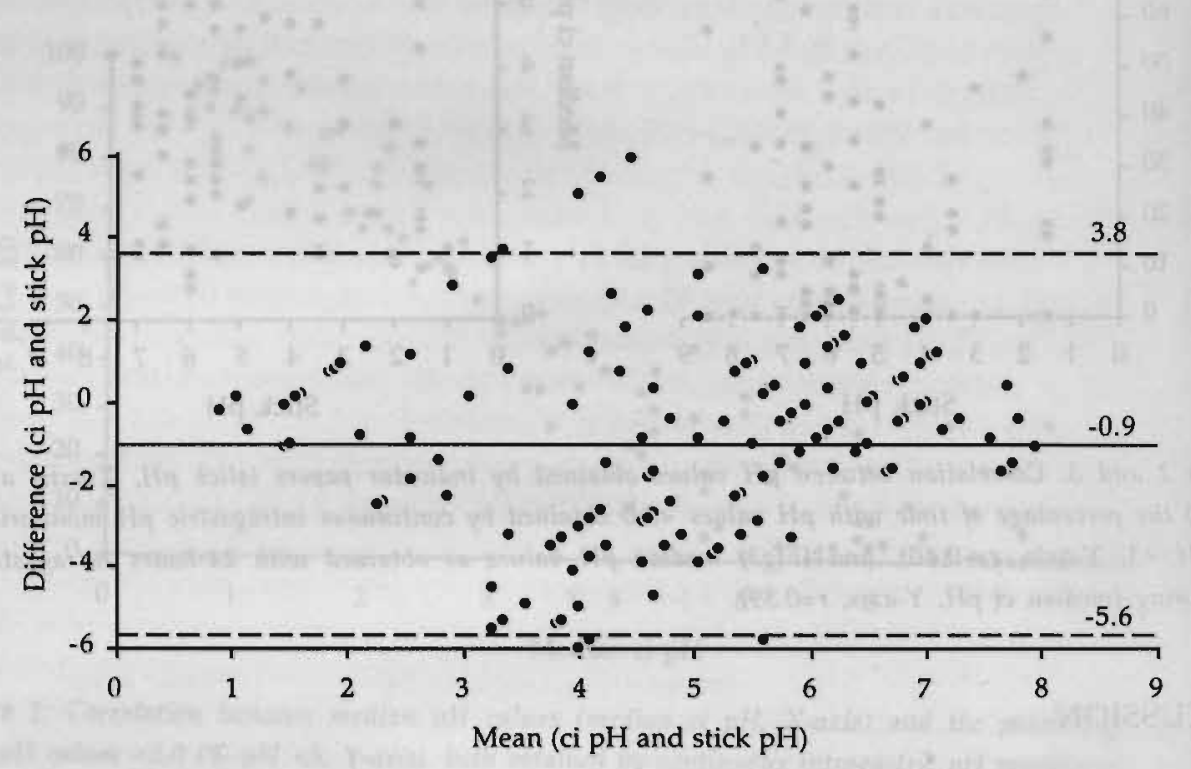

Figure 4: Disagreement between $p H$ paper (stick $p H$ ) and continuous $p H$ monitoring $(c i p H)$ values assessed by the difference between methods (continuous monitoring minus $\mathrm{pH}$ paper).

It appears that measurements of $\mathrm{pH}$ values in aspirated gastric samples performed once daily do not accurately reflect 24 -hour $\mathrm{pH}$ values in the intragastric milieu. However, when $\mathrm{pH}$ measurements are performed half-hourly or even hourly there is a good correlation $(17-19,22)$. The need for frequent assessment of intragastric acidity was also stressed by investigators who studied the efficacy of antacids to prevent gastrointestinal bleeding in critically ill patients $(23,24)$. In these studies it was emphasized that intragastric acidity should be checked at least every 2 hours.

Several studies in which incidental $\mathrm{pH}$ measurements of gastric juice were used, have addressed the effect of modifying gastric juice $\mathrm{pH}$ on gastric bacterial colonization and the development of nosocomial pneumonia (Table 2). As 
demonstrated in Table 2 significant differences in $\mathrm{pH}$ values for the different stress ulcer prophylactic agents were observed in all studies $(6-9,11)$. However, the frequency of measurements ranged from 3 to 12 times per day. In the study of Driks et al 805 gastric samples were obtained from 130 patients with a mean ICU-stay of 10 days, which implies that gastric acidity was measured every second day (6). In addition to the studies listed in Table 2, the effects of modulation of intragastric acidity by gastric feeding were addressed in three other studies $(10,12,13)$. Heyland et al compared the influence of acidified gastric feeding $(\mathrm{pH}=3.5)$ as compared to nonacidified feeding $(\mathrm{pH}=6.5)$ administered either in the stomach or the duodenum, whilst Lee et al and Spilker et al compared the effects of continuously or intermittently administered gastric feeding on intragastric acidity $(10,12)$. In these three studies gastric $\mathrm{pH}$ was measured once daily with color-scaled papers in aspirated gastric juice.

Based on the data of the present study we feel that the results regarding intragastric acidity from the studies where $\mathrm{pH}$ values were not measured continuously, should be interpreted with caution. However, computerized continuous intragastric monitoring is expensive and may not be available to all investigators. To establish the minimal number of measurements that is required to accurately determine long-term intragastric acidity with indicator papers in aspirated gastric juice, a study comparing this method, using different frequencies of measurement, to computerized intragastric monitoring is needed.

Table 2: Frequencies and results of $\mathrm{pH}$ measurements in aspirated gastric juice using color-scaled indicator papers.

\begin{tabular}{lccccccc} 
Author & $\begin{array}{c}\text { Frequency of } \\
\text { measurement } \\
\text { (per day) }\end{array}$ & $\begin{array}{c}\text { Proportion of samples with } \\
\mathrm{pH}<4.0(\%) \\
\text { Controls }\end{array}$ & p-value & Test & Controls & p-value \\
\hline Driks (6) & unknown & $47.9^{1}$ & $25.3^{2}$ & $(\mathrm{p}<.001)$ & & & \\
Tryba (7) & 3 & $46.5^{1}$ & $10.4^{3}$ & $(\mathrm{p}<.01)$ & & & \\
Kappstein (8) & $<6$ & & & & $4.34^{1}$ & $4.84^{4}$ & $(\mathrm{p}<.05)$ \\
Eddleston (9) & 4 & & & & $4.26^{1}$ & $5.50^{4}$ & $(\mathrm{p}<.01)$ \\
Simms (11) & 12 & $20.0^{1}$ & $11.1^{3}$ & & $4.73^{1}$ & $5.55^{3}$ & $(p<.01)$ \\
& & & $9.4^{4}$ & $(p>.05)$ & & $5.06^{4}$ & $(p>.05)$
\end{tabular}

$1=$ Test patients received sucralfate; ${ }^{2}=$ Control patients received antacids and/or $\mathrm{H}_{2}$-antagonsists

${ }^{3}=$ Control patients received antacids; ${ }^{4}=$ Control patients received $\mathrm{H}_{2}$-antagonist 
We conclude that changes in intragastric $\mathrm{pH}$ values cannot be accurately studied when measuring acidity only once daily or even less frequently. The correlation between modulation of intragastric acidity by different treatment regimens and the subsequent development of gastric bacterial colonization and nosocomial pneumonia should be re-evaluated using continuous intragastric $\mathrm{pH}$ monitoring. 


\section{REFERENCES}

1. Heyland D, Mandell LA. Gastric colonization by Gram-negative bacilli and nosocomial pneumonia in the intensive care unit patients: evidence for causation. Chest 1992; 101: 187-193

2. Tryba M. The gastropulmonary route of infection - fact or fiction? Am J Med 1991; 91 (Suppl 2A): 135-146

3. Du Moulin, Paterson DG, Hedley-White J, Lisbon A. Aspiration of gastric bacteria in antacidtreated patients: a frequent cause of postoperative colonisation of the airway. Lancet 1982; i: 242-245

4. Hillman KM, Riordan T, O'Farrel SM, Tabaqchal S. Colonization of gastric contents in critically ill patients. Crit Care Med 1982; 10: 444-447

5. Garvey BM, McCambley JA, Tuxen DV. Effects of gastric colonization on bacterial colonization in critically ill patients. Crit Care Med 1989; 17: 211-216

6. Driks MR, Craven DE, Celli BR, Manning M, Burke RA, Garvin GM, Kunches LM, Farber HW, Wedel SA, McCabe WR. Nosocomial pneumonia in intubated patients give sucralfate as compared with antacids of histamine type 2 blockers. New Engl J Med 1987; 317: 1376-82

7. Tryba M. Risk of acute stress and nosocomial pneumonia in ventilated intensive care patients: Sucralfate versus antacids. Am J Med 1987; 83 (Suppl 3B): 117-124

8. Kappstein I, Schulgen G, Friedrich T, Hellinger P, Geiger K, Daschner FD. Incidence of pneumonia in mechanically ventilated patients treated with sucralfate or cimetidine as prophylaxis for stress bleeding: bacterial colonization of the stomach. Am J Med 1991; 91 (Suppl 2A): $125 \mathrm{~S}-131 \mathrm{~S}$

9. Eddleston JM, Vohra A, Scott P, Tooth JA, Pearson RC, McCloy RF, Morton AK, Doran BH. A comparison of the frequency of stress ulceration and secondary pneumonia in sucralfate- or ranitidine-treated intensive care patients. Crit Care Med 1991; 19: 1491-6

10. Lee B, Chang RWS, Jacobs S. Intermittent nasogastric feeding: A simple and effective method to reduce pneumonia among ventilated ICU-patients. Clin Intensive Care 1990; 1: 100-102

11. Simms HH, DeMaria E, McDonald L, Peterson D, Robinson A, Burchard KW. Role of gastric colonization in the development of pneumonia in critically ill trauma patients: results of a prospective randomized trial. J Trauma 1991; 31: 531-537

12. Spilker CA, Hinthron DR, Pingleton SK. Intermittent enteral feeding and gastric colonization in critically ill patients. [abstract] Am Rev Respir Dis 1993; 147: A200

13. Heyland D, Bradley C, Mandell LA. Effect of acidified enteral feedings on gastric colonization in the critically ill patient. Crit Care Med 1992; 20: 1388-1394

14. Caballero GA, Ausman RK, Quebbeman EJ, Schulte WJ, Lin L. Gastric secretion pH measurement: what you see is not what you get! Crit Care Med 1990; 18: 396-99

15. Dobkin ED, Valcour A, MCCloskey CR, Allen L, Kambe JC, Gleason E, Orlando III R, Berger R, Yeston NS. Does pH paper accurately reflect gastric pH? Crit Care Med 1990; 18: 985-8

16. Fimmel CJ, Etienne A, Ciluffo $\mathrm{T}$ et al. Long-term ambulatory gastric $\mathrm{pH}$ monitoring: validation of a new method and effect of $\mathrm{H}_{2}$-antagonists. Gastroenterology $1985: 88$; $1842-51$ 
17. Savarino V, Mela GS, Scalabrini P, Magnolia MR, Percario G, Di Timoteo E, Celle G. 24-h Comparison between $\mathrm{pH}$ values of continuous intraluminal recording and simultaneous gastric aspiration. Scand J Gastroenterol 1987; 22: 135-40

18. Andersen J, Naesdal J, StrÖm. Identical 24-hour gastric $\mathrm{pH}$ profiles when using intragastric antimony or glass electrodes or aspirated gastric juice. Scand J Gastroenterol 1988: 23; 375-9

19. Savarino V, Mela GS, Zentilin P, Magnolia MR, Scalabrini P, Valle F, Moretti M, Bonifacino G, Celle G. Gastric aspiration versus antimony and glass $\mathrm{pH}$ electrodes. A simultaneous comparative in vivo study. Scand J Gastroenterol 1989: 24; 434-9

20. Bland JM, Altman DG. Statistical methods for assesing agreement between two methods of clinical measurement. Lancet 1986; i: 307

21. Meiners D, Clift S, Kaminski D. Evaluation of various techniques to monitor intragastric pH. Arch Surg 1982; 117: 288-291

22. Albin M, Friedlos J, Hillman $\mathrm{K}$. Continuous intragastric $\mathrm{pH}$ measurement in the critically ill and treatment with parenteral ranitidine. Intensive Care Med 1985; 11: 295-299

23. Hastings PR, Skillman JJ, Bushnell LS, Silen W. Antacid titration in the prevention of acute gastrointestinal bleeding. A controlled, randomized trial in 100 critically ill patients. N Engl J Med 1978; 298: 1041-1045

24. Priebe HJ, Skillman JJ, Bushnell LS, Long PC, Silen W. Antacid versus cimetidine in preventing acute gastrointestinal bleeding. A randomized trial in 75 critically ill patients. N Engl J Med $1980 ; 302: 426-430$ 
Chapter 9

THE RELEVANCE OF THE STOMACH AS A SOURCE FOR COLONIZATION OF THE UPPER RESPIRATORY TRACT AND PNEUMONIA IN ICU-PATIENTS 
Sequences of colonization of different species of microorganisms and the importance of gastric colonization for the development of nosocomial pneumonia were determined prospectively in 64 patients admitted to two identical ICU's of a university hospital. All patients were studied for at least 5 days, and, 59 were intubated. Microbiological cultures of serially taken samples of gastric aspirates, oropharyngeal swabs and tracheal aspirates were performed on admission and subsequently twice a week. Diagnosis of pneumonia was based on quantitative cultures from bronchoalveolar lavage and protected specimen brush. Sequences of colonization were examined by comparing isolates of the same species, with concordance of MIC-values to six antibiotics.

Eleven patients developed 14 episodes of nosocomial pneumonia, yielding 20 species of microorganisms. Seventeen out of 20 species $(85 \%)$, associated with pneumonia, were cultured, previous to or on the day of diagnosis, from tracheal aspirates and six out of $20(30 \%)$ species were cultured from gastric samples. For none of these six species a sequence of colonization from the stomach to the upper respiratory tract eventually leading to pneumonia was observed. Initial colonization with Pseudomonas aeruginosa and Enterobacter species was more often demonstrated in the trachea $(16 / 24$ and $13 / 25$ cases) as compared to the stomach $(1 / 24$ and $6 / 25$ cases; $p<0.0001$ and $p=0.02$ respectively). In contrast, initial colonization with Klebsiella species and Enterococcus faecalis was more frequently demonstrated in the stomach $(13 / 28$ and $8 / 15$ cases) as compared to the trachea $(6 / 28$ and $0 / 15$ cases; $p=0.02$ and $p<0.0001$ respectively).

Based on studying sequences of colonization in ICU-patients we concluded that the stomach is unlikely to be an important source of pathogens leading to nosocomial pneumonia. Furthermore, the initial site and route of colonization might not be the same for all microorganisms. 


\section{INTRODUCTION}

Seriously ill ICU-patients are prone to life-threatening nosocomial infections, such as pneumonia (1). There is no doubt about the causal relationship between preceding colonization of oropharynx and trachea with potentially pathogenic microorganisms (ppmo) and the development of nosocomial pneumonia (2). However, the exact sources and routes involved in acquiring colonization of oropharynx and trachea are still under debate. Microorganisms can colonize the oropharynx and trachea from exogenous sources, such as medical equipment and hands of medical and nursing staff, or from endogenous sources, i.e. the intestinal tract. In the latter scenario intestinal microorganisms possibly colonize the upper respiratory tract via the stomach (the endogenous route of colonization). The endogenous route of colonization has been assumed to be of main importance in the development of nosocomial pneumonia and many preventive regimens have been developed with the idea of interfering with this route of colonization (3). However, the central role of gastric colonization in the pathogenesis of nosocomial pneumonia has been questioned recently $(4,5)$.

Analysis of initial sites of colonization might indicate where colonization with microorganisms originates. For instance, Niederman et al demonstrated that Pseudomonas spp. preferentially colonized the trachea rather than the oropharynx and the stomach, indicating that the exogenous route of colonization probably is more important for colonization with this group of microorganisms than the endogenous route (6). However, what is apparent for Pseudomonas spp. may not apply to other species of microorganisms.

In order to determine the importance of gastric colonization for the development of nosocomial pneumonia we prospectively examined colonization of trachea, oropharynx, stomach and rectum by several microorganisms, the occurrence of bacterial pneumonia as well as their time course in 64 adult patients, admitted to the ICU for at least five days.

\section{MATERIAL AND METHODS}

\section{Study-design}

The study was conducted prospectively in two identical eight-bed ICU's in the University Hospital of Maastricht. Both ICU's contained a mixed population of trauma, medical, surgical and neurological patients. Patients were enrolled in the study if they were older than 15 years and intubated, with an expected period of intubation of at least five days. Thirty-four patients received antacids, 10 patients received $\mathrm{H}_{2}$-antagonists, and 6 patients received omeprazole during the whole 
study period. Fourteen patients initially received $\mathrm{H}_{2}$-antagonists on the first day of admission to ICU, but in these patients stress ulcer prophylaxis was discontinued for unknown reasons. Sucralfate was not used for stress ulcer prophylaxis as this agent might decrease gastric colonization $(7,8)$. To assess the severity of acute illness the APACHE II score was calculated on admission to the ICU as described elsewhere (9). Informed consent was obtained from the patient or, if this was not possible because of the clinical condition, from a representative of the family. The study protocol was approved by the hospital ethical committee.

\section{Definitions}

Colonization was defined as the isolation of microorganisms, in the absence of infection, from gastric aspirate, oropharyngeal swab or tracheal aspirate. Colonization on admission was established by a positive culture obtained within 24 hours after admission to the ICU. Colonization was designated as 'acquired' if there were positive cultures of the same species of microorganism from at least two consecutive samples, the first of which was taken no sooner than 24 hours after admission to the ICU. Sterile cultures or colonization with normal oropharyngeal flora were labelled 'no colonization'.

The initial site of colonization was defined as that site at which colonization was identified first. A sequence of colonization was examined by comparing isolates of the same species, cultured from two or more sites. These strains were considered identical when the MIC's to six antimicrobial agents were concordant. Concordance implied that the MIC-values for one strain differed from those of the other strain by no more than one step of a twofold dilution sequence in the MIC determination and for no more than three antimicrobial agents. In case of concordance, a time sequence of strain isolation from different sites was assumed to indicate the direction of colonization.

Exogenous colonization was defined as colonization originating from exogenous sources and as a consequence, the trachea or oropharynx acted as the initial site of colonization. In case the stomach was the initial site of colonization the route of colonization was labelled as endogenous.

In the analysis of colonization being present on admission or acquired during ICUstay species of microorganisms were grouped as follows: Enterobacteriaceae, Pseudomonadaceae, Staphylococcus aureus and finally Enterococcus faecalis.

Pneumonia was considered as ICU-acquired if a clinical condition fulfilling the criteria for pneumonia developed after the patient had been in the ICU for at least three days. In case of a clinical suspicion of pneumonia Bronchoalveolar Lavage (BAL) was performed. In general, a Protected Specimen Brush (PSB) was performed as well. The diagnosis of pneumonia was established when a positive quantitative culture of samples was obtained by BAL (cutoff point $10^{5} \mathrm{cfu} / \mathrm{ml}$ ) or PSB (cutoff 
point $10^{3} \mathrm{cfu} / \mathrm{ml}$ ), and a new or persistent infiltrate was seen on chest radiograph and when at least three of the following criteria were met: (1) rectal temperature above $38.0^{\circ} \mathrm{C}$ or below $35.5^{\circ} \mathrm{C}$, (2) blood leukocytosis $\left(>10.10^{3} / \mathrm{mm}^{3}\right)$ and /or left shift or blood leukopenia $\left(<3.10^{3} / \mathrm{mm}^{3}\right)$, (3) more than ten leukocytes per highpower field in gram stain of tracheal aspirate and (4) a positive culture from tracheal aspirate. BAL was performed as described elsewhere (10), using 5 aliquots of $20 \mathrm{ml}$ of sterile saline for lavage. PSB was performed as originally described by Wimberley (11). PSB always preceded the BAL.

\section{Bacteriologic monitoring}

Colonization was assessed by culturing gastric aspirates, oropharyngeal swabs, tracheal aspirates and rectal swabs on admission and subsequently at least twice a week (every Monday and Thursday). Gastric juice was aspirated into a sterile vial after the first $10 \mathrm{ml}$ was discarded. In non-intubated patients sputum was obtained after spontaneous production by the patient. Colonization was analyzed semiquantitatively as follows: oropharyngeal swabs, gastric aspirate $(10 \mu \mathrm{l})$, and tracheal aspirate $(10 \mu \mathrm{l})$ were streaked using the four-quadrant streak method on sheep blood, CLED, chocolate, and Sabauroud plates. All media were incubated at $35.0^{\circ} \mathrm{C}$ for 18 to 24 hours. Growth density was graded as follows: growth in the first quadrant $=+1$, in the second quadrant $=+2$, in the third quadrant $=+3$, and on the whole plate $=+4$. All samples were processed and cultured by the same analyst.

Samples obtained by BAL and PSB were cultured quantitatively. Rectal swabs were stored immediately at $-20^{\circ} \mathrm{C}$ and, in case of pneumonia, retrospectively analysed semi-quantitatively. Aerobic or facultatively anaerobic Gram-negative rods were identified using the API20E/20NE-system. The susceptibility pattern to antimicrobial agents was determined by measurement of minimal inhibitory concentrations by means of broth microdilution method.

Statistical analysis

Frequency comparisons were analyzed by Chi-square test. A probability value of less than 0.05 was considered to be significant.

\section{RESULTS}

\section{Patients}

The characteristics of all 64 patients are listed in table 1 . Age ranged from 17 to 96 years with a mean of 61 years. The mean duration of ICU-stay was 25 days, with a range of 5-145 days. The mean APACHE II-score was 18. Most patients were medical or surgical $(63 \%)$ and 59 out of 64 remained intubated for at least 5 days. 
Table 1: Characteristics of the patients studied

$\begin{array}{lll}\text { age } & \text { mean (range) } & 61.0(17-96) \\ \mathrm{M} / \mathrm{F} & & 42 / 22 \\ \text { days on ICU } & \text { mean (SD): } & 25.1(28,7) \\ \text { APACHE II } & \text { mean (SD): } & 18.0(8.0)\end{array}$

Medical conditions: ${ }^{1}$

cardiovascular disease $\quad 29$

gastrointestinal disease $\quad 10$

respiratory disease $\quad 24$

alcoholism/drug abuse $\quad 4$

neoplastic disease $\quad 14$

diabetes mellitus $\quad 8$

neurologic disease $\quad 10$

No intubated $\quad 59$

Admitting service:

$\begin{array}{ll}\text { surgery } & 24 \\ \text { trauma } & 9 \\ \text { medical } & 16 \\ \text { pulmonology } & 10 \\ \text { neurology } & 5\end{array}$

$1=$ more than one condition possible per patient

Colonization on admission

Gastrio samples

On admission gastric samples of 36 patients $(57 \%)$ were not colonized (Figure 1). Enterobacteriaceae were cultured from gastric aspirates of 23 patients (36\%). Gastric colonization with Pseudomonadaceae, Staphylococcus aureus or Enterococcus faecalis on admission was demonstrated in $1(2 \%), 4(7 \%)$ and $8(12 \%)$ patients, respectively.

Oropharyngeal swabs

Enterobacteriaceae were cultured from oropharyngeal swabs of 27 patients (42\%), Pseudomonadaceae in 5 patients $(8 \%)$ and no colonization was demonstrated in 29 patients $(46 \%)$ on admission. Enterococcus faecalis and Staphylococcus aureus were cultured from the oropharynx of $6(10 \%)$ and $3(4 \%)$ patients, respectively.

Tracheal aspirates

Nearly half of the patients ( 29 out of $64,46 \%$ ) were not colonized with bacterial species in the trachea on admission and none of the patients harbored Enterococcus 
faecalis in the trachea. Among those colonized on admission Enterobacteriaceae were most frequently cultured (17 out of $64,27 \%$ ), while Staphylococcus aureus was cultured from tracheal aspirates of $12(18 \%)$ patients. Three patients $(5 \%)$ harbored Pseudomonadaceae in the trachea on admission (Figure 1).

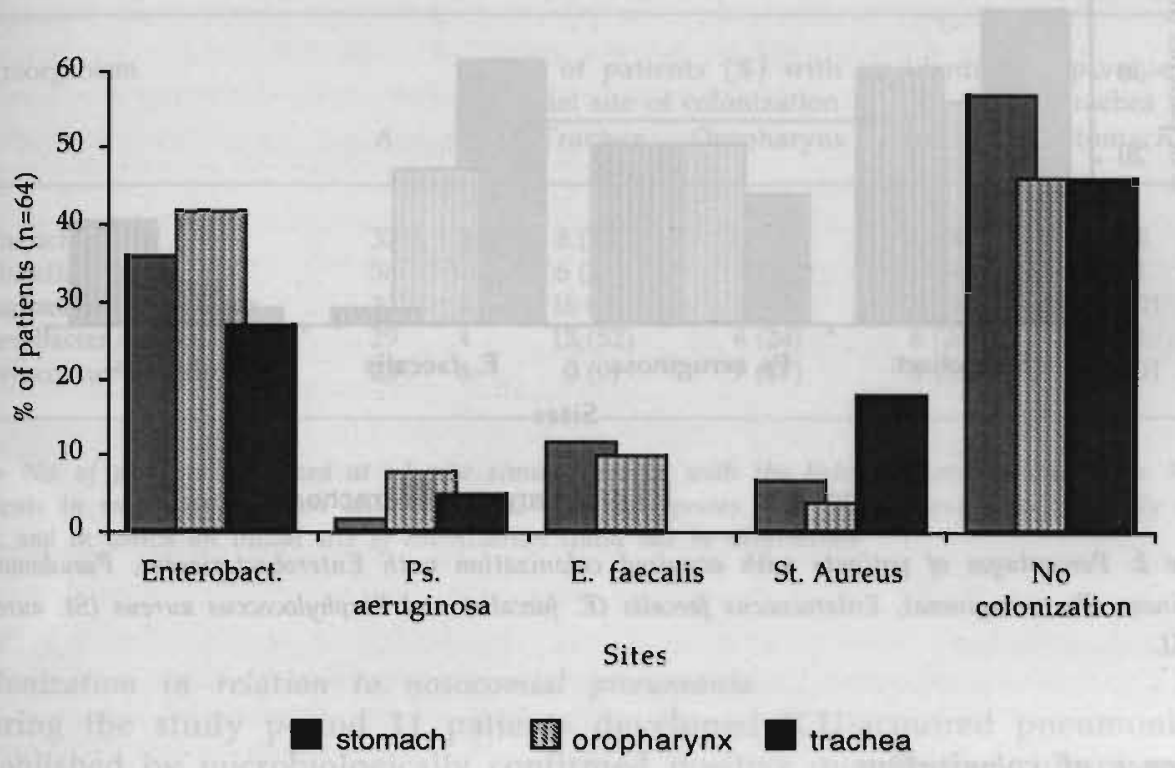

Figure 1: Percentages of patients with 'no colonization' or colonized with Enterobacteriaceae (Enterobact.), Pseudomonas aeruginosa (Ps. aeruginosa), Enterococcus faecalis (E. faecalis), or Staphylacoccus aureus (St. aureus) in stomach, oropharynx and trachea on admission to the ICU.

Acquired colonization

Acquired colonization with Enterobacteriaceae and Pseudomonadaceae in the stomach, oropharynx and trachea were observed with equal frequency, the number of patients ranging from 17 to $24(27 \%$ to $38 \%)$ for Enterobacteriaceae and from 10 to $14(16 \%$ to $22 \%)$ for Pseudomonadaceae ( $>0.05$, chi-square) (Figure 2). Colonization with Enterococcus faecalis was less often acquired in trachea (1 patient, $2 \%$ ) as compared to both oropharynx (12 patients, 19\%) ( $\mathrm{p}<0.05$, chi-square) and stomach (20 patients, $32 \%)(\mathrm{p}<0.0001$, chi-square). 


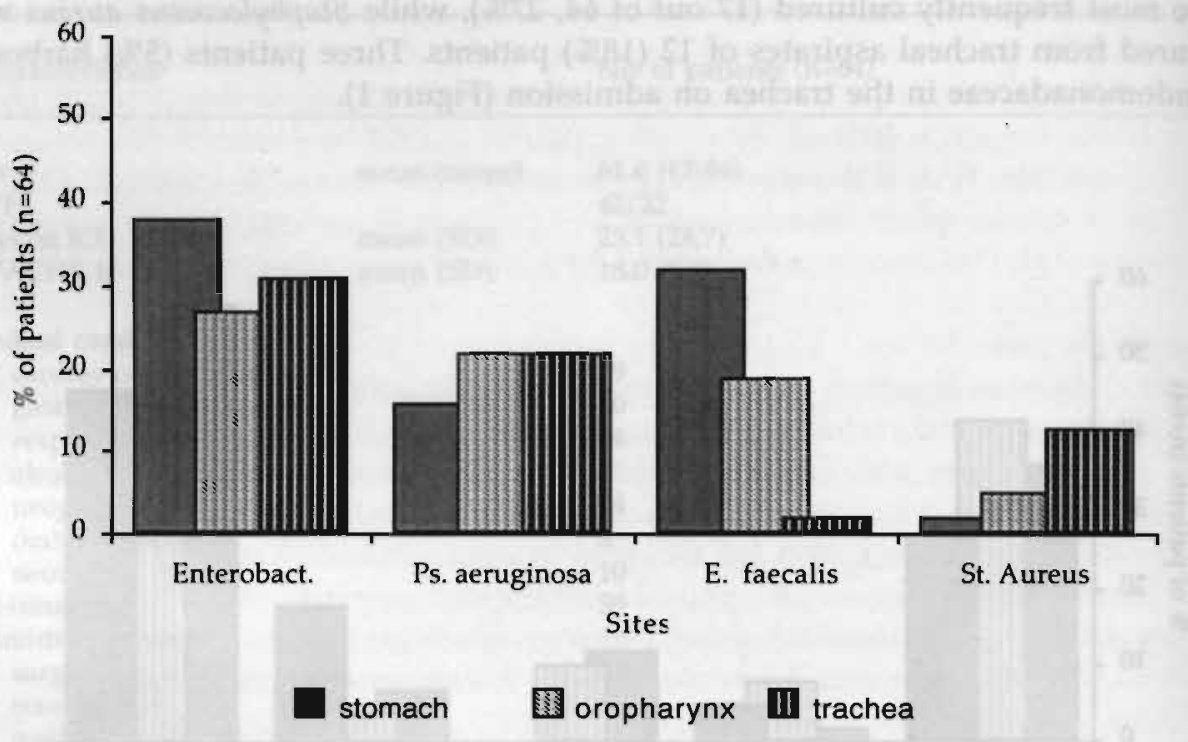

Figure 2: Percentages of patients with acquired colonization with Enterobacteriacene, Pseudomonas aeruginosa (Ps. aeruginosa), Enterococcus faecalis (E. faecalis) and Staphylococcus aureus (St. aureus) in $\mathrm{ICU}$.

\section{Sequence of colonization}

Simultaneous colonization at more than one site with one out of five species of microorganisms, listed in table 2, was demonstrated in 62 out of 64 patients, yielding 154 different cases of colonization (column A). In 35 cases newly acquired colonization was demonstrated at more than one site at the same time (column B), which precluded the identification of an initial site of colonization. Thus, for five different bacterial species 119 cases of initial colonization could be determined.

The trachea was more often an initial site of colonization than the stomach for both Pseudomonas aeruginosa and Enterobacter species $(p<0.0001$ and $p<0.05$, respectively, chi-square). In contrast, colonization with Klebsiella species and Enterococcus faecalis originated more often in the stomach as compared to the trachea ( $\mathrm{p}=0.02$ and $\mathrm{p}<0.0001$, respectively, chi-square). Although colonization with Escherichia coli originated more often in the stomach than in the trachea (11 and 6 out of 27 cases respectively) the difference did not reach statistical significance $(\mathrm{p}=0.08$, chi-square). According to the definition of concordance used in this study, strains isolated from several places in the same patient generally were 
phenotypically similar. No statistical significant differences in sequences of colonization were observed when patients receiving $\mathrm{H}_{2}$-antagonists or omeprazole were compared to patients receiving antacids.

Table 2: Primary site of colonization

\begin{tabular}{lcccccc} 
Microorganism & \multicolumn{8}{c}{$\begin{array}{c}\text { No of patients }(\%) \text { with an identified } \\
\text { initial site of colonization }\end{array}$} & $\begin{array}{c}\text { p-value } \\
\text { (Trachea vs } \\
\text { Stomach) }\end{array}$ \\
\hline Escherichia coli & A & B & Trachea & Oropharynx & Stomach & \\
Klebsiella species & 32 & 5 & $6(22)$ & $10(37)$ & $11(41)$ & $>.05$ \\
Pseudomonas aeruginosa & 38 & 10 & $6(21)$ & $9(32)$ & $13(46)$ & 0.02 \\
Enterobacter species & 32 & 8 & $16(67)$ & $7(29)$ & $1(4)$ & $<.0001$ \\
Enterococcus faecalis & 29 & 4 & $13(52)$ & $6(24)$ & $6(24)$ & 0.02 \\
& 23 & 8 & $0(0)$ & $7(47)$ & $8(53)$ & $<.0001$
\end{tabular}

$A=$ No. of patients colonized at $\geq 1$ site simultaneously with the listed bacterial species; $B=$ No. of patients in which colonization with the listed bacterial species was first present simultaneously at $>1$ site, and in which an initial site of colonization could not be determined.

Colonization in relation to nosocomial pneumonia

During the study period 11 patients developed ICU-acquired pneumonia as established by microbiologically confirmed positive quantitative culture results from BAL or PSB, and in which 20 different species were involved (Table 3 ). In two patients pneumonia occurred more than once and in total 14 episodes of nosocomial pneumonia were diagnosed. For 17 of the 20 species $(85 \%)$ isolates of the same species were previously or simultaneously cultured from tracheal aspirate, and for 10 out of 20 species (50\%) isolates of the same species were cultured from oropharynx before or on the day pneumonia was diagnosed. Preceding or simultaneous colonization of the stomach was observed for 6 of 20 species (30\%). However, in four cases, microorganisms initially colonized the oropharynx or trachea before colonization of the stomach occurred and in the other two cases colonization of the stomach was demonstrated at the same time as colonization of oropharynx and trachea. Thus, a sequence of colonization from stomach to the upper respiratory tract eventually leading to pneumonia was never observed.

Simultaneous isolation of the same species from samples of BAL/PSB and rectal swabs were observed for five out of 17 species; no rectal swabs were taken from two patients. Escherichia coli was isolated from rectal swabs, reflecting rectal colonization, prior to or simultaneously with the diagnosis of four episodes of 
pneumonia in three patients. In one of these episodes species of Proteus vulgaris were isolated from both the rectal swab and PSB and BAL. Of the 11 patients developing nosocomial pneumonia, seven received antacids and four received $\mathrm{H}_{2}$. antagonists for stress ulcer prophylaxis (not significant).

Table 3: Correlation between positive quantitative cultures from BAL and preceding or simultaneous colonization of trachea, oropharynx and stomach and sequence of colonization.

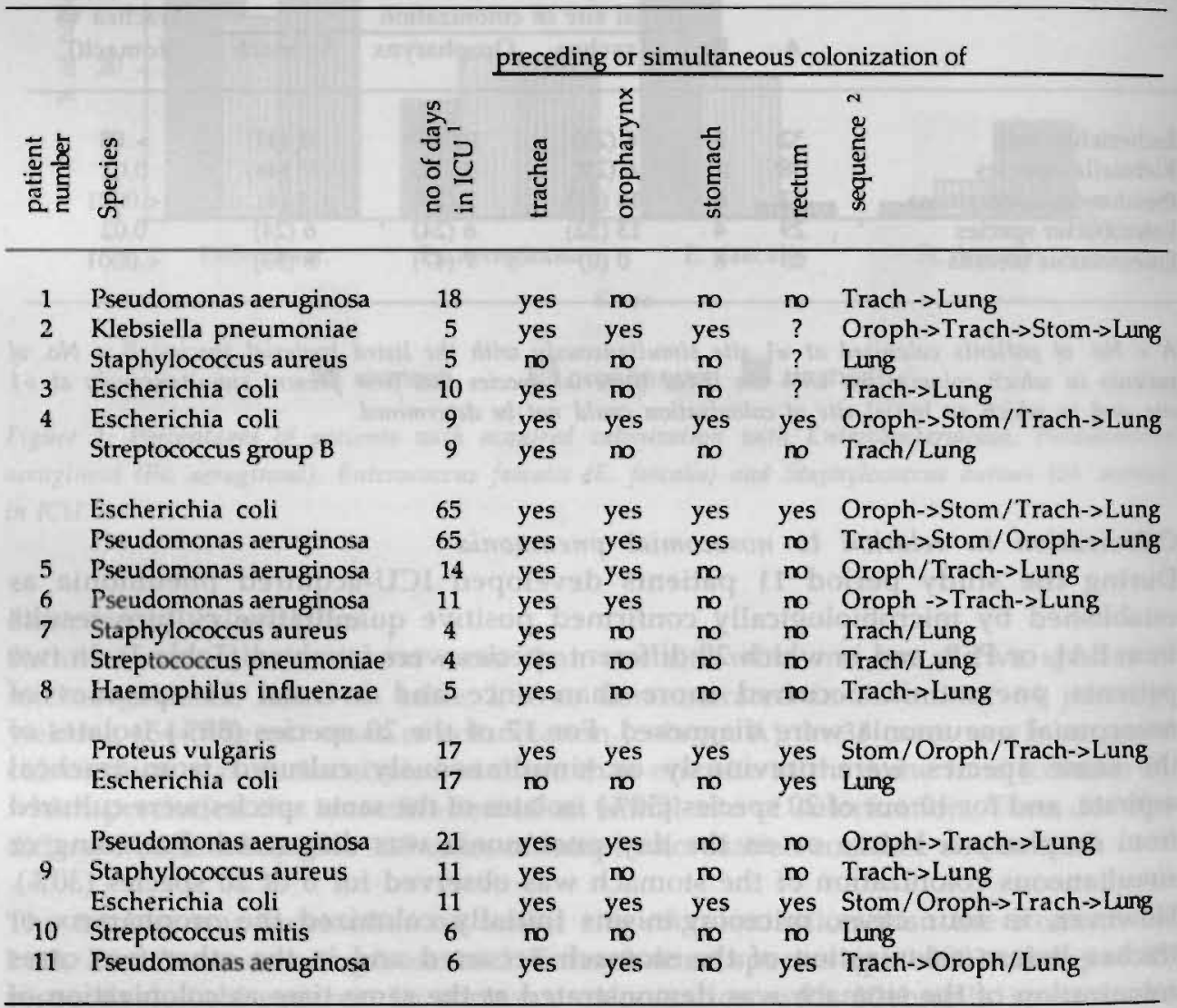

$1:=$ on the day of diagnosing pneumonia; $2:->=$ indicates direction of colonization based on the time differences of commencing of colonization with the same species at different sites; $-\%-=$ colonization demonstrated simultaneously at two or three sites and no direction of colonization could be analyzed. Oroph $=$ colonization of the oropharynx, Trach $=$ colonization of the trachen, Stom $=$ colonization of the stomach, Lung = bacteria cultured from PSB or BAL and associated with nosocomial pneumonia 


\section{DISCUSSION}

The results of this study suggest that gastric colonization may not be the main source for nosocomial pneumonia in ICU-patients. Eleven out of 64 patients (17\%) developed 14 episodes of ICU-acquired pneumonia, established by positive quantitative cultures from BAL or PSB. A sequence of colonization from the stomach to the upper respiratory tract with the causative agent was never observed. Moreover, the initial site of colonization was markedly different for several species of microorganisms and colonization with Pseudomonas aeruginosa and Enterobactericeae in most cases was found to start in the trachea.

The study population was at risk for developing nosocomial pneumonia, since one or more risk factors were present in all 64 patients, i.e. intubation, presence of a nasogastric tube and ICU-stay exceeding five days $(1,12,13)$. Moreover, none received sucralfate as stress ulcer prophylaxis, an agent that has been reported to prevent nosocomial pneumonia $(7,8)$.

On admission, tracheal colonization with Enterobacteriaceae was observed in 17 out of 64 patients $(27 \%)$ and another 20 patients $(31 \%)$ acquired colonization with these microorganisms during their ICU-stay. Pseudomonas aeruginosa was cultured in tracheal aspirates from only 3 out of 64 patients $(5 \%)$ on admission, and acquired colonization occurred in another 14 patients $(22 \%)$. These percentages are comparable to those observed by others. Johanson et al reported acquired colonization with Pseudomonas aeruginosa in $26 \%$ (2) and Olson et al in $16 \%$ of ICU-patients on mechanical ventilation (14).

Colonization of the upper respiratory tract has been assumed to originate from the inanimate environment or the gastrointestinal tract $(15,16)$. Determination of the initial site of colonization could help in establishing the origin of colonization (6). This analysis, however, is hampered by some unavoidable pitfalls, such as taking samples twice a week (every Monday and Thursday). In addition, numbers of microorganisms below the culture threshold might lead to false negative culture results. Despite these limitations, an initial site of colonization could be established in 119 cases. Pseudomonas aeruginosa was isolated more frequently from trachea and oropharynx than from the stomach and often earlier from the trachea than from the oropharynx or stomach. This is in line with observations made by others $(6,15)$. Niederman et al described primary colonization of the trachea with Pseudomonas aeruginosa in four of 14 intubated patients, whereas other Gramnegative microorganisms never followed this pattern (6). In addition, the same authors observed that Pseudomonas aeruginosa, in contrast to other Gramnegative microorganisms, preferentially colonized the lower respiratory tract in patients with chronic tracheostomy (17). These data may indicate that colonization 
of the upper respiratory tract with this species takes place via an exogenous route. The in vitro capacity of tracheal cells to adhere Pseudomonas aeruginosa strains more easily than buccal cells do $(17,18)$, might explain the observation that colonization more frequently occurred first in trachea than in oropharynx.

Similar to Pseudomonas aeruginosa, we found that Enterobacter species initially and preferentially colonized the trachea $(52 \%$ of all patients colonized with Enterobacter species), indicating that colonization with these microorganisms occurred via exogenous routes. This is in line with conclusions drawn by Flynn et al (19). These authors demonstrated spreading of these microorganisms, accompanied by heavy throat carriage, among cardiac surgery patients who were intubated for at least five days. Unfortunately, in that study gastric samples were not cultured and sequences of colonization could not be determined.

A total of six patients had Pseudomonas aeruginosa pneumonia. Although initial colonization of the trachea with this species was a common finding in our study, two out of six patients suffering from Pseudomonas aeruginosa pneumonia had oropharyngeal to tracheal transfer of colonization. Therefore, the oropharyngeal to tracheal route might be of some importance in the pathogenesis of pneumonia.

In contrast to Pseudomonas aeruginosa and Enterobacter species, Klebsiella species and Enterococcus faecalis were isolated earlier from gastric samples than from the tracheal aspirates, indicating that the intestine is a possible source of colonization. In fact, both species belong to the commensal colon flora. Although Escherichia coli shares the same reservoir, no preferential initial site of colonization could be determined for this species, indicating that colonization may take place via either the exogenous or endogenous route.

In some studies an association between nosocomial pneumonia and treatment with $\mathrm{H}_{2}$-antagonists or antacids has been observed in ICU-patients on mechanical ventilation. However, the role of gastric colonization as a source of pathogens causing pneumonia was not evaluated in these studies $(7,8,20)$. Although gastric colonization with ppmo occurred frequently, only six of the 20 isolates of species, associated with nosocomial pneumonia, were cultured from gastric samples, prior to or on the same day as the diagnosis was established. However, for these six isolates no sequence of colonization from the stomach to the upper respiratory tract could be demonstrated.

The fact that sucralfate was not used as stress ulcer prophylaxis reinforces two points. In the first place, our finding that gastric colonization is not important in the pathogenesis of pneumonia is not the result of artificial suppression of gastric bacterial growth, and secondly, it can be questioned whether elevation of gastric $\mathrm{pH}$ is a pathogenetically important mechanism for the development of nosocomial pneumonia. The observations of the present study are in agreement with those 
reported by Reusser et al (4). Among 40 patients, 15 developed nosocomial pneumonia and the stomach was the evident source of pneumonia in only one case. However, in that study exclusively neurosurgical patients with a median age of 34 years were studied for only seven days, and the diagnosis of pneumonia was not established with quantitative cultures of samples obtained from the lower respiratory tract. In another study of 100 ICU-patients, gastric colonization preceded infection of the respiratory tract with the same microorganism in 6 out of 35 episodes of infection (5).

At this point it is important to recognize that the possibility still exists that the intestinal flora is the origin of strains colonizing the oropharynx, albeit not through retrograde colonization via the stomach. We, therefore, analyzed the temporal relationship between colonization of the rectum by ppmo and the occurrence of pneumonia caused by a pathogenic microorganism of the same species. Preceding or concurrent colonization of the rectum by the same species as that of the strain(s) of the pathogenic microorganism, was only observed if pneumonia was caused by Escherichia coli or Proteus vulgaris. Since these species belong to the commensal flora of the large intestine, the above finding cannot be interpreted until further microbiological identity is established for fecal and pathogenic strains. The question whether the intestinal flora is relevant as a source of colonization and infection of the respiratory tract, has already been put forward by Brun-Buisson et al (21). These investigators studied selective decontamination of the digestive tract without decontamination of the oropharynx and systemic prophylaxis. Although intestinal decontamination decreased intestinal colonization with Gram-negative microorganisms, it had no effect on infection rates.

In conclusion, the results of this study do not support the alleged importance of the stomach as a source of colonization of the oropharynx or trachea by ppmo, prior to the development of pneumonia.

Firstly, colonization of the trachea by Pseudomonas aeruginosa and Enterobacter species was only sporadically found to be associated with colonization of the stomach. Secondly, gastric colonization by those strains, that were identified as pathogenic agents for pneumonia, was never found to precede colonization of the oropharynx or trachea in any of the 14 episodes of nosocomial pneumonia in this study. Furthermore, the initial site of colonization may not be the same for all microorganisms.

If these results are confirmed in further studies, preventive regimens should be directed against colonization of the oropharynx and trachea rather than against colonization of the stomach. 


\section{REFERENCES}

1. Craven DE, Kunches LM, Kilinsky V, Lichtenberg DA, Make BJ, McCabe WR. Risk factors for pneumonia and fatality in patients receiving continuous mechanical ventilation. Am Rev Respir Dis 1986; 133: 792-796

2. Johanson WG, Pierce AK, Sanford JP, Thomas GD. Nosocomial respiratory infections with gramnegative bacilli: the significance of colonization of the respiratory tract. Ann Intern Med 1972; 77: 701-706

3. Stoutenbeek CP, van Saene HKF, Miranda DR, Zandstra DF. The effect of selective decontamination of the digestive tract on colonisation and infection rate in multiple trauma patients. Intensive Care Med 1984; 10: 185-192

4. Reusser P, Zimmerly W, Scheidegger D, Marbet GA, Buser M, Gyr K. Role of gastric colonization in nosocomial infections and endotoxemia: a prospective study in neurosurgical patients on mechanical ventilation. J Infect Dis 1989; 160: 414-421

5. Cade JF, McOwat E, Siganporia R, Keighley C, Presneill J, Sinickas V. Uncertain relevance of gastric colonization in the seriously ill. Intensive Care Med 1992; 18: 210-217

6. Niederman MS, Mantovani R, Schoch P, Papas J, Fein AM. Patterns and routes of tracheobronchial colonization in mechanically ventilated patients. Chest 1989; 95: 155-61

7. Driks MR, Craven DE, Celli BR, Manning M, Burke RA, Garvin GM, Kunches LM, Farber HW, Wedel SA, McCabe WR. Nosocomial pneumonia in intubated patients given sucralfate as compared with antacids or histamine type 2 blockers. New Engl J Med 1987; 317: 1376-82

8. Kappstein I, Schulgen G, Friedrich T, Hellinger P, Benzing A, Geiger K, Daschner FD. Incidence of pneumonia in mechanically ventilated patients treated with sucralfate or cimetidine as prophylaxis for stress bleeding: bacterial colonization of the stomach. Am J Med 1991; 91 (suppl 2A): $125-131$

9. Knaus WA, Draper EA, Wagner DP, Zimmerman JE. APACHE II: A severity of disease classification system. Crit Care Med 1985; 13: 818-829

10. Thorpe JE, Baughman RP, Frame PT, Wesseler TA, Staneck JL. Bronchoalveolar lavage for diagnosing acute bacterial pneumonia. J Infect Dis 1987; 155: 855-861

11. Wimberley N, Faling LJ, Bartlett JG. A fiberoptic bronchoscopy technique to obtain uncontaminated lower airway secretions for bacterial culture. Am Rev Respir Dis 1979; 119: 33743

12. Fagon JY, Chastre J, Domart Y, Trouillet JL, Pierre J, Darne C, Gibert C. Nosocomial pneumonia in patients receiving continuous mechanical ventilation. Am rev Respir Dis 1989; 139: 877-884

13. Joshi N, Localio AR, Hamory BH. A predictive risk index for nosocomial pneumonia in the intensive care unit. Am J Med 1992; 93: 135-142

14. Olson B, Weinstein RA, Nathan C, Chamberlin W, Kabins SA. Epidemiology of Pseudomonas aeruginosa: Why infection control efforts have failed. J Infect Dis 1984; 150: 808-816

15. Schwartz SN, Dowling JN, Benkovic C, DeQuittner-Buchanan M, Prostko T, Yee RB. Sources of gram-negative bacilli colonizing the trachea of intubated patients. J Infect Dis 1978; 138: 227-31 
16. Heyland DK, Mandell LA. Gastric colonization and nosocomial pneumonia: evidence for causation. Chest 1992; 101: 187-193

17. Niederman MS, Ferranti RD, Ziegler A, Merril WW, Reynolds HY. Respiratory infection complicating long-term tracheostomy: the implication of persistent gram-negative tracheobronchial colonization. Chest $1984 ; 85: 39-44$

18. Niederman MS, Rafferty TD, Sasaki CT, Merril WW, Matthay RA, Reynolds HY. Comparison of bacterial adherence to ciliated and squamous epithelial cells obtained from the human respiratory tract. Am Rev Respir Dis 1983; 127: 85-90

19. Flynn DM, Weinstein RA, Nathan C, Gaston MA, Kabins SA. Patients' endogenous flora as the source of "nosocomial" Enterobacter in cardiac surgery. J Infect Dis 1987; 156: 363-368

20. Tryba M. Risk of acute stress bleeding and nosocomial pneumonia in ventilated intensive care unit patients: sucralfate versus antacids. Am J Med 1987; 83 (suppl 3B): 117-124

21. Brun-Buisson C, Legrand P, Rauss A, Richard C, Montravers F, Besbes M, Meakins JL, Soussy CJ, Lemaire $F$. Intestinal decontamination for control of nosocomial multiresistant gram-negative bacilli. Study of an outbreak in an Intensive Care Unit. Ann Intern Med 1989; 110: 873-881 
wack

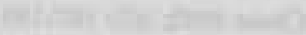

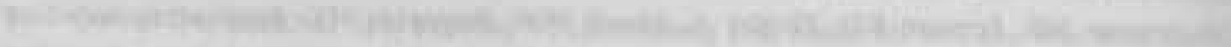

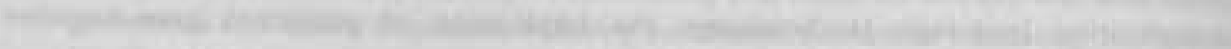

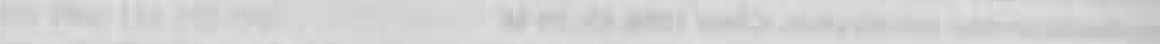

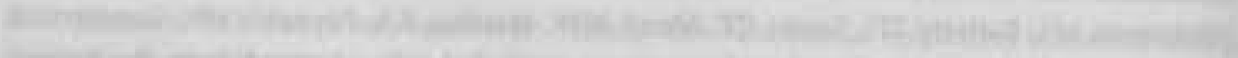
-

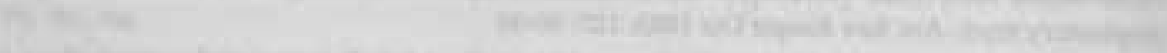

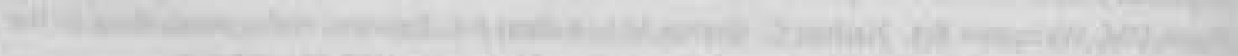

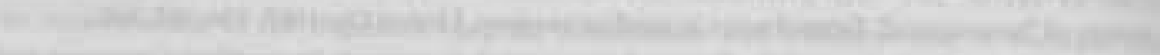

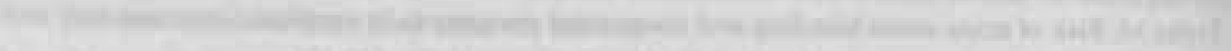

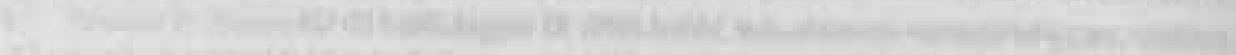

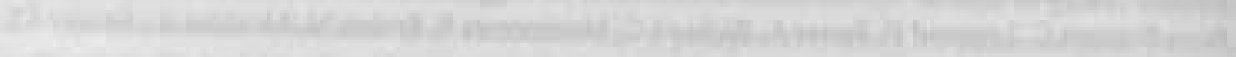

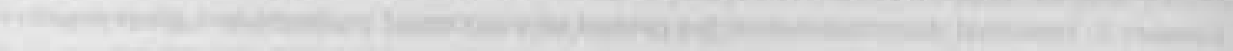

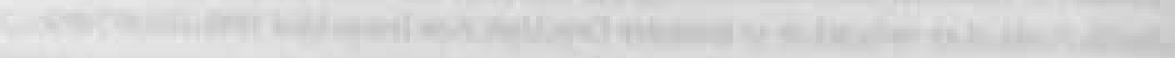

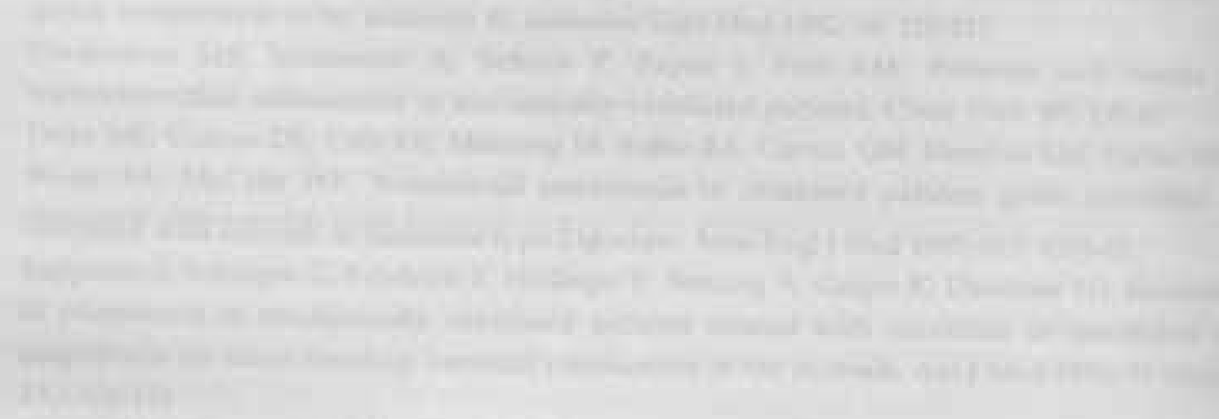


Chapter 10

COLONIZATION OF THE STOMACH AND INTRAGASTRIC ACIDITY ARE NOT IMPORTANT FOR THE DEVELOPMENT OF RESPIRATORY TRACT COLONIZATION AND INFECTION IN MECHANICALLY VENTILATED ICUPATIENTS 


\section{SUMMARY}

Gastric bacterial colonization, stimulated by decreased gastric acidity, has been assumed to be important for the development of Ventilator-associated pneumonia (VAP) in ICU-patients. Sucralfate has been associated with a lower incidence of VAP as compared to patients receiving antacids and/or $\mathrm{H}_{2}$-antagonists. To evaluate the effects of sucralfate and antacids, we conducted a randomized double-blind trial in mechanically ventilated ICU-patients, in which patients were stratified on initial gastric $\mathrm{pH}$. Intragastric acidity was measured with computerized continuous intragastric monitoring. The diagnosis of VAP was established with Protected specimen brush and/or Bronchoalveolar lavage.

Altogether 141 patients were included (74 receiving Antacids, 67 Sucralfate) and continuous intragastric $\mathrm{pH}$-monitoring was performed in 112 patients (58 Antacids, 54 Sucralfate), with a mean of \pm 75 hours per patient. No significant differences in median pH-values $(4.7 \pm 2.2$ and $4.5 \pm 2.0$ for Antacids and Sucralfate respectively) were observed. Median $\mathrm{pH}$-values were higher in patients with gastric bacterial colonization than in non-colonized patients $(5.5 \pm 2.1$ and $3.3 \pm 2.0, \mathrm{p}<0.01)$, but colonization of oropharynx and trachea was not related to intragastric acidity. A sequence of colonization from the stomach to the trachea was demonstrated twice for Enterobacteriaceae and 4 times for Pseudomonas aeruginosa in 141 patients. Thirty-one patients $(22 \%)$ developed VAP, with a similar incidence in both treatment groups. Of the 58 bacteria associated with VAP, the stomach was the initial site of colonization in only 1 case.

Antacids and Sucralfate had a similar effect on intragastric acidity, colonization rates and incidence of VAP. Intragastric acidity influenced gastric colonization, but not colonization of the upper respiratory tract or the incidence of VAP. The stomach seldom was an initial site of colonization, and therefore it is unlikely that the gastropulmonary route is important for the development of VAP. 


\section{INTRODUCTION}

Ventilator Associated Pneumonia (VAP) is an infection associated with increased morbidity and mortality among mechanically ventilated patients (1). Enteric Gramnegative bacteria, Pseudomonas aeruginosa and Staphylococcus aureus are the most frequent pathogens causing this infection (2), mostly after preceding colonization of the oropharynx (3). Currently it is widely assumed that the stomach is an important reservoir for bacteria causing VAP via the so-called gastropulmonary route of infection, especially when gastric $\mathrm{pH}$ is raised above bactericidal levels $(4,5)$. Evidence for a causative relationship between gastric colonization and development of VAP is based on studies relating gastric colonization to species causing pneumonia $(6,7,8)$. Craven et al investigated risk factors for pulmonary infection in patients undergoing long-term mechanical ventilation (9). Stress ulcer prophylaxis, aimed to decrease gastric acidity, was associated with a higher risk on VAP. In keeping with these results, Driks et al described the effect of modification of intragastric acidity on the incidence of VAP (10).

Indeed, in critically ill patients gastric $\mathrm{pH}$ may be raised artificially by stress ulcer prophylaxis (11). In theory, patients receiving stress ulcer prophylactic agents which do not influence gastric acidity, should have lower rates of gastric bacterial colonization and thus a lower risk on VAP. Sucralfate is a stress ulcer prophylactic agent which does not influence gastric $\mathrm{pH}$ values (12). In several studies, a lower incidence of VAP among patients receiving sucralfate than among patients receiving antacids and/or $\mathrm{H}_{2}$-antagonists $(10,13-15)$ was reported, thereby furnishing supportive evidence for the proposed importance of the gastropulmonary route of infection. However, interpretation of the studies underscoring the importance of the gastropulmonary route of infection is seriously hampered. In the first place, in all studies VAP was diagnosed on the basis of clinical criteria in combination with radiography, which has a poor specificity to establish the diagnosis in mechanically ventilated patients (16). Secondly, species causing VAP were not related to identical strains that previously colonized the stomach. Furthermore, gastric $\mathrm{pH}$ values were determined once daily or even less frequently with an indicator stick in aspirated gastric juice, a method which has been demonstrated to be unreliable $(17,18)$. And finally, none of the studies used a double-blind design.

The aim of the present study was to establish the role of gastric acidity in the development of gastric and respiratory tract colonization and pneumonia in mechanically ventilated patients. We compared sucralfate to high dosages of antacids with regard to intragastric $\mathrm{pH}$, colonization of stomach and respiratory 
tract and the occurrence of VAP. In addition, we studied the importance of the gastropulmonary route for the development of VAP. The influence of the two stress ulcer prophylactic agents was studied in a randomized double-blind fashion, in which patients were stratified according to the initial gastric $\mathrm{pH}$.

\section{METHODS}

\section{Study population}

All patients admitted to the ICU between August 1992 and 1993, who were mechanically ventilated, and had an expected ICU-stay of at least three days were eligible for this clinical trial. Patients were not eligible if they were less than 15 years of age, when they were admitted for massive gastric hemorrhage or bleeding esophageal varices, after esophageal or gastric surgery, when a nasogastric tube could not be placed or when receiving $\mathrm{H}_{2}$-antagonists or $\mathrm{H}^{+} \mathrm{K}^{+}$ATPase inhibitors.

\section{Study design}

Sucralfate (Ulcogant ${ }^{\circledR}$, Merck, Mannheim, Germany) and antacids (Antagel $\mathrm{PCH}^{\circledR}$, Pharmachemie b.v., Haarlem, The Netherlands) were compared in a double-blind fashion and analyzed according to a prospectively developed plan that used definitions adopted before the treatment-allocation code was broken. Gastric $\mathrm{pH}$ values were determined within 24 hours after admission using continuous intragastric monitoring. Patients were stratified into two groups, according to the gastric $\mathrm{pH}$ value measured on the first day of admission, being $<3.0$ or $\geq 3.0$. If intragastric $\mathrm{pH}$ monitoring was not possible, stratification occurred after determination of $\mathrm{pH}$ with color-scaled indicator paper in aspirated gastric juice.

Demographic characteristics, diagnosis on admission, underlying diseases, vital signs, medications and laboratory values were recorded prospectively. The APACHE II scoring system was used to assess the severity of illness (19). Clinical and laboratory values were recorded daily.

Samples of gastric and tracheal aspirates and oropharyngeal swabs were collected serially on admission and subsequently twice weekly. Additional specimens were collected and analyzed as required. The attending physician was unaware of the results of oropharyngeal and gastric samples. Patients were studied until extubation, death, or the institution of therapy influencing gastric acidity. In general, all patients were in supine position during controlled mechanical ventilation and if possible in semirecumbent position during weaning.

The protocol was approved by the institutional review board of the hospital and informed consent was obtained from all participants, or if this was not possible because of the clinical condition, from a representative of the family. 


\section{Treatment}

Patients were randomly allocated to receive sucralfate ( 1 gram every four hours, at 0.00 through 20.00 hour) or antacids ( $30 \mathrm{ml}$ every four hours, at 2.00 through 22.00 hour). Patients receiving sucralfate also received an antacid-placebo at the hours that antacids were administered, and vice versa (sucralfate-placebo, Merck, Mannheim, Germany) (double dummy model). The antacid-placebo was developed and produced by the department of clinical pharmacy. In vitro, both placebos had no buffering capacity, a $\mathrm{pH}$ of \pm 6.0 , and could visually not be distinguished from the active treatment. After administration of each of the compounds the nasogastric tube was flushed with $10 \mathrm{ml}$ of sterile water to prevent clogging.

\section{Intragastric $\mathrm{pH}$ monitoring}

A pH stomach probe with a glass electrode at the tip (Lot 440, Ingold AG, Urdorf, Switzerland) was positioned in the stomach with the tip situated approximately 10 $\mathrm{cm}$ below the cardia. The position of the tip was verified radiographically. The distance from tip to nostrils was kept constant for the complete recording period. The $\mathrm{pH}$ was recorded at $3.45-15 \mathrm{~Hz}$, depending on the total length of recording. The $\mathrm{pH}$-tracings were stored in a Digitrapper Mk III (Synectics Medical, Alphen aan den Rijn, The Netherlands) and subsequently transferred to a personal computer. Analysis was performed using Esophagram software (Gastrosoft Inc., Synectics Medical). Electrodes and recorders were calibrated at $20^{\circ} \mathrm{C}$, before and after every experiment, using commercial buffer solutions at $\mathrm{pH} 7.0$ and 1.3 (Ingold AG). The validation and accuracy of computerized continuous intragastric $\mathrm{pH}$-monitoring was described previously $(20,21)$. The duration of monitoring, median $\mathrm{pH}$ value and percentage of time with an intragastric $\mathrm{pH}<3.0$ and $<4.0$ were calculated from each measurement. All analyses were performed for both the percentage of time with $\mathrm{pH}<3.0$ and $\mathrm{pH}<4.0$. The outcome was comparable for both analyses, and therefore only the values for $\mathrm{pH}<3.0$ are shown. Results were expressed as median values with the Interquartile Range (IQR).

\section{Bronchoscopy}

In case of clinical suspicion of pneumonia bronchoscopy with protected specimen brush (PSB) and bronchoalveolar lavage (BAL) was performed as described elsewhere (22). In brief, the fiberoptic bronchoscope was introduced and advanced to the bronchial orifice of a lung segment containing a new or persistent infiltrate. A PSB was advanced into a wedged, peripheral position to obtain lower airway secretions. After brushing, the bronchoscope was positioned in the adjacent subsegment and BAL was performed using one aliquot of $20-\mathrm{ml}$ of sterile saline $(0.9 \% \mathrm{NaCl})$ followed by three aliquots of $50-\mathrm{ml}$. The liquid recovered after the first aliquot was discarded and the remaining lavage fluid was pooled. In all cases PSB was performed first. 


\section{Bacteriologic examination}

Colonization was analyzed semi-quantitatively as follows: Oropharyngeal swabs, 10 $\mu \mathrm{l}$ of gastric aspirate, or $10 \mu \mathrm{l}$ of tracheal aspirate were streaked using the fourquadrant streak method on sheep blood, CLED, chocolate, and Sabauroud plates. All media were incubated at $35^{\circ} \mathrm{C}$ for 18 to 48 hours. Growth density was graded as follows: Growth in the first quadrant $=+1$, in the second quadrant $=+2$, in the third quadrant $=+3$, and on the whole plate $=+4$. Normal oropharyngeal flora included alpha-hemolytic streptococci, non-pathogenic neisseria, micrococci and diptheroids. Potential pathogenic microorganisms (ppmo) included Enterobacteriaceae (Escherichia coli, Klebsiella species, Enterobacter species, Proteus species, Morganella morganii, Citrobacter freundii, Acinetobacter species), Pseudomonadaceae (Pseudomonas aeruginosa, Xanthomonas maltophilia), and Staphylococcus aureus.

\section{Enteral feeding}

Enteral feeding (Nutrison, Nutricia, The Netherlands, $\mathrm{pH}=7.0$ ) was administered continuously and intragastrically, and delivered in sterile containers, containing volumes for 24 hours, by the nutritional support department.

The influence of enteral feeding on intragastric acidity was analyzed as follows: a group of patients in which continuous intragastric $\mathrm{pH}$ monitoring was performed without administration of enteral feeding (group 1) was compared to a group of patients in which enteral feeding was given throughout the whole registration period (group 2). In addition, a group of patients in which enteral feeding was started during the continuous $\mathrm{pH}$-monitoring was analyzed (group 3 ). In this group, measurements before and after institution of enteral feeding were analyzed separately, without changing the position of the electrode or interrupting the procedure.

Furthermore, the effect of enteral feeding on acquired colonization was analyzed. This analysis was restricted to the first ten days in study. Three different nutritional regimens could be distinguished: patients not receiving enteral feeding in this period (group A), patients receiving enteral feeding for the whole study period (group B), and patients in whom enteral feeding was started after the first day in study (group C). In group C, only the days after institution of enteral feeding were analyzed.

\section{Statistical analysis}

The sample size of both patient groups was calculated to detect a reduction in the incidence of VAP from an assumed $30 \%$ in the antacid group to an expected incidence of $10 \%$ in the sucralfate group $(\alpha=0.05$ and $\beta=0.2)$. The percentages of infection were based on data available at the time the study was designed. Groups were compared by Student's t-test and chi-square test for categorical variables. 
Median intragastric $\mathrm{pH}$ values were compared by Mann-Whitney U-test (MWU). A p-value $<0.05$ was deemed statistically significant.

\section{DEFINITIONS}

Ventilator-associated pneumonia

The diagnosis of VAP was established when: (A) at least three of the following criteria were met (1) rectal temperature $>38.0^{\circ} \mathrm{C}$ or $<35.5^{\circ} \mathrm{C}$, (2) blood leucocytosis $\left(>10.10^{3} / \mathrm{m} \mathrm{m}^{3}\right)$ and/or left shift or blood leucopenia $\left(<3.10^{3} / \mathrm{m} \mathrm{m}^{3}\right)$, (3) $>10$ leucocytes per high-power field in gram stain of tracheal aspirate and (4) a positive culture from tracheal aspirate, in combination with (B) a new or progressive infiltrate on chest radiograph, and (C) the presence of (1) a positive quantitative culture of a sample of secretions obtained by bronchoalveolar lavage (cutoff point $\geq 10^{4} \mathrm{cfu} / \mathrm{ml}$ ) or protected specimen brush (cutoff point $\geq 10^{3} \mathrm{cfu} / \mathrm{ml}$ ), or (2) a positive blood culture unrelated to another source and obtained within 48 hours before and after respiratory sampling, or (3) a positive pleural fluid culture. Episodes of pneumonia diagnosed within the first 24 hours of admission were considered present on admission.

Gastrointestinal tract bleeding

Suspicion of gastrointestinal tract bleeding was endoscopically confirmed and treated according to standard clinical practice. The patient was excluded from the study from that day on.

\section{Colonization}

Colonization was defined as the isolation of microorganisms in the absence of infection, from gastric aspirate, oropharyngeal swab or tracheal aspirate. Colonization on admission was established by a positive culture obtained within 24 hours. Colonization was designated as 'persistent' when present on admission and persisting for at least three days. Colonization was designated as 'acquired' if there were positive cultures of the same species of microorganism from at least two consecutive samples, the first of which was taken no sooner than 24 hours after admission. Sterile cultures or colonization with normal oropharyngeal flora were labelled 'no colonization'.

\section{Initial site of colonization}

The initial site of colonization was defined as that site at which colonization was identified first. A sequence of colonization was examined by comparing isolates of the same species, cultured from two or more sites. Enterobacteriaceae and Staphylococcus aureus were deemed identical when the Minimal Inhibitory Concentrations (MIC) to six antimicrobial agents were concordant, i.e. when no 
more than three out of six MIC-values differed no more than one step of a twofold dilution sequence in the MIC determination. For Enterobacteriaceae identity was further grounded on identical biochemical reactions (i.e. API20E-profile).

Isolates of Pseudomonas aeruginosa were considered identical on the basis of MIC. values, biochemical profile (API20NE-system) and evaluation of plasmid analysis, serotyping, phagetyping and analysis of outer membrane proteins.

In case of concordance, a time sequence of strain isolation from different sites was assumed to indicate the direction of colonization.

\section{RESULTS}

\section{Study population}

A total of 155 patients were eligible for the trial, of which four refused participation, and 10 succumbed within 24 hours. Of the remaining 141 patients, 74 received antacids and 67 sucralfate (Figure 1). The two treatment groups were similar in terms of demographic characteristics and severity of illness on admission (Table 1). Stratification was based on measurements obtained with continuous intragastric monitoring in 84 and indicator papers in 57 patients (Figure 1): in 28 of the latter group continuous $\mathrm{pH}$ monitoring was performed later on.

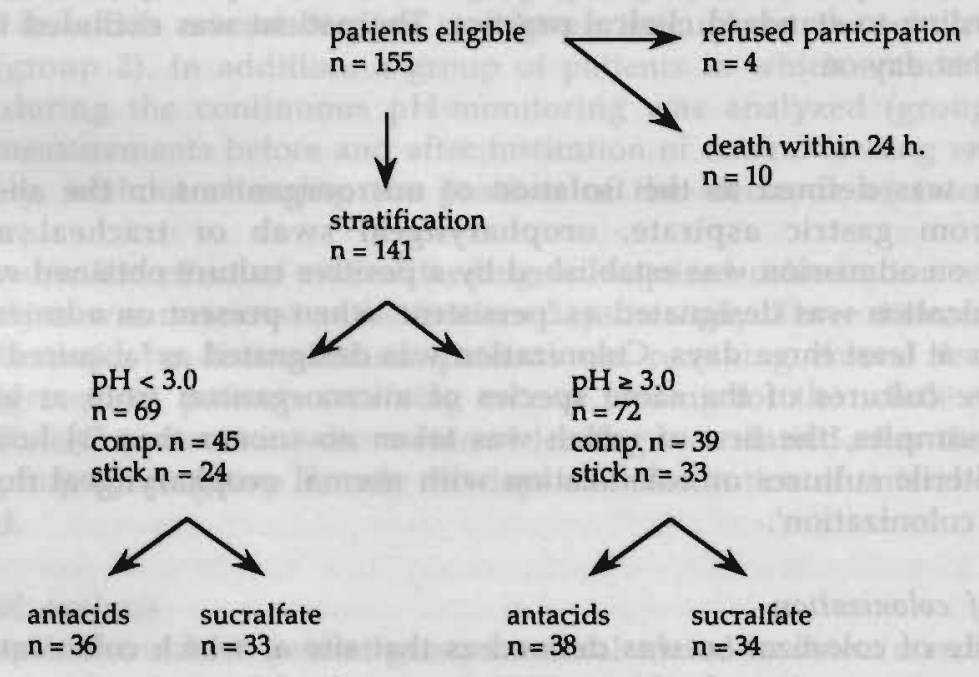

Figure 1: Scheme of inclusion, stratification and randomization of all patients eligible for the trial. COMP = stratification based on computerized intragastric $p H$-measurement, $S T I C K=$ stratification based on pH-mensurement with color-scaled indicator paper. 
Table 1: Characteristics of the 141 patients, according to treatment group. *

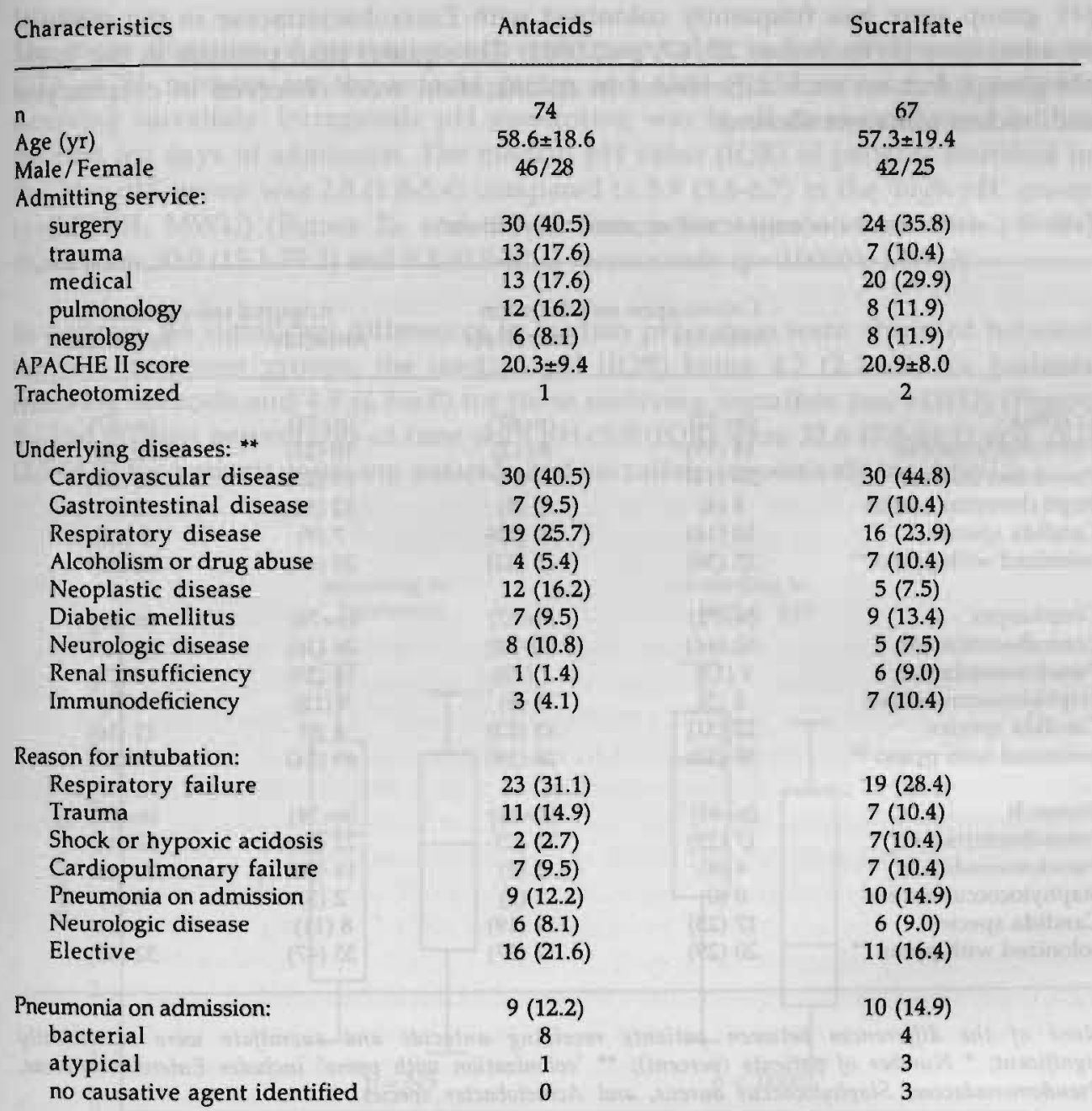

*Plus-minus values are means $\pm S D$. Numbers in parentheses are percentages of group: ** More than 1 condition possible per patient none of the differences between patients receiving antacids and sucralfate were statistically significant 
On admission no significant differences in colonization rates were observed between both treatment groups (Table 2). As expected, patients stratified in the 'low $\mathrm{pH}^{\prime}$ group were less frequently colonized with Enterobacteriaceae in the stomach on admission (5/66 versus $27 / 67, \mathrm{p}<0.0001$, Chi-square) than patients in the 'high' $\mathrm{pH}$ group, but no such differences in colonization were observed in oropharynx and trachea (data not shown).

Table 2: Colonization on admission and acquired colonization*

\begin{tabular}{|c|c|c|c|c|}
\hline \multirow{2}{*}{ 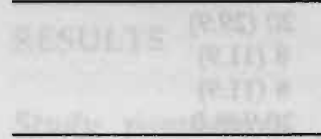 } & \multicolumn{2}{|c|}{ Colonization on admission } & \multicolumn{2}{|c|}{ Acquired colonization } \\
\hline & Antacids & Sucralfate & Antacids & Sucralfate \\
\hline \multirow{6}{*}{$\begin{array}{l}\text { Trachea } \\
\text { Enterobacteriaceae } \\
\text { Pseudomonadaceae } \\
\text { Staphylococcus aureus } \\
\text { Candida species } \\
\text { colonized with ppmo ** }\end{array}$} & $(n=72)$ & $(n=67)$ & $(n=74)$ & $(n=67)$ \\
\hline & $14(19)$ & $8(12)$ & $16(23)$ & $19(29)$ \\
\hline & $10(14)$ & $4(6)$ & $19(27)$ & $23(35)$ \\
\hline & $3(4)$ & $5(8)$ & $12(16)$ & $5(7)$ \\
\hline & $10(14)$ & $10(15)$ & $7(9)$ & $9(13)$ \\
\hline & $25(36)$ & $15(22)$ & $35(47)$ & $32(48)$ \\
\hline \multirow{6}{*}{$\begin{array}{l}\text { Oropharynx } \\
\text { Enterobacteriaceae } \\
\text { Pseudomonadaceae } \\
\text { Staphylococcus aureus } \\
\text { Candida species } \\
\text { colonized with ppmo ** }\end{array}$} & $(n=72)$ & $(n=67)$ & $(n=74)$ & $(n=67)$ \\
\hline & $32(44)$ & $20(30)$ & $26(36)$ & $32(48)$ \\
\hline & $9(13)$ & $7(10)$ & $18(25)$ & $19(29)$ \\
\hline & $2(3)$ & $4(6)$ & $9(12)$ & $3(4)$ \\
\hline & $22(31)$ & $15(22)$ & $6(8)$ & $11(16)$ \\
\hline & $38(53)$ & $26(39)$ & $49(54)$ & $38(57)$ \\
\hline \multirow{6}{*}{$\begin{array}{l}\text { Stomach } \\
\text { Enterobacteriaceae } \\
\text { Pseudomonadaceae } \\
\text { Staphylococcus aureus } \\
\text { Candida species } \\
\text { colonized with ppmo ** }\end{array}$} & $(n=69)$ & $(n=64)$ & $(n=74)$ & $(n=67)$ \\
\hline & $17(25)$ & $15(23)$ & $22(31)$ & $30(46)$ \\
\hline & $4(6)$ & $2(3)$ & $14(20)$ & $10(15)$ \\
\hline & $0(0)$ & $1(2)$ & $2(3)$ & $0(0)$ \\
\hline & $17(25)$ & $12(19)$ & $8(11)$ & $3(4)$ \\
\hline & $20(29)$ & $17(27)$ & $35(47)$ & $32(48)$ \\
\hline
\end{tabular}

Nane of the differences between patients receiving antacids and sucralfate were statistically significant; "Number of patients (percent); ** 'colonization with ppmo' includes Enterolncteriacene, Pseudomonadacene, Staphylococtus aureus, and Acinetobacter species

Intragastric $\mathrm{pH}$ monitoring

Continuous intragastric $\mathrm{pH}$ monitoring was performed in 112 patients; 58 patients receiving antacids $(78.4 \%)$ and 54 patients receiving sucralfate $(80.6 \%)$. For safety reasons intragastric $\mathrm{pH}$ monitoring was not performed in patients with trauma of head or neck region ( $n=7)$, intracerebral bleeding $(n=4)$, coagulation disorders $(n=3)$ 
or esophageal obstruction ( $n=4)$. In addition, 6 patients (or relatives) refused intragastric $\mathrm{pH}$ monitoring and in five patients data were lost due to technical failures.

The mean duration of measurements was comparable in both treatment groups: $4310 \pm 1786$ minutes for the antacid group and $4500 \pm 1833$ minutes for patients receiving sucralfate. Intragastric $\mathrm{pH}$ monitoring was in all cases performed within the first ten days of admission. The median $\mathrm{pH}$ value (IQR) of patients stratified in the 'low $\mathrm{pH}^{\prime}$ group was 2.8 (1.8-5.4) compared to 5.9 (3.6-6.7) in the 'high $\mathrm{pH}^{\prime}$ group $(\mathrm{p}<0.00001, \mathrm{MWU}$ ) (Figure 2), and the median percentages of time with $\mathrm{pH}<3.0$ (IQR) were $50.0(15.1-75.2)$ and $9.2(0.5-42.4)$ respectively $(\mathrm{p}<0.00001, \mathrm{MWU})$.

In contrast, no significant differences in median $\mathrm{pH}$ values were observed between the two treatment groups, the median pH (IQR) being 4.7 (2.2-6.2) for patients receiving antacids and 4.5 (2.7-6.0) for those receiving sucralfate (ns, MWU) (Figure 2). The median percentages of time with $\mathrm{pH}<3.0$ (IQR) were 32.6 (7.8-64.1) and 26.0 (3.3-66.0) for patients receiving antacids and sucralfate respectively (ns, MWU).

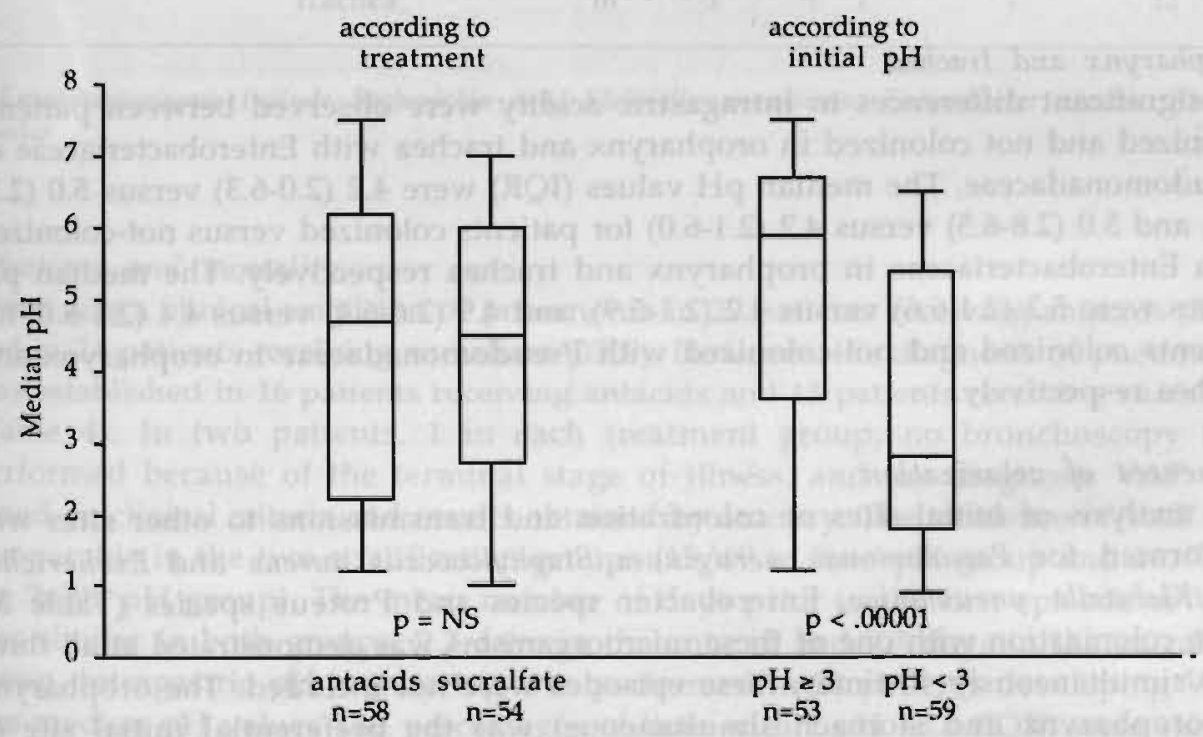

Figure 2: Median intragastric pH-values $(5,25,50,75$ and 95-percentiles), as obtained with continkous intragastric monitoring, according to treatment and initial intragastric $p H$ before stratification. Statistical analysis: Mann-Whitney U-test. 


\section{Colonization and intragastric $p H$}

No significant differences in acquired colonization in stomach, oropharynx or trachea were observed between patients according to treatment groups (Table 2). The relationship between intragastric $\mathrm{pH}$ levels and colonization in the first 10 days of admission were analyzed for patients in whom $\mathrm{pH}$ monitoring was performed $(n=112)$.

\section{Stomach}

Gastric colonization with Enterobacteriaceae was related to median $\mathrm{pH}$ values: colonized patients had a median $\mathrm{pH}$ value (IQR) of 5.5 (2.8-6.5), and non-colonized patients of $3.3(1.9-5.7)(\mathrm{p}<0.01 \mathrm{MWU})$. The percentages of time with $\mathrm{pH}<3.0$ were $12.6(3.0-52.4)$ in colonized, and $44.9(8.6-74.4)$ in non-colonized patients $(p<0.05$ MWU).

Comparable observations were made regarding gastric colonization with Pseudomonadaceae; colonized patients had higher median intragastric $\mathrm{pH}$ values (IQR) $(5.9(2.8-6.8)$ versus $4.1(2.2-6.0)$ respectively, $\mathrm{p}<0.05$, MWU) and lower percentages of time with $\mathrm{pH}<3.0$ as compared to non-colonized patients $(7.8$ (0.538.0 ) versus $35.0(7.5-72.4)$ respectively, $\mathrm{p}<0.05 \mathrm{MWU})$.

\section{Oropharynx and trachea}

No significant differences in intragastric acidity were observed between patients colonized and not colonized in oropharynx and trachea with Enterobacteriaceae or Pseudomonadaceae. The median $\mathrm{pH}$ values (IQR) were $4.2(2.0-6.3)$ versus 5.0 (2.3$6.0)$, and $5.0(2.8-6.5)$ versus $4.2(2.1-6.0)$ for patients colonized versus not-colonized with Enterobacteriaceae in oropharynx and trachea respectively. The median $\mathrm{pH}$ values were $5.2(2.4-6.6)$ versus 4.2 (2.1-5.9), and $4.9(2.6-6.4)$ versus 4.4 (2.1-6.0) for patients colonized and not-colonized with Pseudomonadaceae in oropharynx and trachea respectively.

\section{Sequences of colonization}

The analysis of initial sites of colonization and transmissions to other sites was performed for Pseudomonas aeruginosa, Staphylococcus aureus and Escherichia coli, Klebsiella pneumoniae, Enterobacter species and Proteus species (Table 3). Since colonization with one of these microorganisms was demonstrated at all three sites simultaneously 40 times, these episodes were not included. The oropharynx (or oropharynx and stomach simultaneous) was the preferential initial site of colonization for the Enterobacteriaceae, whereas Pseudomonas aeruginosa and Staphylococcus aureus most frequently colonized the upper respiratory tract first. A gastropulmonary route of colonization (from stomach to trachea) was demonstrated only twice for Enterobacteriaceae, four times for Pseudomonas aeruginosa, and not for Staphylococcus aureus (Table 3). 
Table 3: Sequences of colonization with Enterobacteriaceae, Pseudomonas aeruginosa and Staphylococcus aureus according to the initial site of colonization.

\section{Number of sequences to}

\begin{tabular}{|c|c|c|c|c|c|c|}
\hline Microorganism & Initial site & $\mathbf{n}$ & Stomach & Oropharynx & Trachea & No sequence \\
\hline \multirow[t]{5}{*}{ Enterobacteriaceae * } & stomach & 20 & - & 8 & 2 & 12 \\
\hline & stomach / oropharynx & 31 & - & - & 13 & 18 \\
\hline & oropharynx & 48 & 16 & - & 17 & 22 \\
\hline & oropharyn $\mathrm{x} /$ trachea & 10 & 4 & - & - & 6 \\
\hline & trachea & 11 & 2 & 1 & - & 9 \\
\hline \multirow[t]{5}{*}{ Pseudomonas aeruginosa } & stomach & 4 & - & 4 & 4 & 0 \\
\hline & stomach/oropharynx & 3 & - & - & 3 & 0 \\
\hline & oropharynx & 14 & 10 & - & 11 & 3 \\
\hline & oropharynx/trachea & 18 & 8 & - & - & 10 \\
\hline & trachea & 7 & 4 & 3 & - & 4 \\
\hline \multirow[t]{5}{*}{ Staphylococcus aureus } & stomach & 0 & - & 0 & 0 & 0 \\
\hline & stomach/oropharynx & 3 & - & - & 0 & 3 \\
\hline & oropharynx & 5 & 0 & - & 0 & 5 \\
\hline & oropharynx/trachea & 10 & 1 & - & - & 9 \\
\hline & trachea & 16 & 3 & 7 & - & 12 \\
\hline
\end{tabular}

* Enterobacteriaceae include Escherichia coli, Klebsiella pneumonia, Enterobacter species, Proteus species.

\section{Infections and mortality}

There was a clinical suspicion of pneumonia in 29 patients receiving antacids (34\%) and in 24 patients receiving sucralfate (35\%). However, the diagnosis of pneumonia was established in 16 patients receiving antacids and 15 patients receiving sucralfate (Table 4). In two patients, 1 in each treatment group, no bronchoscopy was performed because of the terminal stage of illness, and the diagnosis VAP was based on clinical criteria and results obtained by autopsy. The incidence of VAP was comparable in the two stratification groups (15/69 in 'low' $\mathrm{pH}$ group and 16/72 in the 'high' $\mathrm{pH}$ group). The mean number of days prior to the first episode of VAP was similar in both groups; 9.2 days in the antacid and 9.3 days in the sucralfate group. Intragastric $\mathrm{pH}$ monitoring was performed in 24 patients developing VAP. The median $\mathrm{pH}$ values and percentages of time with a $\mathrm{pH}<3.0$ (IQR) were similar between patients with and without VAP: median pH 4.1 (2.7-6.2) and 4.8 (2.2-6.0), and percentages of time 36.7 (3.8-53.3) and $26.6(5.4-70.4)$ respectively.

Since antacids and sucralfate had a similar effect on intragastric acidity, patients were divided into 2 groups according to median intragastric $\mathrm{pH}$ values lower or 
higher than 4.0. The first group ( $\mathrm{pH}<4.0, \mathrm{n}=50,27$ antacids, and 23 sucralfate) had a median $\mathrm{pH}(\mathrm{IQR})$ of $2.1(1.5-2.8)$. The second group ( $\mathrm{pH} \geq 4.0, \mathrm{n}=62,31$ antacids, and 31 sucralfate) had a median $\mathrm{pH}$ of 6.0 (5.2-6.6). Gastric colonization with Enterobacteriaceae during the first 10 days in study was significantly less frequently observed in patients of group $1(\mathrm{pH}<4.0,30 \%)$ as compared to patients of group 2 ( $\mathrm{pH}>4.0,56 \%, \mathrm{p}=0.004)$. However, no differences were observed for colonization of the oropharynx ( $54 \%$ and $48 \%)$, the trachea $(22 \%$ and $29 \%)$, or the incidence of VAP $(22 \%$ and $21 \%)$.

Since VAP was polymicrobial in 19 episodes, a total of 58 isolates were associated with VAP. For these isolates initial sites of colonization could be determined in 51 cases. The upper respiratory tract (oropharynx and/or trachea) was the predominant initial site of colonization of microorganisms eventually causing VAP (41 out of 58 cases). In one case a microorganism causing VAP initially colonized the stomach, whereas initial colonization of the stomach and oropharynx simultaneously occurred five times.

The incidence of infections other than VAP, the mean durations of time spent in study and in ICU, the use of antibiotics, and the mortality rates were comparable in both treatment groups (Table 4 ). Ten patients receiving sucralfate and 4 receiving antacids were tracheotomized ( $p=n s)$, but only 2 patients, 1 in each treatment group, developed VAP after being tracheotomized.

\section{Upper gastrointestinal tract bleeding}

In seven patients (four receiving antacids and three receiving sucralfate) the study protocol was discontinued because an $\mathrm{H}^{+} \mathrm{K}^{+}$ATPase inhibitor $(n=6)$, or an $\mathrm{H}_{2}$ antagonist $(n=1)$ was instituted. In two of these patients (one in each treatment group) a bleeding ulcer was diagnosed and surgical intervention was performed. One patient, receiving antacids, eventually succumbed in hypovolaemic shock. 
Table 4: Numbers of patients with ICU-acquired infections according to treatment groups. *

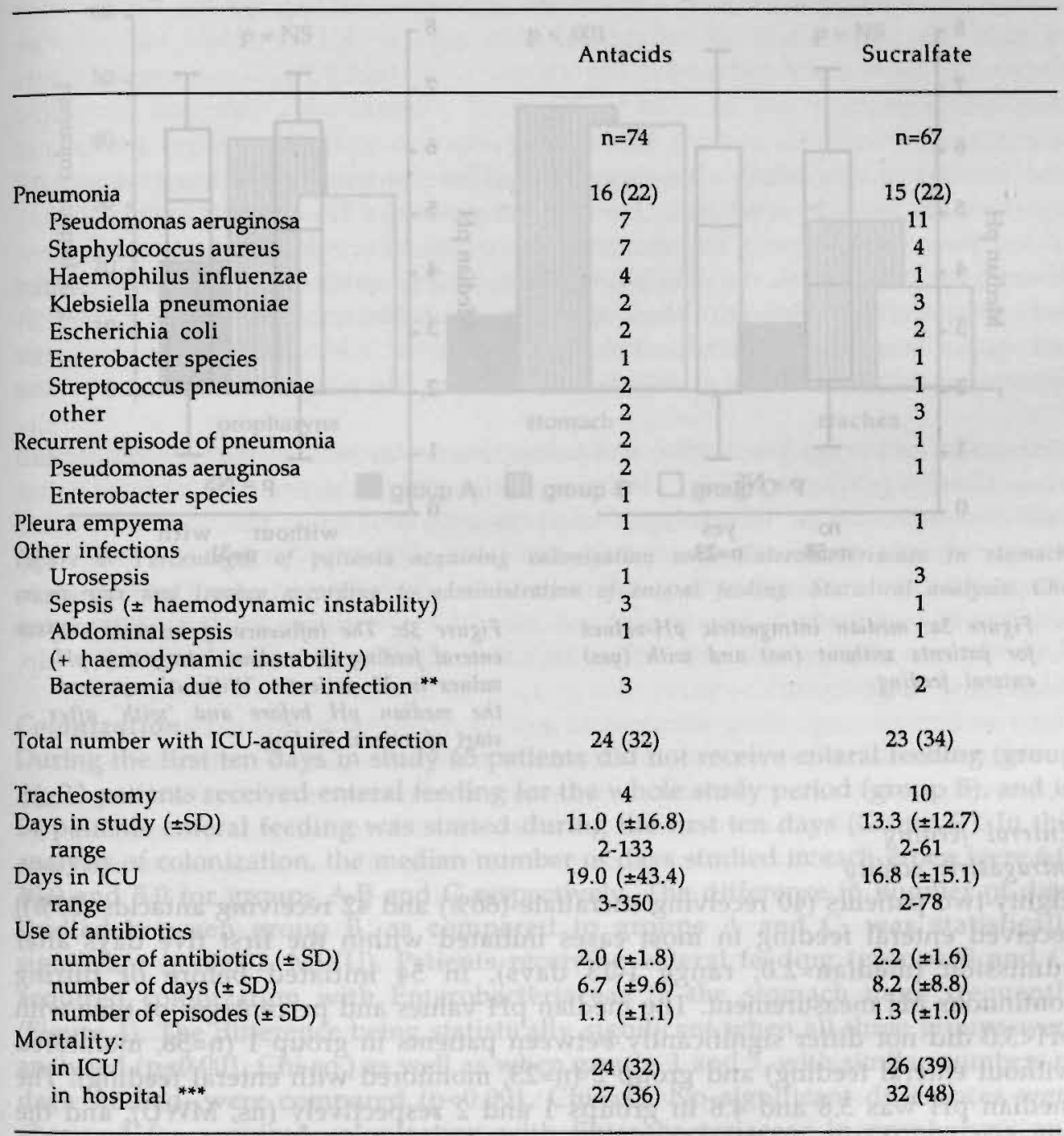

other include: Moraxella catarrhalis, Acinetobacter species, Morganella morganii, Serratin liquefaciens, Proteus mirabilis; * Plus-minus values are means $\pm S D$. Numbers in parentheses are percentages of group; ** Bacteremia due to linesepsis $(n=3)$, woundinfection $(n=1)$ and sinusitis $(n=1)$; *** Patients discharged to other hospitals or still in our hospital were considered alive.

None of the differences between patients receiving antacids and sucralfate were statistically significant. 


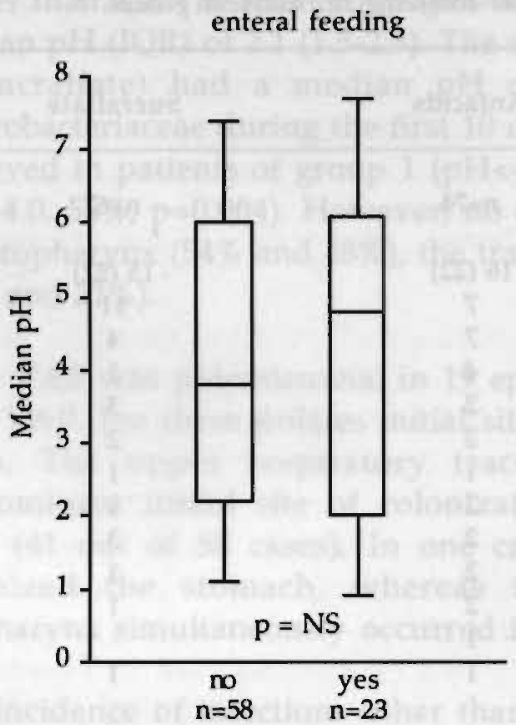

Figure 3a: median intragastric pH-values for patients without (no) and with (yes) enteral feeding. enteral feeding

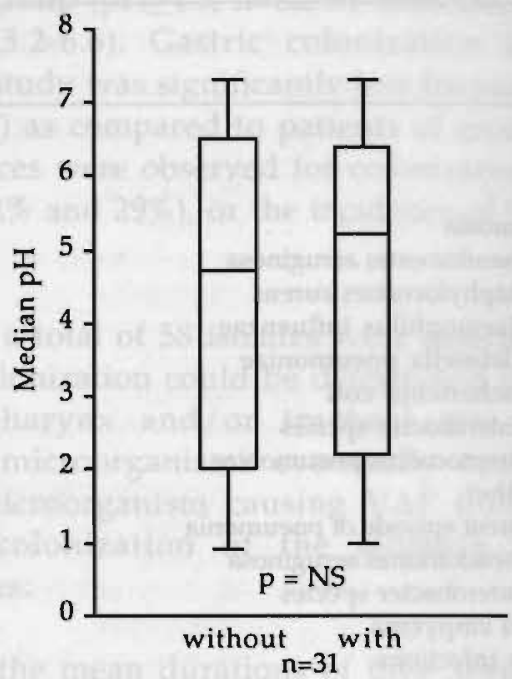

Figure $3 b$ : The influence of institution of enteral feeding on median intragastric $\mathrm{pH}$ values in 31 patients. 'Without' represents the median $\mathrm{pH}$ before and 'with' after start of enteral feeding.

\section{Enteral feeding}

\section{Intragastric acidity}

Eighty-two patients (40 receiving sucralfate $(60 \%)$ and 42 receiving antacids $(57 \%)$ ) received enteral feeding in most cases initiated within the first five days after admission (median=2.0, range 1-23 days), in 54 initiated before or during continuous $\mathrm{pH}$ measurement. The median $\mathrm{pH}$ values and percentages of time with $\mathrm{pH}<3.0$ did not differ significantly between patients in group $1(n=58$, monitored without enteral feeding) and group $2(n=23$, monitored with enteral feeding). The median pH was 3.8 and 4.8 in groups 1 and 2 respectively (ns, MWU), and the percentages of time with $\mathrm{pH}<3.0$ were $39.0 \%$ and $25.0 \%$ in group 1 and 2 respectively (ns, MWU) (Figure $3 a$ ). In the remaining 31 patients (group 3, enteral feeding started during monitoring) median $\mathrm{pH}$ values and percentages of time with $\mathrm{pH}<3.0$, of periods without and with enteral feeding, did not differ significantly. The median $\mathrm{pH}$ was 4.7 and 5.2 respectively (ns, Wilcoxon rank test for matched pairs), and the percentages of time with $\mathrm{pH}<3.0$ were $26.5 \%$ and $9.9 \%$ respectively (ns, Wilcoxon rank test for matched pairs) (Figure $3 b$ ). 


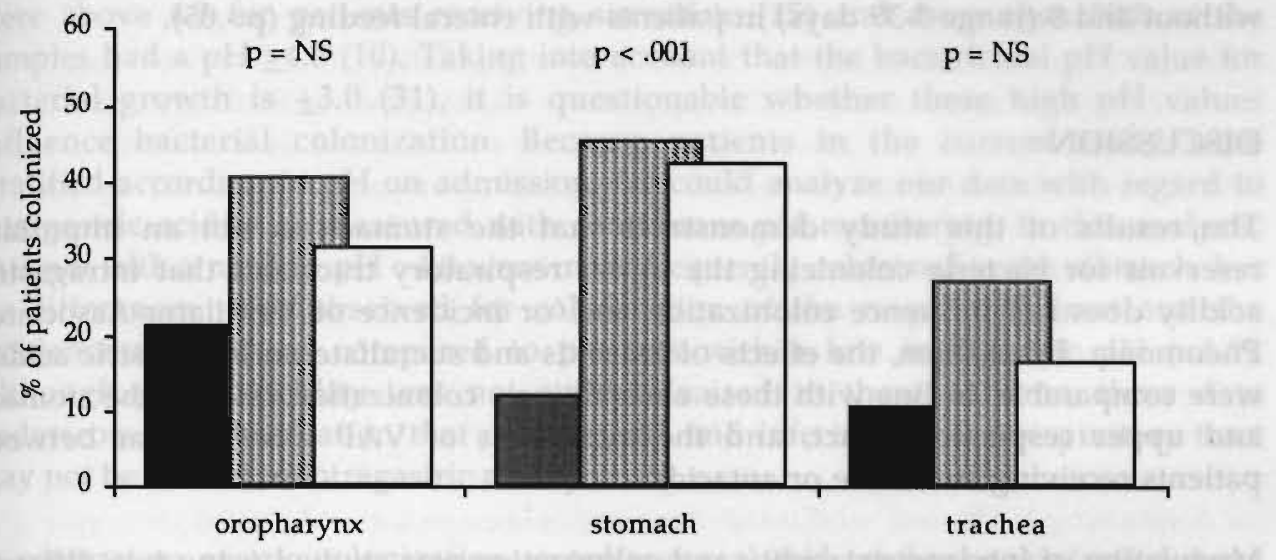

$\square$ group A 国 group B $\square$ group C

Figure 4: Percentages of patients acquiring colonization with Enterobacteriacaea in stomach, oropharynx and trachea according to administration of enteral feeding. Statistical analysis: Chisquare

\section{Colonization}

During the first ten days in study 65 patients did not receive enteral feeding (group A), 22 patients received enteral feeding for the whole study period (group B), and in 54 patients enteral feeding was started during the first ten days (Group C). In this analysis of colonization, the median number of days studied in each groep were 6.0, 10.0 and 5.0 for groups $A, B$ and $C$ respectively. The difference in number of days studied between group B, as compared to groups A and C, was statistically significant ( $\mathrm{p}<0.001, \mathrm{MWU}$ ). Patients receiving enteral feeding (groups $\mathrm{B}$ and $\mathrm{C}$ ) acquired colonization with Enterobacteriaceae in the stomach more frequently (Figure 4). The difference being statistically significant when all three groups were analyzed ( $p<0.001$, Chi-sq.) as well as when groups 1 and 3 , with similar numbers of days studied, were compared ( $p<0.001$, Chi-sq.). No significant differences were observed for acquired colonization with Enterobacteriaceae in oropharynx and trachea or for acquired colonization with Pseudomonadaceae. These results suggest that gastric colonization with Enterobacteriaceae is related to enteral feeding rather than to intragastric acidity, as measured with long-term continuous intragastric $\mathrm{pH}$ monitoring. Eighteen patients developed an episode of VAP after enteral feeding had been instituted (11 receiving antacids and 7 receiving sucralfate, $p>05$ ). The 
median days at which VAP was diagnosed was 5 (range 3-23 days) in patients without and 8 (range 3-39 days) in patients with enteral feeding ( $p>05$ ).

\section{DISCUSSION}

The results of this study demonstrate that the stomach is not an important reservoir for bacteria colonizing the upper respiratory tract and that intragastric acidity does not influence colonization and/or incidence of Ventilator-Associated Pneumonia. In addition, the effects of antacids and sucralfate on intragastric acidity were comparable. In line with these observations, colonization rates of the stomach and upper respiratory tract, and the incidences of VAP were similar between patients receiving sucralfate or antacids.

Modulation of intragastric acidity and colonization was studied using two different stress ulcer prophylactic agents. However, a high dosage of antacids $(30 \mathrm{ml}, 6$ times daily), comparable to the dosages used by others $(13,23)$, resulted in median intragastric $\mathrm{pH}$-values and percentages of time with a $\mathrm{pH}$ below 3.0 that were comparable to the values from patients receiving sucralfate (Figure 2). Our results confirm observations made by others, also demonstrating limited efficacy of antacids to raise gastric $\mathrm{pH}$ when tested with continuous intragastric $\mathrm{pH}$ monitoring $(24,25)$.

Many of the data regarding intragastric acidity in intensive care patients originate from studies determining intragastric acidity with color-scaled indicator papers in aspirated gastric juice, with frequencies ranging from one to 12 measurements per day $(6,7,10,13-15,23)$. However, the reliability of color-scaled indicator papers has been criticized $(17,18)$, and the accuracy of determination of intragastric acidity is related to the frequency of measurements $(26)$, since incidentically measured $\mathrm{pH}$ values neither detect temporary changes in acidity (27), nor necessarily reflect the mean acidity.

As expected, patients with a gastric $\mathrm{pH}$ above 3.0 on admission were more frequently colonized with Enterobacteriaceae and Pseudomonadaceae in the stomach, and patients with gastric colonization had significantly higher median intragastric $\mathrm{pH}$ values as compared to non-colonized patients. These observations are in line with other reports $(6,28-30)$. Overall, no differences in gastric colonization rates observed between patients receiving sucralfate or antacids, reflecting the similar median intragastric $\mathrm{pH}$ values in both treatment groups. Although lower colonization rates have been reported in sucralfate treated patients

- as compared to patients receiving antacids and/or $\mathrm{H}_{2}$-antagonists $(10,16)$, the results of these studies cast doubt on the hypothesis that the differences in colonization 
could be explained by sucralfate's lack of effect on gastric $\mathrm{pH}$. The mean $\mathrm{pH}$ values were above 4.3 for patients receiving sucralfate (15) and more than $50 \%$ of the samples had a $\mathrm{pH} \geq 4.0(10)$. Taking into account that the bactericidal $\mathrm{pH}$ value for bacterial growth is \pm 3.0 (31), it is questionable whether these high $\mathrm{pH}$ values influence bacterial colonization. Because patients in the current study were stratified according to $\mathrm{pH}$ on admission, we could analyze our data with regard to intragastric acidity as measured with continuous $\mathrm{pH}$ monitoring. In this analysis, patients with a median $\mathrm{pH}>4.0$ were more frequently colonized in the stomach, but no differences were observed for colonization of the respiratory tract and the incidence of VAP, as compared to patients with a low intragastric $\mathrm{pH}(<4.0)$. Although gastric acidity was not actively raised in these patients, these data underscore the observation that colonization and infection of the respiratory tract may not be related to intragastric acidity.

In contrast to gastric colonization, oropharyngeal and tracheal colonization were not related to intragastric acidity, which questions the assumed importance of the stomach as a source for bacteria causing colonization of the upper respiratory tract and VAP. Moreover, the stomach was only sporadically the initial site of colonization, and a sequence of colonization from the stomach to the trachea was demonstrated only four times with Pseudomonas aeruginosa and two times with Enterobacteriaceae in 141 patients. Our data underscore observations recently made by others $(32,33)$. Inglis et al and Cade et al demonstrated chronological patterns of colonization from the stomach to the tracheobronchial tree in only six and eight out of 100 mechanically ventilated ICU-patients respectively $(32,33)$. The results of the present study also confirm our previous observations that Pseudomonas aeruginosa and Enterobacter species initially colonized the trachea rather than the stomach, and that routes of colonization differ between species of microorganisms (34).

The incidence and etiology of VAP in the present study are in line with data from other reports $(1,10,35)$. Importantly, colonization of the upper respiratory tract and the development of VAP were not related to stress ulcer prophylaxis or intragastric $\mathrm{pH}$. The analysis of sequences of colonization of bacteria eventually causing VAP indicates that the gastropulmonary route is not important in the pathogenesis of VAP, which confirms observations made previously by us and Reusser et al $(34,36)$. The observation that colonization with bacteria, eventually causing VAP, most frequently originated in the oropharynx and/or trachea, underscores the importance of colonization at these sites prior to development of VAP, which was first reported by Johanson et al (3). 
Thus, the results of this study put questions to the hypothesis that the gastropulmonary route of colonization is important in the pathogenesis of VAP, although this has been accepted by many investigators $(4,5)$. However, data from the literature do not provide solid support for this notion. Indeed, several studies clearly demonstrated a relation between gastric colonization and bacteria causing VAP, but incidences of chronological patterns of colonization from the stomach to the lungs, including colonization of the oropharyngeal cavity, were not studied $(6,7,8,10,13,14,29)$. Secondly, reported beneficial effects of sucralfate on the incidence of VAP were also considered to provide evidence for the importance of the gastropulmonary route of colonization $(4,5)$, although the small differences between gastric $\mathrm{pH}$ values in these studies $(4.26-4.73$ versus $4.85-5.55)$ could hardly explain the differences in incidences of VAP $(10,13-15,37)$. Moreover, no sophisticated methods were used for the measurement of intragastric acidity and for diagnosing VAP, and no double-blind study-design was employed.

Enteral feeding has been associated with an increased risk of gastric bacterial colonization and pneumonia (38). In the present study the numbers of patients receiving, and the day on which enteral feeding was instituted were comparable in both treatment groups. Although, the results of the present study do not underscore the relationship between enteral feeding and VAP, this study was not designed specifically to determine the influence of enteral feeding on intragastric acidity, colonization, and VAP, and this presumed relationship therefore remains to be elucidated.

In conclusion, antacids and sucralfate had a similar effect on intragastric acidity, and as a result sucralfate had no preventive effect on the incidences of colonization and infection in these patients. Moreover, intragastric acidity and colonization was not associated with colonization of the upper respiratory tract and development of pneumonia in mechanically ventilated ICU-patients. The results of this study provide evidence that the gastropulmonary route may not be important for the development of VAP in mechanically ventilated ICU-patients. 


\section{REFERENCES}

1. Fagon JY, Chastre J, Hance AJ, Montravers P, Novara A, Gibert C. Nosocomial pneumonia in ventilated patients: a cohort study evaluating attributable mortality and hospital stay. Am J Med 1993; 94: 281-8

2. Rello J, Quintana E, Ausina V, et al. Incidence, etiology, and outcome of nosocomial pneumonia in mechanically ventilated patients. Chest 1991; 100: 439-444

3. Johanson WG, Pierce AK, Sanford JP, Thomas GD. Nosocomial respiratory infections with Gramnegative bacilli: The significance of colonization of the respiratory tract. Annals Intern Med 1972; 77: 701-6

4. Tryba M. The gastropulmonary route of infection: fact or fiction? Am J Med 1991; 91 (Suppl 2A): 135-146

5. Heyland D, Mandell LA. Gastric colonization by Gram-negative bacilli and nosocomial pneumonia in the Intensive Care patient. Evidence for causation. Chest 1992; 101: 187-193

6. Du Moulin GC, Hedley-White J, Paterson DJ, Lisbon A. Aspiration of gastric bacteria in antacidtreated patients: a frequent cause of postoperative colonisation of the airway. Lancet 1982; 1 : 242-245

7. Atherton ST, White DJ. Stomach as a source of bacteria colonising respiratory tract during artificial respiration. Lancet 1978; 2: 968-969

8. A Torres, El-Ebiary M, Gonzalez J, et al. Gastric and pharyngeal flora in nosocomial pneumonia acquired during mechanical ventilation. Am Rev Respir Dis 1993; 148: 352-357

9. Craven DE, Kunches LM, Kilinsky V, Lichtenberg DA, Make BJ, McCabe BJ. Risk factors for pneumonia and fatality in patients receiving continuous mechanical ventilation. Am Rev Respir Dis 1986; 133: 792-796

10. Driks MR, Craven DE, Celli BR, et al. Nosocomial pneumonia in intubated patients given sucralfate as compared with antacids or histamine type 2 blockers: the role of gastric colonization. New Engl J Med 1987; 317: 1376-82

11. Hastings PR, Skillman JJ, Bushnell LS, Silen W. Antacid titration in the prevention of acute gastrointestinal bleeding. A controlled randomized trial in 100 critically ill patients. N Engl J Med 1980; 298: 1041-1045

12. McCarthy DM. Sucralfate. New Engl J Med 1991; 325: 1017-23

13. Tryba M. Risk of acute stress bleeding and nosocomial pneumonia in ventilated intensive care patients: sucralfate versus antacids. Am J Med 1987; 83 (Suppl 3B): 117-24

14. Eddleston JM, Vohra A, Scott P, et al. A comparison of the frequency of stress ulceration and secondary pneumonia in sucralfate - or ranitidine-treated intensive care unit patients. Crit Care Med 1991; 19: 1491-1496

15. Kappstein I, Schulgen G, Friedrich T, et al. Incidence of pneumonia in mechanically ventilated patients treated with sucralfate or cimetidine as prophylaxis for stress bleeding: bacterial colonization of the stomach. Am J Med 1991; 91 (Suppl 2A): 125-131 
16. Fagon JY, Chastre J, Hance AJ, Domart Y, Trouillet JL, Gibert C. Evaluation of clinical judgement in the identification and treatment of nosocomial pneumonia in ventilated patients. Chest 1993; 103: $547-553$

17. Caballero GA, Ausman RK, Quebbman EJ, Schulte WJ, Lin L. Gastric secretion pH measurement: what you see is not what you get! Crit Care Med 1990; 18: 396-99

18. Dobkin ED, Valcour A, McCloskey CR, et al. Does $\mathrm{pH}$ paper accurately reflect gastric $\mathrm{pH}$ ? Crit Care Med 1990; 18: 985-8

19. Knaus WA, Draper EA, Wagner DP, Zimmerman JE. APACHE II: a severity of disease classification system. Crit Care Med 1985; 13: 818-29

20. Fimmel CJ, Etienne A, Cilufo, et al. Long-term ambulatory gastric $\mathrm{pH}$ monitoring: validation of a new method and effect of $\mathrm{H}_{2}$-antagonists. Gastroenterology 1985; 88: 1842-1851

21. Savarino V, Mela GS, Scalabrini P, et al. 24-h Comparison between $\mathrm{pH}$ values of continuous intraluminal recording and simultaneous gastric aspiration. Scand J Gastroenterol 1988; 23: 375379

22. Meduri GU, Chastre J. The standardization of bronchoscopic techniques for ventilator-associated pneumonia. Chest 1992; 102 (Suppl 1): 557-564

23. Simms HH, DeMaria E, McDonald L, Peterson D, Robinson A, Burchard KW. Role of gastric colonization in the development of pneumonia in critically ill trauma patients: results of a prospective randomized trial. J Trauma 1991; 31: 531-537

24. Etienne A, Fimmel J, Rey JP, Blum AL. Long-lasting effect of $\mathrm{Al} / \mathrm{Mg}$ liquid antacid on nocturnal intragastric acidity recorded by continuous $\mathrm{pH}$-metry. Gastroenterology 1984; 86: 1071

25. Bauerfeind P, Ciluffo T, Armstrong D, et al. Fate of antacid gel in the stomach. Site of action and interaction with food. Dig Dis Sci 1990; 35: 553-558

26. Meiners D, Clift S, Kaminski D. Evaluation of various techniques to monitor intragastric $\mathrm{pH}$. Arch Surg 1982; 117: 288-291

27. Moore JG, Englert E. Circadian rythm of gastric acid secretion in man. Nature 1970; 226: 1261-1262

28. Hillman KM, Riordan T, O'Farrell SM, Tabaqchali S. Colonization of the gastric contents in critically ill patients. Crit Care Med 1982; 10: 444-447

29. Daschner FD, Reuschenbach K, Pfisterer J, et al. The influence of stress ulcer prophylaxis on the incidence of pneumonia in artificially ventilated patients. Anaesthesist 1987; 36: 9-18

30. Garvey BM, McCambley JA, Tuxen DV. Effects of gastric alkalization on bacterial colonization in critically ill patients. Crit Care Med 1989; 17: 211-216

31. Mehta S, Archer JF, Mills J. pH-dependent bactericidal barrier to gram-negative aerobes: its relevance to airway colonisation and prophylaxis of acid aspiration and stress ulcer syndromes. Study in vitro. Intensive Care Med 1986; 12: 134-136

32. Inglis TJJ, Sheratt MJ, Sproat LJ, Gibson JS, Hawkey PM. Gastroduodenal dysfunction and bacterial colonisation of the ventilated lung. Lancet 1993; 341: 911-913

33. Cade JF, McOwat E, Siganporia R, Keighly C, Presneill J, Sinickas V. Uncertain relevance of gastric colonization in the seriously ill. Intensive Care Med 1992; 18: 210-217 
34. Bonten MJM, Gaillard CA, van Tiel FH, Smeets HGW, van der Geest S, Stobberingh EE. The relevance of the stomach as a source for colonization of the upper respiratory tract and pneumonia in ICU-patients. Chest (in press)

35. Torres A, Aznar R, Gatell JM, et al. Incidence, risk, and prognosis factors of nosocomial pneumonia in mechanically ventilated patients. Am Rev Respir Dis 1990; 142: 523-8

36. Reusser P. Zimmerli W, Scheidegger D, Marbet GA, Buser M, Klaus G. Role of gastric colonization in nosocomial infections and endotoxemia: a prospective study in neurosurgical patients on mechanical ventilation. J Infect Dis 1989; 160: 414-421

37. Cook DJ, Laine LA, Guyatt GH, Raffin TA. Nosocomial pneumonia and the role of gastric $\mathrm{pH}$. A meta-analysis. Chest 1991; 100: 7-13

38. Pingleton SK, Hinthorn DR, Liu C. Enteral nutrition in patients receiving mechanical ventilation. Am J Med 1986; 80: 827-32 


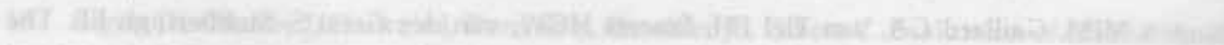

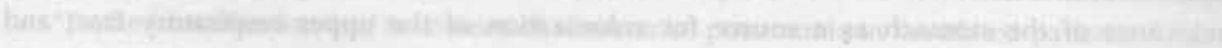
(17)

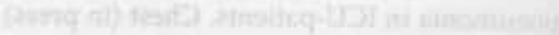

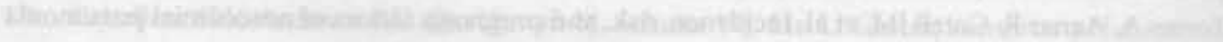

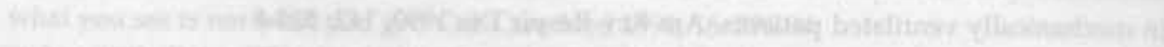

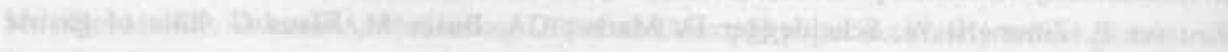

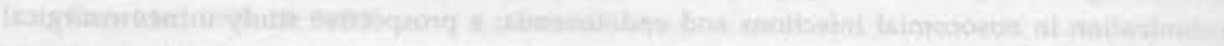

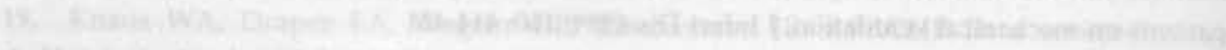

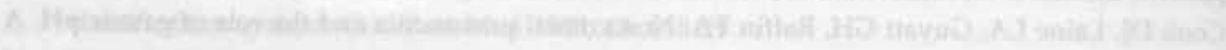

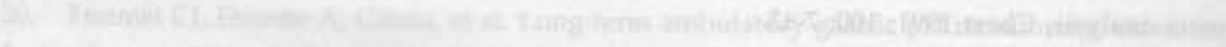

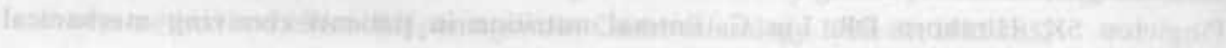

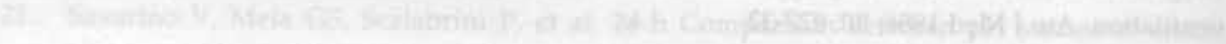

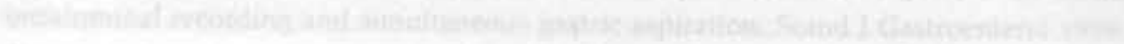

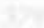

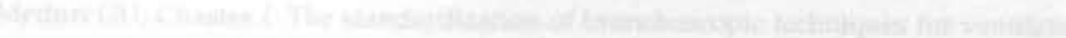

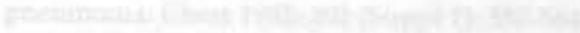

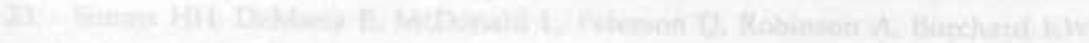

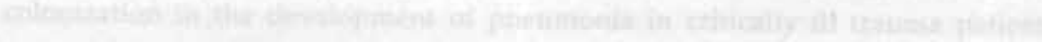

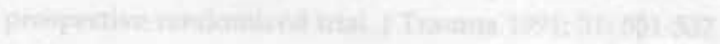

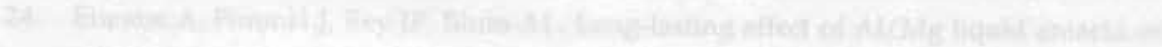

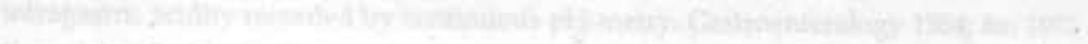

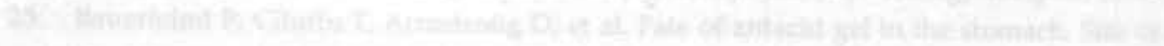

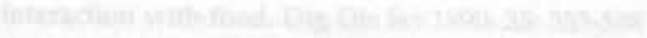

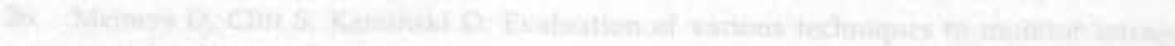

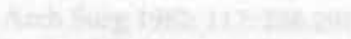

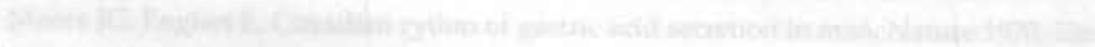

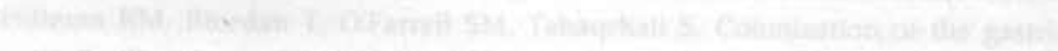

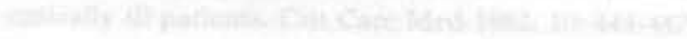

14.

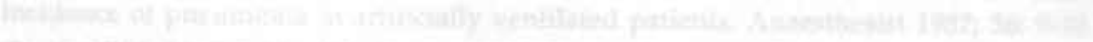

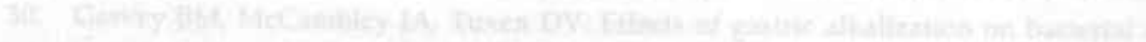

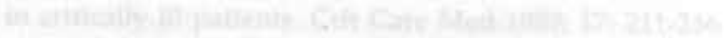

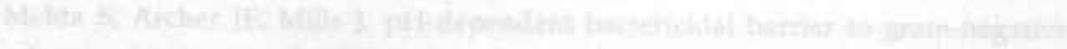

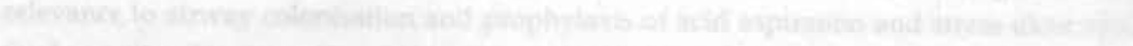

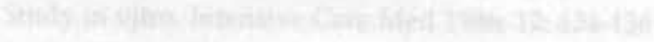

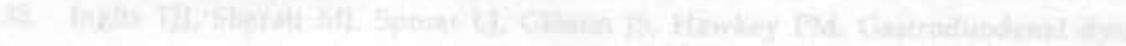

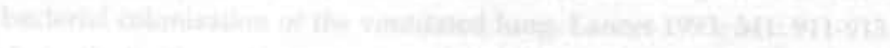




\section{Chapter 11}

SUMMARY, ANSWERS TO THE QUESTIONS, AND CONCLUDING REMARKS 


\section{Summary}

This thesis describes studies on the role of colonization of the upper gastrointestinal tract in the pathogenesis of nosocomial pneumonia in mechanically ventilated ICU-patients. Nosocomial pneumonia, sometimes called late or secondary pneumonia, is an infection developing after at least three days of admission to hospital. Among mechanically ventilated ICU-patients this infection has also been called ventilator-associated pneumonia (VAP). In chapter 1 the pathogenesis of ventilator-associated pneumonia was reviewed. It is widely accepted that most bacteria causing pneumonia originate from an endogenous reservoir, i.e. the digestive tract, and that the gastropulmonary route of colonization is of main importance for the development of nosocomial pneumonia. However, data from the literature do not, in our opinion, provide convincing evidence for this hypothesis. Although many preventive strategies, such as selective decontamination of the digestive tract and the use of sucralfate for stress ulcer prophylaxis, have been developed, based on the gastropulmonary route of colonization, the clinical benefits of each attempt have been disputed. A critical appraisal of the literature led to the conclusion that most studies, addressing the prevention of VAP, suffer from methodological inadequacies: i.e. the endpoint of most studies, nosocomial pneumonia, was not diagnosed adequately, colonization of several body sites was not monitored in time, and modulation of intragastric acidity was not studied reliably.

Selective Decontamination of the Digestive tract (SDD) is the preventive regimen most frequently used and most extensively studied. In this regimen of infection prevention non-absorbable antimicrobial agents are applied to the oropharynx, stomach and intestine. The antibacterial spectrum of the antibiotics include Enterobacteriaceae, Pseudomonas aeruginosa and Staphylococcus aureus, the potential pathogenic microorganisms (ppmo) most frequently associated with VAP. The term "selective" refers to the fact that the anaerobic bacteria are not to be eliminated since these are believed to increase colonization resistance. Despite many studies, the benefits of SDD have not been unequivocally established. Moreover, interpretation of the studies, especially those performed before 1990, is seriously hampered because of methodological flaws. Seven studies on SDD, published after 1991, have been reviewed in chapter 2. All studies were prospective and randomized with at least 100 patients in each study: 6 studies were placebocontrolled, and 3 were double-blind. Only 2 studies showed a significant decrease in the incidence of ICU-acquired pneumonia. Moreover, data from these studies and other recent publications demonstrated an increased incidence of colonization and infection due to Gram-positive bacteria, an increasing number of bacteria resistant to the antibiotics used in SDD, and high costs associated with this method of infection prevention. It was concluded that the recently published well-designed 
studies failed to show any beneficial effects of SDD on mortality, the incidence of VAP, or other parameters such as duration of mechanical ventilation or ICU-stay.

As an accurate diagnosis of nosocomial pneumonia is essential when studying its pathogenesis, problems in diagnosing pneumonia were reviewed in chapter 3. Since most ICU-patients are heavily colonized with bacteria in the upper respiratory tract, it is rather difficult to distinguish colonization from infection. In addition, bedside chest radiographs often are difficult to interprete, and therefore not reliable enough to establish or reject the diagnosis of VAP, even in combination with clinical parameters. Bronchoscopic techniques, such as Protected Specimen Brush (PSB) and Bronchoalveolar Lavage (BAL) have been developed to obtain uncontaminated samples from distal airways. Quantitative microbiological analysis of these samples, in combination with clinical parameters of infection and interpretation of chest radiographs, probably is the optimal method to diagnose VAP. Several studies demonstrated a good sensitivity and an acceptable specificity for diagnosing VAP with these methods. Therefore, in all studies described in this thesis quantitative microbiological analysis of samples obtained by Protected Specimen Brush and Bronchoalveolar Lavage, in combination with clinical parameters, were used for diagnosing VAP.

In chapter 5 the influence of topical antimicrobial prophylaxis (TAP) of oropharynx and stomach on colonization of the upper respiratory tract was studied. In contrast to conventional SDD, intestinal decontamination was not aimed for and systemic prophylaxis was not administered. In order to maintain the aerobic and anaerobic intestinal flora, the amounts of non-absorbable antibiotics administered via the nasogastric tube into the stomach were lower as compared to those used in SDD. The results of this study demonstrated that colonization of the upper respiratory tract with ppmo could be prevented without intestinal decontamination. However, a tendency towards increased colonization of the upper respiratory tract with Grampositive bacteria, especially Enterococcus faecalis, intrinsically resistant to the antibiotics used, was observed. Moreover, of 61 patients receiving TAP, 6 developed polymicrobial pneumonia and 2 bacteremia with Enterococcus faecalis, which species was generally considered not to cause respiratory tract infection.

In chapter 6 we studied gastric colonization in patients receiving and not-receiving the TAP-regimen, described in chapter 5. TAP, including sucralfate, prevented gastric colonization effectively. Patients receiving 'gastric $\mathrm{pH}$ raising' stress ulcer prophylaxis acquired gastric colonization more frequently. Interestingly, in both patient groups gastric colonization occurred more frequently and more rapidly when enteral feeding was administered simultaneously. 
In chapter 7 the influence of TAP on colonization with ppmo of the upper respiratory tract was investigated both in patients receiving TAP $(n=22)$ as well as in 2 groups of patients not receiving TAP. These two control groups included patients treated within the same ICU-ward $(n=21)$ as the patients receiving TAP, and patients treated in another identical ICU $(n=54)$, where none of the patients received TAP. Patients receiving TAP were less frequently colonized in oropharynx or trachea as compared to patients not receiving TAP. However, among both control groups, those patients treated in the ICU where other patients received TAP were less frequently colonized as compared to the patients treated in the ICU where no TAP was instituted. Moreover, of the patients not colonized on admission, those admitted to the ICU where TAP was administered remained free of colonization for a longer period of time. Furthermore, in the ICU where no prophylaxis was administered more patients were colonized simultaneously and cross-acquisition occurred more frequently. From this study it was concluded that TAP influenced colonization of oropharynx and trachea both in patients receiving as well as in patients not-receiving the prophylaxis within the same ICU. This strongly suggests that cross-acquisition plays an important role in colonization of patients within an ICU.

Chapter 8 addressed the topic of measuring intragastric acidity with optimal accuracy. Generally speaking, intragastric acidity is determined by $\mathrm{pH}$ measurements with color-scaled indicator papers in aspirated gastric juice, with sampling frequencies ranging from 6 times daily to twice weekly. However, this method had been criticized for several reasons. In the first place the reliability of the color-scaled papers had been questioned. Secondly, a large interobserver variability has been reported. And finally, incidental measurements can never accurately reflect changes in intragastric acidity. Computerized continuous intragastric pH-monitoring, the reliability and reproducibility of which has been clearly demonstrated, overcomes these problems. In chapter 8 we tested the accuracy of color-scaled indicator papers and compared the $\mathrm{pH}$ values obtained with this method to the median $\mathrm{pH}$ values obtained with continuous intragastric $\mathrm{pH}$ monitoring during 24 hours. The accuracy of the color-scaled papers as verified with a laboratory $\mathrm{pH}$ meter was high, both in colorless buffered solutions with variable $\mathrm{pH}$ values as well as in gastric juice. However, when used once daily, the $\mathrm{pH}$ values had a poor correlation with median $\mathrm{pH}$ values obtained with continuous intragastric monitoring, probably because changes in intragastric acidity could not be measured well. Therefore, continuous intragastric $\mathrm{pH}$ monitoring should be used to investigate the influence of certain manoeuvres on intragastric acidity. 
In the study described in chapter 9 colonization of the stomach, the oropharynx and the trachea was monitored serially and chronologically in order to determine sequences of colonization. Eleven patients developed VAP and cultures from PSB and BAL yielded 20 species of microorganisms. Previously to or on the day that pneumonia was diagnosed, 17 of these species associated with VAP were cultured from tracheal aspirates, and 6 from gastric aspirates. For none of these 6 species a sequence of colonization from the stomach to the upper respiratory tract could be demonstrated. The initial site of colonization with Pseudomonas aeruginosa and Enterobacter spp. was more frequently the trachea than the stomach. In contrast, species such as Klebsiella spp. and Enterococcus faecalis, preferentially colonized the stomach first. Based on these data, it seemed unlikely that the stomach was an important source of bacteria causing VAP. In addition, different species of bacteria probably had different initial sites and routes of colonization.

The influence of intragastric acidity on gastric colonization, colonization of the upper respiratory tract and the incidence of VAP was described in chapter 10. In addition, the influence of 2 different regimens for stress ulcer prophylaxis, namely sucralfate and antacids, on these parameters were compared. The latter was done in a prospective randomized double-blind fashion, in which patients were stratified on initial gastric $\mathrm{pH}$. No significant differences in median $\mathrm{pH}$ values were observed. Furthermore, colonization rates in the stomach, the oropharynx and the trachea were comparable in both treatment groups. However, patients colonized with ppmo in the stomach had higher median $\mathrm{pH}$ values as compared to noncolonized patients, underscoring the relation between intragastric acidity and gastric colonization. In contrast, no significant differences in intragastric acidity were observed between colonized and non-colonized patients in oropharynx or trachea. In addition, sequences of colonization from the stomach to the trachea were demonstrated twice for Enterobacteriaceae and 4 times for Pseudomonas aeruginosa in 141 patients. In agreement with the data on colonization, no differences were observed in the incidence of VAP between both treatment groups ( $22 \%$ in both), and only 1 of the 48 bacteria associated with VAP initially colonized the patient in the stomach. The results of this study provide convincing evidence, further to the observations already made in chapter 9, that the stomach is not an important source of bacteria causing VAP. Moreover, sucralfate and antacids had comparable effects on intragastric acidity, and as a result sucralfate did not prevent colonization and infection.

Another feature of this study was that the oropharynx and trachea were the most important initial sites of colonization, which strongly points to the importance of exogenous routes of colonization, thus confirming our previous observations made in chapter 7. 
In this study also the influence of enteral feeding on intragastric acidity and gastric colonization was investigated in a post-hoc analysis. In contrast to the results in other studies, administration of gastric nutrition did not seem to change intragastric acidity. However, this might be explained by the difference in methodology, as described in chapter 8. Although gastric nutrition did not significantly raise the intragastric $\mathrm{pH}$, it stimulated gastric colonization with ppmo, which is in keeping with the main observations described in chapter 6.

\section{Answers to the Questions}

1. Can colonization of the upper respiratory tract be modulated without influencing colonization of the colon? Colonization of the upper respiratory tract can be modulated by a regimen of topical antimicrobial prophylaxis (TAP), containing antimicrobial agents applied to the oropharynx and administered into the stomach, but without decontaminating the intestine or administering systemic prophylaxis.

2. Can colonization of the stomach be modulated by topical antimicrobial prophylaxis of stomach and oropharynx? The TAP-regimen effectively prevented gastric colonization.

3. Does continuous enteral feeding influence the protective effect of topical antimicrobial prophylaxis of the stomach? The protective effects of the TAPregimen on gastric colonization decreased when continuous gastric nutrition was administered simultaneously.

4. Does modulation of the bacterial flora of the upper respiratory tract by topical antimicrobial prophylaxis influence colonization in other patients notreceiving prophylaxis and treated within the same ICU-ward? Modulation of colonization of the upper respiratory tract by TAP decreased colonization of other patients, not-receiving TAP, treated within the same ICU, thereby confirming the importance of cross-acquisition.

5. What is the role of the gastropulmonary route of colonization in the pathogenesis of nosocomial pneumonia in mechanically ventilated patients? Based on the results of 2 studies, described in this thesis, it seems unlikely that the gastropulmonary route is important in the pathogenesis of pneumonia in mechanically ventilated ICU-patients.

6. Do incidentally obtained measurements of acidity in aspirated gastric juice accurately reflect 24 hour values of intragastric acidity, as obtained with computerized continuous monitoring? Although color-scaled indicator papers accurately measure $\mathrm{pH}$ values, incidental measurements of gastric acidity with this method do not accurately reflect the median $\mathrm{pH}$ values obtained by continuous 24 hour monitoring. Therefore, computerized continuous intragastric $\mathrm{pH}$ monitoring is recommended when studying the influence of 
certain manoeuvres on intragastric acidity. The data regarding gastric $\mathrm{pH}$ from studies where indicator papers were used should be interpreted with caution.

7. What is the influence of sucralfate on intragastric acidity as compared to high dosages of antacids? Sucralfate $(1 \mathrm{~g} / \mathrm{q} 4 \mathrm{~h})$ and Antagel $(30 \mathrm{ml} / \mathrm{q} 4 \mathrm{~h})$ had comparable effects on intragastric acidity in mechanically ventilated patients, irrespective of their initial gastric $\mathrm{pH}$ (above or below 3.0).

8. Does sucralfate influence colonization rates and the incidence of pneumonia as compared to the effect of high dosages of antacids? The incidence of VAP and colonization of the stomach, the oropharynx and the trachea were comparable in patients receiving sucralfate or antacids.

9. What is the role of intragastric acidity and gastric colonization in the pathogenesis of pneumonia in mechanically ventilated ICU-patients? Intragastric acidity and gastric colonization are unlikely to be important in the pathogenesis of VAP.

10. What is the influence of enteral feeding on intragastric acidity and gastric colonization? Continuous gastric nutrition did not seem to raise intragastric $\mathrm{pH}$ values, as determined with continuous monitoring, but continuous gastric nutrition was associated with an increase in gastric colonization.

\section{Concluding Remarks}

The main feature of this thesis is that the gastropulmonary route of colonization is unlikely to be important in the pathogenesis of pneumonia in mechanically ventilated patients. This has, in our opinion, major implications for the development of preventive regimens for this infection. According to our findings, the use of sucralfate has no beneficial effects on the incidence of VAP.

Another feature of this thesis is the relationship between continuous gastric nutrition and development of gastric colonization, and, interestingly, this relation seemed to be independent of intragastric acidity. However, it was also demonstrated that increased gastric colonization was not a risk factor for colonization of the upper respiratory tract and pneumonia. The modulatory effect of enteral feeding on gastric colonization, therefore, is an important issue for further studies, although, based on this thesis, beneficial effects on colonization and infection of the respiratory tract are not expected. The latter has been suggested by several investigators, but these studies suffered from important methodological drawbacks.

Instead of the stomach, the oropharynx seems to be the pivotal tissue in the pathogenesis of VAP, since this was the initial site of colonization for most bacteria. Therefore, modulation of the oropharyngeal flora should be the next step in 
studying the pathogenesis of VAP. Although two studies reported a reduced incidence of VAP whit decontamination of the oropharynx, several other studies did not demonstrate a beneficial effect of SDD, with oropharyngeal decontamination incorporated. If the oropharynx really is crucial in the pathogenesis, why then did oropharyngeal decontamination fail? In the first place, application of non-absorbable antimicrobial agents into the oropharyngeal cavity might have led to false negative culture results of oropharyngeal swabs. If so, effective decontamination may have never occurred and the rapidly observed colonization with Gram-negative bacteria after the application of the antibiotics had been stopped, as reported by several investigators, would be explained as well. Another explanation might be overgrowth and an increased number of infections with Gram-positive bacteria, that are intrinsically resistant to the antimicrobial agents used. Finally, it is possible that decontamination of the oropharynx stimulates other routes of colonization leading to pneumonia, but this can only be demonstrated when patterns of colonization are determined accurately. In summary, a study looking at the effects of decontamination of the oropharyngeal cavity with a combination of antimicrobial agents covering Gram-negative as well as Gram-positive bacteria, and accurate monitoring of colonization patterns would shed more light on these questions.

The studies described in this thesis also strongly suggest that so-called potential pathogenic microorganisms have different colonization characteristics. For instance, Pseudomonas aeruginosa and Staphylococcus aureus colonized the patient in most cases initially in the upper respiratory tract, whereas some species of Enterobacteriaceae most frequently colonized the stomach first. Moreover, within the group of Enterobacteriaceae differences in colonization patterns were demonstrated between different species. These variable colonization patterns indicate that different bacteria cause pneumonia via different routes. This speciesspecific preference probably reflects the different capacity of bacteria to adhere to different types of epithelial cells. For instance, a preference of Pseudomonas aeruginosa to adhere to tracheal cells has been reported. In addition, the preference for the initial site of colonization might reflect the importance of the different routes of colonization present in the ICU. In line with this hypothesis, the colonization rates and etiology of ventilator-associated pneumonia within an ICU might reflect the importance of the responsible routes of colonization. High colonization rates with one particular species and an important etiologic role of that species, known to preferentially colonize patients via the exogenous route, might indicate that infection prevention could be achieved by improving hygienic procedures. On the other hand, the predominance of species preferentially colonizing the upper respiratory tract via the stomach would suggest that interruption of the gastropulmonary route might decrease colonization and 
infection rates. Therefore, adequate microbiological monitoring of colonization and infection might guide the strategy of infection prevention.

If the gastropulmonary route of colonization is of minor importance in the pathogenesis of VAP, where do the bacteria come from? The results of the different studies demonstrated that the oropharynx was the pivotal tissue, suggesting colonization via exogenous routes. However, this does not imply that the sources of these bacteria are exogenous as well. For instance, bacteria colonizing the rectum might reach the oropharynx, either after colonization of the skin or via vectors, such as hands of the nursing and medical staff. When studying this rectooropharyngeal route of colonization, it will be essential to determine the identity of bacteria colonizing the patient at different sites. It is also possible that phenotypically similar but genotypically different species colonize a patient, both at different sites as well as in one culture site simultaneously. Molecular biochemical techniques are indispensable for answering these questions.

Besides the intestine, other patients treated in the ICU-ward proved to be important sources of bacteria as well. Therefore, cross-acquisition is important in the ICU, although its existence in most cases cannot be demonstrated easily. The hands of the nursing and medical staff have been demonstrated to be the most important vector for transmission of microorganisms from patient to patient. Strict hygienic procedures are therefore of major importance within the ICU. However, they probably never will abandon cross-acquisition, especially not when the patientnurse ratio further increases, indicating increasing number of contacts with different patients for each nurse. On the other hand, cross-acquisition might be imperceptibly present. For instance, spreading of typical ICU-bacteria with a normal antibiotic susceptibility pattern is hard to detect, and cases of cross-acquisition probably go unnoticed. The only alternative is to study cross-acquisition within the ICU with molecular biological typing methods.

Active prevention of colonization of the upper respiratory tract with topical antibiotics might be an option to decrease cross-acquisition. Patients with an expected long ICU-stay and not treated in isolation might be candidates to receive prophylaxis. The hypothesis is that topical antimicrobial prophylaxis can be used to protect other patients in the ICU, which is the opposite of the principle of SDD. In SDD decontamination of the whole intestinal tract was achieved to protect the individual patient against infection, and as a matter of fact it was advocated to use SDD in all patients admitted to the ICU, since bacteria colonizing nondecontaminated patients might, exogenously, colonize patients receiving SDD as well. 
The importance of each of theses routes of colonization should be elucidated, in order to develop effective preventive regimens. A predominant pathogen within an ICU might be the first indication of the predominant route of colonization. It is also imaginable, that the impact of each route of transmission differs between ICU's, and in that case individual ICU's would need different preventive regimens. In addition, the continuous care to prevent contamination of medical equipment or enteral nutrition remains mandatory.

In conclusion, the studies on the pathogenesis of ventilator associated pneumonia demonstrate that the gastropulmonary route of colonization probably is not important, that the oropharynx seems to the pivotal source in the pathogenesis, that cross-acquisition is important within the ICU, and that enteral feeding may influence gastric colonization. However, ventilator-associated pneumonia still is the most important ICU-infection, with an enormous impact on morbidity, antibiotic use, antibiotic resistance, medical costs, and possibly mortality. Prevention of this infection, therefore, remains warranted, but this can only be instituted successfully if and when the pathogenesis of this infection has been elucidated. 
Dit proefschrift beschrijft studies over de rol van bacteriële kolonisatie van het bovenste deel van de tractus digestivus in de pathogenese van nosocomiale pneumonie bij mechanisch beademde IC-patiënten. Nosocomiale pneumonie, soms ook secundaire pneumonie genoemd, is een infectie die optreedt nadat de patiënt minimaal drie dagen in het ziekenhuis is opgenomen. Bij mechanisch beademde IC-patiënten wordt nosocomiale pneumonie ook wel "ventilatorassociated pneumonia" (VAP) genoemd. In hoofdstuk 1 wordt een overzicht gegeven van verschillende hypothesen omtrent de pathogenese van VAP. Het is algemeen geaccepteerd dat de meeste bacteriën die VAP veroorzaken afkomstig zijn van een endogeen reservoir, de tractus digestivus. De gastropulmonale route van kolonisatie geldt als het belangrijkste pathogenetisch model voor het ontstaan van VAP. Volgens deze hypothese koloniseren bacteriën de maag, waarna kolonisatie van de orofarynx en aspiratie van bacteriën in de luchtwegen optreedt. De zuurgraad van de maag speelt een belangrijke rol in dit model. Bij gezonde mensen is de intragastrische zuurgraad hoog, waardoor bacteriën niet kunnen overleven. Bij ernstig zieke en beademde IC-patiënten kan de zuurgraad om een aatal redenen verlaagd zijn. Een belangrijke oorzaak hiervoor is stress ulcus profylaxe, welke de patiënten krijgen ter bescherming van de maag. De meeste middelen beschermen de maag door de zuurgraad te verlagen. Een bijkomend effect is dat bacteriën nu wel in staat zijn in de maag te overleven. Ook sondevoeding zou een dergelijk effect kunnen veroorzaken.

Hoewel op basis van de gastropulmonale route verschillende preventieve strategieën zijn ontwikkeld, leveren de literatuurdata geen sluitende bewijzen voor deze hypothese. De klinische voordelen van deze strategieën (b.v. selectieve darmdecontaminatie en het gebruik van sucralfaat voor stress ulcus profylaxe) staan echter nog steeds ter discussie. De meeste studies die preventie van VAP hebben bestudeerd vertonen ernstige methodologische tekortkomingen (hoofdstuk 1). Zoals bijvoorbeeld het niet adekwaat diagnostiseren van VAP, het niet in de tijd bestuderen van kolonisatie op verschillende plaatsen in het lichaam, en het niet betrouwbaar meten van veranderingen van de zuurgraad in de maag.

Selectieve decontaminatie van de tractus digestivus (SDD) is in dit kader de meest gebruikte en bestudeerde methode van infectie preventie. Bij deze methode worden niet-resorbeerbare antibiotica aangebracht in de orofarynx, maag en darm. 
De gebruikte antimicrobiële middelen zijn gericht tegen de belangrijkste verwekkers van VAP: Enterobacteriaceae, Pseudomonas aeruginosa en Staphylococcus aureus, de zogenaamde potentieel pathogene micro-organismen (ppmo's). De anaerobe bacteriën worden niet geëlimineerd, vandaar "selectieve" decontaminatie. Men verondersteldt dat deze anaerobe bacteriën de kolonisatie resistentie verhogen. Ondanks een groot aantal studies is het effect van SDD niet onomstotelijk vastgesteld, mede doordat interpretatie van de meeste voor 1990 verrichte studies ernstig bemoeilijkt wordt door methodologische tekortkomingen. Zeven SDD-studies, gepubliceerd na 1991, worden besproken in hoofdstuk 2. In tegenstelling tot eerder uitgevoerde studies waren deze studies allen prospectief gerandomiseerd met minimaal 100 patiënten. Zes studies waren placebogecontroleerd en drie studies waren dubbel-blind. Slechts twee studies toonden een significante vermindering van het aantal IC-verworven pneumonieën bij patiënten die SDD kregen. Daarnaast tonen de gegevens van deze studies en van andere recente publikaties aan, dat het gebruik van SDD leidt tot kolonisatie en infecties met Gram-positieve bacteriën en tot een toename van het aantal bacteriën resistent voor de in SDD gebruikte antibiotica. Daarnaast gaat het gebruik van SDD gepaard met extra kosten. Geconcludeerd wordt dat deze recent gepubliceerde studies geen positief effect van SDD op mortaliteit, incidentie van VAP of andere parameters, zoals beademingsduur en opnameduur, aantonen.

Een accurate diagnose van pneumonie is essentieel wanneer pathogenese en preventie van deze infectie bestudeerd worden. De problemen die met de diagnostiek van VAP gepaard kunnen gaan worden beschreven in hoofdstuk 3 . Omdat de meeste IC-patiënten gekoloniseerd zijn met bacteriën in de bovenste luchtwegen, kan het onderscheid tussen kolonisatie en infectie vaak niet gemaakt worden. Daarnaast zijn thoraxfoto's van bedlegerige IC-patiënten moeilijk te interpreteren en daardoor niet betrouwbaar genoeg om de diagnose VAP te stellen of te verwerpen, zelfs niet in combinatie met klinische parameters. Bronchoscopische technieken, zoals de "protected specimen brush" (PSB) en "bronchoalveolaire lavage" (BAL) zijn ontwikkeld om materiaal uit de onderste luchtwegen te verkrijgen zonder verontreiniging met bacteriën van de bovenste luchtwegen. Kwantitatieve microbiologische analyse van deze monsters, in combinatie met klinische parameters van infectie en interpretatie van thoraxfoto's, is waarschijnlijk de beste methode om VAP te diagnostiseren. Verschillende studies beschrijven een goede sensitiviteit en acceptabele specificiteit voor de diagnose VAP met deze methoden. In alle studies, beschreven in dit proefschrift, wordt de diagnose VAP gesteld op basis van kwantitatieve microbiologische kweken van monsters verkregen via PSB en/of BAL in combinatie met klinische parameters en thoraxfoto's. 
In hoofdstuk 5 wordt de invloed van lokale antimicrobiële profylaxe ("topical antimicrobial prophylaxis" =TAP) van orofarynx en maag op kolonisatie van de bovenste luchtwegen bestudeerd. In tegenstelling tot de conventionele SDDmethode is geen darm decontaminatie nagestreefd en is geen systemische profylaxe gegeven. Teneinde de aerobe en anaerobe darmflora in stand te houden, zijn, ten opzichte van SDD-schema's, geringere hoeveelheden niet-resorbeerbare antibiotica in de maag gegeven. De resultaten van deze studie tonen aan dat kolonisatie van luchtwegen met ppmo kan worden voorkomen zonder de darmflora te beïnvloeden. Echter, bij patiënten die TAP krijgen, wordt vaak kolonisatie van de bovenste luchtwegen met Gram-positieve bacteriën, vooral Enterococcus faecalis, waargenomen. Deze bacteriën zijn intrinsiek resistent voor de gebruikte antibiotica. Van de in totaal 61 patiënten die TAP kregen, ontwikkelden zes een polymicrobiële pneumonie en twee een bacteriëmie met Enterococcus faecalis; deze bacterie veroorzaakt normaal gesproken geen infecties van de luchtwegen.

In hoofdstuk 6 is de maagkolonisatie bestudeerd bij patiënten die wel en geen TAP hebben gekregen. TAP in combinatie met sucralfaat als stress ulcus profylaxe voorkomt maagkolonisatie. Patiënten die stress ulcus profylaxe krijgen met middelen die de zuurgraad van de maag verminderen zijn vaker gekoloniseerd in de maag. In beide patiëntengroepen treedt maagkolonisatie frequenter en sneller op indien sondevoeding gegeven wordt.

In hoofdstuk 7 is het effect van TAP op kolonisatie van de bovenste luchtwegen bestudeerd bij een groep patiënten die TAP kregen $(n=22)$ en bij twee groepen patiënten die geen TAP kregen. Deze twee controle groepen bestonden uit patiënten die in dezelfde IC-afdeling $(n=21)$ verpleegd en bestudeerd werden als de patiënten met TAP-medicatie en uit patiënten die in een IC-afdeling werden bestudeerd $(n=54)$ waar geen enkele patiënt TAP kreeg. Kolonisatie van orofarynx en trachea trad minder vaak op bij patiënten die TAP kregen vergeleken met patiënten die geen TAP kregen. Binnnen de twee controle groepen werden echter eveneens verschillen in kolonisatie gevonden: Patiënten die bestudeerd werden in de IC waar de andere helft van de patiënten TAP kreeg, waren minder vaak gekoloniseerd dan de andere controle groep. Daarnaast bleven patiënten die nog niet gekoloniseerd waren bij opname en die opgenomen werden op de IC-afdeling waar TAP-medicatie gegeven werd, langer kolonisatie vrij. In de IC-afdeling waar geen TAP gegeven werd waren meer patiënten gelijktijdig gekoloniseerd en trad ook vaker kruis-acquisitie op. Deze studie toont aan dat TAP de kolonisatie van orofarynx en trachea beïnvloedt, zowel bij patiënten die TAP krijgen als bij patiënten die geen TAP krijgen maar die in dezelfde afdeling verpleegd worden. Dit is een duidelijke aanwijzing dat kruis-acquisitie een belangrijke rol speelt bij de kolonisatie van patiënten in de Intensive Care. 
In hoofdstuk 8 wordt de methodiek van het meten van de intragastrische zuurgraad bestudeerd. In andere studies, onder andere hoofdstuk 6, is de intragastrische zuurgraad van geaspireerd maagsap bepaald met behulp van kleurindicator papiertjes, waarbij de frequentie van metingen varieerde tussen zesmaal daags tot twee maal per week. Deze methode werd om verschillende redenen echter ter discussie gesteld. In de eerste plaats worden vraagtekens geplaatst bij de betrouwbaarheid van de kleur-indicator papiertjes. Daarnaast wordt bij het gebruik. van deze methode een grote inter-observer variatie gevonden. Ook is het onwaarschijnlijk dat incidentele metingen een representatieve weergave zijn van veranderingen van de intragastrische zuurgraad. Deze problemen kunnen voorkomen worden door gebruik te maken van gecomputeriseerde continue intragastrische $\mathrm{pH}$-registratie, een methode die betrouwbaar en reproduceerbaar is. In hoofdstuk 8 wordt de betrouwbaarheid van kleur-indicator papiertjes bestudeerd en vergeleken met de resultaten van een continue intragastrische 24-uurs meting. De betrouwbaarheid van de kleur-indicator papiertjes - geverifieerd met een laboratorium pH-meter - is hoog, zowel in kleurloze vloeistof als in geaspireerd maagsap. Anderzijds blijkt de correlatie tussen de $\mathrm{pH}$-waarde van de eenmaal daagse meting in geaspireerd maagsap en de mediane $\mathrm{pH}$-waarde van de 24-uurs meting slecht te zijn, waarschijnlijk omdat veranderingen in $\mathrm{pH}$ met een eenmalige meting gemist worden. De continue intragastrische $\mathrm{pH}$-registratie dient daarom gebruikt te worden indien modulatie van de intragastrische zuurgraad bestudeerd wordt.

In hoofdstuk 9 worden kolonisatie van maag, orofarynx en trachea bij 64 patiënten gedurende de gehele IC-opname bestudeerd, teneinde chronologische kolonisatie patronen te analyseren. Elf patiënten ontwikkelden een VAP, waarbij met behulp van $\mathrm{PSB}$ en/of BAL in totaal 20 micro-organismen als verwekkers werden geïdentificeerd. Voorafgaande aan, of op de dag van de diagnose VAP werden 17 van deze micro-organismen geïsoleerd uit de trachea en zes uit de maag. Voor geen van deze zes bacteriën kon een kolonisatie patroon van de maag naar de bovenste luchtwegen worden aangetoond. De initiële plaats van kolonisatie van Pseudomonas aeruginosa en Enterobacter spp. was vaker de trachea dan de maag. Anderzijds werden species zoals Klebsiella spp. en Enterococcus faecalis vaker als eerste in de maag aangetroffen. De resultaten van deze studie suggereren dat de maag in de pathogenese van VAP geen belangrijke bron van bacteriën is. Tevens werd aangetoond dat de initiële plek en route van kolonisatie waarschijnlijk verschillend zijn voor verschillende soorten bacteriën.

De invloed van de intragastrische zuurgraad op maagkolonisatie, kolonisatie van de bovenste luchtwegen en de incidentie van VAP is bestudeerd in hoofdstuk $\mathbf{1 0}$. In deze studie is eveneens de invloed van twee verschillende middelen van stress 
ulcus profylaxe - sucralfaat en antacida - op deze parameters vergeleken. Deze vergelijking is prospectief, gerandomiseerd en dubbel-blind gedaan, waarbij de patiënten gestratificeerd zijn op de initiële intragastrische $\mathrm{pH}$. Tussen beide middelen werden geen significante verschillen in intragastrische zuurgraad aangetoond. Ook kolonisatie in de maag, orofarynx en trachea met ppmo waren vergelijkbaar in beide behandelingsgroepen. Patiënten gekoloniseerd met ppmo in de maag hadden een significant hogere mediane intragastrische $\mathrm{pH}$ vergeleken met niet-gekoloniseerde patiënten, waarmee de relatie tussen zuurgraad en maag kolonisatie bevestigd werd. Er werden echter geen significante verschillen aangetoond in intragastrische zuurgraad tussen patiënten die wel en niet gekoloniseerd waren met ppmo in de bovenste luchtwegen. Daarnaast werden kolonisatie patronen van de maag naar de trachea slechts twee maal aangetoond voor Enterobacteriaceae en vier maal voor Pseudomonas aeruginosa bij 141 patiënten. Analoog aan de kolonisatie data werden geen verschillen gevonden in de incidentie van VAP tussen beide behandelingsgroepen ( $22 \%$ in beide); slechts één van de 48 geïsoleerde verwekkers die een VAP veroorzaakten werd initieel in de maag gevonden. De resultaten van deze studie bevestigen de resultaten van de studie beschreven in hoofdstuk 9 en suggereren nogmaals dat de maag in de pathogenese van VAP geen belangrijke bron van bacteriën is. Daarnaast is aangetoond dat sucralfaat en antacida een vergelijkbaar effect hebben op de intragastrische zuurgraad en dat sucralfaat geen bescherming biedt tegen het ontstaan van een VAP. Een andere observatie van deze studie is, dat de orofarynx en trachea de belangrijkste initiële plekken van kolonisatie zijn. Dit suggereert een belangrijk aandeel van exogene routes voor kolonisatie, analoog aan de resultaten beschreven in hoofdstuk 7 .

In hoofdstuk 10 is tevens de invloed van sondevoeding op intragastrische zuurgraad en maagkolonisatie bestudeerd. In tegenstelling tot de resultaten van andere studies lijkt het geven van sondevoeding de intragastrische zuurgraad niet te beïnvloeden. Deze schijnbare tegenstelling met de resultaten van andere studies kan echter het gevolg geweest zijn van verschillen in methodiek zoals beschreven in hoofdstuk 8. Hoewel sondevoeding geen wezenlijk effect heeft op de intragastrische zuurgraad, lijkt er wel een duidelijk stimulerend effect te zijn op het ontstaan van maagkolonisatie met ppmo, waarmee de resultaten beschreven in hoofdstuk 6 ten dele bevestigd worden.

Samenvattend kan gesteld worden, dat de studies beschreven in dit proefschrift aantonen dat maagkolonisatie geen belangrijke rol speelt in de pathogenese van "ventilator-associated pneumonia". In het pathogenetisch model van deze infectie lijken kolonisatie van orofarynx en kruis-acquisitie binnen de IC-afdeling belangrijk. Tevens suggereren de verschillende studies dat sondevoeding een stimulerend effect heeft op maagkolonisatie. 


\section{LIST OF PUBLICATIONS}

Bonten MJM, Philips J, Houben T, Stobberingh EE. High prevalence of antibiotic resistant Escherichia coli in faecal samples of students in the south-east of the Netherlands. Journal of Antimicrobial Chemotherapy 1990; 26: 585-92

Bonten MJM, Stobberingh EE, Philips J, Houben A. Antibiotic resistance of Escherichia coli in fecal samples of healthy people in two different areas in an industrialized country. Infection 1992; 20: 258-63

Bonten MJM, van Tiel FH, van der Geest S, Stobberingh EE, Gaillard CA. Enterococcus faecalis pneumonia complicating Topical Antimicrobial Prophylaxis. [letter] The New England Journal of Medicine 1993; 328: 209-210

Bergmans DCJJ, Bonten MJM, Stobberingh EE. Bactericidal effect of sucralfate. [letter] European Journal of Gastroenterology and Hepatology 1993; 5: 397

Bonten MJM, van Tiel FH, van der Geest S, Smeets H, Stobberingh EE, Gaillard CA. Topical antimicrobial prophylaxis of nosocomial pneumonia in mechanically ventilated patients. Microbiological observations. Infection 1993; 21: 137-40

Bonten MJM, van der Geest S, Gaillard CA. Diagnosis of pneumonia in mechanically ventilated patients: Clinical judgement or bronchoscopy. Netherlands Journal of Medicine 1993; 43: 97-99

Bonten MJM, Gaillard CA, van der Geest S. Selective decontamination of the digestive tract: benefit remains unproven. [letter] British Medical Journal 1993; 307: 1559-1560

Bonten MJM, Gaillard CA, van Tiel FH, van der Geest S, Stobberingh EE. The stomach is not a source for colonization of the upper respiratory tract and pneumonia in ICU-patients. Chest 1994; 105: 878-84

Bonten MJM, Gaillard CA, van Tiel FH, van der Geest S, Stobberingh EE. Continuous enteral feeding counteracts preventive measures for gastric colonization in ICU-patients. Critical Care Medicine 1994; 22: 939-44 
Bonten MJM, Stobberingh EE, van Tiel FH, van der Geest S, Gaillard CA. Selectieve Decontaminatie van de tractus digestivus bij patiënten op een intensive care afdeling: meer argumenten contra. Ned Tijdschr Geneesk 1993 (geaccepteerd voor publikatie)

Bonten MJM, Gaillard CA, Wouters EFM, van Tiel FH, Stobberingh EE, van der Geest S. Problems in diagnosing nosocomial pneumonia in mechanically ventilated patients: a review. Critical Care Med (in press)

Bonten MJM, Gaillard CA, Johanson WGM, van Tiel FH, Smeets HGW, van der Geest S, Stobberingh EE. Colonization in patients receiving and not-receiving topical antimicrobial prophylaxis. American Journal of Respiratory \& Critical Care Medicine (formerly American Review of Respiratory Diseases) (in press)

Bonten MJM, Gaillard CA. Ventilator associated pneumonia: Do the bacteria come from the stomach? Netherlands Journal of Medicine (in press)

Bergmans DCJJ, Bonten MJM, Gaillard CA, van Tiel FH, van der Geest S, Stobberingh EE. In vitro antibacterial activity of sucralfate. European Journal of Clinical Microbiology \& Infectious Diseases (in press)

Bonten MJM, Gaillard CA, Stockbrügger RW, van Tiel FH, van der Geest S, Stobberingh EE. Assesment of gastric acidity in intensve care patients: Incidental pH registration can not replace continuous $\mathrm{pH}$-monitoring (submitted)

Bonten MJM, Gaillard CA, van der Geest S, van Tiel FH, Coomans MAA, Beysens AJ, Smeets HGW, Stobberingh EE. Colonization of the stomach and intragastric acidity are not important for the development of respiratory tract colonization and infection in mechanically ventilated ICU-patients. A stratified double-blind study sucralfate versus antacids. (submitted) 
In de 30 maanden die uiteindelijk tot dit proefschrift leidden is er waarschijnlijk even vaak over voetbal als over wetenschap gesproken. Elke maandagochtend en de meeste donderdagochtenden begonnen met een grondige analyse van de gebeurtenissen van de dag of avond voorafgaande. Uiteindelijk waren we het er altijd over eens dat zowel Ajax als het Nederlands elftal, om maar te zwijgen van Feyenoord, zwaar te lijden hadden van het feit dat wij voor een medische beroep gekozen hadden in plaats van een carrière als voetbalcoach.

In feite had ons onderzoeksgroepje veel weg van een voetbalteam. Een nieuw team dat nog niet ingespeeld was en dat zijn plaats in de competitie nog moest verwerven.

Het 'Dreh-und-Angelpunkt' van het team was zonder enige twijfel Carlo Gaillard. Carlo, jij bedacht de taktiek, leidde de verdediging en zette de aanval op. Als het even tegenzat schroomde je de tackle niet. Door je snelheid van handelen, je inzicht en je creativiteit was je van onmisbare waarde. Je was het type speler waarvan gezegd wordt dat je hem kost wat kost moet behouden. Helaas is dat laatste inmiddels mislukt, maar ik hoop ook in de toekomst nog onderzoek met je te doen.

De funderingen van het middenveld werden links en rechts gevormd door Ellen Stobberingh en Siebe van der Geest. Ellen, jij was het loopwonder. Je was voortdurend in beweging, kwam regelmatig ergens te laat en eenmaal aangekomen stond je altijd weer op het punt om te vertrekken. Gelukkig bleef je er altijd (nou ja, bijna altijd) bij lachen. Daarnaast ben ik speciale dank aan je verschuldigd omdat je mij in dit team introduceerde. Siebe, jij vormde het aanspreekpunt binnen de IC. Daarnaast kon je de dagelijkse zaken uitstekend relativeren door het onderwerp van gesprek te verleggen naar echt belangrijke dingen van het leven, zoals eten en drinken, vakanties en de herinneringen aan het studentenleven. Het viermans middenveld werd gecomplementeerd door Frank van Tiel, die alle fouten corrigeerde en de puntjes op de i zette.

De aanval begint bij de verdediging. De centrale positie hierin werd voortdurend door vrouwen bezet. In chronologische volgorde verzetten jullie, Wanda, Monique en Ingrid, letterlijk bergen werk. Ook al werd de druk soms groot en leken de petri-schalen tot aan het plafond te groeien, er ontstond hooguit lichte paniek en uiteindelijk werd alles met grote (en Belgische) accuratesse verwerkt.

De flanken van de verdediging werden afgedekt door de beide paranymfen. Hans Smeets bekeek meer dan duizend thoraxfoto's en wordt dus van harte bedankt 
voor zijn inzicht. Albert Froon hield het al die tijd met mij uit in een kamertje van drie bij drie zonder daglicht of ventilatie. Menigeen zou inmiddels met lichamelijke en/of geestelijke verwondingen het speelveld verlaten hebben. Naast de gezelligheid en collegialiteit bedank ik je speciaal voor het verzorgen van de layout van dit proefschrift. De beste herinneringen aan jullie beiden bewaar ik aan de momenten dat we de zaken en de glazen nog eens op een rijtje zetten aan de bar.

De doelman heeft de ondankbare taak de gemaakte fouten te corrigeren en kan zichzelf geen enkele misstap veroorloven. Gelukkig werd het doel verdedigd door Jolanda, mijn vriendin. Altijd op de post, onberispelijk en streng wanneer er fouten gemaakt of taken niet uitgevoerd werden. Het nadeel voor de doelman is dat hij/zij weleens te weinig in het spel betrokken wordt. Daarom draaien we de rollen nu maar om. Jij gaat lekker promoveren en ik kijk toe.

Tenslotte de aanval. Volgens goed (?) Nederlands gebruik werd er met twee vleugelspitsen gespeeld. De linkerzijde werd bezet door de verpleging van E3 de rechter door de verpleging van D3. Net als in Oranje vormden jullie het kwetsbaarste deel van de ploeg. Want als het op de vleugels niet 'marcheert' komt er geen gevaarlijke bal voor het doel. Maar het 'marcheerde' prima: Geen vraag was teveel en op elke dieptepass werd gerend. Bedankt voor jullie inzet en betrokkenheid.

De spits tenslotte was ikzelf. Niet echt beweeglijk, een paar kilo te zwaar, liever lui dan moe, zelfzuchtig en eigenwijs. Een probleem was dat niet. Mijn taak bestond eruit de niet te missen kansen voor open doel af te ronden. Allemaal bedankt. 


\section{Curriculum vitae}

Marc Bonten, geboren 16 oktober 1964, te Weert

1977-1983 VWO, Scholengemeenschap Philips van Horne te Weert

1983-1991 studie Geneeskunde aan de Rijksuniversiteit Limburg te Maastricht

1991-1994 wetenschappelijk onderzoeker bij de vakgroep Interne Geneeskunde, Academisch Ziekenhuis Maastricht

1994- assistent geneeskundige-in-opleiding tot internist (Academisch Ziekenhuis Maastricht, waarnemend opleider Prof Dr A.C.

Nieuwenhuijzen Kruseman) 

ISBN $90-5278-150-8$ 